\title{
High resolution sedimentary archives of past millennium hurricane activity in the Bahama Archipelago
}

by

\author{
Elizabeth Jane Wallace \\ B.S., University of Virginia (2015) \\ Submitted in partial fulfillment of the requirements for the degree of \\ Doctor of Philosophy \\ at the \\ MASSACHUSETTS INSTITUTE OF TECHNOLOGY \\ and the \\ WOODS HOLE OCEANOGRAPHIC INSTITUTION
}

September 2020

(C) Elizabeth Jane Wallace, 2020. All rights reserved.

The author hereby grants to MIT and WHOI permission to reproduce and to distribute publicly paper and electronic copies of this thesis document in whole or in part in any medium now known or hereafter created.

Author

Joint Program in Oceanography/Applied Ocean Science \& Engineering

Massachusetts Institute of Technology \& Woods Hole Oceanographic Institution July 23, 2020

Certified by

Dr. Jeffrey P. Donnelly

Senior Scientist in Geology \& Geophysics

Woods Hole Oceanographic Institution

Thesis Supervisor

Accepted by

Dr. Oliver Jagoutz

Associate Professor of Geology

Massachusetts Institute of Technology

Chair, Joint Committee for Marine Geology \& Geophysics 


\title{
High resolution sedimentary archives of past millennium hurricane activity in the Bahama Archipelago
}

by

\author{
Elizabeth Jane Wallace
}

Submitted to the MIT-WHOI Joint Program in Oceanography and Applied Ocean Science and Engineering on August 6th, 2020, in Partial Fulfilment of the Requirements for the Degree of Doctor of Philosophy in Paleoceanography.

\begin{abstract}
Atlantic hurricanes threaten growing coastal populations along the U.S. coastline and in the Caribbean islands. Unfortunately, little is known about the forces that alter hurricane activity on multi-decadal to centennial timescales. This thesis uses proxy development and proxy-model integration to constrain the spatiotemporal variability in hurricane activity in the Bahama Archipelago over the past millennium. I present annually-resolved archives of storm activity stretching over the past 1000 to 1500 years in sediment cores from blue holes on three islands in the Bahama Archipelago: South Andros Island, Long Island, and Middle Caicos Island. I explore the sensitivity of each site to coarse-grained sediment deposition for modern storms. I find that the local geomorphologic conditions and the angle of approach and size of passing storms play a more important role in inducing coarse-grained sediment transport than storm intensity. All three paleorecords capture multi-decadal and longer periods of elevated hurricane activity over the past millennium. Dramatic differences between these records suggest localized controls on the hurricane patterns observed by each island. Thus, compiling the records from this thesis together more accurately captures regional variations in hurricane strikes. Integrating our new Bahama Archipelago compilation with compiled paleohurricane records from the U.S. coastline indicates shifting patterns of hurricane activity over the past millennium between the Gulf Coast and the Bahama Archipelago/New England. I attribute these shifting storm patterns to changes in local environmental conditions and/or large-scale variations in hurricane tracks. Finally, I address whether variability in hurricane strikes observed in Bahamian paleohurricane records is related to climate or random variability. Using a large suite of synthetic storms run over past millennium climate, I generate 1000 pseudo paleohurricane records containing centennial-scale signal like our proxy reconstructions. However, the signal observed in any individual record of paleohurricane activity from the Bahama Archipelago is driven more by random variability in hurricane tracks than by climate. This thesis lays the groundwork for creating high-resolution paleohurricane records from coastal karst basins and using hurricane models to inform our interpretations of these records.
\end{abstract}

Thesis Supervisor: Dr. Jeffrey P. Donnelly Title: Senior Scientist in Geology \& Geophysics 


\section{Acknowledgements}

I'm extremely grateful to a vast number of people who made this thesis possible.

To my advisor, Jeff Donnelly, I could not have asked for a better mentor. Right from the beginning, you handed me some incredible datasets and gave me the space to explore them on my own. Your enthusiasm and encouragement throughout this process has helped me gain confidence in my own ideas. I hope that someday I can be half the scientist and mentor you are!

To my labmates, Katie, Jimmy, and Rose: I couldn't have asked for three more wonderful people by my side over the past 5 years. Your positive affirmation, humor, and advice have helped me innumerably to become the scientist and person I am today.

To all the Northeastern interns who worked tirelessly in the lab and the field producing much of the data in this thesis (Emily Griffin, Ethan St. Aubin, Bella Lopez, Phoenix Susak, David Carter, Miranda Cashman, Michelle Chen, Charmille Dizon, Max Besser, Ali LaBella, Dan Litchmore, Abby Llona, Michelle O'Donnell, Patrick Orenstein, Lizzy Soranno, and Mitchell Starr), I could not have completed this research without you. Thank you so much for your enthusiasm and attention to detail.

To Sloan Coats, Kerry Emanuel, and Caroline Ummenhofer, thank you for sharing the magical world of climate and hurricane models with me.

To Jon Woodruff (aka 'JFW'): thanks for inspiring me to become a geoscientist. Without reading the Oceanus article about you, I might never have ended up here.

To Chris Piecuch, I am ever grateful for your enthusiasm and expertise.

To my field family (Nicole D'Entremont, Kelly McKeon, Richard Sullivan, Tyler Winkler, Pete van Hengstum, Charlotte Wiman, Shawna Little, Anne Tamalavage and others), Thanks for your patience, time and time again, teaching me everything I know about coring and using tools in general. I'm sure it was frustrating in the beginning when I didn't know the difference between a flat-head and phillips-head screwdriver. I'm sorry that I dragged some of you on some crazy disaster adventures, but there's no one else I'd rather spend hours on a sinking raft with.

To Ryan, thank you for your continued love and support through this journey. Your willingness to listen to my rants never ceases to amaze me.

Thanks to all my friends for the laughs and good times that helped me retain my sanity these past 5 years. In particular, to Chrissy, for hugs, all the advice, and sharing donuts; to Rachel, for tasty beverages, puns, and plentiful discussion and petting of cats; to Hannah, for Furoshiki shoes; to Jen, for baked goods; to Nathan, for office interruptions, softball, and the Broncos lineup; to Billy, for OGB; to Jeffrey, for feeding me and card games, and to Jake for $4^{\text {th }}$ of July shenanigans.

And finally, to my parents, thank you for taking me on all those camping trips to Newfoundland. Clambering over rocks, exploring tidal pools, and singing sea shanties really instilled in me a love for the ocean and the outdoors. 
This work was funded by the National Science Foundation Graduate Research Fellowship (to E.J.W.), National Science Foundation grant OCE-1356708 (to J.P.D. and P.J.vH.) and the Dalio Explore Foundation. 


\section{Contents}

1. Introduction...........................................................13

1.1. The short observational record of hurricane activity ............................13

1.2. Paleohurricane research in the North Atlantic................................... 15

1.3. The potential of blue hole basins for paleohurricane records in the

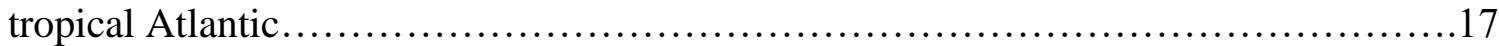

1.4. Paleohurricane modeling studies.......................................... 18

\section{Intense Hurricane Activity Over the Past 1500 Years at South Andros} Island, The Bahamas.........................................................21

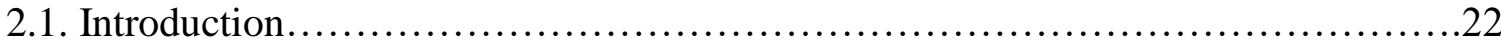

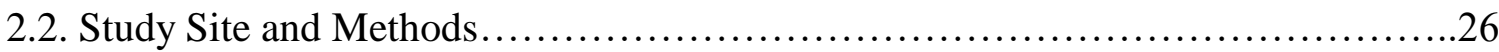

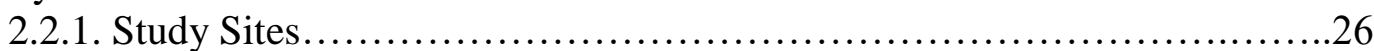

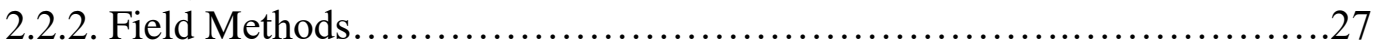

2.2.3. Sediment Analysis and Age Control.................................28

2.2.4. Event threshold, Attribution, and Frequency...............................29

2.2.5. Calculating Expected Event Frequency .................................30

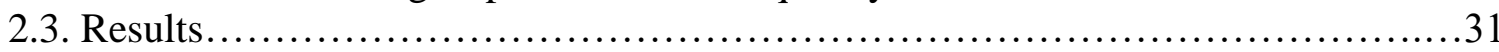

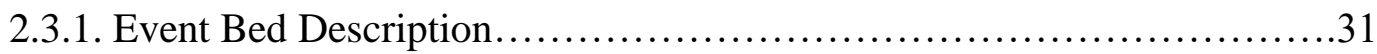

2.3.2. Changing Event Frequency ............................................32

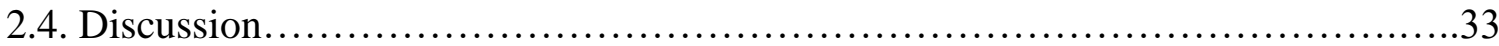

2.4.1. Potential Influence of Changing Sea Level.............................33

2.4.2. Modern Event Calibration....................................................34

2.4.3. South Andros Site Comparison.......................................... 37

2.4.4. Climatic Forcing of Hurricane Activity on South Andros Island............38

2.4.5. Comparison to Other High-Resolution Hurricane Records.................43

2.5. Conclusions ..................................................................... 47

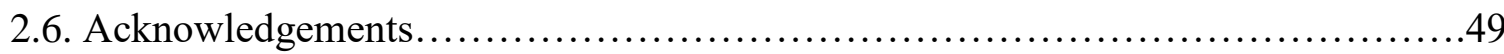

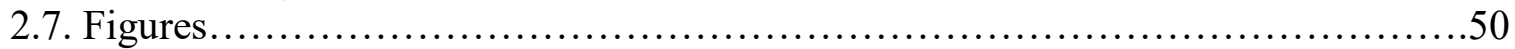

2.S. Supplemental material..........................................................

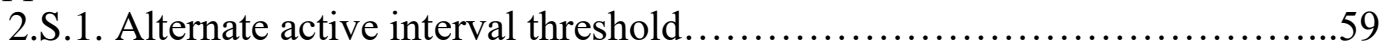

2.S.2. AM5 age model modifications....................................60

2.S.3. Supplemental figures and tables...................................60

3. 1000 years of hurricane strikes on Long Island in The Bahamas..........71

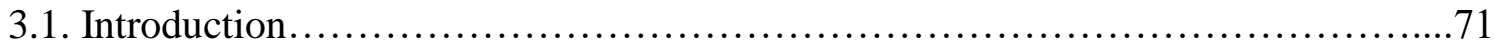

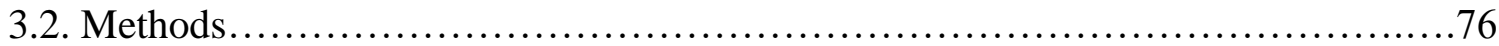

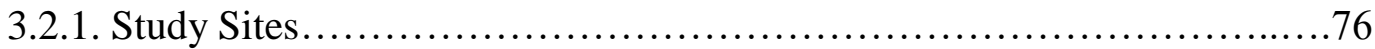

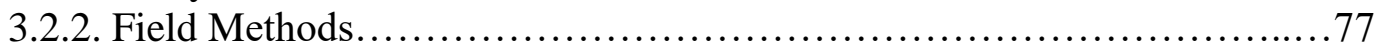

3.2.3. Sediment Analysis and Age Control.....................................77

3.2.4. Event threshold, attribution, and frequency...........................79

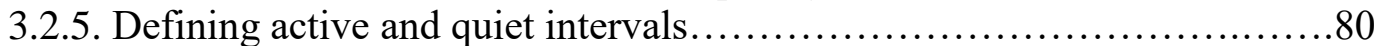

3.2.6. Estimating storm surge using SLOSH................................ 81

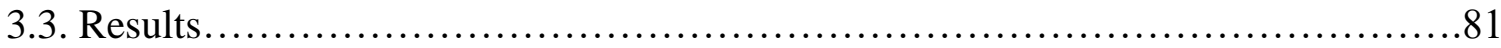

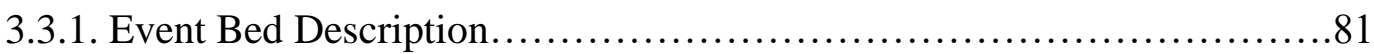

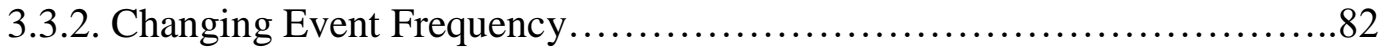


3.3.3. Irma 2017 Tilt Current Meter (TCM) data...........................83

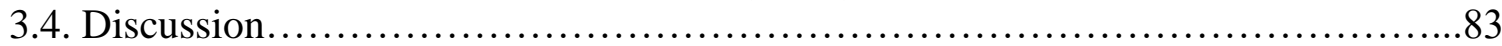

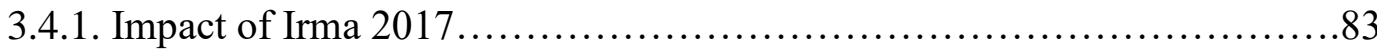

3.4.2. Event Attribution................................................ 85

3.4.2.1. Establishing a modern analog: Hurricane Joaquin..............85

3.4.2.2. Interpreting the other modern deposits.....................87

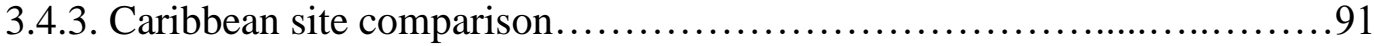

3.4.4. Basin-wide comparison........................................... 94

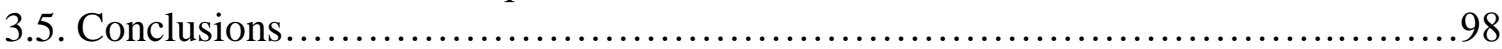

3.6. Acknowledgements................................................. 100

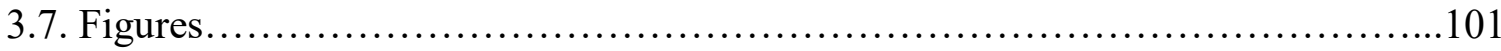

3.S. Supplemental material................................................... 108

3.S.1. Methods for CTD data collection................................... 108

3.S.2. Tiltmeter data: Temperature and bottom current speed and direction......108

3.S.3. Justification for unused radiocarbon results.............................109

3.S.4. Methods for Florida, New England, and

Bahamas sediment compilation........................................110

3.S.5. Supplemental figures and tables..................................112

\section{Sedimentary deposits of paleohurricane activity for the past 1500 years captured in a transect of cores from a blue hole off Middle Caicos in the} Turks \& Caicos Islands.........................................................129

4.1. Introduction............................................................ 129

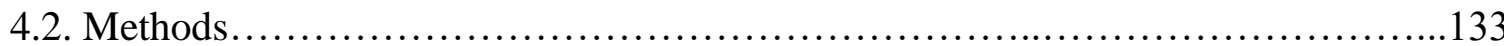

4.2.1. Study sites....................................................... 133

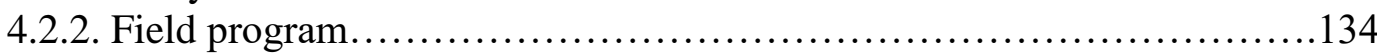

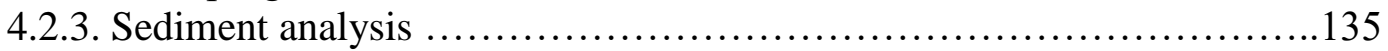

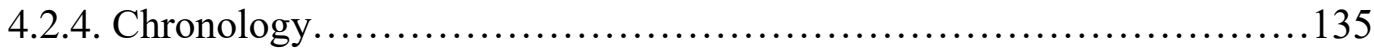

4.2.5. Event thresholds and frequency....................................136

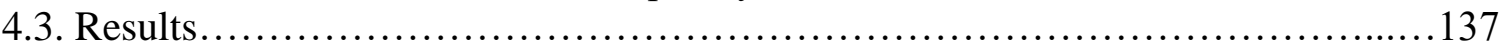

4.3.1. Correlating event beds across cores...............................137

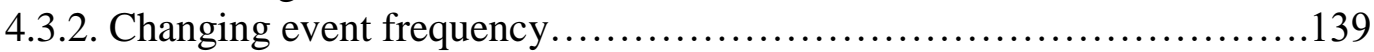

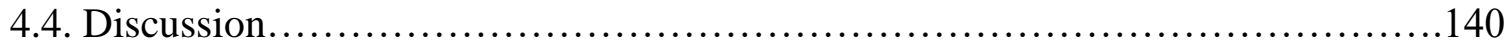

3.4.1. Event Attribution............................................... 140

3.4.2. Caribbean site comparison.......................................... 145

3.4.3. Basin-wide comparison........................................ 147

4.5. Conclusions ........................................................ 152

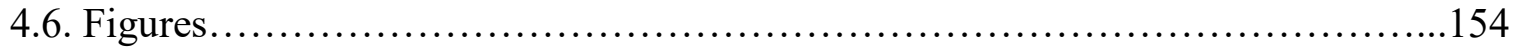

4.S. Supplemental material.................................................. 162

4.S.1. Analysis of Bahama Archipelago NCEP Reanalysis synthetic storms....162

4.S.2. Grain size measurements of modern events using microscopic images....163

4.S.3. Supplemental figures and tables.................................. 164

5. Centennial-scale patterns in individual paleohurricane records in the Bahamas are predominantly driven by randomness.........................181

5.1. Introduction ........................................................ 181 
5.2. Producing paleohurricane activity with synthetic storms .....................184

5.3. Quantifying the climate signal to noise in paleohurricane records................ 184

5.4. A coherent signal across sites in The Bahamas.............................. 185

5.5. Implications for paleohurricane research.................................. 187

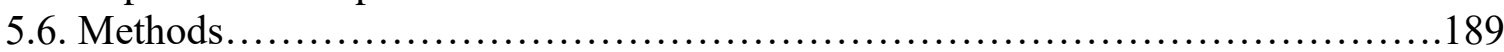

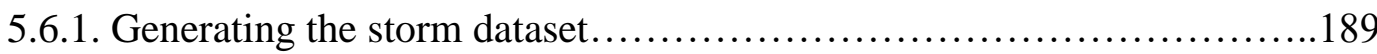

5.6.2. Creating a pseudo sediment record ................................191

5.6.3. Define active and quiet intervals in the pseudo sediment records...........192

5.6.4. Defining the climate signal and quantifying the

signal-to-noise ratio (SNR)......................................... 193

5.6.5. Creating a pure Poisson record...................................... 193

5.7. Acknowledgements.................................................. 194

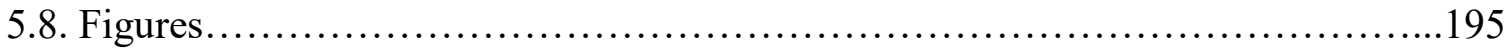

5.S. Supplemental Material...................................................... 198

5.S.1. Supplemental Figures...............................................198

6. Summary and conclusions.............................................202

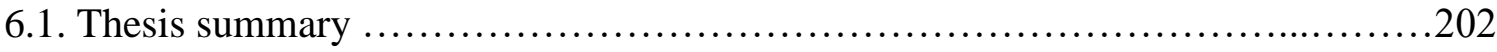

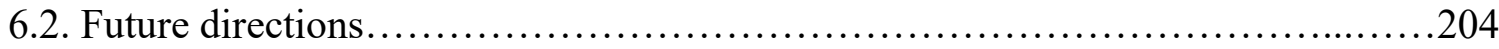

Appendices..........................................................................206

A. Visual correlation of events in the transect of cores from Middle Caicos...........206

References..............................................................................211 


\section{List of figures}

2.1. A conceptual model of the environment around the South Andros blue holes................50

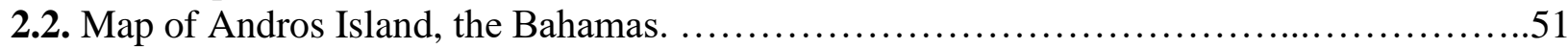

2.3. Percent sand fraction $(>63 \mu \mathrm{m})$ vs. depth in core from AM2, AM5, and AM4.............52

2.4. Age model (red dashed) derived from radiocarbon dates for AM4, AM5, and AM2 ........53

2.5. Coarse anomaly plots for AM4, AM5, and AM2 as a function of time....................54

2.6. Event frequency per century for AM4 with a 100 -year and 50 -year sliding window.........55

2.7. Historical hurricane tracks passing within $100 \mathrm{~km}$ for the AM4 blue hole.................56

2.8. Comparison of hurricane proxy records from the Atlantic basin...........................57

2.9. 100-year window event frequency for paleohurricane records in the North Atlantic.........58

S2.1. Optical dissolved oxygen and salinity in the AM2, AM4 and AM5 blue holes..............61

S2.2. Underwater image of the rim of the AM4 blue hole.................................66

S2.3. Percent sand fraction versus depth in core for AM4 D2 and AM4 D3 ..................63

S2.4. Min, max, and median 100-year moving window event frequency per century

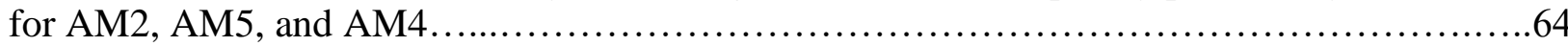

S2.5. AM4 coarse anomaly compared to Blackwood sinkhole record.........................65

S2.6. Age model derived for Salt Pond, MA core and Mullet Pond, FL ...............................66

S2.7. Schematic for regional estimate of expected event frequency .........................67

3.1. Map of Long Island, The Bahamas..................................................101

3.2. Percent sand fraction $(>63 \mu \mathrm{m})$ vs. depth in core from LIBH2 ..............................102

3.3. Coarse anomaly plot for LIBH2 as a function of time................................ 103

3.4. Bottom current speeds in September 2017, under ambient conditions, during

Hurricane Irma, during Hurricane Maria......................................................... 104

3.5. Coarse anomaly data for the modern interval (1850-2016) from LIBH2 ..................105

3.6. 100-year moving window event frequency for Bahamas reconstructions...................106

3.7. Compilations of paleohurricane records from northwest Florida, New England,

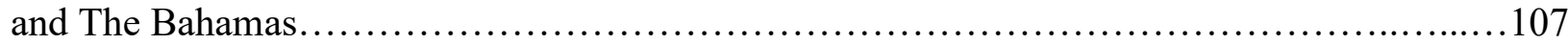

S3.1. Temperature, salinity, and optical dissolved oxygen

in the Long Island blue hole (LIBH) .................................................. 112

S3.2. Percent sand fraction vs depth in core for the polycarbonate surface drive and LIBH $2 \ldots 113$

S3.3. Lead-210 activity with depth in the LIBH2 core..................................113

S3.4. Event frequency per century for LIBH2 with a 100-year and a 50-year sliding window..114

S3.5. Percent sand fraction $(>63 \mu \mathrm{m})$ vs. depth in core from LIBH2 and LIBH1 ...............115

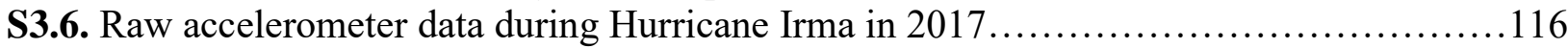

S3.7. Historical hurricane tracks passing within $100 \mathrm{~km}$ of the Long Island

blue hole from 1850-1900 CE..............................................................117

S3.8. Pinpointing the overlap point between the first section of the Long Island

surface drive (LIBH1 D2) and the first section of the longer drive (LIBH2 D1) ...............118

S3.9. Map showing radii around Bahamas sites and historical hurricane tracks..................119

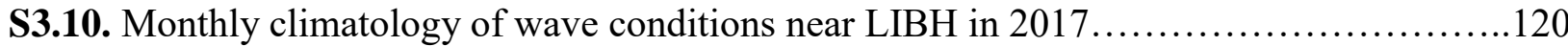

S3.11. Monthly average temperature for the bank near Long Island blue hole in $2017 \ldots \ldots \ldots \ldots .121$

S3.12. Components of regional compilations of hurricane counts from 900-2016 CE...........123

S3.13. Florida HT and LT paleohurricane compilation, The Bahamas paleohurricane compilation, and New England paleohurricane compilation unsmoothed.......................125

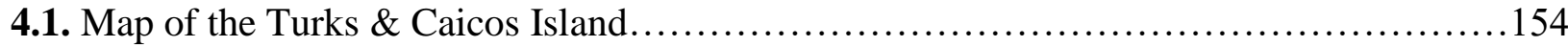


4.2. Optical images and coarse fraction data of the shorter surface drives from

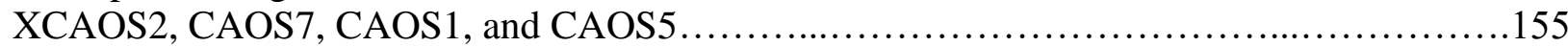

4.3. Percent sand fraction vs. depth in core for CAOS7, CAOS1, and CAOS5 ..................156

4.4. Age model and coarse fraction data for CAOS7 ......................................157

4.5. Coarse anomaly plot for CAOS7 as a function of time............................... 158

4.6. Coarse anomaly data for the modern interval (1850-2019) from CAOS7 .................159

4.7. 100-year moving window event frequency for Bahamas blue hole reconstructions.........160

4.8. Compilations of paleohurricane records from northwest Florida, New England,

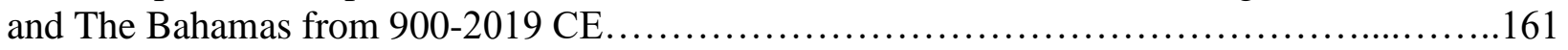

S4.1. Temperature, salinity, $\mathrm{pH}$, and optical dissolved oxygen

in the Middle Caicos blue hole............................................................... 164

S4.2. Overlap point between the first section of each surface drive of CAOS7, CAOS1, and CAOS5 and the first section of their respective longer drives............................166

S4.3. CAOS combined age model with rejected enriched $\delta 13 \mathrm{C}$ values.......................167

S4.4. Coarse anomaly plot for CAOS7 with event beds identified visually or with a coarse fraction event bed threshold........................................................... 168

S4.5. Event frequency/century for CAOS7 with a 100-year and a 50-year sliding window......169 S4.6. Map showing radii around Bahamas sites and historical hurricane genesis

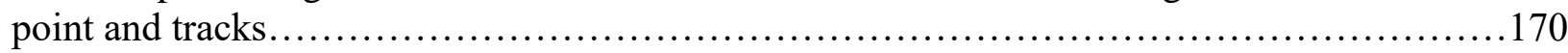

S4.7. Historical hurricane tracks passing within $100 \mathrm{~km}$ of the Middle Caicos blue hole........171

S4.8. D50 and D90 for $>63 \mu \mathrm{m}$ sediment samples across the transect of cores at CAOS........172

S4.9. Regression of compilation storms to all storms in the Bahama Archipelago............173

S4.10. Components of regional compilations of hurricane counts from 500-2019 CE...........175

S4.11. Florida HT and LT paleohurricane compilation, the Bahama Archipelago paleohurricane compilation, and New England paleohurricane compilation unsmoothed........177

S4.12. Example of image processing steps for measuring the grain size of modern event samples....

5.1. South Andros paleohurricane sediment reconstruction compared

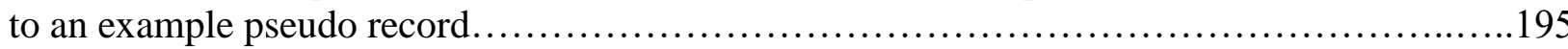

5.2. A single pseudo record compared to the 1000 -member ensemble average ..................196

5.3. Comparison of climate signals for neighboring paleohurricane sites in the Caribbean......197 S5.1. Genesis, track, and intensity comparisons between synthetic

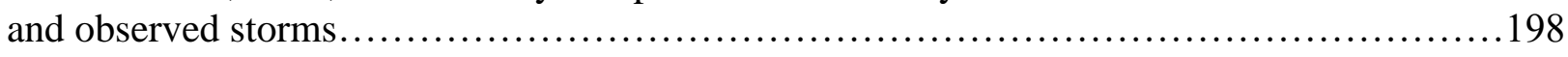

S5.2. Comparing properties of the South Andros Island paleohurricane reconstruction and the pseudo sediment records

S5.3. The number of members needed to converge on the climate signal for South Andros pseudo sediment records................................................................. S5.4. An example of a pure Poisson process based record with its 1000-member ensemble

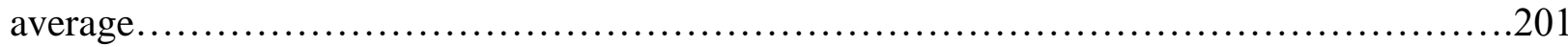
A1-5. Optical images from the ITRAX X-ray fluorescence scanner and coarse fraction....206-210 


\section{List of tables}

S2.1. Radiocarbon results from leaf and plant matter in AM4, AM2, and AM5 ...............68

S2.2. Unused radiocarbon results from leaf and plant matter in AM4, AM2, and AM5.........69

S2.3. Alternate active interval thresholds..........................................69

S2.4. New radiocarbon results from leaf and plant matter in Mullet...........................70

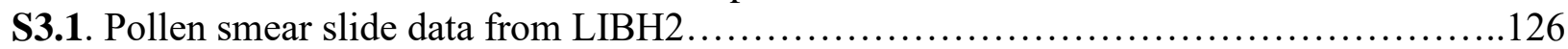

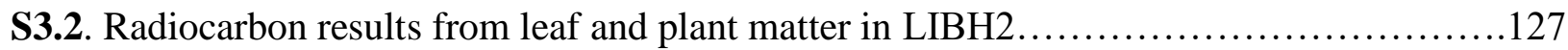

S3.3. Unused Radiocarbon results from leaf and plant matter in LIBH2 and LIBH1 ............127

S4.1. Radiocarbon results from leaf and plant matter in CAOS7 and CAOS5 ................179

S4.2: Unused Radiocarbon results from leaf and plant matter

in CAOS7, CAOS1, and CAOS5 .................................................. 180 


\section{Introduction}

\subsection{The short observational record of hurricane activity}

Coastal communities are home to 40 percent of the U.S. population ( 126 million people) and massive amounts of infrastructure and wealth. In the last three Atlantic hurricane seasons (2017-2019), Hurricanes Dorian, Florence, Michael, Harvey, Irma, and Maria provided vivid examples of the threats that tropical cyclones (TCs) pose to coastal populations and infrastructure. These three hurricane seasons caused more than 300 billion USD in damages and more than 3000 casualties (Kishore et al., 2018; Pasch et al., 2019; Cangialosi et al., 2018).

Climate changes forced by anthropogenic greenhouse gases also have the potential to dramatically change future hurricane hazards in the near and long term. Studies predict that global warming will lead to increased hurricane inundation levels with rising sea levels (e.g., Garner et al. 2017; Lin et al. 2012; Little et al. 2015), a global increase in tropical cyclone precipitation (e.g., Knutson and Tuleya 2004; Patricola and Wehner 2018; Villarini and Vecchi 2013; Wright, Knutson, and Smith 2015), and more intense tropical cyclones (e.g., Bhatia et al. 2018; Emanuel 2013; Knutson et al., 2020; Korty et al. 2017; Sobel et al. 2016; Walsh et al. 2016; Zhang et al. 2017). There are other less confident projections that there will be a decrease in global TC frequency and a slowdown in tropical cyclone translation speed (Knutson et al. 2020). Many of these less confident projections arise from a lack of clear observational evidence to support the relationship between these phenomena and recent global warming.

The International Best Track Archive for Climate Stewardship (IBTrACS) serves as the global observational record of tropical cyclone activity (Knapp et al., 2010). Unfortunately, it is both short and suffers from observation bias (Frappier et al. 2007; Landsea et al. 2010; Landsea and Franklin 2013; Landsea et al. 2004; Vecchi and Knutson 2008, 2011; Villarini et al. 2011). In particular, Atlantic tropical cyclone records only extend back to $1851 \mathrm{CE}$. The earliest data (before the 1940's) is uncertain as it is drawn predominantly from reports from coastal stations, islands, and ships. During this time, it is likely that many storms were missed, particularly short lived or low intensity storms, and others were only observed a few times over their lifetime (Emanuel 2003). During World War II, our ability to detect storms increased with some of the

first aircraft reconnaissance missions into tropical cyclones. Finally, by the 1970's, virtually all 
tropical cyclones worldwide were documented by satellite observations (Emanuel 2003). As a result, it is difficult to determine how much of the changes in TC behavior we observe is due to climate variability versus changes in observing systems.

Due to these uncertainties, many tropical cyclone modeling studies only use the approximately fifty years of data from the satellite era (1970-present) for validation. With such a short dataset, it is difficult to improve or corroborate future projections of tropical cyclone activity. This is particularly true for metrics like tropical cyclone frequency where different models offer diverging predictions for the future (Knutson et al. 2020) and there is no clear anthropogenic influence since the 1970s (Knutson et al. 2019). For example, a recent study found both increasing and decreasing global TC frequency projected for the future depending on the moisture variable used in their TC genesis model (Lee et al., 2020). Unfortunately, both versions of their model created very similar results over the short observational interval (1981$2005 \mathrm{CE}$ ), so it was impossible for the authors to determine which moisture variable was more appropriate.

In addition, the short observational dataset does not allow for elucidating hurricaneclimate interactions on long timescales (multi-decadal to centennial) or during climatic regimes not analogous to the modern in which humans have been significantly influencing the system. Many studies have tied changes in TCs to mechanisms that alter large-scale ambient environmental conditions in the Atlantic. In particular, sea surface temperatures (SSTs) and vertical wind shear (VWS) strongly influence hurricane potential intensity (Emanuel 1987, 1988) and genesis (Camargo, Emanuel, and Sobel 2007; Emanuel 1989), respectively. Warmer SSTs provide energy to tropical cyclones in the form of moist enthalpy, and TCs only develop over ocean water with surface temperature exceeding $26^{\circ} \mathrm{C}$ (Emanuel 2003; Gray 1998). Vertical wind shear, on the other hand, is defined as the difference between horizontal winds in the upper $(200 \mathrm{hPa})$ and lower $(850 \mathrm{hPa})$ troposphere. Lower vertical wind shear favors hurricane convective organization and intensification (Merrill, 1987; Rios-Berrios and Torn, 2017).

There are a variety of different climate oscillations and external forcing factors that influence changes in the SST and VWS patterns in the Atlantic. These include the North Atlantic Oscillation (Elsner and Kocher 2000; Kossin, Camargo, and Sitkowski 2010), Atlantic Multidecadal Oscillation (Goldenberg et al., 2001; Clement et al., 2015; Ting et al., 2019), El 
Niño Southern Oscillation (ENSO) (Goldenberg and Shapiro, 1996; Gray, 1984; Chu, 2004), and volcanic eruptions (Evan, 2012; Korty et al., 2012; Pausata and Camargo, 2019), among others. Many of these mechanisms have multivariate, multi-scalar, and non-linear responses and occur on different timescales. This makes it very difficult to fully characterize the response of TC activity to these phenomena, especially over the short observational record.

For example, studies show that large volcanic eruptions release aerosols into the atmosphere which result in cooling of the ocean surface (Hansen et al., 2005) and subsurface (Church et al., 2005) reducing TC activity on short timescales (1-3 years) (Evan 2012; Korty, Camargo, and Galewsky 2012). However, much of this work is based on a relatively small number of eruptions, since there have only been $\sim$ five large volcanic eruptions since $1970 \mathrm{CE}$ (Church et al., 2005). With so few events, it is difficult to fully characterize the response of TC activity to volcanic eruptions. Indeed, modeling studies suggest the time of year an eruption occurs (Stevenson et al., 2017), its latitude (Pausata and Camargo, 2019), and the initial climate conditions (Zanchettin et al., 2019) dramatically impact the response of the climate system and in turn the TC response to volcanic activity.

\subsection{Paleohurricane research in the North Atlantic}

Paleohurricane records allow us to extend observations of hurricanes back thousands of years using both documentary records (e.g., Boose, Chamberlin, and Foster 2001; Chenoweth and Divine 2008; Ludlum 1997; Tucker 1982) and geological and biological archives of hurricane activity. Commonly used natural archives of paleohurricane activity include tree-ring (Altman et al., 2018; Miller et al., 2006), coral-ring (Nyberg et al., 2007), speleothem archives (Baldini et al. 2016; Frappier et al. 2007) as well as sedimentary archives from coastal lakes, lagoons, and marshes (e.g., Bregy et al. 2018; Donnelly et al. 2015; Lane et al. 2011; Liu and Fearn 1993). These records provide a valuable perspective on the longer term relationship between climate and hurricane activity.

The vast majority of paleohurricane records document coarse-grained overwash deposits in sedimentary archives from back-barrier environments (e.g., lagoons, ponds, marshes). During a hurricane event, there are high winds and waves which suspend and transport coarse-grained (sand-sized or greater) material from a seaward locale and deposit it into coastal basins where 
finer-grained sediments dominate. Sediment cores from these basins indicate distinct coarsegrained deposits called event beds interbedded with fine-grained mud. Event beds are often distinguished visually (i.e., light colors, larger particles, massive bedding) and using grain-size analyses (Wallace et al., 2014). Many of these coarse layers date within uncertainties to historical hurricanes of a known intensity that passed close to the site. These modern analogues allow researchers to provide a rough estimate of the storm intensity required for inducing overwash at the site. For example, cores collected from a back-barrier lagoon on Vieques, Puerto Rico (Donnelly and Woodruff, 2007) captured coarse deposits from the nearby passage of two intense storms (i.e., Hugo 1989, San Felipe hurricane 1928). From this information, the authors set the sensitivity of the site to only intense hurricanes (Category 3 and above).

In the last few decades, there has been a growing number of paleohurricane studies in the North Atlantic that document local hurricane strikes over several millennia (e.g., Boldt et al. 2010; Brandon et al. 2013; Bregy et al. 2018; Donnelly et al. 2015; Lane et al. 2011). These archives indicate extended periods of historically unprecedented levels of intense hurricane activity in the Atlantic ('active intervals') followed by periods of very few storm passages ('quiet intervals'). Taken together, reconstructions from the U.S. coastline indicate spatial heterogeneity in the timing of these active and quiet intervals over the past 2000 years. Coastal pond and marsh records from New England capture increased hurricane strikes from 1400-1675 CE (van de Plassche et al., 2006; Donnelly et al., 2015; Boldt et al., 2010). At the same time, records from back-barrier ponds and sinkholes in northwest Florida (Brandon et al., 2013; Lane et al., 2011) indicate relative quiescence. Instead, these records from the Gulf Coast indicate increased storm strikes from 1100-1400 CE, a time span when the New England records showed fewer storm landfalls. Explaining this spatial heterogeneity in North Atlantic hurricane activity is still an open question in part because of the low spatial coverage of high resolution paleohurricane records in the Atlantic and the confounding effects of the stochastic nature of hurricane landfalls at a site.

Unfortunately, it has been difficult to increase the spatial coverage of high resolution records from the U.S. coastline, because many paleohurricane sites (Donnelly and Woodruff, 2007; Toomey et al., 2013; van Hengstum et al., 2016; McCloskey and Liu, 2012a; Liu and Fearn, 1993) have low sediment accumulation rates and high flooding thresholds which result in low resolution records of only the highest magnitude events. The low sediment accumulation 
rates are a particularly important problem, because they can result in individual deposits or clusters of deposits becoming amalgamated together and thus indistinguishable (Wallace et al., 2014). In addition, the random nature of hurricane strikes makes it difficult to tell whether paleohurricane patterns are due changes in climate or just random clustering of events under a stationary climate (Woodruff et al., 2008). Quantifying how much of the variability in paleohurricane records is due to randomness is an important unsolved question in the field. In this thesis, I generate some of the first high resolution records of paleohurricane activity from the Bahama Archipelago and use these records both to address the spatial heterogeneity in paleohurricane patterns observed in the Atlantic and to quantify the role randomness plays in generating paleohurricane signals.

\subsection{The potential of blue hole basins for paleohurricane records in the tropical Atlantic}

Recent work has explored the suitability of blue hole environments to paleohurricane research (Gischler et al., 2008; van Hengstum et al., 2014; Shinn et al., 1996). Blue holes are a type of coastal karst basin and are found throughout the carbonate terrain of the hurricane-prone tropical and subtropical Atlantic. These basins are submerged deep vertical holes that likely formed through internal dissolution of limestone bedrock, cave development, and subsequent collapse of cave ceilings (Mylroie et al., 1995; Gischler et al., 2013; Dill, 1977). These basins are typically located in high-energy environments on shallow carbonate platforms with ample local sediment sources (e.g., reefs, beaches) (Gischler et al., 2008; Shinn et al., 1996). Blue holes are ideal environments for paleohurricane research, because they 1) have poor water circulation which promotes anoxic bottom water and little to no bioturbation (Gischler et al., 2008), 2) have plenty of accommodation space for sediments (Dill, 1977), and 3) serve as an effective sediment trap (Shinn et al., 1996). Indeed, preliminary studies have discovered coarse-grained sand to silt layers ranging from about a centimeter to a meter thick in blue hole basins interbedded with finegrained carbonate mud (van Hengstum et al., 2014; Gischler et al., 2008; Denommee et al., 2014). These layers have been interpreted as high energy deposits from tropical cyclones passing over the basins. In Chapter 2-4, I present high resolution records of hurricane activity over the past 1500 years captured from cores taken from blue holes on South Andros Island (Chapter 2), Long Island (Chapter 3) and Middle Caicos Island (Chapter 4) in the Bahama Archipelago. I use 
these records to evaluate temporal variability in hurricane strikes in the region and how those patterns relate to records from the U.S. coastline.

Although blue hole basins do capture coarse-grained deposits during proximal hurricane passages, there is not a lot known about the sedimentary processes occurring in these environments during hurricane strikes. This is predominantly because it is extremely difficult to observe blue holes during an intense hurricane event. In-situ instruments are often damaged or lost. Unlike back-barrier environments, blue holes are fully submerged making it difficult to remotely sense geomorphic changes after storm events. In addition, these blue hole sites are often located in remote areas that are difficult to access, complicating a return to the sites in the immediate aftermath of a destructive hurricane. Unlike many back-barrier basins in which coarse sediment enters through overtopping a coastal barrier, coarse sediment can be transported to a blue hole from all sides. Therefore, local conditions in the blue hole system likely play a large

role in determining whether a particular storm leaves a coarse deposit. In Chapters 3 and 4, I use empirical data from passage of Hurricane Irma in 2017 collected at blue hole sites on two different islands to investigate the importance of local conditions in instigating coarse-grained sediment transport.

\subsection{Paleohurricane modeling studies}

Very little work has been done to integrate paleohurricane records with existing tropical cyclone models. Tropical cyclone modeling involves simulating hurricanes using global climate models (GCMs). Unfortunately, the current generation of GCMs from the Coupled Model Intercomparison Project Phase 5 (CMIP5), and those expected from CMIP6, are not high enough resolution to simulate the inner cores of hurricanes $(\sim 10 \mathrm{~km})$. Attempts to simulate hurricanes directly in GCMs result in TC-like storms that are typically larger in size and much weaker than observed storms (e.g., Camargo 2013; Walsh et al. 2013; Walsh et al. 2015).

Fortunately, there are multiple different methods that can be used to simulate hurricanes without the resolution issues including regional models, downscaling models, and TC indices (Camargo and Wing, 2016). Simulating hurricanes directly in smaller regional climate models can allow for much higher resolutions $(\sim 20 \mathrm{~km})$. The regional models are forced at their boundaries by environmental variables from global models. Unfortunately, such regional model 
simulations typically fail to reproduce intense tropical cyclones (>Category 3) (e.g., Knutson et al. 2007; Wu et al. 2014). Downscaling methods, on the other hand, can reproduce even the most intense storms. These techniques typically produce large numbers of synthetic storms using the coarsely resolved boundary conditions of the GCM as inputs into statistical or dynamical simulations of individual storms (e.g., Emanuel 2006; Knutson et al. 2013; Lee et al. 2020; Villarini and Vecchi 2013b). Finally, many studies use various indirect measures of TC activity like Genesis Potential Indices (e.g., Emanuel 2010; Tippett, Camargo, and Sobel 2011) or Potential Intensity (e.g., Emanuel 1988).

Most of these tropical cyclone modeling studies focus on twentieth century climate (e.g., Knutson et al. 2007) and future climate change scenarios (e.g., Emanuel 2013; Lee et al. 2020; Villarini and Vecchi 2013b) — there has been very little work done using paleoclimate runs from global climate models. Of the studies that have been done, most are focused on more distant past climates (i.e., Pliocene (Fedorov et al., 2010), Last Glacial Maximum (LGM), Holocene (Pausata et al., 2017; Korty et al., 2012)). Many of these studies show that cooler climates do not necessarily generate fewer tropical cyclones globally. For example, studies of tropical cyclones in the cooler climate associated with the LGM found more global TCs (Sugi et al., 2015; Korty et al., 2011) or little difference (Yoo et al., 2016) in TC populations compared to today. Unfortunately, most of these studies are focused on timescales outside the past few millennia covered by paleohurricane proxies. Only two recent studies have investigated millennial-scale tropical cyclone simulations (Kozar et al., 2013; Reed et al., 2015). Both of these studies indicate that counts of landfalling tropical cyclones over the past millennium match relatively well with basin-wide TC activity in the Atlantic. In Chapter 5, I present the first work comparing paleohurricane records to downscaled storms run over the past millennium. In particular, I use these synthetic storms to interpret the paleohurricane proxies presented in Chapters 2-4 and assess whether the signal in Bahamian paleohurricane records is dominated by climate variability or stochasticity. 


\title{
2. Intense Hurricane Activity Over the Past 1500 Years at South Andros Island, The Bahamas
}

This chapter was originally published as: Wallace, E.J., Donnelly, J.P., van Hengstum, P.J., Wiman, C., Sullivan, R.M., Winkler, T.S., D’Entrement, N.E., Toomey, M.R., and Albury, N.A., 2019, Intense hurricane activity over the past 1500 years at South Andros Island, The Bahamas: Paleoceanography and Paleoclimatology, doi: 10.1029/2019PA003665. Used with permission as granted in the original copyright agreement.

\begin{abstract}
Hurricanes cause substantial loss of life and resources in coastal areas. Unfortunately, historical hurricane records are too short and incomplete to capture hurricane-climate interactions on multidecadal and longer timescales. Coarse-grained, hurricane-induced deposits preserved in blue holes in the Caribbean can provide records of past hurricane activity extending back thousands of years. Here we present a high resolution record of intense hurricane events over the past 1500 years from a blue hole on South Andros Island on the Great Bahama Bank. This record is corroborated by shorter reconstructions from cores collected at two nearby blue holes. The record contains coarse-grained event deposits attributable to known historical hurricane strikes within age uncertainties. Over the past 1500 years, South Andros shows evidence of four active periods of hurricane activity. None of these active intervals occurred in the past 163 years. We suggest that Intertropical Convergence Zone position modulates hurricane activity on the island based on a correlation with Cariaco Basin titanium concentrations. An anomalous gap in activity on South Andros Island in the early 13th century corresponds to a period of increased volcanism. The patterns of hurricane activity reconstructed from South Andros Island closely match those from the northeastern Gulf of Mexico but are anti-phased with records from New England. We suggest that either changes in local environmental conditions (e.g., SSTs) or a northeastward shift in storm tracks can account for the increased activity in the western North Atlantic when the Gulf of Mexico and southeastern Caribbean are less active.
\end{abstract}




\subsection{Introduction}

In modern climate the North Atlantic basin experiences on average 12 named tropical cyclones per year (coast.noaa.gov/hurricanes, 2017). Many of these storms will either form in or pass through the warm waters of the Gulf of Mexico and Caribbean Sea on their way to the North American East Coast or Gulf Coast, putting coastal property and lives at risk. In 2017, Hurricanes Harvey, Irma, and Maria struck many Caribbean islands and locations along the U.S. coastline including Texas, Puerto Rico, and the Florida Keys. These three intense hurricanes killed thousands of people and caused approximately 215 billion USD in damage (Kishore et al., 2018; Munich Re, 2017). In 2018, Hurricanes Florence and Michael devastated portions of the U.S. coastline causing approximately 50 billion USD in damage and killing hundreds of people (https://www.ncdc.noaa.gov/billions/, 2019). Just this year (September 1, 2019), Hurricane Dorian made landfall in the northern Bahamas at Category 5 strength with sustained winds at 82 $\mathrm{m} / \mathrm{s}$ and storm surge estimated at $7 \mathrm{~m}$ (www.nesdis.noaa.gov/content/hurricane-dorian-2019, 2019).

Despite the destructive nature of storms such as these, little is known about the forces that alter hurricane activity, particularly on multi-decadal to centennial timescales. One challenge is that the current observational record is short; Atlantic hurricane records maintained by the National Oceanic and Atmospheric Administration (NOAA) only extend back to $1851 \mathrm{CE}$ and suffer from observation bias (Frappier et al., 2007; Landsea \& Franklin, 2013). This relatively short and potentially incomplete dataset prevents a rigorous examination of the climate forcing mechanisms that influence storm activity on multi-decadal to centennial timescales. This deficiency inhibits our ability to resolve hurricane/climate-interactions during climatic regimes not analogous to the short instrumental (and anthropogenically altered) period.

In the last decade, high-resolution sedimentary records of paleohurricane activity from coastal basins have been developed in an attempt to extend the hurricane record back in time (Denommee et al., 2014; Donnelly et al., 2015; Donnelly \& Woodruff, 2007; Gischler et al., 2008; Lane \& Donnelly, 2012; Lane et al., 2011; Toomey et al., 2013; van Hengstum et al., 2014). Strong winds, storm surge, currents, and waves generated by hurricanes displace and transport coarse grains such as shell fragments, sand, and gravel into depositional environments where finer grained sediments typically dominate. There, they form distinct layers of coarse 
material among the silt and/or clay that typically accumulate in these coastal basins, thereby providing a natural geological archive of past hurricane occurrence.

All of these reconstructions show periods of elevated hurricane activity interspersed by intervals of relative quiescence. Two records from the western coast of Florida (Mullet Pond (Lane et al., 2011); Spring Creek Pond (Brandon et al., 2013)) show marked variability in the frequency of high intensity events in the Gulf of Mexico. Lane et al. (2011) documented several active periods of intense hurricanes with the most active interval stretching from 2800 to 2300 years BP (years before present with present defined as 1950 CE by convention) with almost six intense events/century. Records from the Caribbean also show significant changes in hurricane frequency over the past millennium (Denommee et al., 2014; van Hengstum et al., 2014).

A growing number of paleohurricane reconstructions document the regional heterogeneity of past storm activity in the North Atlantic. In particular, records from the U.S. East Coast (Boldt et al., 2010; Donnelly et al., 2015; Mallinson et al., 2011) suggest heightened hurricane activity between 1400 and $1675 \mathrm{CE}$, while records from the Gulf of Mexico and Caribbean (Brandon et al., 2013; Lane et al., 2011; Denommee et al., 2014) suggest relatively low numbers of storms over this same period. These Gulf of Mexico and Caribbean records remain active up until the early 1400s while the U.S. East Coast records are quiet. This regional variability likely stems either from unfavorable local environmental conditions around the U.S. East Coast, from climate driven geographic variability in hurricane tracks and intensity, and/or random variability in hurricane paths. Using NCEP/NCAR Reanalysis data since 1948, Kossin (2017) illustrates the unfavorable local environmental conditions hypothesis by documenting periods in which vertical wind shear and sea surface temperature (SST) values in the Main Development Region (MDR) of the Atlantic were favorable for hurricane growth and survival while regional conditions along the U.S. East Coast were not. Other studies offer support for a second hypothesis suggesting that shifts in the positioning of the North Atlantic subtropical high (NASH) can dramatically change where hurricanes track (Elsner et al., 2000; Liu \& Fearn, 1993). In particular, a more southwesterly position of the NASH might result in more straight moving hurricanes that track through the Caribbean Sea and make landfall in the Gulf of Mexico. Finally, the stochastic nature of hurricane landfalls makes it possible that the number of storms impacting a particular location might change from one sampled period to the next even if overall Atlantic hurricane activity remained stationary through time. 
More paleohurricane records are needed from the Caribbean Sea to investigate the regional coherency of the existing records from the North American coastline or to identify any time transgressive shifts in hurricane activity across records. In addition, of the records we do have from the Caribbean (e,g., Donnelly \& Woodruff, 2007; Toomey et al., 2013; van Hengstum et al., 2016), many have low sediment accumulation rates and high flooding thresholds, which result in rather low resolution records of only the highest magnitude events. A combination of undercounting in cores with low sedimentation rates (Woodruff et al., 2008) and the low occurrence rates of hurricanes in these records makes it difficult to distinguish between significant changes in hurricane tracks and random clustering of storm events at a particular location.

The ample accommodation space of relatively deep coastal karst depressions can result in systems with exceedingly high sedimentation rates where ambient fine-grained sediment fluxes are high. These basins are also often located in regions of the Atlantic prone to hurricane activity. In addition to the two published records of high-energy marine flooding events developed from a western Florida sinkhole (Lane et al., 2011) and a sinkhole on Abaco Island in The Bahamas (van Hengstum et al., 2016), there have been several records developed from coastal karst basins in the Caribbean Sea. Gischler et al. (2008) and Denommee et al. (2014) documented a 1500year sedimentary archive of hurricane passages in the $125 \mathrm{~m}$ deep Lighthouse Reef Blue Hole, Belize. van Hengstum et al. (2014) further assessed the suitability of blue holes for hurricane reconstructions and presented a sediment record of hurricane-induced event deposits from a blue hole on the Little Bahama Bank. Overall, deep coastal karst basins, like blue holes and sinkholes, provide several advantages for cyclone research: (i) after deposition, the sediments remain protected from ongoing wave action and coastal perturbations (e.g., other hurricanes) (Shinn et al., 1996); (ii) low benthic productivity, or even anoxia, limits bioturbation (Gischler et al., 2008); (iii) adjacent reefs, beaches, and/or flats provide abundant regional sediment supply (Gischler et al., 2008; Shinn et al., 1996); (iv) the basins provide accommodation space for sediments that is less dependent on sea level changes than other environments such as coastal wetlands or shallow lagoons (Dill, 1977); and (v) many coastal karst basins are not subject to complicating barrier beach dynamics (see Otvos, 2011).

Blue holes are water filled vertical openings that develop from the internal dissolution and cave development of carbonate banks and islands and subsequent ceiling collapse (Gischler 
et al., 2008, Gischler et al., 2013; Mylroie et al., 1995). Their high background sedimentation rates and wide distribution in hurricane prone regions make blue holes ideal candidates for increasing the spatial coverage of hurricane reconstructions. Background sedimentation in blue holes is typically clay- to silt-sized carbonate particles produced locally through inorganic precipitation in carbonate lagoons and peritidal flats (Milliman et al., 1993; Shinn et al., 1969). Coarse-grained gravel to sand layers in blue holes interbedded with allochthonous fine-grained carbonate clay and silt have been interpreted as high-energy deposits related to proximal hurricane passage (Denommee et al., 2014; Gischler et al., 2008; van Hengstum et al., 2014).

Similar to back-barrier environments, during a storm, currents and waves transport coarse-grained sediment from the surrounding reef flat or carbonate bank into the blue hole (Figure 2.1) (Gischler et al., 2008). Unlike back-barrier environments, the transported sediment can be sourced from all sides of the blue hole as well as from a collapse of the sediment slope on the rim of the hole (Brown et al., 2014). Since the blue hole is fully submerged, the transported sediment does not need to overtop a coastal barrier to leave a deposit. Instead, bottom currents need to be strong enough to suspend and transport larger grains over the hole. Once these grains are deposited in the hole, they cannot be reworked due to the ample accommodation space and large water depths in many blue holes. In addition, the rate of sediment accumulation in blue holes is often much higher than back-barrier lagoons, because blue holes receive more finegrained sediment under normal wave and tide conditions (Milliman et al., 1993). Additionally, it is unlikely that the sedimentary records contained in blue holes have been impacted by sea level driven shoreward barrier migration which has seriously affected the sensitivity of many backbarrier sites to storm overwash during the Holocene (Wallace et al., 2014).

Event beds identified in the modern facies of sediment cores from blue holes can be attributed to storms documented in the NOAA best track dataset (coast.noaa.gov/hurricanes, 2017) that passed close to the site of the core. For example, van Hengstum et al. (2014) found two coarse-grained event deposits in the instrumental period from Thatchpoint Bluehole on Abaco Island, The Bahamas. These event beds dated within uncertainties to Hurricane Floyd in 1999 and Hurricane Jeanne in 2004 that passed directly over Abaco.

In this study, we present three temporally overlapping high-resolution records of the frequency of event beds in blue holes from South Andros Island in The Bahamas. The longer reconstruction (AM4), spans the last 1500 years and is corroborated by results from shorter 
records (AM5 and AM2) from two nearby blue holes. The two most recently deposited event beds temporally correlate to the two most intense direct hurricane landfalls on South Andros (Unnamed 1919 and 1945 category 3 storms). The AM4 sediment record is one of the longest continuous cores collected from a blue hole to date $(18 \mathrm{~m})$ and is one of the best resolved records (in temporal resolution and length) of Atlantic paleohurricane activity. It is also well situated to assess the regional coherency of long-term hurricane activity from the Caribbean and U.S. coastline. We evaluate the temporal variability of hurricane activity on South Andros and the geographic patterns of hurricane activity along the U.S. East Coast, Gulf Coast, and the Caribbean over the past 1500 years by comparing this record to other reconstructions.

\subsection{Study Sites and Methods}

\subsubsection{Study Sites}

Andros Island is a carbonate island located on the Great Bahama Bank in the northeastern Caribbean (Figure 2.2). It is separated from the North American mainland by the Florida Strait to the northwest. This strait carries the Florida Current, the beginning of the Gulf Stream, the warm western boundary current that runs along the U.S. eastern coastline toward Newfoundland. The Great Bahama Bank is made up of horizontally bedded limestones of a shallow water marine origin (Spencer, 1967; Mullins and Lynts, 1977). The banktop Holocene parasequence consists of carbonate sand, clay, and silt and living reefs with shallow marine, coral, and eolian limestone exposed in some sections. Andros Island is the largest of the Bahama islands and has at least 200 blue holes (Juberthie and Iliffe, 1994). It is made up of three main land areas, North Andros, Mangrove Cay, and South Andros, which are separated by tidal channels (Figure 2.2). The eastern margin of Andros is at a higher elevation and composed of sub-aerially exposed Pleistocene eolianite (Carew et al., 1998), while the western margin is dominated by tidal carbonate flats and algal marshes that are dissected by tidal channels (Shinn et al., 1969; Black, 1933; Maloof and Grotzinger, 2012). Radiocarbon dating of facies identified in cores suggests that the modern geomorphic setting of the marsh and tidal flats was established by 2000 years ago (Maloof and Grotzinger, 2012). The focus of our study is on cores taken from blue holes within the channels of the carbonate tidal flats on South Andros (Figure 2.2).

We collected cores $\left(\mathrm{AM} 4-\mathrm{N} 23.78^{\circ}, \mathrm{W} 77.72^{\circ}\right.$; AM2 - N 23.79 $; \mathrm{W} 77.65^{\circ}$; AM5 - N $23.77^{\circ}, \mathrm{W} 77.71^{\circ}$ ) from three different blue holes on the southwestern margin of South Andros 
Island in November 2014 (Figure 2.2). All three blue holes lie in tidal channels (<4 $\mathrm{m}$ in depth) within carbonate flats. Both red and black mangroves species grow on the tidal flats and algal marshes surrounding the blue holes. The sediments of the flats surrounding the blue holes are composed of unconsolidated carbonate mud that is mostly inorganically precipitated aragonite, with sand $(>63 \mu \mathrm{m})$ to gravel $(\sim 25 \mathrm{~mm})$ sized particles largely consisting of shell fragments (see Black, 1933; Milliman et al., 1993; Shinn et al., 1969). The most common fauna are gastropods, pelecypods, and foraminifera (Shinn et al., 1969).

The AM5, AM2, and AM4 blue holes are $150 \mathrm{~m}, 95 \mathrm{~m}$, and $80 \mathrm{~m}$ in diameter, respectively, with maximum depths of $17 \mathrm{~m}, 18 \mathrm{~m}$, and $95 \mathrm{~m}$, respectively (Figure 2.2). Conductivity, temperature and depth (CTD) profiles for each of these circular basins indicates a halocline, below which the water in the blue hole is thermally and salinity stratified, and dissolved oxygen profiles show that the bottom conditions in each blue hole are dysoxic to anoxic (Figure S2.1).

Andros Island is positioned along the paths of many observed hurricanes that formed in the North Atlantic Ocean and Caribbean Sea. Since 1851 CE, 13 tropical storms and 7 hurricanes (category 1-5 on the Saffir-Simpson Scale) passed within $50 \mathrm{~km}$ of South Andros Island according to the NOAA best track dataset (coast.noaa.gov/hurricanes, 2017).

\subsubsection{Field Methods}

To assess the suitability of each field site as a coring location, we used an Edgetech 3100 Chirp sub-bottom sonar system to map sub-bottom stratigraphy, sweeping a bandwidth range from 4-24 kHz (Figure S2.2). These data, in combination with CTD profiles (Figure S2.1), allowed us to identify blue hole locations with a sizeable sediment package and where underwater caves connecting to the open ocean are unlikely.

Coring was carried out using a Rossfelder P-3 underwater vibracorer from a portable raft. We collected continuous vibracores from the blue holes: AM4 ( 18 m in length), AM2 ( 7 m) and AM5 ( 8 m). In the case of the longer AM4 core, we failed to recover the sediment-water interface due to degassing of the sediment upon recovery and therefore, collected a short surface core from the same location using a clear polycarbonate tube with a core catcher to ensure that the sediment water interface was intact. The top $108 \mathrm{~cm}$ of the AM4 record is drawn from the replicate core where we carefully curated the core top. A comparison of the coarse fraction data 
from the longer drive and the replicate core indicate the point of overlap between the two sediment records (Figure S2.3).

\subsubsection{Sediment Analysis and Age Control}

Following recovery, cores were sectioned and transported to the laboratory where they were split and described. In order to determine the percentage of coarse material, each core was sampled contiguously at $1-\mathrm{cm}$ resolution. Samples of approximately $2 \mathrm{~cm}^{3}$ were dried at $100{ }^{\circ} \mathrm{C}$ for 8 hours and then weighed to determine their dry mass. Each sample was wet sieved at $63 \mu \mathrm{m}$ to retain the sand size, and greater, fraction and then dried to determine its 'coarse fraction' by dry weight (Figure 2.3).

Age constraints for the cores were derived from radiocarbon dating of terrestrial plant macrofossils. Mangrove leaves and plant matter preserved within the cores were dated at the National Ocean Science Accelerator Mass Spectrometer (NOSAMS) facility at Woods Hole Oceanographic Institution (WHOI). AM5, AM2, and AM4 have 15 dates over $780 \mathrm{~cm}$, 17 dates over $720 \mathrm{~cm}$, and 28 dates over $1761 \mathrm{~cm}$, respectively (Table S2.1 and S2.2). The radiocarbon results were calibrated with IntCal13 (Reimer et al., 2013). Age models were developed using the Bayesian accumulation histories for deposits (BACON v 2.2) software (Blaauw and Christen, 2011). For the top of each core, age control was established using post-bomb radiocarbon dates with fraction modern values $\left(\mathrm{F}^{14} \mathrm{C}\right)$ exceeding 1.000 , meaning these samples were alive post1950 AD. These samples were calibrated with CALIbomb using the compiled Northern Hemisphere Zone 2 dataset (Hua et al., 2013).

Four radiocarbon samples were excluded from the age chronology of AM5 and two samples from AM2 as they lay outside the age depth ordering implied by the remainder of the dating evidence (Table S2.2 and Figure 2.4). In AM4, all 28 ages are in chrono-stratigraphic order. In the top of the record, there is a high density of dated samples with multiple possible calibrated age ranges, which results in abrupt changes in sedimentation rate in the Bayesian agemodel analysis that are not correlated with event bed deposition. Therefore, we excluded four samples from the top $250 \mathrm{~cm}$ of the AM4 age model (Figure 2.4A). Removing these dates results in a near linear slope of the age model that matches the other $1700 \mathrm{~cm}$ of core and suggests a nearly constant sedimentation rate. The four samples omitted from the BACON age-model 
calculation contain calibrated ages ranges that date to within the $95 \%$ uncertainty bounds of the AM4 age model (Figure 2.4A).

\subsubsection{Event threshold, Attribution and Frequency}

We identified event beds in the cores based on visual inspection and using the coarse fraction data. The visible event beds were cross checked against the coarse fraction peaks identified as storms. Event beds in the South Andros sediment cores vary in appearance. Most event beds contain abrupt lower contacts, are light grey colored (Munsell color 2.5Y 6-1), contain visibly coarser grains, contain no sign of laminations, and range from one to fifteen centimeters in thickness. In a few cases, however, a coarse-grained event bed can only be distinguished visually by higher concentrations of mangrove leaf fragments. Event beds thicker than ten centimeters were reduced down to one centimeter in thickness for the age model as the event beds represent nearly instantaneous deposition.

In addition, we established an event bed cutoff in the coarse fraction data for each sediment core following the procedures of Donnelly et al. (2015). First, the coarse anomaly for each sediment core was calculated by subtracting a 10-point moving average from the coarse fraction data (Figure 2.3). This filter limits the influence of decadal variations in local background sedimentary processes while preserving coarse fraction peaks that are likely associated with short-lived storm events. We excluded coarse fraction peaks over $10 \%$ from this filter to prevent higher magnitude coarse fraction peaks from exerting a large influence on the filter and causing the exclusion of neighboring smaller peaks.

We define events as coarse anomaly peaks that exceed one sigma (68\%) of the cumulative distribution of the coarse fraction data in the observational interval. The observational interval extends back to $1851 \mathrm{CE}$, the start of the best track dataset. The coarse fraction thresholds for AM4, AM2, and AM5 are 5.87\%, 2.77\%, and 4.94\%, respectively (Figure 2.5).

Having established an event bed threshold and identified all the events in the records, we calculated an event frequency per century using the approach of Lane et al. (2011). This involved counting the number of events in a 100-year sliding window. This time window was chosen to allow for centennial scale comparisons in the record and to facilitate comparison with other records using century scale windowing (Figure 2.5). Event frequency plots using the $95 \%$ 
confidence bounds for the age of each event are included in the supplemental material (Figure S2.4). Results for 50-year sliding windows are also presented to allow for study of the multidecadal variations in the record (Figure 2.6). To assess the sensitivity of the sites to hurricane induced deposition, we compared event deposits in the top sections of the core to observational storm data.

\subsubsection{Calculating expected event frequency}

The number of storms hitting an island may vary as a result of changes in hurricane climate or random chance. Therefore, to determine the significance of changes in event frequency on South Andros, we calculated the cumulative Poisson probability $(P)$ of the event frequency equaling or exceeding some value $(k)$ :

$$
P(x, \lambda)=1-\sum_{k=0}^{k} \frac{\lambda^{k} e^{-\lambda}}{k !}
$$

We calculated two estimates for the expected frequency $(\lambda)$ for South Andros sites: 1) a site-specific estimate calculated using the frequency of category 3 or above hurricanes that passed within $50 \mathrm{~km}$ of the AM4 blue hole in the best track dataset (1851-2014), and 2) a regional estimate calculated using the methods described in Section 2.S.1. For the site-specific estimate, two storms passed within a 50-km radius at category 3 and above strength (coast.noaa.gov/hurricanes, 2017), resulting in an expected frequency of 1.23 events/century. For discussion of the site radius and storm intensity cutoff choices for the site-specific expected frequency calculation, see Section 2.4.1. The regional estimate results in an expected frequency of 2.12 events/century.

We determined active periods in the core using confidence intervals encompassing the expected random variability of hurricane strikes. Assuming event occurrence follows a Poisson process with a mean rate of 1.23 events/century for the site-specific estimate and 2.12 events/century for the regional estimate, we computed solutions for the $95^{\text {th }}$ and $5^{\text {th }}$ percentile (Ulm, 1990). For our AM4-specific estimate, these values are 3.86 and 0.22 events/century, respectively, and for our regional estimate, they are 5.16 and 0.65 events/century, respectively (Figure 2.6 and Table S2.3). Over the observational period, fewer storms on average have passed by South Andros than other regions in the Caribbean included in our regional estimate (coast.noaa.gov/hurricanes, 2017). Thus, our regional estimate, which applies to the entire 
northern Caribbean, overestimates the random variability in storm tracks on South Andros where there have been fewer storms on average. Therefore, we define active periods on South Andros Island using the site-specific estimates but still show the regional estimate cutoffs in Figure 2.6. 'Active periods' were characterized as time intervals when the 100-year window event frequency exceeded each site's specific threshold.

To define significant quiet intervals, we calculated the probability of having each time gap between event beds in the record. The probability of having no events $\left(P_{T}\right)$ for $r$ number of years between each event in the record is given by:

$$
P_{T}=(1-1 / T)^{r}
$$

The recurrence interval $(T)$ was set at 81.5 year/event based on the two intense hurricanes that passed the AM4 blue hole over the length of best track dataset (163 years). Time gaps between events in the record where the probability of having no events over this length of time $\left(P_{T}\right)$ was below $50 \%$ are characterized as quiet intervals. We also calculated the same probability using a recurrence interval spanning over all events in the record (29 year/event) for comparison (Figure 2.6).

\subsection{Results}

\subsubsection{Event bed description}

On visual inspection, sediment cores from all three blue holes have similar lithofacies: light grey (Munsell color 2.5Y 6-1) colored sediment with tan (Munsell color 2.5Y 7-4) and white (Munsell color 2.5Y 8-1) laminations. The sediment is predominantly fine-grained carbonate with occasional very-fine gravel $(2-4 \mathrm{~mm})$ to medium sand $(0.25-0.5 \mathrm{~mm})$ layers (Figure 2.3D and 2.3E). There is no evidence of bioturbation.

Both the AM2 and AM4 sediment cores exhibit a reduced rate of sediment accumulation moving up-core (past to present). AM2 starts with a sedimentation rate of $1.0 \mathrm{~cm} / \mathrm{yr}$ for first 530 $\mathrm{cm}$ of the core then decreases to $0.7 \mathrm{~cm} / \mathrm{yr}$ for the top $185 \mathrm{~cm}$ (Figure 2.4C). AM4 starts with a sedimentation rate of $1.4 \mathrm{~cm} / \mathrm{yr}$ for the bottom approximately $1100 \mathrm{~cm}$ of the core and decreases to $\sim 0.9 \mathrm{~cm} / \mathrm{yr}$ for top $600 \mathrm{~cm}$ of the core (Figure 2.4A). The AM5 record, on the other hand, maintains a nearly uniform sedimentation rate of $1.0 \mathrm{~cm} / \mathrm{yr}$ over the entire $771 \mathrm{~cm}$ length of the core (Figure 2.4B). All three records are near annually-resolved such that on average a one $\mathrm{cm}$ sample represents close to one year's worth of sedimentation. 
The coarse fraction of event beds in the South Andros cores ranges from 6 to $40 \%$ sand sized $(>63 \mu \mathrm{m})$ or larger particles. Many event beds contain white shell fragments $(\sim 2 \mathrm{~mm})$ and concentrated amounts of mangrove leaf fragments. Some event beds are topped with higher concentration of the mangrove leaves while other event beds have leaf fragments scattered throughout the layer. Since the late $5^{\text {th }}$ century CE, AM4 has recorded 51 events (Figure 2.5C). While AM5 extends back only to about 1190 CE, it captures 34 events (Figure 2.5B). The AM2 record captured fewer events than AM5 with only 29 events observed since about $1175 \mathrm{CE}$ (Figure 2.5A). Both AM4 and AM5 document only two coarse-grained event deposits that date post-1851 CE (Figure 2.5). The resultant average event frequencies for the time period of overlap (1190 CE-present) in AM4, AM5, and AM2 are 2.98, 4.49, and 3.72 events/century, respectively.

\subsubsection{Changing event frequency}

Over the past 1500 years, all three records show evidence of active and quiescent periods of event frequency spanning a century or more. Looking at the 100-year window event frequency, AM4 exhibits four active intervals from approximately 640 to $815 \mathrm{CE}, 920$ to 1035 $\mathrm{CE}, 1145$ to $1205 \mathrm{CE}$, and 1300 to $1450 \mathrm{CE}$ (Figure 2.6A). The time interval with the most activity was from 640 to $815 \mathrm{CE}$ at 6.3 events/century, almost double that of the average event frequency for the entire record. Using the site-specific expected frequency $(\lambda)$, the probability of exceeding 5 events/century is $0.17 \%$. Compared to the modern event frequency on South Andros, these active intervals exceed what would be expected based on the random nature of hurricane occurrence (>3.86 events/century- the $90 \%$ confidence interval). The 50-year window event frequency emphasizes periods of extremely high activity, namely from 690 to $710 \mathrm{CE}, 960$ to $990 \mathrm{CE}$ and 1280 to $1300 \mathrm{CE}$. During these periods, using the 50-year moving window, the frequency of storm occurrence exceeds nine events per century with a probability of $7.0 \times 10^{-5} \%$.

We define seven quiet intervals in the record in which the cores record zero event beds and the probability of having zero events over each time interval is below $50 \%$. These quiet intervals range from 535 to $600 \mathrm{CE}, 890$ to $955 \mathrm{CE}, 1070$ to $1130 \mathrm{CE}, 1205$ to $1270 \mathrm{CE}, 1530$ to $1680 \mathrm{CE}, 1700$ to 1760 and 1840 to $1930 \mathrm{CE}$ (Figure 2.6C). Of these intervals, the quietest periods occur later in the record. In particular, the probability of having 150 years of sustained 
inactivity from 1530 to $1680 \mathrm{CE}$ is only $16 \%$ given the recurrence interval of hurricane events throughout the record.

\subsection{Discussion}

\subsubsection{Potential influence of changing sea level}

Large sea-level changes could greatly impact the susceptibility of the AM4, AM2, and AM5 blue holes to hurricane-induced event deposits by changing their depositional environment. The South Andros blue holes most likely formed during sea level oscillations in the Quaternary (Mylroie et al., 1995; Peltier \& Fairbanks, 2006). During the Holocene (12 kyr BP to present), the environmental conditions in these basins changed in response to relative sea-level rise. Sealevel curves from the Caribbean (Fairbanks, 1989; Hubbard et al., 2005; Khan et al., 2017; Milne $\&$ Peros, 2013; Toscano \& Macintyre, 2003) suggest rapid sea-level rise ( $\sim 5 \mathrm{~mm} / \mathrm{yr})$ up until 8 kyr BP, with slower rates between $8 \mathrm{kyr} \mathrm{BP}$ and $4 \mathrm{kyr} \mathrm{BP}$, and leveling off to a stable rise of $\sim 0.4$ $\mathrm{mm} / \mathrm{yr}$ over the past 3000 years. With sea-level rise, the blue holes on South Andros transitioned from sinkholes in a subaerial landscape to marine dominated conditions in tidal carbonate flats (Gischler et al., 2013; Gregory et al., 2017; van Hengstum et al., 2016). None of the cores from South Andros blue holes penetrated deep enough to recover the facies associated with terrestrial sinkhole environments (i.e., algal sapropel, lacustrine marl). In addition, all three cores do not show meaningful changes in sedimentation rate (Figure 2.4). This suggests that the tidal and wave environment in and around these blue holes has not changed significantly over the past 1500 years.

The depositional environment around South Andros has likely also remained stable over the past 1500 years. The tide dominated coasts of Andros allow tidal flats to remain open to the sea and experience unrestricted tidal flushing and freshwater flows (Maloof and Grotzinger, 2012). This provides the perfect environment for expansive development and growth of mangroves (Mckee et al., 2007; Ramcharan \& McAndrews, 2006). The presence of mangrove leaves and plant matter throughout the length of our cores suggest that intertidal carbonate flats and algal marshes have consistently surrounded our blue holes over the past 1500 years. In addition, a recent study of a tidal carbonate flat in northwest Andros suggests that the tidal channels in this environment predominantly remained stationary over the past 1200 years (Maloof and Grotzinger, 2012). Taken together, the modest sea-level change over the last 1500 
years $(\sim 60 \mathrm{~cm}$ given the recent rise at $0.4 \mathrm{~mm} / \mathrm{yr})$, the stable sedimentation rates found in the cores, and the consistency of the macro flora throughout the length of the cores suggest relative geomorphic stability on South Andros over the time period of study.

\subsubsection{Modern event calibration}

Event beds in the cores are likely a result of predominantly coarse-grained sediment transport from the surrounding tidal carbonate flats into the holes during high-energy wave and storm surge events. In the shallow coastal waters around South Andros, both waves and currents are important to sediment transport (Black, 1933; Bourrouilh-Le Jan, 2007; Shinn et al., 1969). During minor storms and the waxing and waning stages of more intense storms, elevated current velocities in tidal channels create strong bottom shear stress values and bottom currents, which transport fine-grained sediment. There is well documented evidence for off-bank export of fine sediments in The Bahamas (Boardman \& Neumann, 1984; Gischler et al., 2008; Kier \& Pilkey, 1971; Pilskaln et al., 1989; Shinn et al., 1993; Wilber et al., 1990). This leads to winnowing of fines in tidal channels, leaving behind a coarse-grained sediment source that can be mobilized during severe storms.

During a severe storm, (i.e., intense hurricane), high winds and waves at the site create currents and storm surge (Figure 2.1), raising water levels and inundating the intertidal and supratidal zones (Black, 1933; Bourrouilh-Le Jan, 2007). Thus, during the height of intense hurricanes, sediment transport is likely no longer restricted to tidal channels. The surface wave and current activity during these storms increases bottom shear stress around the blue holes and transports coarse sediment into the blue hole after a critical bottom shear stress threshold is crossed (Miller et al., 1977). The heavier grains settle to the bottom of the blue hole first followed by lighter particles (Brown et al., 2014; Maiklem, 1968) and mangrove fragments.

At least fourteen hurricanes passed within $100 \mathrm{~km}$ of South Andros since $1851 \mathrm{CE}$ (Figure 2.7), but many of these were likely locally too weak to instigate event-bed deposition in the blue holes or had offshore directed maximum winds that can inhibit event-bed deposition. While an array of storm characteristics combines to influence local conditions, typically the proximal passage of intense storms is required to deposit event beds (Brandon et al., 2013; Donnelly et al., 2015; Lin et al., 2014; Woodruff et al., 2008). In the case of hurricanes leaving deposits in coastal sinkholes on Apalachee Bay, Florida, hydrodynamic modeling of a large suite 
of downscaled hurricane simulations revealed that a wide range of different storm characteristics (e.g., intensity, track, and size) could produce large enough storm surges to overtop the coastal barrier and leave a sediment record at the site. However, the vast majority of storms that actually left a deposit at the site were nearby landfalls of category 3 or greater intensity (Lin et al., 2014). We expect similar local intensity threshold type of behavior to be operating in blue hole settings.

In the case of AM4 and AM5, only two coarse-grained event beds were deposited over

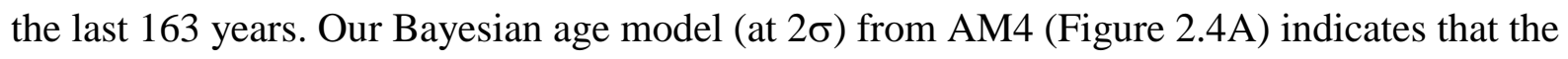
upper most event bed (event bed 1: 44-50 cm) dates between 1944 and 1973 CE (with a median age of 1958). According to the best track data, only two hurricanes passed within $100 \mathrm{~km}$ of the site between 1944 and 1973, and both occurred in 1945. Both storms made direct landfall on South Andros (Figure 2.7). The first struck South Andros from the southeast on September 15 as it transitioned from category 3 to category 4 intensity with sustained winds of approximately 58 $\mathrm{m} / \mathrm{s}$ en route to a landfall in Miami, Florida six hours later. The second hurricane to strike South Andros in 1945 occurred on October 12 as a category 1 storm with sustained winds of $\sim 41 \mathrm{~m} / \mathrm{s}$. This storm approached South Andros from the southwest (Figure 2.7; coast.noaa.gov/hurricanes, 2017).

The two calibrated radiocarbon samples (Table S2.1 and Figure 2.3) from above and below this event bed constrain the age of emplacement to between 1936 and $1950 \mathrm{CE}$. The sample from one centimeter above the first event bed yields three calibrated age ranges: 16481669 CE (0.52), 1781-1798 CE (prob. 0.45), and 1946-1950 CE (prob. 0.029). The sample below the event bed has four calibrated age ranges: 1663-1682 CE (prob. 0.23), 1737-1757 CE (prob. 0.11), 1761-1804 CE (prob. 0.46), and 1936-1950 CE (prob. 0.20). Only the youngest calibration for each sample are both in stratigraphic order and intersect with the Bayesian age model (Figure 2.4A). Thus, considering only the youngest age range from the radiocarbon results for these two samples, event bed 1 was deposited as early as $1936 \mathrm{CE}$ and no later than $1950 \mathrm{CE}$. Other than the two 1945 storms, there were no other storms passing close by South Andros over this time span. We attribute event bed 1 to the more intense September 15 landfall; however, we cannot rule out the less intense landfall 27 days later from also contributing to the deposit.

A small peak in coarse fraction between 62 and $64 \mathrm{~cm}$ in AM4 that does not make our statistical detection threshold dates to between 1924 and 1956 CE (with a median age of 1943) in our age model. Four events impacted South Andros in this interval. Since we have attributed the 
first event layer to one of the 1945 storms, we are left with two other storms. The first is a category 4 storm that passed approximately $70 \mathrm{~km}$ to the northeast of the AM4 blue hole on September 17, 1926. The second storm was the infamous Labor Day Hurricane of 1935, which made direct landfall at South Andros as a category 1 storm with sustained winds of $36 \mathrm{~m} / \mathrm{s}$ (Figure 2.7). Assuming that this small peak in coarse fraction is the result of one of these two hurricanes, the fact that a direct strike category 1 and/or a more distal passage of a category 4 hurricane were not able to leave a deposit that meets our detection threshold suggests that the majority of event beds that exceed our detection limit are deposited by direct strikes of intense hurricanes.

This assessment is further supported by the fact that no event beds are present that date to the relatively close passage (within $75 \mathrm{~km}$ ) of two category 1 hurricanes in 2001 (Michelle) and 1979 (David) or the passage of the 1908 (category 2), 1899 (category 3), and 1896 (category 2) hurricanes east of our study sites (Figure 2.7). The lack of the event bed in AM4 from Hurricane Michelle in 2001 is supported by a study presenting observations from Andros Island posthurricane (Rankey et al., 2004). Rankey and others found minimal impact on shorelines or tidal flats in the aftermath of Michelle, which suggests that it was too weak to create major geomorphic changes on the island.

The second event bed in AM4 that exceeds our detection threshold (event bed 2: 72-75 $\mathrm{cm}$ ) dates to between 1910 and $1946 \mathrm{CE}$ (median age 1932) based on our age model. Five hurricanes are potential candidates for this event bed: the two 1945 storms, the 1926 and 1935 hurricanes discussed above, and a category 3 hurricane in 1919. This 1919 hurricane directly struck South Andros on September 8, 1919 with sustained winds of 53 m/s (Figure 2.7; coast.noaa.gov/hurricanes, 2017). Given the uncertainty of the current age model, we are unable to eliminate the category 1 storm in 1935 or the category 41926 hurricane that passed $70 \mathrm{~km}$ to the northeast as possibly depositing event bed 2 . However, we provisionally attribute this event bed to the direct landfall of the 1919 storm. This interpretation is supported by the fact that other hurricanes of similar character to the 1935 and 1926 events (the 2001, 1979, 1899, and 1896 hurricanes mentioned above) failed to leave a detectable event bed in AM4. Given our assessment of the historical storms that both left an event bed and failed to leave a discernible deposit, we infer that the AM4 sedimentary archive is generally capturing intense hurricanes (>category 3) passing within approximately $50 \mathrm{~km}$ of the site. However, we do acknowledge that 
this is a rough estimate given the uncertainty associated with estimates of maximum winds speeds for the best track dataset and the lack of reliable radius of maximum wind data for these earlier storms. In addition, we also note that it is conceivable that certain combinations of storm characteristics (e.g., size, translational velocity, intensity, track) could result in some lower intensity storms leaving a deposit at the site (Lin et al., 2014). Future work on hydrodynamic modeling of hurricanes over carbonate tidal flats is needed to better constrain what storm characteristics are important for leaving deposits in blue holes.

The AM5 core also contains two event beds that were deposited during the interval covered by the best track data. The uppermost event bed dates to $1952 \pm 10 \mathrm{CE}$ and the second one dates to $1894 \pm 30 \mathrm{CE}$. These event beds are also consistent with deposition associated with the 1945 and 1919 category 3 hurricane strikes. The AM2 reconstruction, in contrast, contained no event beds over the last 160 years of deposition and thus lacks any modern analog. The AM2 blue hole is located about $7 \mathrm{~km}$ east of the AM4 and AM5 blue holes which places it closer to the protective sub-aerially exposed bedrock portion of the eastern margin of South Andros (Figure 2.2). This location may have sheltered it from the most extreme hydrodynamic conditions attendant with the 1945 and 1919 hurricanes.

\subsubsection{South Andros Site Comparison}

While all three blue holes on South Andros are located in the same depositional environment, they have slightly different settings and are thus subject to somewhat different sediment sources and transport pathways. The AM2 blue hole is both farther inland and closer to the eastern side of the island compared to the AM4 and AM5 blue holes. It is also located directly on a large tidal channel which does not directly connect to the larger channel containing the AM4 and AM5 blue holes (Figure 2.2). It is possible that the AM2 blue hole's different, more inland, location within the carbonate tidal flat environment makes it susceptible to a different population of landfalling storms (e.g., intensity, duration, track, size). This might explain why it does not record the two most recent category 3 events passing over South Andros (1945 and 1919). In addition, this might also explain a gap in activity from 1302-1415 CE observed only in AM2 (Figure 2.5). Overall, AM2 still shows similar event frequency patterns (Figure 2.5) as AM4 and AM5. Like both AM5 and AM4, AM2 shows heightened hurricane activity from 1575 to $1800 \mathrm{CE}$ and 1400 to $1475 \mathrm{CE}$. 
The AM5 record corroborates the results from AM4 (Figure 2.5). Located $1.5 \mathrm{~km}$ southsoutheast of the AM4 blue hole in the same tidal channel (Figure 2.2), AM5 also exhibits similar active and quiescent periods showing high hurricane numbers from approximately 1600 to 1800 $\mathrm{CE}$ and 1300 to $1500 \mathrm{CE}$ and low hurricane frequency from 1500 to $1580 \mathrm{CE}$ and $1820 \mathrm{CE}$ to the present. Both records document a decrease in hurricane activity in early $13^{\text {th }}$ century. However, the overall frequency of event bed deposition at AM5 is higher than at AM4, recording approximately one additional event per century throughout the entire record. This could be a result of the AM5 blue hole's increased exposure to currents within the tidal flat system. The AM5 blue hole is located in a channel between carbonate tidal flats (Figure 2.2), whereas the AM4 blue hole is more sheltered and located directly offshore a small supratidal algal marsh ( $80 \mathrm{~m}$ away). Both the AM2 and AM5 sediment records confirm the overall temporal variability observed in AM4 within age uncertainties, thus we use the longer and better dated AM4 reconstruction when discussing hurricane frequency changes on South Andros Island.

\subsubsection{Climatic forcing of hurricane activity on South Andros Island}

Our high-resolution record from South Andros Island indicates dynamic patterns of intense hurricane activity over the past millennium. Much like other reconstructions of hurricane activity from the North Atlantic including Blackwood Sinkhole (van Hengstum et al., 2016), Laguna Playa Grande in Puerto Rico (Donnelly and Woodruff, 2007), and Salt Pond in Massachusetts (Donnelly et al., 2015), there are pronounced active and quiet intervals of intense hurricane strikes on South Andros. Given that these active intervals lie outside our $90 \%$ confidence intervals encompassing the random variability of hurricane strikes (Section 2.2.5), these variations in hurricane activity are likely due at least in part to the complex interactions of climate variables over this time period. Our sedimentary archive sheds light on some climate mechanisms controlling hurricane variability on longer time scales.

A recently published lower resolution hurricane reconstruction from Blackwood Sinkhole on Abaco Island in The Bahamas (van Hengstum et al., 2016) suggests that the Intertropical Convergence Zone (ITCZ) position modulates paleohurricane activity in the Caribbean. A more northerly position of the ITCZ decreases vertical wind shear in the Atlantic Main Development Region (MDR) favoring cyclogenesis and thus, increasing the likelihood of intense hurricane landfalls (Kossin et al., 2010; Kossin \& Vimont, 2007; Schneider et al., 2014). 
The Abaco Island record shows decreased hurricane activity from 1000 to $1500 \mathrm{CE}$, which was attributed to a southward shift in the ITCZ. In contrast, the record from South Andros Island shows increased numbers of intense hurricanes in The Bahamas over this time span (1145-1205 CE and 1300-1450 CE) (Figure 2.8). The dramatically different resolutions, sensitivities, and timescales of the South Andros and Abaco records make comparing their hurricane histories and potential climatic forcing difficult (Figure S2.5). For example, only ten events are recorded at Blackwood over the last 1500 years while fifty-one events are recorded at South Andros. The Blackwood Sinkhole record is valuable for looking at the connections between the landfalls of the highest intensity hurricanes and the ITCZ on multi-centennial timescales. However, the lower resolution of the Blackwood record compared with our blue hole sites, prevents direct comparisons.

While caution should be exercised in using only a single reconstruction to infer climatically meaningful patterns, here we explore the potential role of subtle multi-decadal shifts in the ITCZ on Caribbean hurricane activity by comparing the AM4 reconstruction with the similarly resolved Cariaco Basin Ti record (Haug et al., 2001). The position of the ITCZ is generally thought to have shifted southward over most of the Holocene (Schneider et al., 2014). Superimposed on this Holocene trend are more moderate but abrupt shifts in the ITCZ position over the past 2000 years as indicated by the Cariaco Basin Ti record (Haug et al., 2001). Many of these multi-decadal to centennial scale shifts correspond to times of changes in hurricane activity on South Andros. Throughout most of the record, increased hurricane activity on South Andros corresponds to local maxima in Cariaco Basin Ti counts (Figure 2.8D) and thus, a more northerly position of the ITCZ. This includes active intervals from 920 to $1035 \mathrm{CE}, 1145$ to $1205 \mathrm{CE}$, and 1300 to $1450 \mathrm{CE}$ as well as increased numbers of events from the mid-16 ${ }^{\text {th }}$ century to the mid$17^{\text {th }}$ century. Similarly, the largest gap in hurricane activity on South Andros (1530-1680 CE) occurred during the Little Ice Age when there were cooler SSTs in the North Atlantic (Mann et al., 1999; Richey et al., 2009) and the ITCZ had moved southward (minimum in Ti counts) (Figure 2.8D). However, this trend does not apply during the earliest active interval on South Andros from 640 to $815 \mathrm{CE}$ when the ITCZ is inferred to be in a southerly position (Cariaco Basin Ti counts at a local minimum) (Figure 2.8D).

For most of the last 1500 years, we reconstruct multi-decadal scale changes in intense hurricane activity on South Andros occurring simultaneously with multi-decadal changes in 
ITCZ position (Figure 2.8). In general, when the position of the ITCZ is more northerly, we see increased storm activity in our cores from South Andros Island. Only in the first 400 years of the record (640-815 CE) do we observe high hurricane activity with little change in ITCZ position. More highly resolved tropical cyclone reconstructions are needed from across the western North Atlantic (and globally) to better assess the connection between ITCZ position and tropical cyclone variability on multi-decadal time scales.

In the time span between the two most recent active intervals, South Andros experienced an unusual quiet interval from 1204 to $1273 \mathrm{CE}$. This multi-decadal scale gap in activity is most clearly shown in the 50-year window event frequency but is smoothed out in the 100-year window frequency (Figure 2.6). Over this 69-year period, there were no hurricane strikes recorded in the sediment record (Figure 2.8). Based on the recurrence interval of hurricanes over the past 163 years, there is a $43 \%$ likelihood of seeing a gap in storm activity of this size. It is even less likely (10\%) if we calculate our recurrence interval based on the entirety of the record (Figure 2.6).

Age-model uncertainties in the AM2 and AM5 records make it difficult to assess whether these cores show a similar gap in activity over this same time period. While both records show less activity occurring over this time span, they do not observe a complete lack of event beds like AM4. Both AM2 and AM5 contain two event beds from 1204 to 1273 CE (Figure 2.5). However, both AM2 and AM5 also have much higher age uncertainties than AM4 (Figure 2.4). The end of the AM5 core, encompassing this time interval, shows the largest uncertainty in its age model containing four dates which were out of stratigraphic order and excluded from the age model (Figure 2.4B). Given the dating uncertainty in these two nearby records, we will continue to assess this gap in activity using the timing constrained by the AM4 age model.

Interestingly, over this same time period within the AM4 age-model uncertainties, ice cores from Greenland (Gao et al., 2008) and Antarctica (Sigl et al., 2014) record increased sulfate aerosol loading in the atmosphere indicative of abundant volcanic eruptions (Figure 2.8C). Indeed, the strongest eruption on record in these cores was the Samalas Volcano in Indonesia in 1257 (Gao et al., 2008). Cooling of the ocean surface (Hansen et al., 2005) and subsurface (Church et al., 2005) associated with aerosols from volcanic activity can cause short term reductions (1-3 years) in tropical cyclone intensity (Evan, 2012; Korty et al., 2012), but very little is known about longer timescale impacts. Surface ocean heat content plays an 
important role in hurricane formation and growth. Typically, hurricanes require localized warm SST to provide energy to the storm and only develop over ocean water with surface temperature exceeding $26^{\circ} \mathrm{C}$ (Emanuel, 2003; Gray, 1998; Wallace et al., 2014). Perhaps the rapid introduction of aerosols to the atmosphere beginning around the mid-12 $2^{\text {th }}$ century and continuing across the span of this anomalous quiet period in hurricane activity cooled the ocean surface in the MDR and/or locally in The Bahamas enough to reduce the number of high intensity storms in the Atlantic that could leave a deposit at sites like the AM4 blue hole. Records from Iceland (Sicre et al., 2008) and the Cariaco Basin (Haug et al., 2001) suggest that climate changes induced by these volcanic eruptions may have been strong enough to affect both high latitude and low latitude climate. These proxies suggest both colder high latitude ocean surface temperature and a southward shift in the ITCZ. Indeed, the Cariaco Basin Ti record shows an interval of reduced Ti counts from 1220 to 1277 (Figure 2.8D) suggesting a coeval oscillation of the ITCZ. Recent work reconstructing precipitation over the past 300 years in Mesoamerica found further evidence of long-lasting volcanic effects on tropical climate. The authors observed multi-decadal declines in precipitation coinciding with clusters of large volcanic eruptions in the $19^{\text {th }}$ and $20^{\text {th }}$ centuries (Winter et al., 2015).

If more frequent explosive volcanism during the $13^{\text {th }}$ century contributed to a lull in Atlantic hurricane activity, more broadly we might expect to see a lull in activity in other highresolution reconstructions. The reconstruction from Salt Pond, MA (Donnelly et al., 2015) is generally inactive from the $12^{\text {th }}$ through the $14^{\text {th }}$ century and thus does not provide evidence of a short term lull in activity in the $13^{\text {th }}$ century. Relatively high levels of hurricane activity are inferred from the Mullet Pond reconstruction (Lane et al., 2011) during the mid-12 $2^{\text {th }}$ to the late $13^{\text {th }}$ centuries (Figure 2.8). Thus, while The Bahamas were seeing a decrease in landfalling storms, regional climate in the Gulf of Mexico was promoting storm survival and growth. Pausata \& Camargo (2019) found that large volcanic eruptions can alter the spatial distribution of tropical cyclones on short timescales ( 4 years) rather than globally reduce them (Pausata and Camargo, 2019). Some areas experience more storms while others experience less depending on the location of the volcanic cooling and the subsequent volcanically induced displacement of the ITCZ. Perhaps a redistribution of tropical cyclone activity during a particular combination of volcanic eruptions might cause this multi-decadal increase in tropical cyclone activity around the Gulf Coast while also concurrently reducing storm activity in The Bahamas. To assess this 
hypothesis, we need more modeling work and proxies/multi-proxy approaches to investigating global tropical cyclone distributions on decadal timescales after multiple volcanic eruptions of various sizes and character.

In contrast, other intervals of more frequent explosive volcanism do not appear to correspond to a reduction in event bed frequency at AM4. For example, increased volcanism observed in the $18^{\text {th }}$ and early $19^{\text {th }}$ centuries (Gao et al., 2008) corresponds to an interval of increased hurricane activity on South Andros Island (Figure 2.8). Recent modeling work suggests that the climate's response to volcanism is dependent on the initial climate conditions (Zanchettin et al., 2019). Zanchettin et al. (2019) found indistinguishable temperature responses in climate simulations for different realistic combinations of volcanic forcing and initial climate states. Hence, one period of time in our record might see a rapid cooling of the environment and subsequent decrease in hurricane activity (e.g., $13^{\text {th }}$ century) while another time period (e.g., $18^{\text {th }}$ century) may not. Overall, the synchronous occurrence of the gap in hurricane activity on South Andros and increased volcanic activity in ice core records during the $13^{\text {th }}$ century suggests that volcanic activity may have contributed to fewer hurricanes in The Bahamas. However, this same relationship does not necessarily apply for every period of high volcanic activity or for all hurricane records in the Atlantic. If explosive volcanism plays a role in modulating hurricane activity, there may be significant spatial variations in those impacts (Pausata and Camargo, 2019). We need more modeling studies that assess how different combinations of large volcanic eruptions with different initial climate states affect large scale climate and the global distribution of tropical cyclones.

The complete record of hurricane activity from South Andros shows greater centennial scale variability than the Mann et al. (2009) basin-wide hindcast of hurricane activity obtained using a statistical model (henceforth referred to as Mann09) (Figure S2.5). This model drives Atlantic hurricane activity based on proxy reconstructions of the SSTs over the MDR, changes in El Niño Southern Oscillation (ENSO), and the North Atlantic Oscillation (NAO). While both the AM4 and Mann09 records show a peak in activity during the Medieval Warm Period (900-1100 CE) when SSTs were high in the MDR (Figure S2.5), there is very little other centennial scale variability in the Mann09 record. In particular, the Mann09 hindcast does not show a quiet period of hurricane activity in the mid- $13^{\text {th }}$ century when we have suggested increased volcanic activity may have reduced the number of storms in the MDR. A basin-wide estimate like the 
Mann09 record would smooth out any regional differences in paleohurricane activity. Our comparison of the Mann09 record with our South Andros reconstruction suggests either that a modeled combination of SSTs, ENSO, and NAO cannot capture all of the variability we observe at South Andros Island, or that regional variations in hurricane tracks that show up in a singular record like South Andros cannot be inferred from a smoothed basin-wide estimate like the Mann09 record (Mann et al., 2009).

On the whole, our reconstruction from South Andros suggests relatively few hurricanes over the last 200 years compared to the preceding millennia. Indeed, AM4 only captured two events in the modern era (1850 to present). This relative quiescence is not typical of the record over the last 1500 years and suggests that South Andros may be at higher risk of intense hurricane strikes than implied by the instrumental record. This matches the nearby Blackwood Sinkhole record from Abaco Island (van Hengstum et al., 2016) making it the second record from The Bahamas to show far fewer hurricanes over the observational interval.

\subsubsection{Comparison to other high-resolution hurricane records}

Examining reconstructions from throughout the Atlantic basin helps us to better constrain what inter-regional changes in hurricane activity in the Atlantic were like over the past 1500 years. Comparing AM4 to similarly resolved records from Mullet Pond on the Florida Gulf Coast (Lane et al., 2011) and Salt Pond in Massachusetts (Donnelly et al., 2015), South Andros and Florida activity directly contrast with records from the U.S. East Coast. To test whether transitions from active to inactive or inactive to active are synchronous or time transgressive, we plot the age distributions for the beginnings and ends of some of the more recent active intervals in the Salt Pond, Mullet Pond, and AM4 records (Figure 2.9). To create our age distributions, we sampled 1000 different age ensembles from our Bayesian age models for Salt Pond, Mullet Pond, and AM4 outputs (Figure 2.4A and Figure S2.6). The age models for Salt Pond and Mullet Pond were recreated using BACON software (Blaauw and Christen, 2011) and the 100-year window event frequency in each record was computed (Figure 2.9). In order to better constrain the age of the transition in hurricane activity at Mullet Pond (Lane et al., 2011), three new radiocarbon dates were added to the previously published chronology and are documented in the supplementary material (Figure S2.6b and Table S2.4). By comparing the 100-year event 
frequency in each of these locations, we capture the centennial scale variations in hurricane strikes at each location and how they compare.

For the first 500 years of the reconstructions ( 450-1000 CE), most active intervals in the Mullet Pond High Threshold (HT) and South Andros Island records occur during the same time periods. In contrast, Mullet Pond HT and South Andros activity is not synchronous with Salt Pond activity (Figure 2.9). Increased hurricane activity at Mullet Pond and on South Andros tends to start just as hurricane activity on Salt Pond ends and vice versa (i.e., Figure 2.9E). This is true even given the larger uncertainties associated with the Mullet Pond age model (Figure S2.6b).

For the past millennium, a slightly different pattern emerges. Active intervals at Mullet Pond and South Andros begin at approximately the same time ( 1150 CE) within age uncertainties (Figure 2.9). The Mullet Pond HT record remains active until $1320 \mathrm{CE}$. Even with 40 years of age uncertainty, this termination of activity is well before Salt Pond's most recent active interval begins in $1420 \mathrm{CE}$ (Figure 2.9F). Salt Pond experiences increased activity from approximately 1420 to $1675 \mathrm{CE}$ containing ten event beds, with five of these events occurring from 1500 to $1600 \mathrm{CE}$, an interval that is relatively quiescent at Mullet Pond and South Andros. While South Andros first transitions into higher levels of activity at approximately the same time as Mullet Pond (Figure 2.9E), it remains active approximately a century after Mullet Pond transitions to lower levels of activity (until $\sim 1470 \mathrm{CE}$ ). Its termination is outside of the age distribution of Mullet Pond's termination in activity and occurs after the start of the Salt Pond's active interval (Figure 2.9E).

The hurricane patterns from the last millennium in Salt Pond and Mullet Pond are confirmed by a variety of lower resolution hurricane proxy records along the U.S. East Coast and Gulf of Mexico. A nearby paleohurricane record from Spring Creek Pond in Apalachee Bay, Florida (Brandon et al., 2013) and a record from a coastal pond in Hancock County, Mississippi (Bregy et al., 2018) confirm the increased hurricane activity from 1150 to $1350 \mathrm{CE}$ observed at Mullet Pond and South Andros. Both records also indicate quiescence from $1350 \mathrm{CE}$ to present. Along the U.S. East Coast, records from New England (van de Plassche et al., 2006; Donnelly et al., 2001; Boldt et al., 2010; Buynevich and Donnelly, 2006) and the Southeast (Mallinson et al., 2011) show increased storminess during the $15^{\text {th }}$ and $16^{\text {th }}$ centuries. A reconstruction from Mattapoisett Marsh in Massachusetts is the most active from 1400 to 1675 CE with nine 
overwash deposits identified (Boldt et al., 2010). Other marsh records from southeastern Massachusetts (Buynevich and Donnelly, 2006), Rhode Island (Donnelly et al., 2001), and Connecticut (van de Plassche et al., 2006) show signs of increased storminess during this period including overwash deposits and extensive erosion events. Moving south, a record of barrier island breaching from the Outer Banks in North Carolina documents fifteen barrier-beach breaches from 1400 to $1675 \mathrm{CE}$ compared to the one to two breaches that occurred in the preceding and following two centuries (Mallinson et al., 2011). Overall, this suggests that coherency observed between our South Andros record and the Mullet Pond record and the disconnect observed between South Andros and Salt Pond applies to the whole Gulf Coast and U.S. East Coast not just western Florida and Massachusetts.

Increased hurricane activity observed during the past millennium at Lighthouse Reef Blue Hole in Belize (Denommee et al., 2014) matches with the Mullet Pond HT reconstruction (Figure 2.9). Like Mullet Pond, higher levels of activity in Belize end around $1380 \mathrm{CE}$ before activity at Salt Pond increases. Assessing the synchronicity of active intervals across these records suggests three stages of hurricane activity happening over the past millennium: 1) From $\sim 1150$ to $1350 \mathrm{CE}$, there is more hurricane activity in the southern Caribbean Sea and Gulf of Mexico with storms striking Belize and the Gulf Coast (near western Florida) in combination with more storms in the southern Bahamas (near South Andros Island). 2) From 1350 to 1470 $\mathrm{CE}$, intense hurricane activity is reduced in the southern Caribbean and Gulf of Mexico. We continue to see increased activity in the southern Bahamas and begin to observe increased storm activity along U.S. East Coast. 3) From 1470 to 1675 CE, intense storms are predominantly making landfall only along the U.S. East Coast.

Two possible reasons arise for why we might observe this transition from activity in the Gulf of Mexico/Caribbean Sea to activity solely along the U.S. East Coast: 1) the local environmental conditions were unfavorable for intense hurricanes to maintain their strength until they reached either the U.S. East Coast or Gulf of Mexico (Kossin, 2017) or 2) variability in storms tracks resulted in more storms veering into one basin over the next (Kossin et al., 2010; Daloz et al., 2015).

Recent research has provided support for both hypotheses. Local environmental conditions can have a significant impact on hurricane genesis and growth. Warmer local SSTs provide more energy for storms, and vertical wind shear prevents hurricanes from reaching their 
maximum potential intensity (Emanuel, 2003). Indeed, Kossin (2017) investigated environmental conditions along the U.S. East Coast and in the MDR over the last 50 years. He found that when conditions in the MDR were favorable for hurricane formation, vertical wind shear along the U.S. East Coast was anomalously strong and local SSTs were colder. Essentially, in years when the basin-wide activity was elevated, local environmental conditions along the U.S. East Coast were unfavorable for hurricane growth and survival (Kossin, 2017). It is possible that from 1150 to $1400 \mathrm{CE}$, when activity was low at Salt Pond, such inhibiting conditions were in place along the U.S. East Coast. Alternatively, regional climate can also promote more hurricanes resulting from tropical transition. A subset of storms that impact the U.S. Northeast Coast develop from extratropical disturbances that form in the subtropical western Atlantic in a process known as tropical transition (McTaggart-Cowan et al., 2007). Donnelly et al. (2015) suggested that increased high latitude cooling during the Little Ice Age (1400-1600 CE) shifted the track of extratropical disturbances southward into the subtropical Atlantic facilitating more tropical transitioning hurricanes making landfall at Salt Pond.

Alternatively, many studies have investigated hurricane track variability over decadal timescales to centennial timescales looking at how the position of the North Atlantic Subtropical High (NASH) and Hadley Cell can change the paths of Atlantic hurricanes (Baldini et al., 2016; Elsner, 2003; Elsner \& Kocher, 2000; Lucas et al., 2014; Studholme \& Gulev, 2018; van Hengstum et al., 2016; Wang et al., 2011; Xie et al., 2005). The strength and position of subtropical ridges across the North Atlantic can modulate hurricane tracks. When the NASH is displaced toward the northeast, there is an increased pressure gradient and strong mid-latitude westerlies that pull warm moist air and consequently, hurricane tracks around the western edge of the high. This causes hurricanes to recurve away from the Gulf of Mexico and instead track towards the U.S. East Coast (Elsner, 2003; McCloskey et al., 2013; Ortegren \& Maxwell, 2014). The opposite is true when the subtropical high is positioned more to the southwest. In this case, the subtropical high maintains easterly steering currents and more hurricanes are characterized as straight-moving and intensify at low latitudes moving through the Caribbean Sea into the Gulf of Mexico (Elsner et al., 2000; Elsner, 2003; Kossin et al., 2010; McCloskey et al., 2013; Ortegren $\&$ Maxwell, 2014). The strength of the NASH also plays an important role in determining hurricane track variability. When the NASH is weak and its western ridge erodes, hurricane 
tracks are more likely to recurve northward moving through the eroded region (Kossin et al., 2010).

At the same time, Hadley Cell position can also impact hurricane genesis and tracks. Recent studies have noted a poleward migration of global tropical cyclone genesis and maximum intensity over the past 30 years connected to poleward Hadley Cell expansion (Kossin et al., 2014; Sharmila \& Walsh, 2018; Studholme \& Gulev, 2018). This recent Hadley Cell expansion shifts tropical-cyclone-favorable climate conditions poleward in many major ocean basins, in particular by increasing (decreasing) vertical wind shear in the tropics (subtropics) (Kossin et al., 2014). However, this has not been true for the North Atlantic basin in the last 30 years, in part because of the weak signal for recent Hadley Cell expansion in this basin (Sharmila \& Walsh, 2018; Studholme \& Gulev, 2018). Despite the current uncertain connection between Hadley Cell expansion and poleward shifting hurricane tracks in the North Atlantic, Baldini et al. (2016) suggests that an expanded Hadley Cell contributed to a northward shifted NASH and thus northward recurving hurricane tracks over the past 500 years using both a new stalagmite record from Belize and documentary records of hurricanes in the Atlantic.

Thus, a second possibility is that from 1150 to $1650 \mathrm{CE}$ we see a gradual shift in hurricane tracks to the northeast through a northward shift in the position of the NASH and/or a weakening of the western ridge of the NASH with an expansion of the Hadley Cell. This would shift storms tracks from straight-moving storms impacting the western Caribbean and Gulf Coast to recurving storms that affect the U.S. East Coast. South Andros Island serves as a transitional point for this shift in tracks staying active for most of the time period when storms are hitting the Gulf Coast and remaining active as tracks shift northeastward out of the Gulf of Mexico to up along the U.S. East Coast. More high-resolution paleohurricane reconstructions from throughout the Caribbean and Gulf of Mexico are necessary to determine whether this disconnect between Gulf of Mexico/Bahamas records and U.S. East Coast records is a result of changes in local environmental conditions (e.g., SSTs, thermocline depth), regional variability in hurricane tracks, or some combination of both mechanisms.

\subsection{Conclusions}

This study presents a near annually resolved record of intense hurricane activity derived from three blue holes positioned in the carbonate tidal flats on South Andros Island in The 
Bahamas. The reconstruction is the longest high resolution Caribbean paleohurricane record spanning the past 1500 years. We found that coarse-grained sediment layers in the stratigraphy during the historic period corresponded to the passage of intense hurricane events (category 3 or above) within $50 \mathrm{~km}$ of the site. Sediment records from all three blue holes on the island showed similar patterns of hurricane deposition, despite their different geomorphologic position and orientation.

This study exemplifies the importance of looking to long-term proxy records to make hurricane risk assessments for a particular area. It is clear from this work that historical records of hurricane activity underestimate hurricane landfall recurrence rate at South Andros. In the last 70 years, there has not been a single intense hurricane passing close enough to South Andros to leave an event deposit. There is a 10\% probability of having such a gap in activity given the recurrence interval of storms over the past 1500 years.

The frequency of intense hurricane landfalls on South Andros Island has varied dramatically over the past 1500 years. In particular, we document four multi-decadal periods when hurricane activity on South Andros has significantly exceeded historical levels (640-815 CE, 920-1035 CE, 1145-1205 CE, and 1300-1450 CE). Three of these active intervals correspond to time periods when the ITCZ was farther northward (Haug et al., 2001), which suggests that the ITCZ position plays a role in determining hurricane activity that affects the island. However, the first active interval in the record corresponds to a neutral to southerly ITCZ position, suggesting that other factors were at play during this period of activity. An anomalous quiet period on South Andros in the early 13th century may point to volcanic activity contributing to changes in Atlantic hurricane activity. However, the hurricane response to volcanos differs from region to region and may be dependent on initial climate conditions.

The timing of active intervals over the past millennium ( 1100-2015 CE) of the record suggests that hurricane active (inactive) intervals at South Andros occur simultaneously with increased (decreased) landfalls in a Gulf of Mexico record and a record from Belize. In contrast, records from the U.S. East Coast show increased hurricane activity when South Andros is relatively quiet. We suggest a gradual shift in hurricane tracks to the northeast over the past millennium. Straight-moving storms hitting the western Caribbean and Gulf Coast transform into recurving storms that affect the U.S. East Coast. This could be a result of decadal variability in hurricane tracks related to variations in the mean position and strength of the North Atlantic 
Subtropical High and/or changes in local environmental factors. More high-resolution paleohurricane reconstructions from throughout the Caribbean and Gulf of Mexico are necessary to better constrain how storm activity shifted from lower latitudes to the U.S. East Coast.

\subsection{Acknowledgments}

This work was funded by the National Science Foundation Graduate Research Fellowship (to E.J.W.), National Science Foundation grant OCE-1356708 (to J.P.D. and P.J.vH.), the Dalio Explore Foundation and the USGS Land Change Science Program (M.R.T.). We are grateful to members of WHOI Coastal Systems Group, in particular Stephanie Madsen, for their help in the processing core samples. We thank two anonymous reviewers, Matthew Lachniet, Marci Robinson (USGS) and Miriam Jones (USGS) for their helpful feedback on earlier versions of this manuscript. Any use of trade, firm, or product names is for descriptive purposes only and does not imply endorsement by the U.S. Government. The data are available on the National Climatic Data Center (http://www.ncdc.noaa.gov/dataaccess/paleoclimatologydata) and WHOI Coastal Systems Group (https://web.whoi.edu/coastal-group/) websites. 


\subsection{Figures}

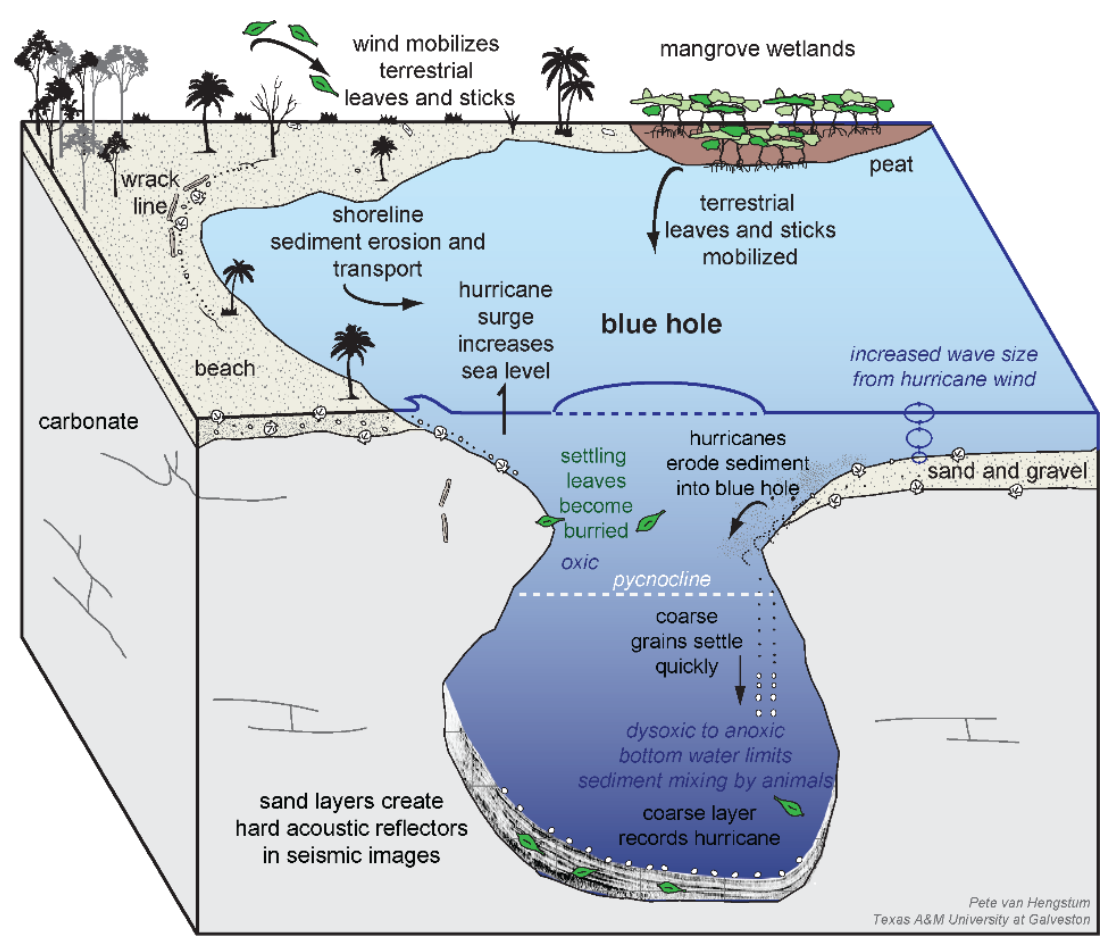

Figure 2.1: A conceptual model of the environment around the South Andros blue holes and the likely processes that create coarse-grained event beds at the bottom of the blue holes during storm events. 


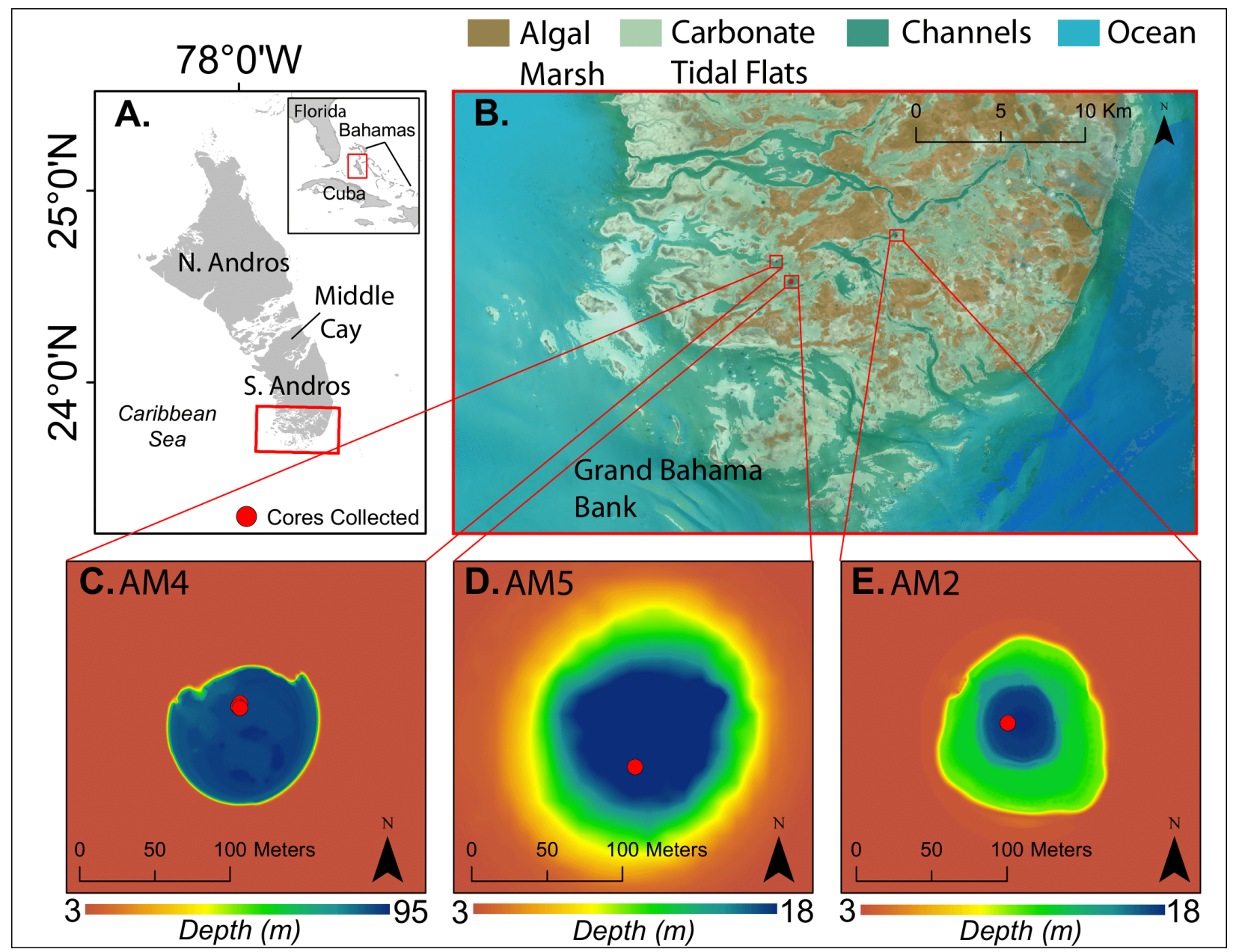

Figure 2.2: (A) Map of Andros Island, the Bahamas. (B) Blue hole locations on South Andros Island. The environment is characterized by algal marsh (brown) and carbonate tidal flats (light green) divided by tidal channels (teal) surrounded by ocean (blue). The bathymetry of each blue

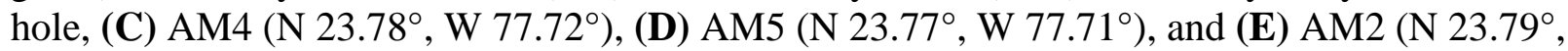
$\left.\mathrm{W} 77.65^{\circ}\right)$, is shown. Note that the color bar range for panel $\mathrm{C}$ is different from $\mathrm{D}$ and $\mathrm{E}$. 

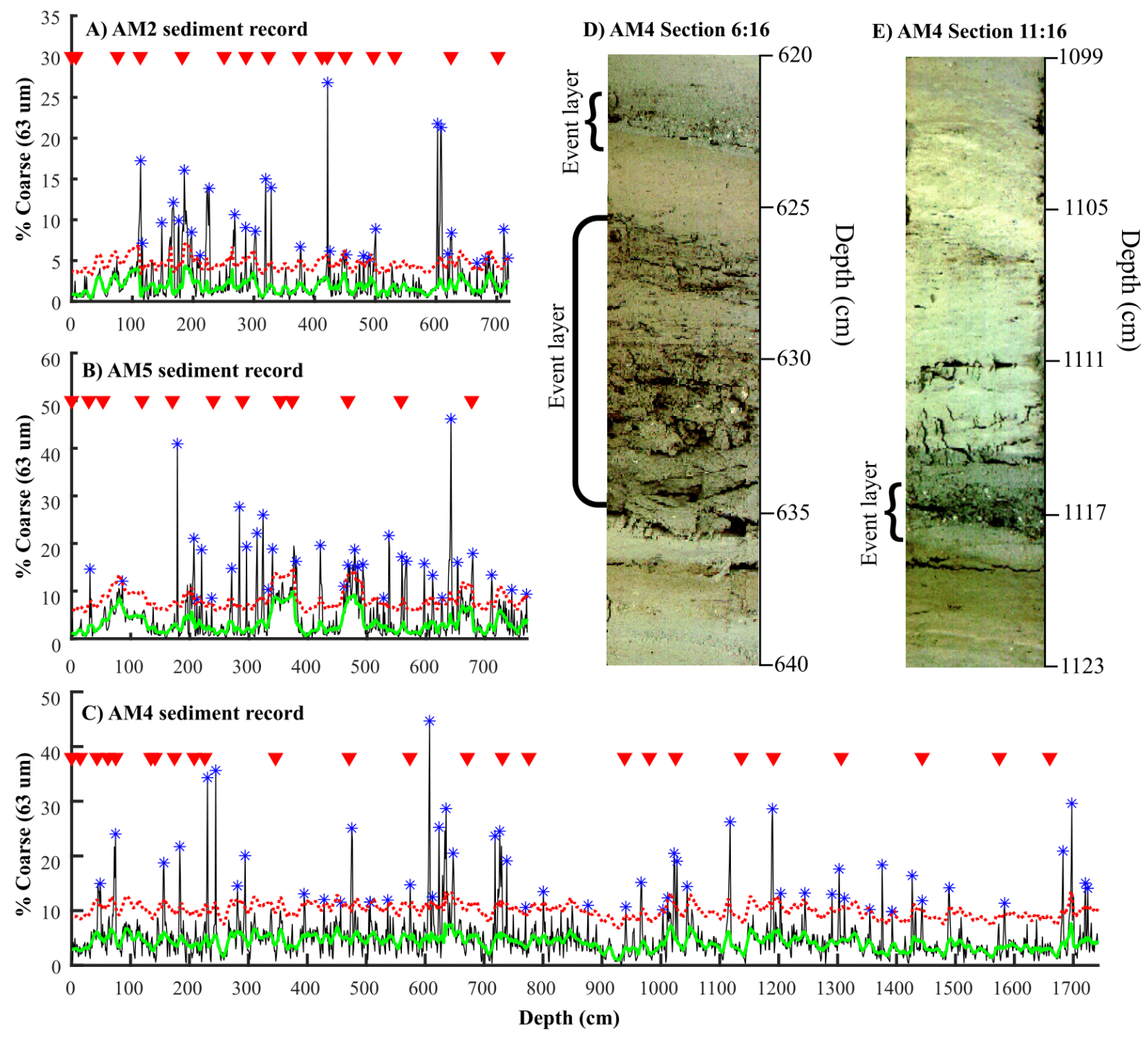

Figure 2.3: Percent sand fraction ( $>63 \mu \mathrm{m})$ vs. depth in core (black) from AM2 (A), AM5 (B), and AM4 (C) with a 10-point running mean filter (green) that excludes coarse fraction values above $10 \%$. The red dashed line is the event cutoff threshold added to the filter. Events in each panel are denoted with a blue star. Location of ${ }^{14} \mathrm{C}$ dates are plotted as red triangles above the coarse fraction data. (D) Image from the sixth section of the AM4 sediment core from 622-640 $\mathrm{cm}$ in depth with two coarse grained layers from $622-623 \mathrm{~cm}$ and $629-636 \mathrm{~cm}$. (E) Image from the eleventh section of the AM4 sediment core from 1099-1123 cm in depth with a coarse grained layer from $1113-1118 \mathrm{~cm}$. 

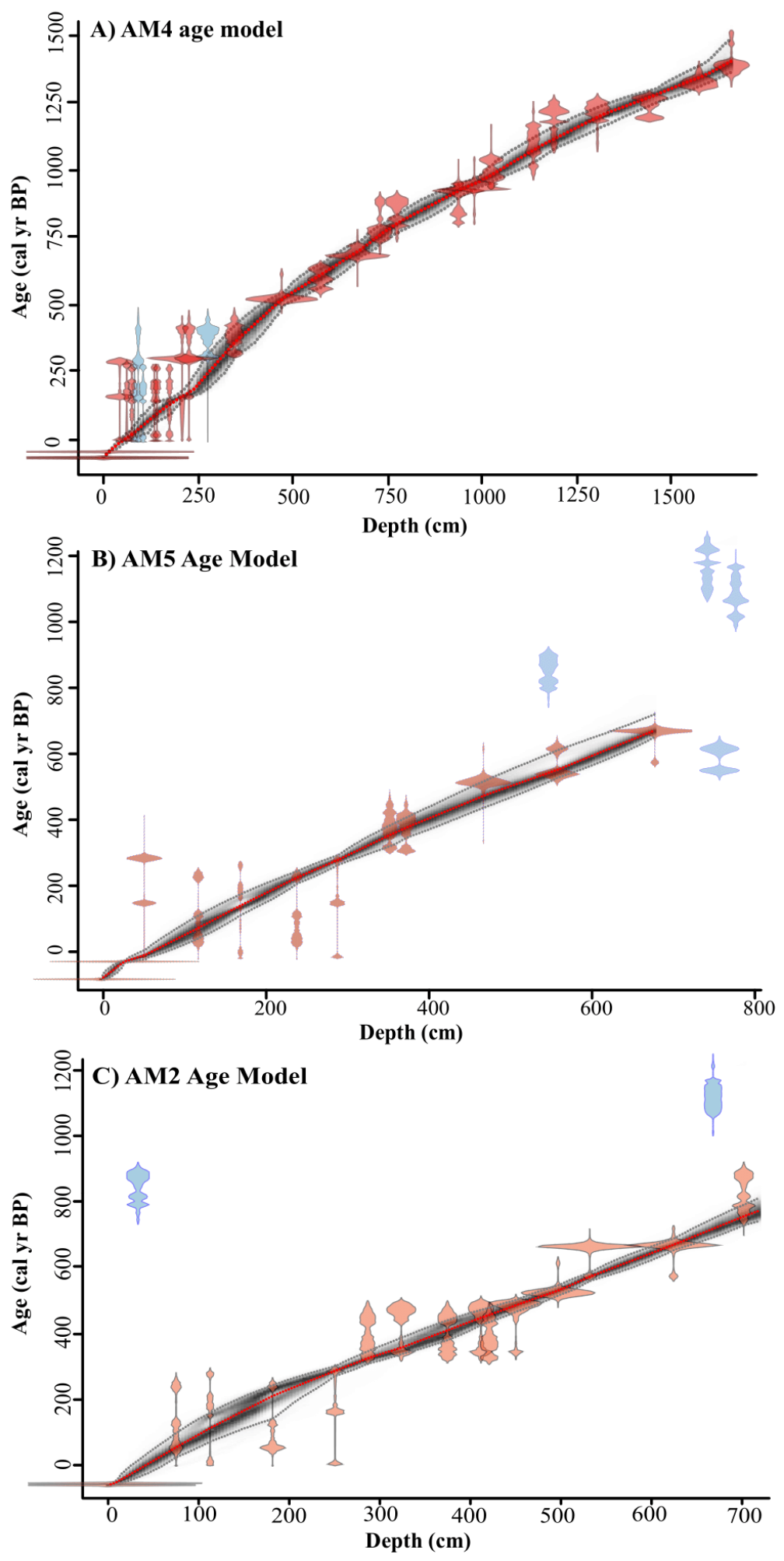

Figure 2.4: Age model (red dashed) derived from radiocarbon dates in Table S2.1 for AM4 (A), AM5 (B) and AM2 (C). 95\% confidence bounds are shaded in grey around the age model. Dates and age uncertainties used for the models are shown in pink. Post-bomb radiocarbon dates and a tie point setting the surface of each core to modern are also shown (pink horizontal bars). Rejected dates and age uncertainties are shown in blue. These figures were generated using BACON v2.2 age modeling software (Blaauw and Christen, 2011). 

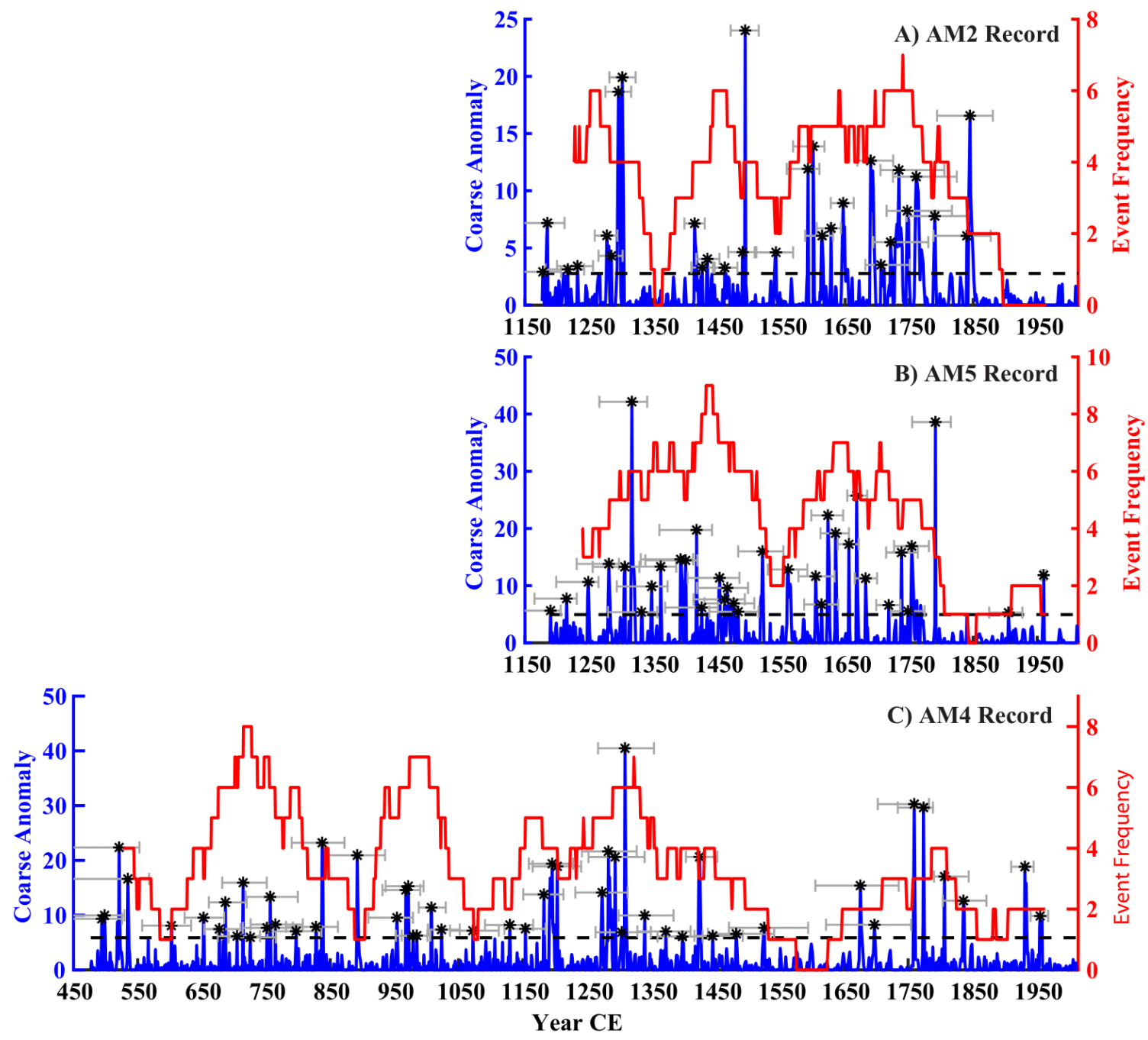

Figure 2.5: (A) Coarse anomaly plot (blue) for AM2 as a function of time derived from 15 radiocarbon dates. The dashed black line is the event bed threshold of $2.77 \%$. (B) Coarse anomaly plot (blue) for AM5 as a function of time derived from 11 radiocarbon dates. The dashed black line is the event bed threshold of 4.94\%. (C) Coarse anomaly plot (blue) for AM4 as a function of time derived from 17 radiocarbon dates. The dashed black line is the event bed threshold of 5.87\%. Events in all panels are denoted as black stars. The 100-year moving window event frequency per century for each core is plotted in red. Grey error bars indicate $95 \%$ confidence bounds for the ages of each event. 

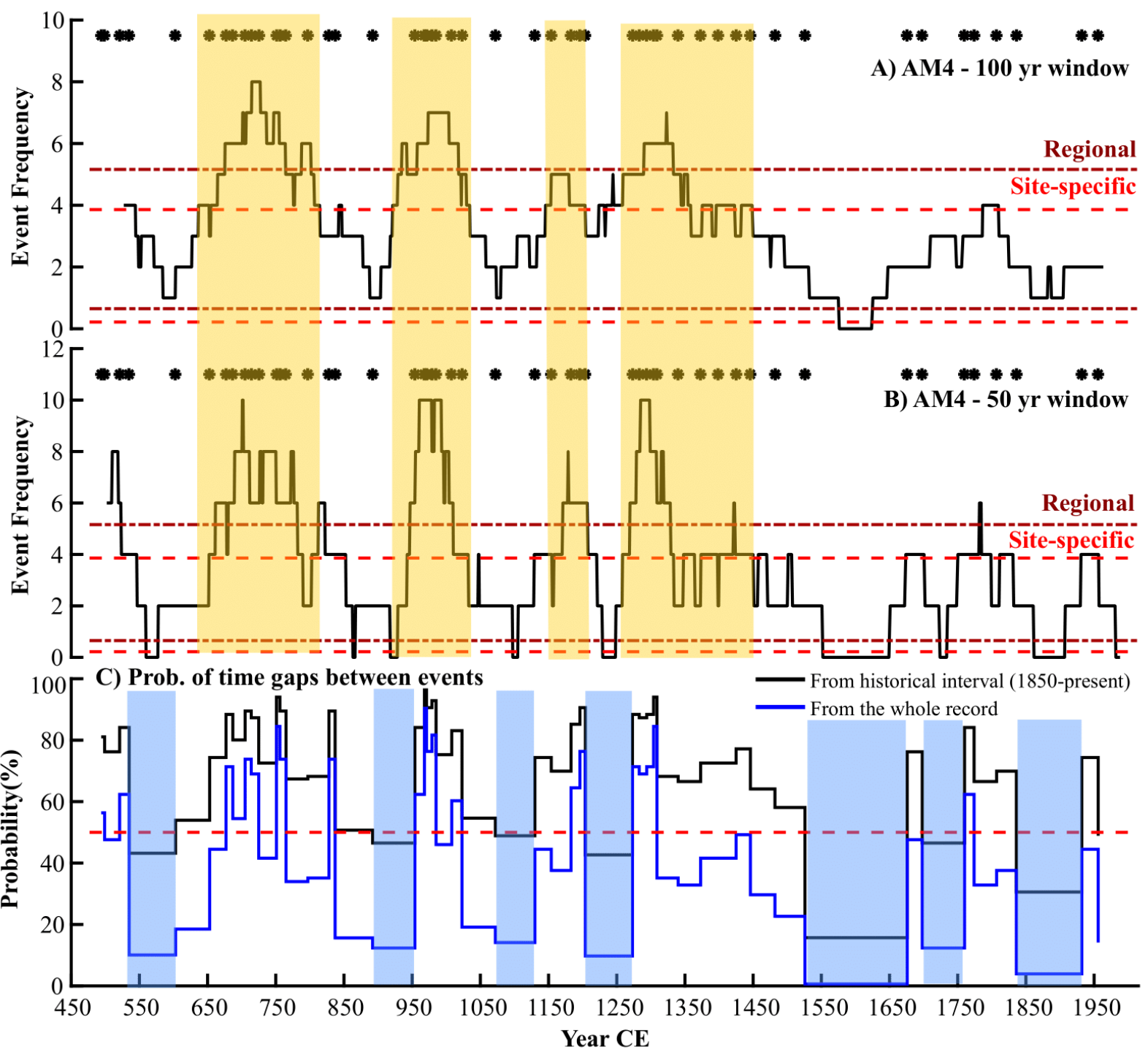

Figure 2.6: Event frequency per century for AM4 (black) with a 100-year sliding window (A) and a 50-year sliding window (B). The probabilities of having no events over the time span between each event in the record $(\mathbf{C})$. The probabilities were calculated based on a recurrence interval of 81.5 over the observational interval (black) and 29 over the whole record (blue). Active and quiet intervals identified on South Andros are shaded in orange and blue, respectively. The dashed red lines are the site-specific and regional cutoffs for active and quiet intervals (3.86 and 0.22 events/century and 5.16 and 0.65 events/century respectively). The timing of each event identified in AM4 is denoted by the black stars above each panel. 


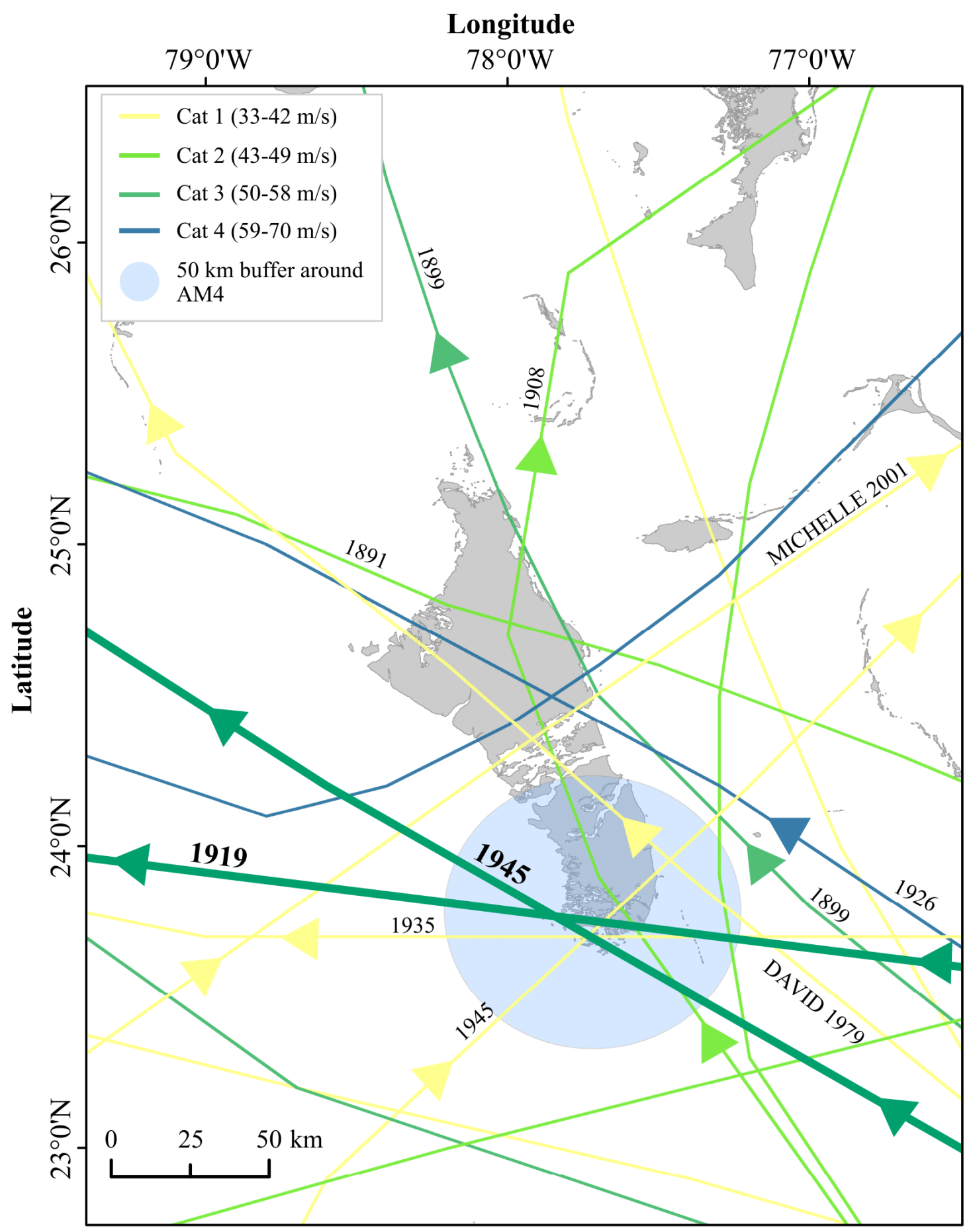

Figure 2.7: Historical hurricane tracks (1850-present) passing within $100 \mathrm{~km}$ for the AM4 blue hole on South Andros Island (N 23.78, W 77.71 ${ }^{\circ}$ ). In bold are the two storms (1945 and 1919) that left a deposit in the South Andros blue holes. 


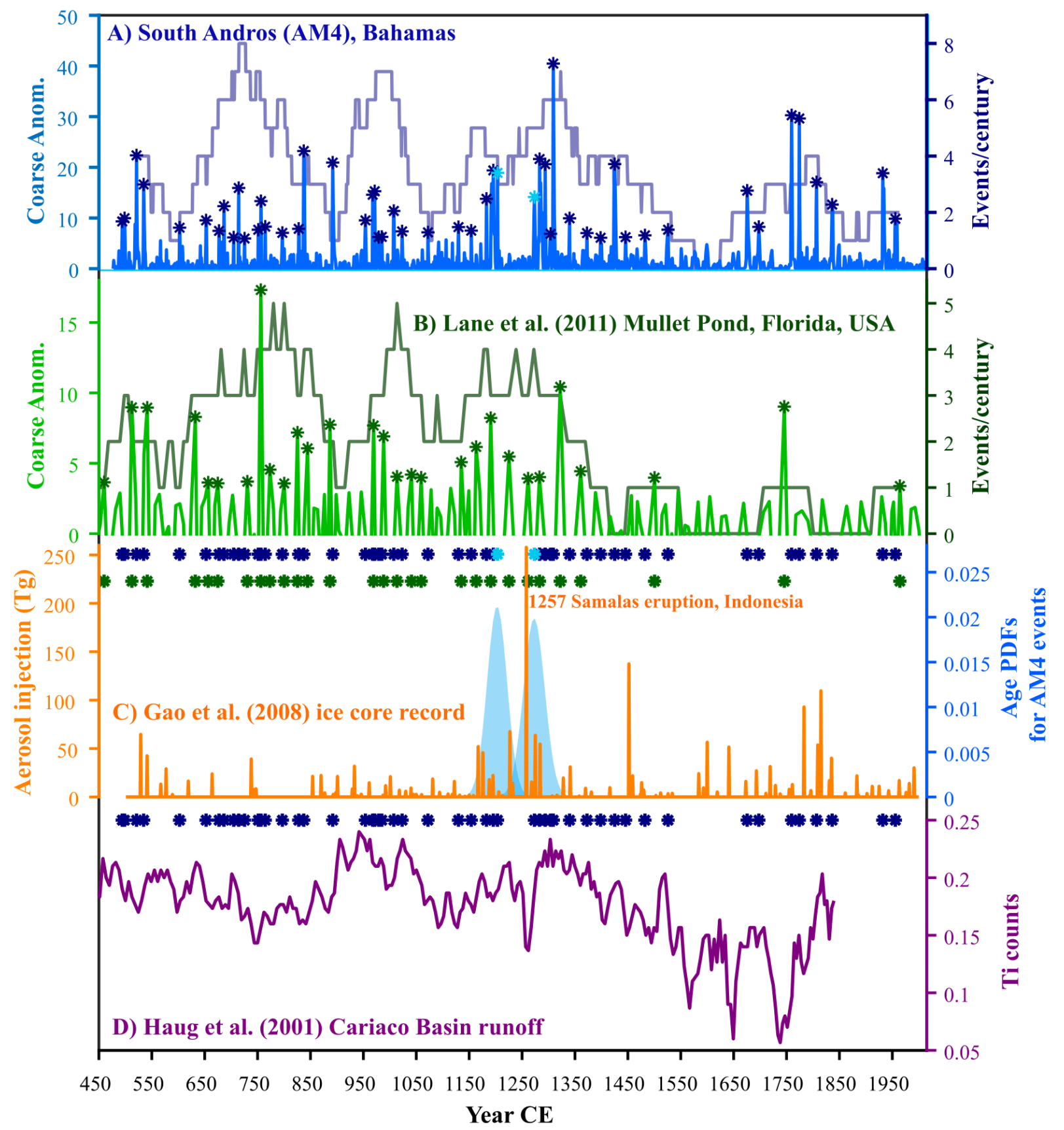

Figure 2.8: Comparison of hurricane proxy records from the Atlantic basin. (A) Coarse anomaly plot (light blue) for AM4 as a function of time. Events are denoted as dark blue stars. The 100-year moving window event frequency per century is plotted in dark blue. (B) Coarse anomaly plot (light green) for Mullet Pond, FL (Lane et al., 2011) as a function of time. Events are denoted as dark green stars. The 100-year moving window event frequency per century is plotted in dark green. (C) Annual stratospheric volcanic sulfate aerosol injection for the past 1500 years from ice core records (Gao et al., 2008). Blue probability distributions depict the age uncertainty for the two hurricane events (light blue stars) on either side of the 70-year gap in activity during the early $13^{\text {th }}$ century. The timing of South Andros (dark blue stars) and Mullet Pond (dark green stars) events are plotted above the data. (D) Ti record from Cariaco Basin reflecting changes in terrestrial runoff and the position of the ITCZ (Haug et al., 2001). 

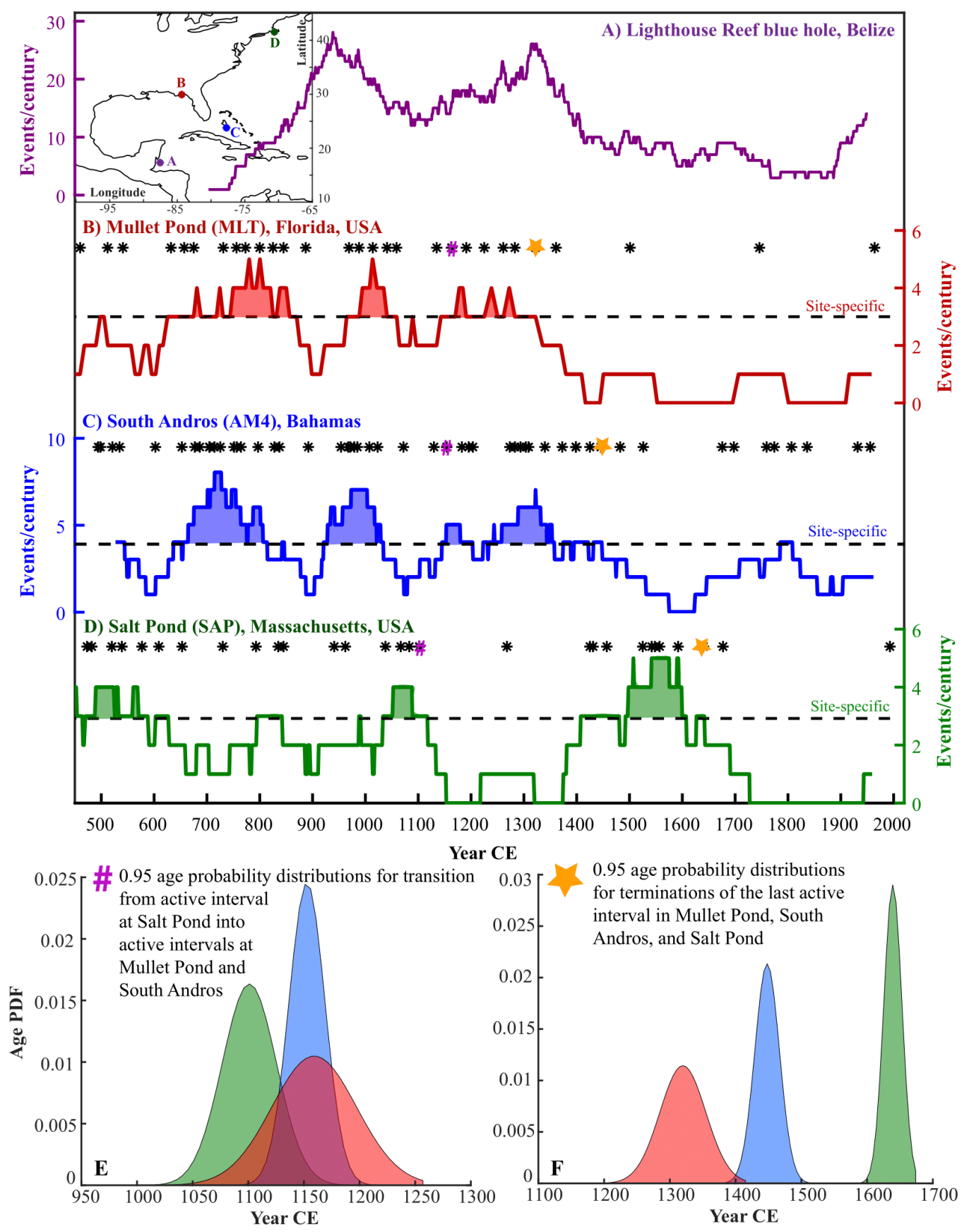

Figure 2.9: 100-year moving window event frequency on (A) Lighthouse Reef Blue Hole, Belize (Denommee et al., 2014) (purple), (B) on Mullet Pond, FL (Lane et al., 2011) (red) with 3 active intervals highlighted in red, (C) South Andros Island (blue) with the 4 active intervals highlighted in blue, and (D) Salt Pond, MA (Donnelly et al., 2015) (green) with 3 active intervals highlighted in green. The timing of each event in the records is denoted by the black stars above each panel. (E and F) $95 \%$ probability distributions (bottom) for the transition from an active interval at Salt Pond (green) to active intervals at South Andros (blue) and Mullet Pond (red) ca. 1120 C.E and the termination of the last active interval in Salt Pond (green), South Andros (blue), and Mullet Pond (red) ca. 1300-1650 CE. The age probability distributions are calculated around the closest event in the record lying within the active interval. Symbols (pound sign for E, star for F) indicate which events were used for the PDFs. Map in the top left corner shows the location of each of the site. 


\section{S. Supplemental material}

\section{S.1. Alternate active interval threshold}

We calculated a regional estimate for AM4 expected event frequency using all the category 3 and above storms in the HURDAT2 (1851-2014) that pass through a $550 \mathrm{~km}$ radius circle centered over $24.08^{\circ} \mathrm{N}$ and $75.39^{\circ} \mathrm{W}$ (Figure S2.7). This area encompasses all islands in the northern Caribbean from Turks and Caicos up to Grand Bahama. We calculated this estimate so that we could provide a uniform number and method for calculating expected event frequency that can be used for any site from the northern Caribbean. However, we expect this estimate is more conservative than site-specific estimates.

We identified the number of storms at or above each Saffir-Simpson Category classification that passed through the $550 \mathrm{~km}$ radius circle over the northern Caribbean over the past 163 years. We then divided each of these storm tracks into a number of smaller $47 \mathrm{~km}$ radius circles (Figure S2.7), representing the average radius of maximum winds for Atlantic storms (Hsu and Yan, 1998). Based on this, it is broadly assumed that any study site occurring within one of these smaller circles would be impacted by the storm. We calculated the number of these $47 \mathrm{~km}$ radius storm impact circles along each storm track when it was within the larger 550 $\mathrm{km}$ radius circle. Then we limited this number to only those circles that surround points on the track where the storm was at or above each Saffir Simpson intensity category (Figure S2.7) to generate the \# of storm impact circles column in the Table S2.3.

For the AM4 threshold calculation, we used the number of storm impact circles for at or above category 3 intensity (Figure S2.7). To calculate expected event frequency $(\lambda)$, we first divide the number of storm impact circles by the area of the $550 \mathrm{~km}$ radius circle divided by the area of the $47 \mathrm{~km}$ radius storm impact circle. This number is further divided by the number of years of Best Track data included in the analysis (1850-2014 - 163 years) and multiplied by 100 years. The regional expected event frequency for category 3 and above storms in the northern Caribbean is 2.12 events/century. The same calculations were performed for each Saffir Simpson scale intensity threshold. Table S2.3 shows the number of impact circles and expected event frequency for each intensity threshold calculated using this method.

Assuming that event occurrence follows a Poisson process, upper and lower $90 \%$ percentile confidence intervals were determined for each intensity classification (Ulm, 1990). The results of these calculations are displayed in the last two columns of Table S2.3. 


\section{S.2. AM5 age model modifications}

The AM5 sediment core contains two event layers like AM4. However, the first event does not date within uncertainties to the 1945 storm. The date of this first event was set predominantly by a single post-bomb radiocarbon date pulled directly above the event layer (Table S2.1). Due to the nonlinear relationship between calendar age and radiocarbon age, there can be multiple calendar age ranges derived from a single radiocarbon date. Indeed, for this particular date, there were two calendar ages that were possible for the interception of the radiocarbon age with the calibration curve. The more probable age dates the first deposit in the core to $1978 \pm 4 \mathrm{CE}$ (Figure 2.4A). The only event to strike in the vicinity of AM5 at this time was Hurricane David in 1979. While passing $33 \mathrm{~km}$ to the northeast of AM5, David was only a Category 1 storm with wind speeds reaching up to $39 \mathrm{~m} / \mathrm{s}$ (https://coast.noaa.gov/hurricanes, 2017). It is unlikely that the AM5 record would capture the distant and less intense Hurricane David while not capturing the 1945 storm passing directly over at higher wind speeds.

Using the less probable calendar age dates the event layer to $1960 \pm 5$ CE. No events passed within the vicinity of AM4 during this time span. However, using this lower probability calibration $(1960 \pm 5 \mathrm{CE})$, the sediment right below the event layer dates within uncertainties to the 1940's (1942-1962 CE). We suggest that the sample from above the event layer was reworked and the age of the event layer is better represented by the sediment laid down before the event. Therefore, we suggest this event is likely the 1945 hurricane layer and its younger date is a result of reworking of the sample during the storm. We use this older less probable calibration in our final age model for the AM5 record.

\section{S.3. Supplemental figures and tables}



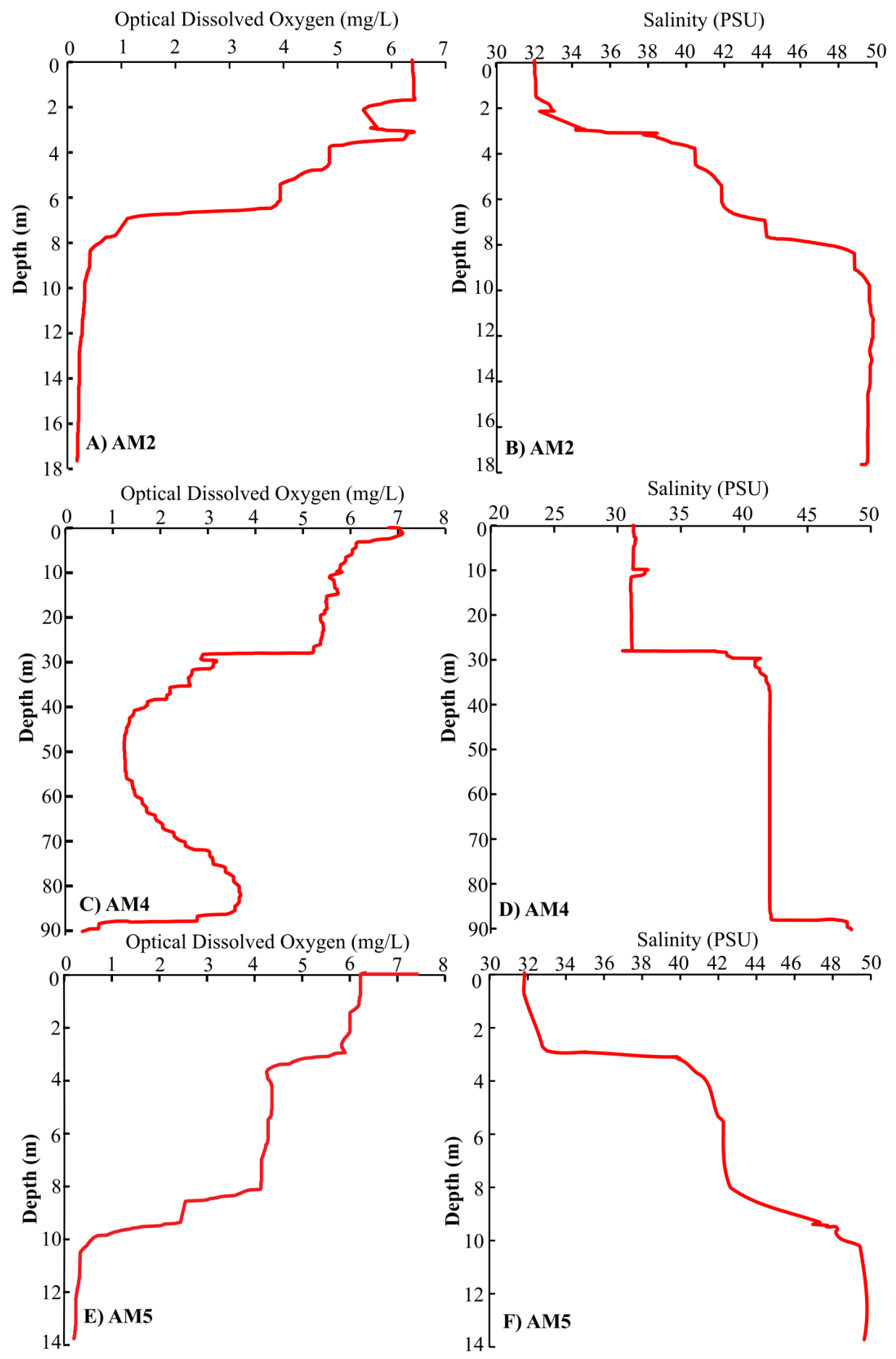

Figure S2.1. Optical dissolved oxygen (A, C, E) and salinity (B, D, F) in the AM2, AM4 and AM5 blue holes. Profiles are from November 2014 and were collected using a YSI EXO1 sonde. All sensors on the sonde were calibrated according to factory recommendations within 24 hours of data collection. The sampling rate of the sonde was two readings per second with an applied rapid averaging (2-3 seconds) to reduce signal noise. The sonde was lowered into the blue hole at a rate of $\sim 1 \mathrm{~cm}$ per second. Sensor accuracy for each parameter is as follows: temperature $= \pm 0.01{ }^{\circ} \mathrm{C}$, salinity $= \pm 0.1 \mathrm{PSU}$, dissolved oxygen $= \pm 0.01 \mathrm{mg} / \mathrm{L}, \mathrm{pH}= \pm 0.01 \mathrm{pH}$ units. 

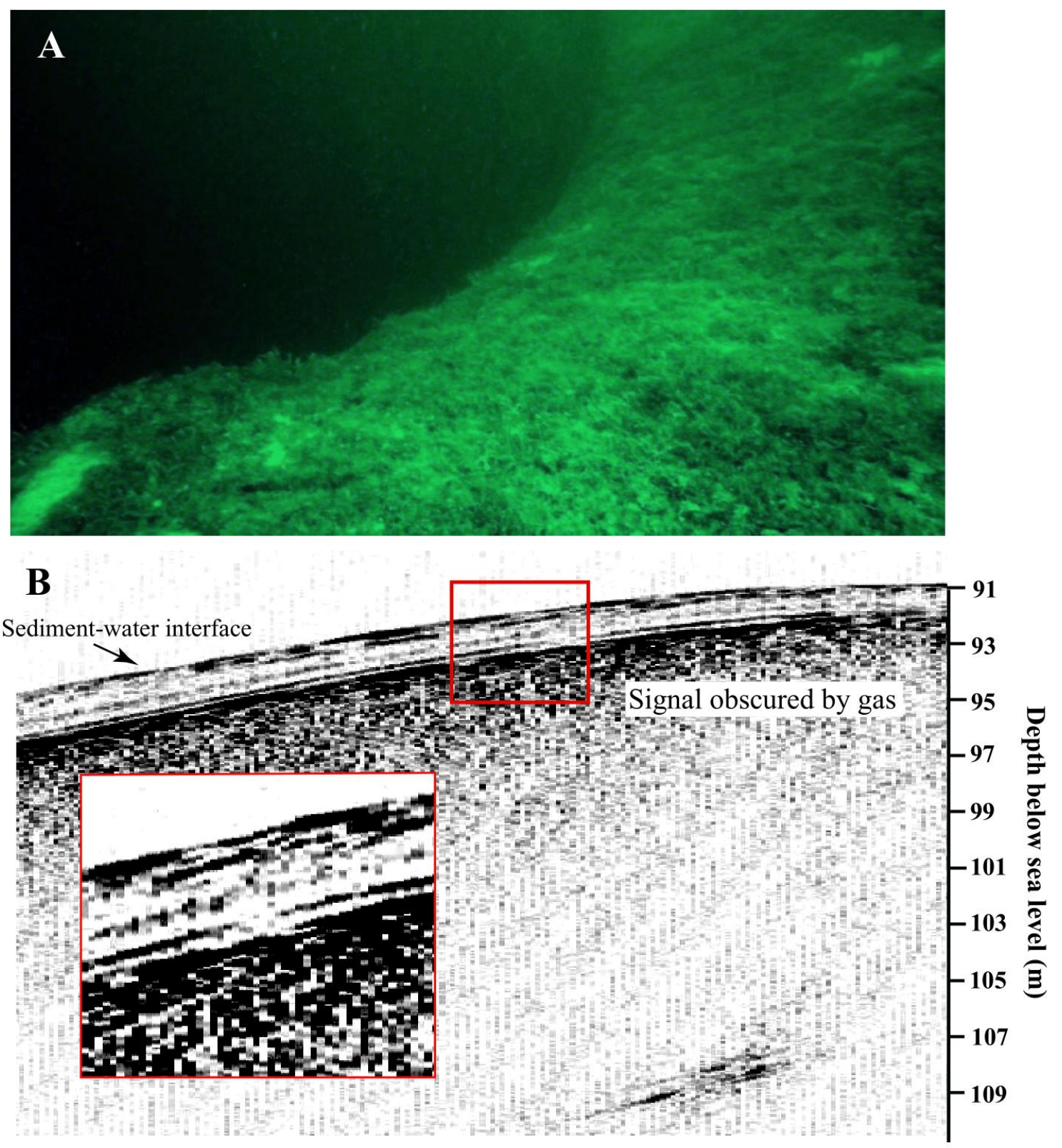

Figure S2.2. Underwater image of the rim of the AM4 blue hole (A). Sub-bottom stratigraphy for the AM4 blue hole imaged with the Edgetech 3100 Chirp sub-bottom sonar system (B). The lateral continuity of horizontal reflectors from 91 to $95 \mathrm{~m}$ below sea level suggests continuous fine-grained layers interspersed with coarser layers (event beds). Below $95 \mathrm{~m}$, the signal is obscured by the presence of gas. The reflector at $109 \mathrm{~m}$ below sea level suggests the presence of sediment at least to this depth. 


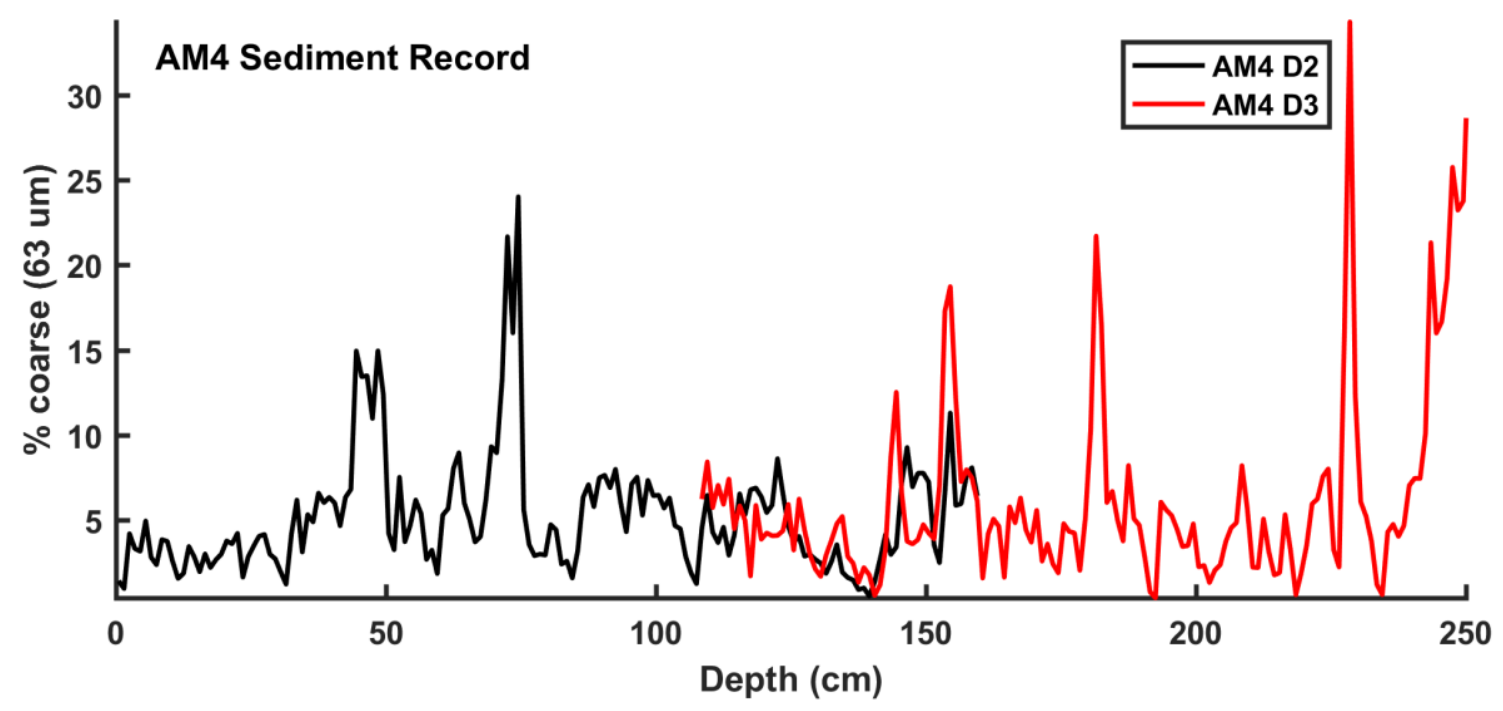

Figure S2.3. Percent sand fraction $(>63 \mu \mathrm{m})$ versus depth in core $(\mathrm{cm})$ for AM4 D2 (polycarbonate surface drive) in black and AM4 D3 (aluminum $18 \mathrm{~m}$ drive) in red. The figure shows where the two drives were assumed to overlap given that AM4 D3 did not capture the sediment water interface. 

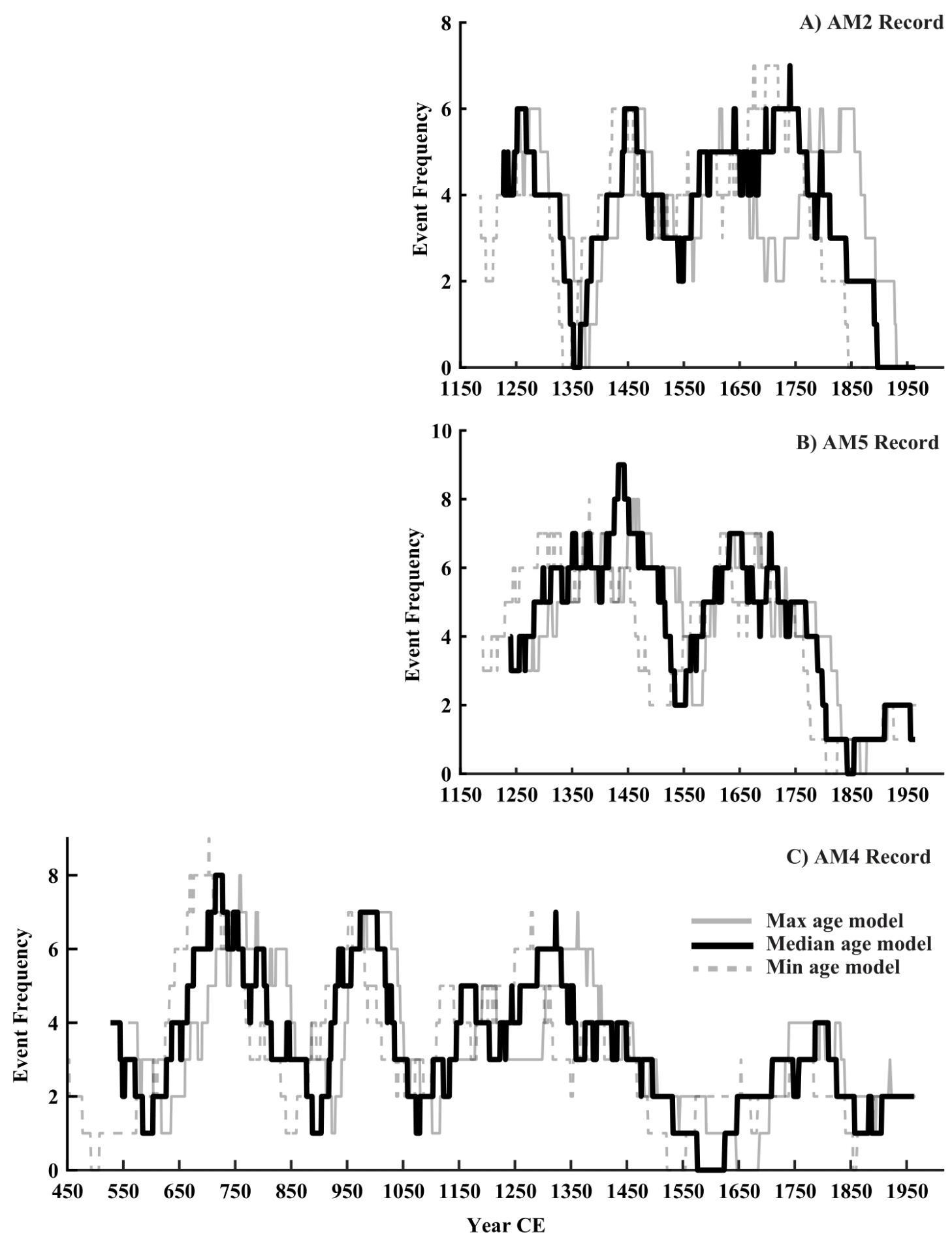

Figure S2.4. 100-year moving window event frequency per century is plotted for AM2 (A), AM5 (B), and AM4 (C) using the lower 95\% confidence bound (grey dashed), upper 95\% confidence bound (grey), and median age model (black). 


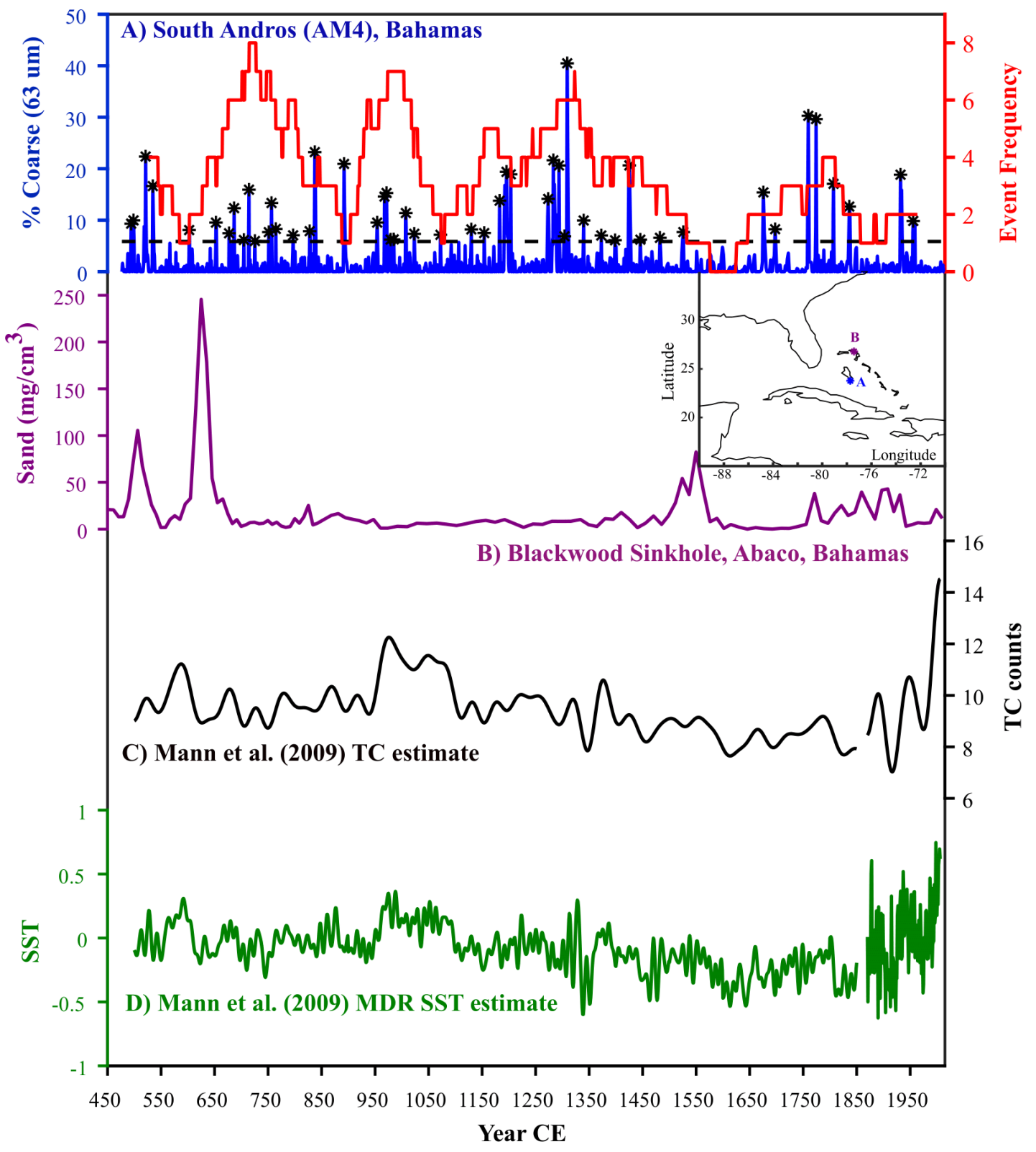

Figure S2.5. (A) Coarse anomaly plot (blue) for AM4 as a function of time. Events are denoted as black stars. The 100-year moving window event frequency per century is plotted in red. (B) Sand deposition into Blackwood Sinkhole, Abaco Island, the Bahamas (van Hengstum et al., 2016). (C) Smoothed modern annual Atlantic tropical cyclone counts and statistical model estimates of basin-wide tropical cyclone counts (black) from 500-1850 CE (Mann et al., 2009). (D) Main Development Region (MDR) SST anomaly reconstruction (dark green) (Mann et al., 2009). NOAA ERSST MDR SST data for 1870-2006 (dark green). Map on right side of panel B shows the location of the AM4 blue hole and Blackwood Sinkhole. 

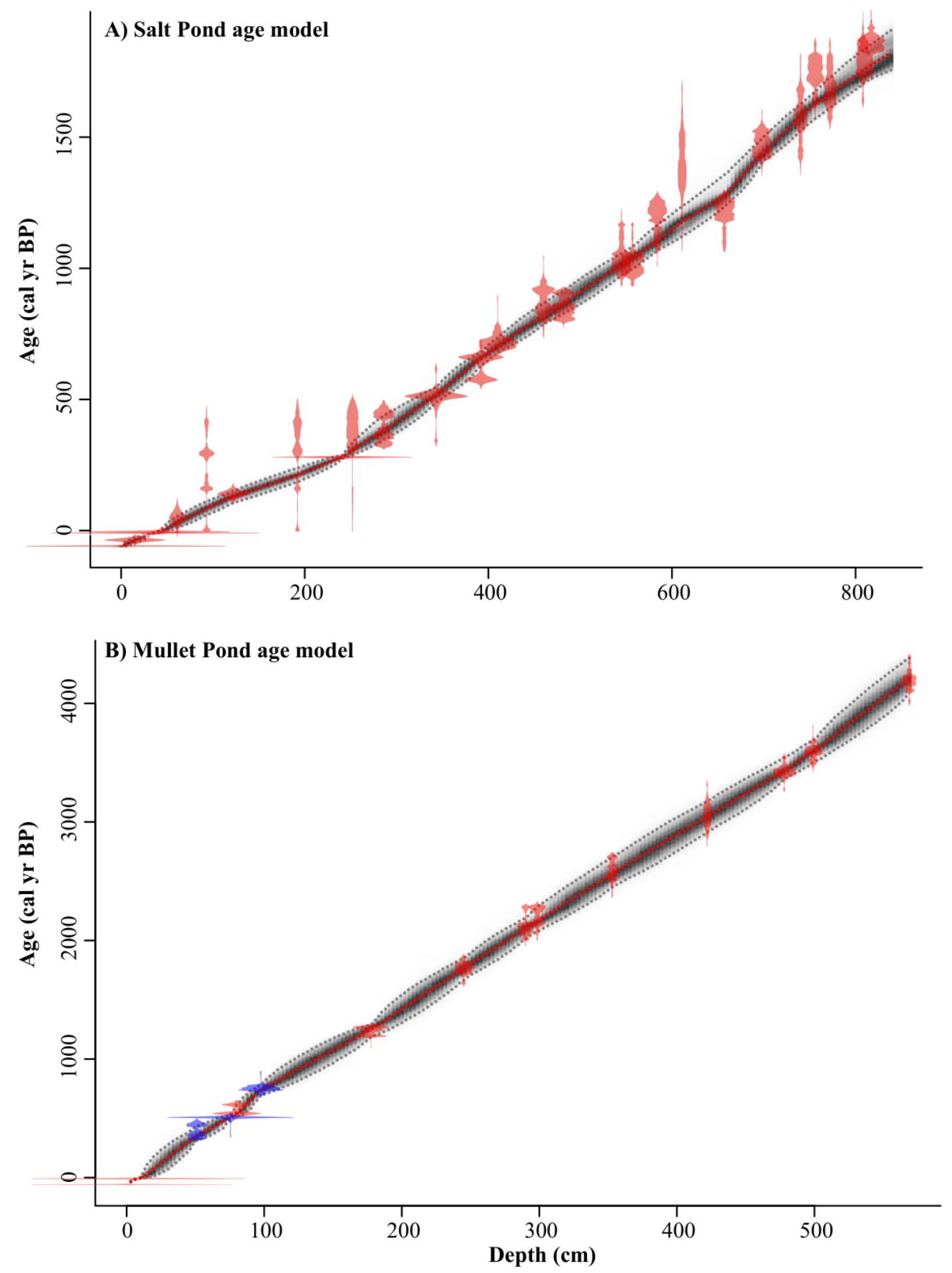

Figure S2.6. Age model derived for Salt Pond, MA core (Donnelly et al., 2015) (A) and Mullet Pond, FL (Lane et al., 2011) (B). The Mullet Pond age model was updated from the previously published version in Lane et al. (2011) with three new dates added at $51 \mathrm{~cm}, 75.5 \mathrm{~cm}$, and $97.5 \mathrm{~cm}$ (shown in blue). 95\% confidence bounds are shaded in grey around the age model. Dates and age uncertainties used for the model are shown in red. These figures were generated using BACON age modeling software (Blaauw and Christen, 2011). 


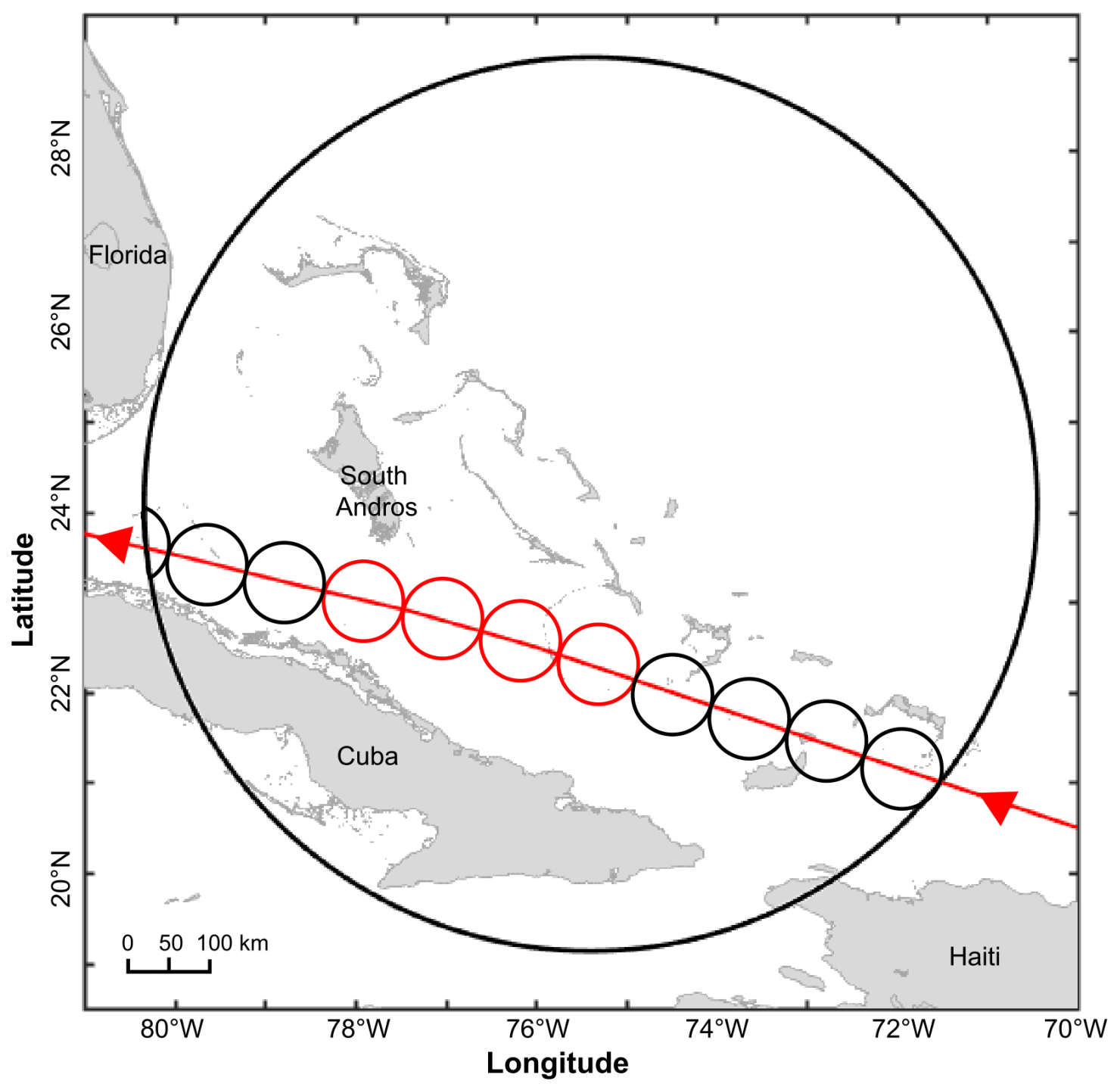

Figure S2.7. Schematic for regional estimate of expected event frequency. In black is shown the $550 \mathrm{~km}$ radius circle over the northern Caribbean. An example storm track (red) passes through this region and is divided into its $47 \mathrm{~km}$ radius storm impact circles. The red circles represent the spots on the track where the storm was category 3 and above. These are the circles counted as events for this track in the expected event frequency calculation. 
Table S2.1. Radiocarbon results from leaf and plant matter in AM4, AM2, and AM5.

\begin{tabular}{|c|c|c|c|c|c|c|c|c|}
\hline Site & $\begin{array}{l}\text { Laboratory } \\
\text { Number }\end{array}$ & $\begin{array}{r}\text { Core } \\
\text { depth } \\
(\mathrm{cm})\end{array}$ & Material dated & $\begin{array}{l}\text { Conventional } \\
{ }^{14} \mathrm{C} \text { age }\end{array}$ & Error & $\begin{array}{c}\mathbf{F} \\
\text { Modern }\end{array}$ & $\begin{array}{c}\mathbf{F} \\
\text { Modern } \\
\text { error }\end{array}$ & D13C \\
\hline AM4 & OS-120469 & 14.5 & leaf/plant matter & -44 & 5 & 1.12480 & 0.00220 & -27.1 \\
\hline AM4 & OS-127430 & 43 & leaf/plant matter & 225 & 15 & 0.97250 & 0.00200 & -25.91 \\
\hline AM4 & OS-120470 & 61.5 & leaf/plant matter & 190 & 15 & 0.97640 & 0.00210 & -23.83 \\
\hline AM4 & OS-120471 & 75 & leaf/plant matter & 145 & 15 & 0.98220 & 0.00210 & -26.03 \\
\hline AM4 & OS-120570 & 134.5 & leaf/plant matter & 155 & 15 & 0.98110 & 0.00210 & -25.98 \\
\hline AM4 & OS-120571 & 141.5 & leaf/plant matter & 150 & 15 & 0.98120 & 0.00200 & -26.87 \\
\hline AM4 & OS-120572 & 174.5 & leaf/plant matter & 145 & 20 & 0.98180 & 0.00220 & -26.22 \\
\hline AM4 & OS-120573 & 208 & leaf/plant matter & 265 & 15 & 0.96740 & 0.00210 & -25.23 \\
\hline AM4 & OS-121302 & 226 & leaf/plant matter & 265 & 25 & 0.96760 & 0.00280 & -24.36 \\
\hline AM4 & OS-119472 & 346 & leaf/plant matter & 320 & 15 & 0.96080 & 0.00200 & -26.64 \\
\hline AM4 & OS-116562 & 471 & leaf/plant matter & 495 & 20 & 0.94030 & 0.00210 & -25.1 \\
\hline AM4 & OS-116561 & 574 & leaf/plant matter & 610 & 20 & 0.92690 & 0.00200 & -25.07 \\
\hline AM4 & OS-116560 & 671.5 & leaf/plant matter & 760 & 20 & 0.90980 & 0.00200 & -26.43 \\
\hline AM4 & OS-119473 & 731 & leaf/plant matter & 875 & 20 & 0.89680 & 0.00230 & -18.49 \\
\hline AM4 & OS-116566 & 776 & leaf/plant matter & 910 & 15 & 0.89300 & 0.00180 & -27.09 \\
\hline AM4 & OS-121307 & 938.5 & leaf/plant matter & 990 & 20 & 0.88430 & 0.00190 & -25.96 \\
\hline AM4 & OS-116802 & 980.5 & leaf/plant matter & 1020 & 15 & 0.88100 & 0.00180 & -26.12 \\
\hline AM4 & OS-119474 & 1025 & leaf/plant matter & 1090 & 20 & 0.87300 & 0.00240 & -26.96 \\
\hline AM4 & OS-121308 & 1136.5 & leaf/plant matter & 1170 & 25 & 0.8642 & 0.0028 & -27.03 \\
\hline AM4 & OS-119475 & 1191 & leaf/plant matter & 1240 & 15 & 0.85660 & 0.00170 & -25.5 \\
\hline AM4 & OS-119476 & 1306 & leaf/plant matter & 1260 & 15 & 0.85520 & 0.00180 & -25.93 \\
\hline AM4 & OS-116803 & 1443.5 & leaf/plant matter & 1300 & 15 & 0.85070 & 0.00180 & -27.4 \\
\hline AM4 & OS-119477 & 1574.5 & leaf/plant matter & 1430 & 20 & 0.83670 & 0.00200 & -29.73 \\
\hline AM4 & OS-116804 & 1660 & leaf/plant matter & 1510 & 15 & 0.82880 & 0.00170 & -26.96 \\
\hline AM5 & OS-131184 & 29 & leaf/plant matter & -11 & 5 & 1.26390 & 0.00270 & -25.62 \\
\hline AM5 & OS-127355 & 53 & leaf/plant matter & 235 & 15 & 0.97110 & 0.00210 & -27.33 \\
\hline AM5 & OS-123857 & 119 & leaf/plant matter & 85 & 20 & 0.9894 & 0.0022 & -28.46 \\
\hline AM5 & OS-127356 & 170.5 & leaf/plant matter & 160 & 20 & 0.98010 & 0.00210 & -28.44 \\
\hline AM5 & OS-123858 & 239.5 & leaf/plant matter & 85 & 20 & 0.9893 & 0.0023 & -26.21 \\
\hline AM5 & OS-127357 & 289 & leaf/plant matter & 210 & 15 & 0.97430 & 0.00190 & -25.94 \\
\hline AM5 & OS-123859 & 353 & leaf/plant matter & 325 & 15 & 0.9603 & 0.0021 & -22.97 \\
\hline AM5 & OS-127358 & 373 & leaf/plant matter & 310 & 15 & 0.96240 & 0.00200 & -27.72 \\
\hline AM5 & OS-124123 & 467.5 & leaf/plant matter & 475 & 25 & 0.94270 & 0.00280 & -27.11 \\
\hline AM5 & OS-127359 & 557.5 & leaf/plant matter & 545 & 20 & 0.93410 & 0.00260 & -26.94 \\
\hline AM5 & OS-127360 & 669 & leaf/plant matter & 705 & 15 & 0.91590 & 0.00190 & -26.43 \\
\hline AM2 & OS-140063 & 7 & leaf/plant matter & -58 & 1 & 1.0544 & 0.0023 & -25.75 \\
\hline AM2 & OS-123853 & 75.5 & leaf/plant matter & 70 & 30 & 0.9916 & 0.0034 & -27.63 \\
\hline AM2 & OS-127348 & 113 & leaf/plant matter & 180 & 20 & 0.9779 & 0.0026 & -25.76 \\
\hline AM2 & OS-123854 & 182 & leaf/plant matter & 60 & 20 & 0.9928 & 0.0022 & -28.11 \\
\hline AM2 & OS-127349 & 251 & leaf/plant matter & 210 & 15 & 0.9743 & 0.0019 & -26.48 \\
\hline AM2 & OS-123994 & 287 & leaf/plant matter & 345 & 20 & 0.9577 & 0.0021 & -27.29 \\
\hline AM2 & OS-127350 & 324 & leaf/plant matter & 375 & 15 & 0.9543 & 0.0019 & -27.84 \\
\hline AM2 & OS-127351 & 375 & leaf/plant matter & 350 & 15 & 0.9574 & 0.0019 & -28.14 \\
\hline AM2 & OS-121309 & 412 & leaf/plant matter & 380 & 20 & 0.954 & 0.0023 & -24.17 \\
\hline
\end{tabular}




\begin{tabular}{|c|c|c|l|c|c|c|c|c|}
\hline AM2 & OS-123855 & 421 & leaf/plant matter & 335 & 15 & 0.9592 & 0.0019 & -23.74 \\
\hline AM2 & OS-127352 & 450.5 & leaf/plant matter & 400 & 15 & 0.9512 & 0.002 & -27.22 \\
\hline AM2 & OS-123856 & 497 & leaf/plant matter & 500 & 20 & 0.9394 & 0.0021 & -27.05 \\
\hline AM2 & OS-127353 & 532 & leaf/plant matter & 700 & 15 & 0.9163 & 0.0019 & -27.63 \\
\hline AM2 & OS-121285 & 624.5 & leaf/plant matter & 715 & 20 & 0.9146 & 0.0022 & -27.92 \\
\hline AM2 & OS-121205 & 702 & leaf/plant matter & 895 & 20 & 0.8944 & 0.0021 & -27.89 \\
\hline
\end{tabular}

Table S2.2. Unused radiocarbon results from leaf and plant matter in AM4, AM2, and AM5.

\begin{tabular}{|l|c|c|l|c|c|c|c|c|}
\hline \multicolumn{1}{|c|}{ Site } & $\begin{array}{c}\text { Laboratory } \\
\text { Number }\end{array}$ & $\begin{array}{c}\text { Core } \\
\text { depth } \\
(\mathbf{c m})\end{array}$ & Material dated & $\begin{array}{c}\text { Conventional } \\
{ }^{14} \mathbf{C} \text { age }\end{array}$ & Error & $\begin{array}{c}\mathbf{F} \\
\text { Modern }\end{array}$ & $\begin{array}{c}\text { F } \\
\text { Modern } \\
\text { error }\end{array}$ & D13C \\
\hline AM4 D2 & OS-120584 & 81.5 & leaf/plant matter & 180 & 15 & 0.97780 & 0.00190 & -29.27 \\
\hline AM4 D2 & OS-127557 & 91.5 & leaf/plant matter & 250 & 40 & 0.96960 & 0.00480 & -26.62 \\
\hline AM4 D2 & OS-120585 & 104.5 & leaf/plant matter & 165 & 15 & 0.98000 & 0.00200 & -26.24 \\
\hline AM4 D3 & OS-119471 & 275.5 & leaf/plant matter & 300 & 20 & 0.96360 & 0.00240 & -26.86 \\
\hline AM5 & OS-124461 & 546.5 & leaf/plant matter & 920 & 15 & 0.8917 & 0.0018 & -26.23 \\
\hline AM5 & OS-124462 & 741.5 & leaf/plant matter & 1230 & 15 & 0.8578 & 0.0017 & -26.53 \\
\hline AM5 & OS-131475 & 756.5 & leaf/plant matter & 570 & 15 & 0.93170 & 0.00200 & -6.66 \\
\hline AM5 & OS-124463 & 776.5 & leaf/plant matter & 1160 & 15 & 0.8651 & 0.0018 & -27.28 \\
\hline AM2 & OS-140062 & 33 & leaf/plant matter & 910 & 15 & 0.8927 & 0.0019 & -28.39 \\
\hline AM2 & OS-127354 & 668 & leaf/plant matter & 1,200 & 15 & 0.8618 & 0.0018 & -11 \\
\hline
\end{tabular}

Table S2.3. Alternate active interval thresholds. This table includes the number of storm tracks passing through the $550 \mathrm{~km}$ radius circle over the northern Caribbean, the number of storm impact circles, the expected event frequency and the $90 \%$ confidence intervals for each intensity bar (as defined by the Saffir Simpson scale).

\begin{tabular}{|l|c|c|c|c|c|}
\hline \multicolumn{1}{|c|}{ Intensity } & $\begin{array}{c}\text { \# of } \\
\text { tracks }\end{array}$ & $\begin{array}{c}\text { \# of storm } \\
\text { impact circles }\end{array}$ & $\begin{array}{c}\text { Expected } \\
\text { frequency per } \\
\text { century }(\boldsymbol{\lambda})\end{array}$ & $\begin{array}{c}\mathbf{9 0 \%} \text { CI } \\
\text { Lower }\end{array}$ & $\begin{array}{c}\text { 90\% CI } \\
\text { Upper }\end{array}$ \\
\hline $\begin{array}{l}\text { Cat. 1 and } \\
\text { above }\end{array}$ & 171 & 1447.74 & 6.49 & 3.59 & 10.84 \\
\hline $\begin{array}{l}\text { Cat. 2 and } \\
\text { above }\end{array}$ & 106 & 826.72 & 3.70 & 1.62 & 7.30 \\
\hline $\begin{array}{l}\text { Cat. 3 and } \\
\text { above }\end{array}$ & 66 & 474.03 & 2.12 & 0.65 & 5.16 \\
\hline $\begin{array}{l}\text { Cat. } 4 \text { and } \\
\text { above }\end{array}$ & 29 & 154.26 & 0.69 & 0.05 & 3.04 \\
\hline $\begin{array}{l}\text { Cat. 5 and } \\
\text { above }\end{array}$ & 5 & 14.22 & 0.06 & 0.00 & 1.96 \\
\hline
\end{tabular}


Table S2.4. New radiocarbon results from leaf and plant matter in Mullet Pond (Lane et al., 2011)

\begin{tabular}{|c|c|c|c|c|c|c|c|c|}
\hline Site & $\begin{array}{c}\text { Laboratory } \\
\text { Number }\end{array}$ & $\begin{array}{c}\text { Core } \\
\text { depth } \\
\text { (cm) }\end{array}$ & Material dated & $\begin{array}{c}\text { Conventional } \\
\mathbf{1 4}^{4} \text { C age }\end{array}$ & Error & $\begin{array}{c}\text { F } \\
\text { Modern }\end{array}$ & $\begin{array}{c}\text { F } \\
\text { Modern } \\
\text { error }\end{array}$ & D13C \\
\hline MLT1 D1 & OS-141078 & 51 & leaf/plant matter & 345 & 15 & 0.9580 & 0.0020 & -24.97 \\
\hline MLT1 D1 & OS-141079 & 75.5 & leaf/plant matter & 450 & 15 & 0.9455 & 0.0020 & -25.1 \\
\hline MLT1 D1 & OS-141080 & 97.5 & leaf/plant matter & 845 & 15 & 0.8999 & 0.0019 & -20.97 \\
\hline
\end{tabular}




\title{
3. 1000 years of hurricane strikes on Long Island in The Bahamas
}

\begin{abstract}
In the last decade, high resolution sedimentary records of past hurricane activity have been developed in the Atlantic. These reconstructions indicate that there have been many centennialscale periods over the past millennium when hurricane activity was much higher than has been observed during the last century. However, the search for the underlying mechanism of these active hurricane periods is confounded by regional variations in their timing. In this work, we present both a new reconstruction of hurricane activity in The Bahamas as well as a synthesis of high resolution paleohurricane reconstructions in the North Atlantic Basin over the past millennium. We reconstruct hurricane strikes over the past 1050 years in sediment cores from a blue hole on Long Island in The Bahamas. We find coarse-grained deposits in these cores that date to the close passage of eight intense hurricanes over the historical interval. This record indicates four active periods of hurricane strikes on Long Island that have different timing than active intervals reconstructed on neighboring islands (Andros and Abaco Island). We show that these three islands do not sample all the same storms despite their proximity, and we compile their reconstructions together to create the first regional compilation of hurricane strikes in The Bahamas over the past millennium. Taken together, paleohurricane records from the North Atlantic indicate increased storminess during the Medieval Warm Period (900-1100 CE). Afterwards, the hurricane patterns in our Bahamian compilation match those reconstructed along U.S. East Coast but are out of phase with records from the northeastern Gulf of Mexico. We argue that this disconnect results from a shifts in local environmental conditions in the North
\end{abstract} Atlantic or shifts in hurricane populations from straight-moving storms to recurving storms over the past millennium.

\subsection{Introduction}

On October $1^{\text {st }}, 2015$, Hurricane Joaquin hovered over the northeast Bahamas at Category 4 strength devastating Crooked Island, San Salvador Island, Rum Cay, and Long Island. The storm killed 34 people, caused over US\$200 million in damages (Berg, 2016), and destroyed the livelihoods of many people on these island nations, flooding homes and fields, killing livestock, and tossing fishing boats ashore. Joaquin was not the only storm to devastate the Bahamas in the past few years. Hurricanes Matthew 2016, Irma 2017, Maria 2017, and Dorian 2019 impacted 
the Bahamas as strong Category 3 or above storms. These five storms (Dorian 2019, Irma 2017, Maria 2017, Matthew 2016, and Joaquin 2015) collectively caused 115 billion USD in damages and a death toll of $\sim 1000$ people (Cangialosi et al., 2018; Kishore et al., 2018; Pasch et al., 2019; Stewart, 2017).

The massive damage associated with these recent storms is in large part due to the increase in coastal population and infrastructure that's occurred in the U.S. over the past century (Mendelsohn et al., 2012; Pielke Jr. et al., 2008). This increasing coastal wealth in concert with rising sea levels has amplified coastal vulnerability to storm inundation (Woodruff et al., 2013). In addition, a growing body of climatological research suggests that global warming will produce stronger hurricanes (Bhatia et al., 2018; Emanuel, 2013; Korty et al., 2017; Sobel et al., 2016; Walsh et al., 2016; Zhang et al., 2017). Yet it is difficult to put these projections into a broader historical context given the short and biased nature of the observational record of hurricane activity (Frappier, Knutson, et al., 2007; Villarini et al., 2011; Landsea et al., 2004; Landsea and Franklin, 2013; Vecchi and Knutson, 2008; Landsea et al., 2010; Knutson et al., 2019). With only 169 years of observations in the Atlantic (NOAA Best Track-Knapp et al., 2010), we cannot rigorously separate concurrent natural and anthropogenic influences on hurricane activity nor can we assess how hurricanes and climate interact on multi-decadal to centennial timescales.

Fortunately, hurricanes, particularly more intense storms, leave behind geologic signatures that allow us to track storm landfalls deeper back in time. When a hurricane strikes a coastal location, high energy currents and waves can mobilize large coarse-grained sediment particles in addition to fine-grained particles and deposit them into deep coastal basins. There, they form distinct layers of coarse material, also known as event beds, among the fine-grained sediment that typically accumulate in these basins (Wallace et al., 2014). Once deposited, these events beds are preserved at depth and isolated from reworking during further high energy events. These sediments can serve as natural archives of hurricane strikes over hundreds or even thousands of years. In the past decade, there has been a growing collection of such sedimentary records of past hurricane activity (e.g., Brandon et al., 2013; Bregy et al., 2018; Donnelly et al., 2015; Lane et al., 2011; van Hengstum et al., 2016; E. J. Wallace et al., 2019). These reconstructions typically indicate that periods of historically unprecedented levels of intense hurricane activity in the Atlantic occurred over the past millennium. 
Since the beginning of the observational record, 180 hurricanes (an average of 1.1 storms/yr) have passed through the Bahamas. Of these storms, 76 of them made landfall somewhere along the U.S. coastline (28 along the Gulf Coast, 29 along the East Coast and 19 in the Florida panhandle). Therefore, understanding hurricane patterns in the Bahamas will help us better assess the risk of such storms to island nations but also to places along the U.S. coastline. Coastal karst basins, such as blue holes and sink holes, scattered across the hurricane-prone tropical Atlantic have provided a suitable environment for creating high-resolution paleohurricane reconstructions. In most cases, these holes have ample accommodation space for sediments largely undisturbed by sea level changes and low benthic productivity limiting bioturbation. Despite their suitability for paleohurricane research, there are currently relatively few reconstructions from these basins (Denommee et al., 2014; Lane et al., 2011; van Hengstum et al., 2016, 2014; Wallace et al., 2019).

Four recent studies confirm the utility of blue hole sediment cores in reconstructing hurricane activity over the past two millennia (Denommee et al., 2014; van Hengstum et al., 2014; Wallace et al., 2019, Winkler et al., in review). All of these blue hole records contain coarse-grained event deposits that correlate with known historical hurricane strikes, have nearannual resolution, and observe prolonged active and quiet periods of hurricane activity. van Hengstum et al. (2014) presents a shorter exploratory record from Thatchpoint blue hole on Abaco Island. It captures two coarse-grained deposits over the instrumental record that date within uncertainties to the passage of Hurricane Jeanne 2004 and Hurricane Floyd 1999. Winkler et al. (in review) presents a series of longer cores $(\sim 9 \mathrm{~m})$ from this same blue hole on Abaco Island in The Bahamas. This new record updates the previous work from Thatchpoint Blue Hole and documents local hurricane strikes on the island over the past 600 years.

Denommee et al. (2014) and Wallace et al. (2019) (Chapter 2) present longer records documenting hurricane strikes in the western and northeastern Caribbean, respectively. Denommee et al. (2014) provide a record of paleohurricane activity over the past 1200 years from sediment cores from Lighthouse Reef blue hole in Belize. Chapter 2's (Wallace et al., 2019) reconstruction documents intense hurricane landfalls over the past 1500 years preserved in three different blue holes on the carbonate tidal flats of South Andros Island, The Bahamas. Winkler et al. (in review) presents a stacked record of hurricane activity on South Andros drawn from the events captured in each of these three blue holes. Both studies from Belize and South 
Andros suggested that active and inactive periods of hurricane activity occur coeval with shifts in hemispheric-scale oceanic and atmospheric climate features such as the Intertropical Convergence Zone (ITCZ) and the North Atlantic Oscillation (NAO) (Denommee et al., 2014; Wallace et al., 2019).

When comparing the Caribbean records to records from U.S. coastline, there is clear regional variation in the timing of these active and quiet intervals. Wallace et al. (2019) noted that the South Andros record showed similar patterns of activity to records from the Florida Gulf Coast (Lane et al., 2011; Brandon et al., 2013) but directly contrasted with a record from Salt Pond in Massachusetts (Donnelly et al., 2015). In particular, the records from the Gulf Coast and South Andros showed high activity from 1100 CE to the mid-fifteenth century but were relatively quiet from 1450-1650 CE when Salt Pond was active. The authors suggested that this shift in tracks was likely tied either to changes local environmental conditions or climate driven geographic variability in hurricane tracks and intensity (Wallace et al., 2019). This is all confounded by the inherent stochasticity associated with hurricane tracks and landfalls. Hurricane tracks might strike one sample location more frequently compared to others over a time period simply as a result of randomness.

To solve this puzzle, we need more paleohurricane proxies throughout the Caribbean to better constrain how storm activity shifted from lower latitudes to the U.S. coastline. There are no other records from the Bahamas that compare in length or resolution to the record on South Andros Island. The recently updated record from Thatchpoint Blue Hole on Abaco Island, The Bahamas (Winkler et al., in review) provides similar resolution ( near-annual) to South Andros but only extends back 700 years. Another record from Abaco Island (Blackwood sinkhole - van Hengstum et al., 2016) is too poorly resolved temporally ( centennial) to compare with any of the decadal to centennial timescale changes in hurricane activity now observed on South Andros (Wallace et al., 2019). Therefore, it is crucial to acquire more high resolution records of the past millennium to assess the regional coherency of storm frequency in the Bahamas.

In tandem with the uncertainties in the climatic interpretations of these blue holes are further uncertainties about the sedimentary processes that are at play in blue hole environments during hurricanes. Our assumption is that during storm events high winds and waves at the surface induce strong bottom current which suspend and transport sediment into the blue hole (Miller et al., 1977). However, this explanation does not account for complicated hydrodynamics 
at play on shallow carbonate platforms during storm events. Shoreline configuration and morphology, wind and current direction during storms, and sediment sources likely play a role in sediment transport at a site. For instance, Wallace et al. (2019) (Chapter 2) observed that the records from the three neighboring blue holes on South Andros did not capture all the exact same events despite their locations in same tidal flat system. The sensitivity of each blue hole site to hurricane event bed deposition is likely influenced by its proximity to different tidal channels, shielding by local topography and local sediment characteristics. We need more information about the processes dictating sedimentation in blue hole systems to aid in interpreting current and future paleohurricane records.

Unfortunately, this information is rather difficult to obtain. It is prohibitively dangerous to observe blue hole sites during intense hurricane strikes and the destructive nature of hurricanes usually results in damaged or lost sensors. These difficulties are all exacerbated by the irregularity in which a hurricane makes landfall near these sites. It is often difficult even to use the observational storms (1850-present) to uncover what types of hurricane leave deposits. Since there is a wealth of storms that impact sites in the Caribbean and age uncertainties associated with each event deposit, it is sometimes difficult to ascertain exactly which modern storms left behind each deposit.

Generally, historical attribution within sedimentary archives reveals that the close passage of an intense storm is often the source of easily distinguished event beds at a site. In the South Andros Island record (Wallace et al., 2019), the authors argued that the two event deposits in the modern corresponded to the proximal passage of the 1945 and 1919 Category 3 storms. However, there are many underlying uncertainties associated with attributing historic event beds to known events of a narrow character (e.g., only intense storms). The most important metric for determining storm surge and coarse-grained transport are not the individual properties of the storm itself but instead the local conditions induced by that storm's passage. Different local conditions (e.g., sources/sinks of sediment; location of geomorphic features, coastline geometry) can dramatically impact whether a site captures an event bed. On South Andros, sediment cores from a different blue hole located only a few kilometers away did not capture coarse deposits during the same two storms (i.e., 1919, 1945). Hydrodynamic modeling work (Lin et al., 2014) on barrier beach environments shows that that a wide range of storm characteristics (intensity, duration, track, size) can produce large enough storm surges to overtop a coastal barrier and 
leave an event deposit in the basin behind. To fully understand the distribution of storm intensities that leave a deposit at a blue hole site, we need reliable simulations of the local conditions near a blue hole and/or actual wave and current observations.

In this study, we present a high resolution record of event bed frequency in a blue hole off the west coast of Long Island, The Bahamas. The record spans the past 1050 years and contains eight event beds which temporally correlate to eight Category 3 and above hurricanes (e.g., Hurricane Joaquin in 2015) that passed over the site since 1850 CE. These historical sediment deposits give us the opportunity to investigate how modern events of a known character leave deposits in blue holes. We also present current speed and direction data measured during the distant passage of Hurricane Irma in 2017. With its position close to records from South Andros (Wallace et al., 2019) and Abaco Island in the Bahamas (van Hengstum et al., 2014, 2016, Winkler et al. in review), this site offers the perfect opportunity to assess the regional coherency of storm frequency in the Bahamas. We use this record to evaluate the temporal variability of hurricane strikes on Long Island and combined with other available reconstructions we assess geographic variability of hurricane strikes along the U.S. coastline and throughout the tropical Atlantic.

\subsection{Methods}

\subsubsection{Study Site}

Long Island is situated on the southeastern tip of the Great Bahama Bank in the central Bahamas. It lies $265 \mathrm{~km}$ east of the location of the South Andros Island reconstruction (Wallace et al., 2019) and $400 \mathrm{~km}$ to the southeast of the location of the reconstruction from Abaco Island (van Hengstum et al., 2016; Winkler et al., in review). These records provide an established geologic context in which to compare our reconstruction and offer an opportunity to test geographic variability in hurricane tracks.

We collected cores in April 2016 from a blue hole off the northwest shore of Long Island (N 23.265, $\mathrm{W} 75.117^{\circ}$ ). The blue hole is situated on a shallow carbonate bank approximately $400 \mathrm{~m}$ from the coast. The blue hole is approximately $150 \mathrm{~m}$ in diameter with a maximum depth of $12 \mathrm{~m}$ (Figure 3.1c). CTD casts taken from the center of the blue hole indicate a gradual thermocline in April starting at $2 \mathrm{~m}$ deep and extending through $6 \mathrm{~m}$ deep. The temperature 
profile in January, on the other hand, suggests a collapsed thermocline in the winter months with much cooler temperatures at surface (Figure S3.1). The bank surrounding the hole is 1-2 m deep.

Long Island is positioned along the trackway of many hurricanes originating in the Caribbean and Atlantic. Since 1850, thirty-four tropical cyclones have passed within a $100 \mathrm{~km}$ radius of Long Island. Of these storms, 14 were classified as hurricanes and over half of those were Category 3 strength and above on the Saffir Simpson scale. Recent years have brought multiple intense hurricane passing within $250 \mathrm{~km}$ of the island. In 2015, the year before the cores were taken, the center of circulation of Hurricane Joaquin passed $40 \mathrm{~km}$ east of the blue hole at Category 4 strength with maximum sustained wind speeds at 115 knots. Months after coring, Hurricane Matthew passed $100 \mathrm{~km}$ to the southeast of the site at Category 3 in September 2016. Hurricane Irma in 2017 passed much further away $(\sim 200 \mathrm{~km})$ to the southeast of the blue hole also at Category 4 strength (see Figure 3.5D).

\subsubsection{Field Methods}

We cored the blue hole using a Rossfelder P-3 vibracore from the $R V$ Arenaria, a customized 6-m pontoon vessel. The Arenaria, personnel and equipment were transported to Long Island aboard the MV Alucia and field operations were supported by the Alucia's tender the Northwind. We collected two long vibracores LIBH1 ( 9 m) and LIBH2 ( 12 m) from the center of the blue hole. Both LIBH1 and LIBH2 do not contain the sediment water interface. Therefore, we collected a short surface core (LIBH1 D2) in which we carefully curated the core top. The first $28 \mathrm{~cm}$ of the LIBH record stems from this surface core which contains an event layer (likely from Hurricane Joaquin) within the first $3 \mathrm{~cm}$. We stratigraphically linked the surface core and longer drive (LIBH2) by matching the coarse fraction data from both cores (Figure S3.2).

In January 2017, we returned to the site and took 2 short surface grabs $(\sim 5 \mathrm{~cm})$ to capture any sediments potentially deposited from Hurricane Matthew in 2016. We also deployed a Lowell Instruments LLC Tilt Current Meter (TCM) approximately $30 \mathrm{~m}$ to the northwest of the hole in $1.5 \mathrm{~m}$ of water (Figure 3.1). This sensor measures bottom current speed and direction as well as temperature. It was recovered in 2018 and captured data during the passage of Hurricane Irma on September 8-10, 2017.

\subsubsection{Sediment Analysis and Age Control}


Following the procedures of Chapter 2 (Wallace et al., 2019), we sampled the cores (LIBH1 and LIBH2) continuously at $1 \mathrm{~cm}$ intervals, dried them for 8 hours in $100^{\circ} \mathrm{C}$, and wet sieved them at $63 \mu \mathrm{m}$. We dried and weighed the residual to determine its coarse fraction by dry weight. Most of chronological control for the longer LIBH2 core was based on radiocarbon dates. However, we also include chronostratigraphic ages from pollen derived evidence of known land use changes and $\mathrm{Pb}-210$ radionuclide activity over the last few centuries into our age model.

Fossil pollen records can document changes in terrestrial flora that can be used as chronological tie points. We established three control points in the top $200 \mathrm{~cm}$ of LIBH2 from pollen horizons in smear slides from 10 different samples from LIBH2 (Table S3.1). Smear slides provide semi-quantitative compositional information which we used to determine the presence and absence of pollen taxa in sedimentary units in LIBH2 without detailed pollen analysis. Vegetation nomenclature follows Correll \& Correll (1982). The furthest downcore samples $(233 \mathrm{~cm}$ and $286 \mathrm{~cm}$ ) indicate that Long Island was dominated by dry tropical hardwood coppice forest with some palms and no agricultural disturbances on the landscape. At both 181 $\mathrm{cm}$ and $198 \mathrm{~cm}$, the pollen in the smear slides start to indicate disturbance in the environment including weedy disturbance taxa like Asteraceae, i.e. Genera Ambrosia and Conyza sp. (Correll and Correll, 1982). In particular, the sample at $193 \mathrm{~cm}$ contains macro-charcoal fragments with nearly all of the coppice pollen taxa are absent. This interval is likely associated with the extensive plantation at Gray's Settlement (1784-1814 CE), one of some 4,000 acres of cotton plantations on Long Island (Craton and Saunders, 1992; Eneas, 1998). We assign the age of the onset of cotton agriculture at $193 \mathrm{~cm}$ to $1795 \pm 10 \mathrm{CE}$. This tie point is consistent with an independent radiocarbon date at $181 \mathrm{~cm}$ (Table S3.2 and Figure 3.2).

The smear slide at $98 \mathrm{~cm}$ also indicated taxa associated with scattered forest disturbance and sisal cultivation including Agavaceae (c.f. Agave sisalana) (Table S3.1). In 1890 CE, the Bahamas had some 100,000 acres in sisal production and Long Island cultivated approximately 250 acres of sisal in 1908 (Eneas, 1998; Little et al., 1977). The Bahamas experienced a sisal production boom in 1916 CE during World War I, and ending in 1920 CE (Eneas, 1998). Thus, we assign the age of the sample from $98 \mathrm{~cm}$ to within the sisal period on Long Island (1905 \pm 15 $\mathrm{CE})$. The two top most smear slide samples $(18 \mathrm{~cm}$ and $40 \mathrm{~cm}$ ) indicate a return to the coppice forest matrix with either small farm clearings or no disturbance taxa (Table S3.1). At $40 \mathrm{~cm}$, the 
presence of the popular agriculture trees (e.g., the hog plum - Spondias sp.) and opaque spherules (indicating fossil fuel combustion) document some human presence on the landscape (Griffin and Goldberg, 1975; Clark and Patterson, 1984). Spherules are sparsely evident in the sample from $18 \mathrm{~cm}$ likely reflecting the population loss and loss of farm sites on Long Island around 1943 CE and continuing through 1960 CE (Craton and Saunders, 1998). Thus, we interpret the age at $18 \mathrm{~cm}$ to be $1980 \pm 20 \mathrm{CE}$.

We measured Lead $210\left({ }^{210} \mathrm{~Pb}\right)$ on bulk sediment samples in top $170 \mathrm{~cm}$ of LIBH2 on Canberra GL2020RS low-energy Germanium gamma well detectors. ${ }^{210} \mathrm{~Pb}$ decays with a halflife of 22.3 years (Faure, 1986). This decay process results in an exponential decrease in ${ }^{210} \mathrm{~Pb}$ with depth that can allow for dating sediment back approximately 100 years. We used the Constant Rate of Supply (CRS) model (Appleby, 2001; Appleby and Oldfield, 1978) to identify and date the ${ }^{210} \mathrm{~Pb}$ equilibrium line (Figure S3.3) at $110 \mathrm{~cm}$ to $1906 \pm 10 \mathrm{CE}$. This ${ }^{210} \mathrm{~Pb}$ control point is consistent with the pollen horizon for sisal cultivation on Long Island at $101 \mathrm{~cm}$ (Figure $3.2)$.

We use 11 radiocarbon dates from $\mathrm{LIBH} 2$ to establish age control through the rest of the core (Figure 3.2 and Table S3.2). All dates were derived from mangrove leaves and plant matter preserved in the cores. They were dated at the National Ocean Sciences Accelerator Mass Spectrometry facility in Woods Hole, MA. We used Bayesian accumulation histories for deposits (BACON) software to create the age model (Blaauw and Christen, 2011). Radiocarbon dates were calibrated using IntCal13 and post-bomb radiocarbon was calibrated with CALIbomb under the compiled Northern Hemisphere Zone 2 dataset (Reimer et al., 2004). We excluded five dates from the chronology (Figure 3.2 and Table S3.3) as they were not chronologically consistent with all the other dating evidence. These samples likely indicate older reworked material from the landscape (Section 3.S.3). Throughout the record, we assume event beds are deposited in hours. Thus, we condense all event beds down to $1 \mathrm{~cm}$ and remove them for age-depth modeling and then reinsert them as instantaneous events.

\subsubsection{Event threshold, attribution, and frequency}

Event beds in the core were identified predominantly using the coarse fraction data. We followed the methods of Donnelly et al (2015) and Chapter 2 (Wallace et al., 2019) to create an event bed cutoff threshold for the coarse fraction data. We calculated the coarse anomaly by 
removing a 10-point moving average from the coarse fraction data. This filter did not include coarse fraction peaks over $10 \%$ to prevent larger peaks skewing the filter and leading to exclusion of neighboring smaller peaks. Event beds are coarse anomaly peaks that exceed two sigma $(95 \%)$ of the cumulative distribution function of coarse anomaly data from 1851 to present. The threshold for LIBH is $5.9 \%$.

We confirmed our choice of event bed cutoff by cross-checking coarse anomaly peaks marked as event beds against the location of visible event beds in the cores. All visible event beds corresponded to a peak in the coarse fraction data. Common visual indicators of event beds include: higher concentrations of organic matter throughout the deposit, visibly coarser grains and lighter colored sediments. We calculated event frequency per century by counting up the number of events in 100-year (Figure 3.3) and 50-year moving windows (Figure S3.4). The 100year window emphasizes centennial scale comparisons within the record while the 50-year window shows multi-decadal shifts in events.

\subsubsection{Defining active and quiet intervals}

We calculated the expected event frequency $(\lambda)$ for the Long Island blue hole using the regional estimate method detailed in Chapter 2 (Wallace et al., 2019) and used by Winkler et al. (in review) for Category 2 and above storms. See Section 3.4.1 for a justification of our choice of storm intensity thresholds for Long Island. This method calculates an expected event frequency for the northern Caribbean from Turks and Caicos up to Grand Bahama using storms in the Best Track dataset (1851-2016 CE). The expected frequency estimate for Category 2 and above hurricanes calculated using this method is 3.7 events/century. We can calculate an upper confidence bound on this expected event frequency estimate by treating a storm's arrival to the site as a Poisson process. We computed a $95^{\text {th }}$ percentile solution (Ulm, 1990), yielding a value of 7.3 events/century. Any activity exceeding this $95 \%$ bound is outside what it is expected based on random variations of hurricane frequency over past 158 years. Thus, we define active intervals as periods of time when the 100 -year window event frequency was above this $95^{\text {th }}$ percentile solution (7.3 events/century) or essentially above what we expect given historical levels of hurricane activity in the northern Caribbean (Figure 3.3).

Quiet intervals were also defined using the same procedures as Chapter 2 (Wallace et al., 2019). The recurrence interval ( $T$ ) was set 16.4 year/event based on the 66 hurricanes that passed 
the blue hole over the entire record (930-2016 CE). The probability of having no events $(P T)$ for $r$ number of years in the record was calculated using:

$$
P_{T}=(1-1 / T)^{r}
$$

Extended periods of time ( $>50$ years) when $P T$ was below $50 \%$ were counted as quiet intervals (Figure 3.3).

\subsubsection{Estimating storm surge using SLOSH}

We simulated max storm surge for every historical hurricane (Saffir Simpson Category 1 and above) that passed within $100 \mathrm{~km}$ of Long Island Blue Hole using the SLOSH (Sea, Lake and Overland Surges from Hurricanes) model from the National Weather Service (Jelesnianski et al., 1992). Storm surge is a rise in water level driven by storm wind and pressure changes that can cause massive destruction of the coastline. SLOSH is a low resolution numerical model that applies the wind and pressure fields from storms together with a digital elevation model of the coastline to simulate storm surges. SLOSH is divided up into a number of polar, hyperbolic and elliptical grids. It includes parameterizations for some sub-grid features like variable friction from vegetation, channel flow, and barriers to flow. We used the only SLOSH simulation grid that encompasses Long Island: Bahamas (bha). This grid is coarsely resolved near Long Island with $\sim 5 \mathrm{~km}$ by $5 \mathrm{~km}$ grid cells. Therefore, we expect SLOSH storm surge estimates for Long Island to be rough estimates of max storm surge at our site. Although, in comparison to other higher resolution models, SLOSH has been found to capture max storm surge pretty well for areas with simple coastal features (Lin et al., 2010). We used the SLOSH estimates for storm surge for each modern storm to help us determine which of these storms likely contributed to event beds found in our cores (See Section 3.4.1).

\subsection{Results}

\subsubsection{Event bed description}

The Long Island blue hole (LIBH) sediment is predominantly fine-grained carbonate mud with scattered coarser layers (ranging from very fine sand $(0.088-0.125 \mathrm{~mm})$ to very coarse sand (1.41-2 mm) sized). The sediment stratigraphy is dominated by pale brown colored (Munsell color 2.5Y 6-3) sediment with gray (Munsell color 2.5Y 7-1) and white (Munsell color 7.5Y 8-1) laminations. There is no evidence of bioturbation in the cores. The LIBH sediment record 
exhibits nearly constant long term sedimentation rate of $\sim 1.1 \mathrm{~cm} / \mathrm{yr}$ for the full $1148 \mathrm{~cm}$. This gives our record near annual resolution with each single $\mathrm{cm}$ sample representing approximately one year of sedimentation.

We identified 66 event beds in the LIBH2 record over past 1050 years. Thus, the average event frequency on Long Island is 6.2 events/century. In most cases, these event beds stand out with visibly coarser grains, white and grey colors (Munsell color 7.5Y 8-1), and/or higher concentrations of plant matter. Event beds also stand out in the coarse fraction data with values ranging from 10 to $48 \%$ sand-sized $(>63 \mu \mathrm{m})$ or larger particles. A vast majority of the event beds (59 of 62) are 1-3 cm thick. We did not find evidence of event beds or coarser sediment in the surface grabs from LIBH taken in 2017 after Hurricane Matthew's passage in October 2016 to the south of Long Island.

We correlated the stratigraphy for LIBH2 and LIBH1 for the overlapping top $\sim 800 \mathrm{~cm}$ (Figure S3.5). Nearly all of the same event beds were identified in the neighboring shorter core (LIBH1) from Long Island blue hole. Over the top $800 \mathrm{~cm}$, we identified 45 events in LIBH2 and 42 events in LIBH1.

\subsubsection{Changing event frequency}

Over the past 1050 years, there have been extended periods (>50 years) with frequent events occurring on Long Island. We define five active intervals on Long Island using the 100year window event frequency from 1245-1290 CE, 1395-1500 CE, 1590-1650 CE, and 1775$1845 \mathrm{CE}$ (Figure 3.3). Of these active intervals, the period with the most events is the most recent active interval from 1775-1845 CE with an average event frequency of 9.3 events/century. The timing of these five active intervals is confirmed in the 50-year window event frequency data. The 50-year window event frequency emphasizes the multi-decadal periods with the highest activity. Long Island experienced five exceptionally active intervals from 1229-1267 CE, 1376-1422 CE, 1485-1516 CE, 1597-1647 CE, and 1780-1835 CE with over 10 events/century, almost double the average event frequency in the whole record (Figure S3.4).

Interspersed between these active intervals are periods with really low event frequency. We define these quiet intervals as periods extending longer than 50 years in which there are zero events beds and the probability of having zero events is below 50\%. According to these criteria, 
the west coast of Long Island is quiet from 1161-1213 CE, 1528-1585 CE, 1651-1713 CE, 1877 -1927 CE and 1933-2003 CE (Figure 3.3).

\subsubsection{Irma 2017 Tilt Current Meter (TCM) data}

The tiltmeter data includes the entirety of September 2017. From this data, we gain an understanding of the average bottom current conditions on the bank nearby the blue hole and how the passage of distant storms changes the hydrodynamics. We compare storm current direction and speed during Hurricane Irma (September 7-9, 2017) and Hurricane Maria (September 22-24, 2017) to ambient conditions (September 1-3, 2017). Under ambient conditions in September, current direction was predominantly to the northwest (Figure 3.4). Bottom velocity varied on an approximately 12-hour cycle with the tides from peak values at $\sim 0.025 \mathrm{~m} / \mathrm{s}$ at ebb and flood tide to $\sim 0.01 \mathrm{~m} / \mathrm{s}$ at high and low tide. Hurricane Irma passed $\sim 200$ $\mathrm{km}$ to the southeast of LIBH at Category 4 strength. Unfortunately, we could not use the data from the tiltmeter during the peak of Hurricane Irma's passage on September 8 from $2 \mathrm{pm}-7 \mathrm{pm}$ because the tiltmeter was no longer fully submerged in water and was lying on its side (For more discussion, see Section 3.4.2). Before the tiltmeter was compromised, current speed increased from $\sim 0.03 \mathrm{~m} / \mathrm{s}$ on September 7 th at 5 am to $\sim 0.5 \mathrm{~m} / \mathrm{s}$ at September 8 th at noon. We also observed a complete change in current direction before and after the storm. Current direction at the beginning of Irma was oriented predominantly to the southwest. In contrast, for the later stages of the storm, current direction switched back to the northwest.

A similar pattern of changing current direction occurred in the case of Hurricane Maria (Figure 3.4). Hurricane Maria passed much further away from the island (>350 km) on the northeast side and had a much less dramatic effect on current speed near Long Island. Nevertheless, current speed during Maria increased to $\sim 0.1 \mathrm{~m} / \mathrm{s}$ (almost one order of magnitude greater than ambient conditions) from September 22-25. In addition, current direction switched from southwest in the beginning of the storm to northeast during the end of the storm. Bottom water temperature next to the blue hole also dropped during the passages of Hurricane Irma and Hurricane Maria. For more discussion of platform temperature during/after these storms, see Section 3.S.2.

\subsection{Discussion}

\subsubsection{Impact of Irma 2017}


On September 8, 2017, Hurricane Irma passed approximately $200 \mathrm{~km}$ to the south of Long Island at Category 4 strength with max sustained wind speeds greater than 135 knots. While Irma passed much too far away from the Long Island blue hole to leave a deposit, its passage likely affected both the wind and wave climate on Long Island. Videos (https://time.com/4935096/long-island-bahamas-irma-hurricane/, 2020) and eye-witness accounts from the storm suggest that much of the water over the shallow carbonate banks of Long Island were sucked away during the storm. This is not an uncommon occurrence for the shallow carbonate banks of the Bahamas (Neely, 2013). The high winds and low pressure center accompanying a hurricane siphon water off the shallow banks of islands in The Bahamas and pile the water near of center of the storm. After the storm's passage, this water flows back onto the bank. In the case of Irma, water was pulled off places like Long Island, Exuma Island, Acklins Island, and Tampa Bay and piled up in the Gulf of Mexico (https://www.theatlantic.com/science/archive/2017/09/irma-sucks/539325/, 2020).

Our tiltmeter data confirms eye-witness accounts, documenting a six-hour period of time during the peak of Irma's passage when the tiltmeter was lying on its side presumably on a dry bank (Figure 3.4). The accelerometer data indicates that the tiltmeter began to droop starting on September $8^{\text {th }}$ at $\sim 10$ am as the water started to drain from the platform (Figure S3.6). By $\sim 1 \mathrm{pm}$, it was fully on its side. It remained this way for six hours before it started to float again around $\sim 7 \mathrm{pm}$ as the water returned to the platform. The change in current direction also provides further evidence for the platform draining. During the peak of Irma, water was siphoned off the platform towards the storm to the southwest and returned 6 hours later, flowing to the northwest. Unfortunately, we cannot tell whether or not the bottom current created from water draining off or returning to the platform during Irma was strong enough to transport sediment. The current speed rose to approximately $0.5 \mathrm{~m} / \mathrm{s}$ before water started draining from the platform and compromised the tiltmeter measurements (Figure 3.4). This is much lower than the current speed of $2 \mathrm{~m} / \mathrm{s}$ simulated by Sahoo et al. (2019) for Hurricane Joaquin. It is therefore unlikely that this storm that the bottom currents generated during this storm suspended coarse sediment on the western Long Island platform.

Hurricane Maria passed too far away $(>350 \mathrm{~km}$ ) to drain the water from the west coast of Long Island. Our tiltmeter continued to collect data throughout the storm. However, we still observe a change in current direction during Maria (Figure 3.4). Maria passed by Long Island to 
the east. South to southwest winds in the top left quadrant of the storm likely created the southwest current we observed on Long Island during the beginning of Maria's passage. The switch in current direction to the northeast as Hurricane Maria passes to the north is likely due to some of the water being siphoned off the bank moving towards Maria. We also observed a drop in water temperature on the platform as both Irma and Maria passed (See Section 3.S.2).

Comparing storm condition current speeds (both measured and simulated) to the observed ambient conditions near Long Island blue hole really highlight the potential for storms to dramatically alter the hydrodynamics on shallow carbonate platforms. Under ambient conditions, the highest bottom current speed we observed in 2017 was $\sim 0.01 \mathrm{~m} / \mathrm{s}$. This is over an order of magnitude lower that the current speeds observed during the very distal passages of Hurricane Irma and Hurricane Maria in September 2017 to the south and northeast, respectively. During these storms, we recorded current speeds near LIBH ranging from 0.1-0.5 m/s. Meanwhile, close moving storms like Hurricane Joaquin in 2015 were simulated to generate bottom currents on the west coast of Long Island at around $2 \mathrm{~m} / \mathrm{s}$, two orders of magnitude higher than we observed for ambient conditions and one order higher than observed for the passage of distant storms like Hurricane Maria and Irma. Hurricane Irma and Maria likely did not leave coarse deposits in LIBH but Hurricane Joaquin did. From this, we can narrow down the range of bottom current speed needed to suspend and transport coarse material on the shallow western platform of Long Island. In particular, we need currents between 0.5-2 m/s (two orders of magnitude larger than ambient conditions) to generate coarse sediment transport.

\subsubsection{Event Attribution}

\subsubsection{Establishing a modern analog: Hurricane Joaquin}

We can gain a first-order understanding of the sensitivity of our Long Island sediment proxy to different types of storm events by identifying which recent storms left behind coarse deposits in the blue hole. This can be challenging given the high number of storms that have passed over The Bahamas in the past 166 years and the age uncertainties associated with each event layer. We cored Long Island blue hole less than a year after the island was impacted by a Category 4 hurricane, Hurricane Joaquin in 2015. This storm provides us with an excellent modern analog and gives us an idea of what wave conditions are sufficient for leaving an event deposit in Long Island blue hole. 
Hurricane Joaquin formed as a tropical low in the eastern Atlantic Ocean on September 19, 2015. Joaquin moved southwest towards The Bahamas, strengthening to Category 4 strength on October 1st. A strong mid- to upper-level trough over the eastern US deepened on October $2^{\text {nd }}$ causing Hurricane Joaquin to slow down and make a clockwise turn to the east of Long Island. It remained within $100 \mathrm{~km}$ of Long Island at Category 4 strength with sustained winds up to 120 knots for an entire day (Berg, 2016). However, during this time, Hurricane Joaquin underwent an eyewall replacement cycle which resulted in an ill-defined eye in satellite imagery of Hurricane Joaquin as it passed Long Island on October 2nd (Berg, 2016). The storm caused severe flooding and damage to homes, vegetation and local fishing vessels on Long Island. Indeed, two thirds of the island remained flooded with 1-2 $\mathrm{m}$ of water days after the storm.

Our cores from Long Island blue hole captured a large event bed starting $2 \mathrm{~cm}$ down in the core. This event bed (1), unlike many others in the core, extends over $20 \mathrm{~cm}$ in thickness. Event bed thickness may be connected to storm duration. A longer lasting storm would transport more coarse-grained sediment into a basin assuming a plentiful supply of that sediment. The thickness of the uppermost event bed suggests it was likely deposited by a slower moving storm, like Hurricane Joaquin. Our age model dates this event bed to between 2011 and 2016 CE (median age: 2014). Since 2011, three hurricanes have passed within $75 \mathrm{~km}$ of Long Island: Hurricane Joaquin in 2015, Hurricane Sandy in 2012, and Hurricane Irene in 2011 (Figure 3.5, Figure S3.7). Satellite imagery indicates that the eyewall of Joaquin rested over LIBH for approximately 10 hours. Both Sandy and Irene passed close to the island and at a faster translational velocity. Neither of their eyewalls rested over LIBH for a long time interval and both were significantly weaker than Joaquin. We cannot completely rule out that Hurricanes Sandy or Irene contributed to this unusually large event bed. Indeed, the event bed does feature a secondary peak in grain size near the bottom of the bed (Figure S3.8). However, given that the subsequent event bed occurs in such close proximity (only $5 \mathrm{~cm}$ downcore) to this larger first coarse deposit, we attribute the first event bed to Hurricane Joaquin and the second event bed to one these faster moving and less intense hurricanes (See Section 3.4.2.2).

A recent study (Sahoo et al., 2019) investigated the surge and wave dynamics on Long Island (and other Bahamian islands) during the passage of Hurricane Joaquin using the coupled ADCIRC-SWAN model (Dietrich et al., 2011a; Dietrich et al., 2011b). They simulated wave heights, storm tides, and current speeds between $3-4 \mathrm{~m}, 0.5-1 \mathrm{~m}$ and $\sim 2 \mathrm{~m} / \mathrm{s}$, respectively, on the 
west coast of Long Island during the storm. We simulated $\sim 0.7 \mathrm{~m}$ of storm surge on Long Island for Joaquin using SLOSH, a lower resolution and more simplified hydrodynamic model (Jelesnianski et al., 1992). SLOSH can only simulate the most idealized wind structures unlike more sophisticated models like ADCIRC+ SWAN. Thus, it is likely less appropriate for storms like Hurricane Joaquin which underwent an eyewall replacement cycle as it made its closest passage to LIBH. Therefore, we should consider further storm surge results from SLOSH presented here as a more conservative estimate of surge. In attributing the other modern deposits, we will use Hurricane Joaquin as modern analog. Thus, we know that storms passing to the east of the island that generate at least $0.7 \mathrm{~m}$ of storm surge may also have resulted in coarse-grained deposition in the blue hole.

\subsubsection{Interpreting the other modern deposits}

In addition to Joaquin in 2015, twenty hurricanes passed within $100 \mathrm{~km}$ of the Long Island blue hole over the observational interval (1851-present). Yet, we only discovered eight event beds in the LIBH record that date within uncertainties to this same time interval (Figure 3.5). To attribute the other seven deposits, we used the criteria established using our modern analog (Hurricane Joaquin), historical observations, as well as storm surge estimates simulated using the SLOSH model (Jelesnianski et al., 1992). In general, storms passing proximal (within a $75 \mathrm{~km}$ radius) and to the east of Long Island created larger storm surge at LIBH (Figure 3.5 and Figure S3.7). This is predominantly due to the L-shaped geometry of the northwest side of the island. When storms are passing to the north or east of the site, the counterclockwise rotational winds of the hurricane are in the same direction as waves piling water onshore. The opposite is true for storms moving to the south and west of the island. Indeed, our empirical data from the passage of Hurricane Irma in 2017 to south of Long Island suggest that water was drained from the platform during this storm instead of piled up (Figure 3.4). Storm surge estimates from SLOSH for historical storms ranged from $0.06 \mathrm{~m}$ to $1.46 \mathrm{~m}$ at LIBH (Figure 3.5).

The second (2) and third (3) coarse-grained deposits follow shortly after the first event bed (attributed to Joaquin) and each extends less than three $\mathrm{cm}$ in thickness (Figure S3.8). Event 2 occurs between 28-30 cm in LIBH and dates between 1996 and 2015 CE (median age: 2008 CE). Event 3 occurs between 35-36 cm in LIBH and dates between 1982 and 2014 CE (median age: 2003). Assuming that the first deposit is Hurricane Joaquin in 2015, there are only four 
storms that could have created these layers: Hurricane Sandy in 2012, Hurricane Irene in 2011, Hurricane Lili in 1996, and Hurricane Erin in 1995 (Figure 3.5). It is unlikely that Hurricane Erin generated either of these two event beds given its lower intensity. Hurricane Erin transitioned from a tropical storm to a Category 1 hurricane with sustained winds up to 70 knots as it passed to the east of Long Island (Figure S3.7). Despite its passage on the eastern side of the island, it only created $\sim 0.4 \mathrm{~m}$ of storm surge in SLOSH at the LIBH site.

Hurricanes Lili, Irene, and Sandy all had SLOSH-simulated storm surges of $1.1 \mathrm{~m}, 0.94$ $\mathrm{m}$, and $0.85 \mathrm{~m}$, respectively for 20 minutes, 60 minutes, and 40 minutes, respectively (Figure 3.5). Both Hurricane Sandy and Hurricane Irene passed very close to Long Island $(<25 \mathrm{~km})$. Hurricane Sandy passed on the west side of the island at Category 2 strength (winds speeds up to 90 knots). Disrupted by its passage over Cuba, Sandy was weakening and had lost most of its eye structure as it passed Long Island (Blake et al., 2013). Hurricane Irene, on the other hand, was more organized as it passed on the east side of the Long Island transitioning from Category 3 to Category 2 strength with sustained wind speeds greater than 95 knots (Avila and Cangialosi, 2011) (Figure S3.7). It is apparent from comparing the storm surges generated by these two storms that their orientation with respect to the island is important for piling up water at the site. We simulated almost $0.1 \mathrm{~m}$ more storm surge for Hurricane Irene (passing to the east) than Sandy (passing to the west) despite their similar distances from the blue hole and intensities.

Hurricane Lili in 1996 passed about $75 \mathrm{~km}$ to the north of Long Island with max sustained winds at 90 knots (Category 2 strength). Lili was strengthening as it traveled north and east through The Bahamas such that its front right quadrant impacted the west coast of Long Island (Figure S3.7). In the Northern Hemisphere, the front right quadrant of a hurricane has both the rotational winds and movement of the storm in the same direction combining to create greater wind speeds and potentially greater storm surge. Although Lili passed further away from LIBH than either Hurricane Sandy or Irene, its radius of maximum winds was estimated between $55-75 \mathrm{~km}$ at the time of closest passage placing the eye wall of Lili directly over the blue hole (Lawrence, 1996). Indeed, we simulated approximately $1.1 \mathrm{~m}$ of surge during Hurricane Lili despite its lower Category 2 intensity (Figure 3.5).

We cannot determine for certain which of these three storms (i.e., Sandy 2012, Irene 2011, Lili 1996) left event beds two and three in the LIBH sediment cores. We think it is more 
likely that Hurricane Irene in 2011 and Hurricane Lili in 1996 created these coarse beds, given that both storms had stronger winds oriented onshore and generated more storm surge.

The next three event beds (\#4-6) are grouped together starting at $96 \mathrm{~cm}$ in LIBH2. Each of these event beds is approximately three $\mathrm{cm}$ away from the next one suggesting that they occurred a few years apart (Figure 3.5). Event beds 4, 5, and 6 date between 1903-1966 CE (median age: $1933 \mathrm{CE}$ ), 1900-1963 CE (median age: $1929 \mathrm{CE}$ ), and 1898-1962 CE (median age: 1927 CE), respectively. Seven hurricane passed within 100 km Long Island from 1923-1933 CE. Given the high number of storms that hit Long Island in rapid succession over this time period, we expect that this cluster of event beds corresponds to some subset of those seven storms. Of the seven storms, only four were intense hurricanes (Category 3 and above) passing within 75 $\mathrm{km}$ of the blue hole (Figure S3.7). On November 10, 1932, a Category 4 hurricane passed across Long Island just south of the blue hole with max sustained winds at 110 knots. Just four years later on September 16, 1928, a Category 4 hurricane passed on the east side of the island with wind speeds at 135 knots. Then in 1926, two intense hurricanes passed Long Island. On July 25, 1926, a Category 4 hurricane passed to the east of the island with sustained wind speeds from 115-120 knots. Observations from after the July 1926 storm suggest massive destruction on Long Island. Light station at North End and Simms were blown away and 25 houses in Clarence Town were destroyed (Neely, 2006). Another Category 4 hurricane (sustained winds: 125 knots) passed Long Island just two months later (September 17) on the western side. We attribute event beds 46 to these four intense storms. Given our high sedimentation rate of $\sim 1 \mathrm{~cm} / \mathrm{yr}$, we cannot distinguish which of the intense 1926 hurricanes created the coarse horizon (Event bed \#6). It is likely that both storms contributed to the event bed. Both of the storms that passed on the eastern side on Long Island generated the largest storm surge estimates in SLOSH (1.37 m for the 1928 storm and $1.46 \mathrm{~m}$ for the July 1926 storm). The 1932 storm and September 1926 storm which passed to the south and west of Long Island, respectively, generated between $0.5 \mathrm{~m}$ to $1 \mathrm{~m}$ less storm surge in SLOSH than the eastern passing storms.

The three other storms that passed Long Island from 1923-1933 CE either passed at lower intensity or further away from the blue hole. None of these three storms generated SLOSH storm surge estimates over $0.4 \mathrm{~m}$ at LIBH and all three passed Long Island at Category 1 strength or lower. On July 23, 1933, a Category 1 hurricane with sustained winds up to 70 knots passed to the northeast of site. On November 10,1924, a Category 1 hurricane with max sustained winds 
at 70 knots passed to the south of LIBH almost $95 \mathrm{~km}$ away. On September 26, 1923, a tropical storm transitioned into a Category 1 hurricane (sustained winds: 60-65 knots) just 35 km from the blue hole on the eastern side of the island. It is unlikely that these storms created event beds 4 through 6 over the more intense and proximal storms in 1932, 1928, and 1926 which generated much larger storm surge at the blue hole (Figure 3.5).

Event beds 7 and 8 occur between 148-168 cm and 200-201 cm in LIBH (Figure 3.5). Event bed 7 is another unusually thick layer stretching over $20 \mathrm{~cm}$ of sediment. Unfortunately, there is large age uncertainty for both of these later event beds with event bed 7 and 8 dating between 1848-1916 CE (median age: 1877) and 1811-1876 CE (median age: 1839), respectively. From 1916 until the end of the observational record, seven more hurricanes track within $100 \mathrm{~km}$ of Long Island. In 1884, 1882, and 1852, Category 1 hurricanes tracked near Long Island. Both the 1884 and the 1852 storms passed to the east of the island with sustained winds greater than 80 knots and 70 knots, respectively. The 1882 storm tracked to the south of the island with sustained winds at 80 knots. We simulated greater storm surge at the site for storms passing to the east (1884 and $1852-0.43 \mathrm{~m}$ and $0.24 \mathrm{~m}$, respectively) than the 1882 storm (surge of $0.21 \mathrm{~m}$ ) which tracked south of the island (Figure 3.5 and Figure S3.7). It is unlikely that any of these less intense storms (Category 1) created large enough wave energy to leave a deposit at LIBH.

There were four other storms that occurred from 1851-1916 CE: two Category 2 storms in 1891 and 1871, a Category 3 storm in 1899, and a Category 4 storm in 1866. Of these four storms only three of them passed within $75 \mathrm{~km}$ of Long Island (Figure S3.7). The 1899 Category 3 storm passed about $85 \mathrm{~km}$ to the southwest of LIBH. Due to its distant passage and the orientation of the storm to the southwest generating offshore-directed winds and currents, there was very little storm surge simulated at the site $(\sim 0.3 \mathrm{~m})$. It's intensity, position relative to the blue hole and distance from the blue hole are all similar to Hurricane Matthew in 2016. Surface sediments we collected after Hurricane Matthew show no sign of coarse-grained deposits tied to this storm in LIBH. Thus, it is unlikely that a storm of similar character (the 1899 hurricane) would leave either of the final two modern deposits (Event beds 7 and 8) in LIBH2. Both the Category 2 storms in 1871 and 1891 passed east of Long Island, but only one of them (1891 storm) went within $75 \mathrm{~km}$ of the site. The 1891 storm passed by with max sustained winds at 85 knots and generated $\sim 0.8 \mathrm{~m}$ of storm surge in SLOSH at the blue hole site (double that of the 1871 storm). Thus, we attributed event bed 7 to this close passing Category 2 storm in 1891 . 
This leaves only the Category 41866 storm as a historical candidate for the eighth event bed. This storm passed within $75 \mathrm{~km}$ of Long Island blue hole on the western side of the island with sustained winds at 120 knots (Figure S3.7). Written accounts from after the storm suggest that Long Island was totally devastated with almost every building swept to the ground. Residents of the island suffered from starvation post storm and all of the cotton plantations were totally destroyed (Neely, 2006). Thus, we attribute event bed 8 to the 1866 Category 4 hurricane (Figure 3.5).

From our assessment of the observational storms that left behind an event bed and those that failed to leave a discernable coarse horizon, we believe the LIBH record is capturing storms based not only on their intensity and proximity to the site but also on their orientation with respect to the island. In general, Long Island blue hole captures all Category 2 and above storms passing to the east or north of Long Island within a $75 \mathrm{~km}$ radius of the site. This includes storms like Hurricane Joaquin 2015, Hurricane Irene 2011, and the 1928 and July 1926 Category 4 storms. We also found that only the most intense hurricanes (Category 4 and above) passing to the west of Long Island generated enough surge to leave a deposit (the September 1926 storm and the 1866 Great Bahamas hurricane). In general, storms passing to the south or west of Long Island generated offshore directed winds which drew water off the carbonate platform on the west side of Long Island. The lower storm surge simulated during these storms (i.e., 1908 and 1899 storms) illustrate this phenomenon. Thus, we suggest that only the most intense of these storms (Category 4 and 5) could generate bottom currents strong enough to suspend and transport coarse material on Long Island western platform. A number of intense storms passed further than $75 \mathrm{~km}$ away from Long Island and did not leave a deposit including Hurricane Matthew in 2016, the August 1933 Category 4 storm, and the 1899 Category 3 hurricane. In addition, lower intensity hurricanes also did not leave a deposit including Hurricane Sandy 2012, Hurricane Erin 1995 and the 1923, 1891, and 1884 storms.

\subsubsection{Caribbean site comparison}

The resolution (near-annual), length (1050 years), and sensitivity (proximal passing Category 3 and above storms) of the LIBH core also make it a good record to compare with the newly published record from South Andros Island in The Bahamas (Wallace et al., 2019 (Chapter 2)). This sedimentary archive from blue holes on South Andros records intense 
hurricane strikes over the past 1500 years. It largely captures the close passage of Category 3 and above hurricanes at near-annual resolution. In addition, both islands are in very close proximity. South Andros is situated approximately $260 \mathrm{~km}$ to the northwest of Long Island (Figure S3.9). We expected that many of the storms that hit Long Island would go on to hit South Andros. In particular, we expected that during active intervals when more storms were traveling past South Andros Island, Long Island would also see more activity. Instead, the resulting patterns were more complicated than our initial expectations (Figure 3.6).

The stacked record from South Andros Island (presented in Winkler et al., in review) has high levels of activity during three intervals over that past 1000 years (920-1035 CE, 1145-1485 CE, and 1600-1780 CE). During the first (920-1035 CE) and last (1600-1780 CE) active intervals on South Andros, there is no concurrent increase in activity on Long Island (Figure 3.6). It is only for the last active interval on Andros Island that we observe any overlap between the two islands. Activity on Long Island ramps up about halfway into the South Andros' second active interval from 1145-1485 CE. Both islands see increased hurricane strikes starting in 1350 $\mathrm{CE}$ and continuing for another century until $1450 \mathrm{CE}$ when South Andros activity drops off. Long Island continues to observe increased event frequency until $\sim 1530 \mathrm{CE}$, almost a century later (Figure 3.6).

Similarly, Long Island is active from 1590-1650 CE and 1775-1845 CE, periods of time when South Andros was experiencing relative quiescence. This carries on into the observational interval (1850-present). Long Island blue hole archived seven event deposits while the South Andros cores archived only two.

Perhaps even more puzzling is the difference we see between the Long Island, the South Andros records, and a new record of hurricane strikes over the past 650 years from Thatchpoint Blue Hole on Abaco Island, The Bahamas (Winkler et al., in review). Abaco Island is approximately $400 \mathrm{~km}$ northwest of Long Island and $275 \mathrm{~km}$ northeast of South Andros Island (Figure S3.9). The Thatchpoint record indicates elevated hurricane activity from 1500-1670 CE (Figure 3.6). During the peak of this activity on Abaco (the $16^{\text {th }}$ century), both Long Island and South Andros show lower activity. They also both see an increase an activity during early $17^{\text {th }}$ century as activity at Thatchpoint is dying down. This increase in activity is short-lived for Long Island which experiences only one hurricane strike from 1651-1767 CE. South Andros, however, remains active throughout most of $17^{\text {th }}$ and $18^{\text {th }}$ centuries. 
These differences between these three records raise questions about whether we should expect islands in the Caribbean spaced relatively close together (100s of kilometers) to observe similar patterns in intense TC activity on multi-decadal to centennial timescales. The tropical Atlantic (including the Bahamas) generally features climate conditions favorable for hurricane growth and survival (i.e. warm sea surface temperatures (Emanuel, 2008), low vertical wind shear (Wong and Chan, 2004; Elsberry and Jeffries, 1996)). Thus, there are consistently storms traveling through the Caribbean. Given that the widespread climate conditions are favorable for hurricane survival, the direction these hurricanes track is likely dictated more by randomness of local conditions (i.e. steering winds and SSTs, topography) than by whole Atlantic or whole Caribbean climate conditions. Winkler et al. (in review) calculated 50-km grid track density of Category 2 and above hurricanes in the Atlantic over the observational interval (1850-present) and found spatial heterogeneity in track density in the Bahamas (Figure 3.1 in Winkler et al, in review). In particular, their results indicate a gradient from lower activity over much of the Greater Antilles (e.g., Cuba, Haiti, Dominican Republic) to higher activity over the northern Bahamas. This is likely a result of a shadow effect created by storms losing intensity as they pass over the large island land masses of the Greater Antilles. South Andros falls within this shadow effect created by Cuba and shows notably less activity than Abaco Island. This suggests that at least over the last 169 years there has been localized differences in hurricane strike frequency in the Bahamas.

The importance of stochasticity, geography, and regional climate/weather conditions almost certainly comes into play for determining if a storm of sufficient intensity will pass on one side of an island or another or even whether it will pass close to a particular site (e.g., $50 \mathrm{~km}$ around South Andros or Thatchpoint Blue Hole). Looking at the tracks of the 24 hurricanes that passed within $75 \mathrm{~km}$ of Long Island in the last 170 years, only one and five of them passed within a $50 \mathrm{~km}$ of South Andros and Thatchpoint, respectively (Figure S3.9). Given the differences in storm populations captured by these three records from the Bahamas, we should not use a single one of these three records to describe Caribbean (or Bahamas for that matter) hurricane climatology over the past millennium. All three records are capturing different subsets of storms in the Bahamas passing over their particular location. Assuming that hurricane tracks through the Bahamas contained similar variability in the past millennium as they do today, we 
would need to combine many different sites in the Bahamas to capture changes in Bahamian hurricane climatology over the past millennium.

However, these same issues do not seem to apply for all paleohurricane sites. In particular, sites in the subtropics (e.g., U.S. Northeast coastline) may capture a more cohesive climate signal simply due to their geography. Unlike the Caribbean, climate is not always favorable for hurricane growth and survival in the subtropics throughout the hurricane season. Thus, it may require a strong climate signal to generate large numbers of storms repeatedly striking along the U.S. East Coast at hurricane intensity. Indeed, paleohurricane records spaced hundreds of kilometers apart along the U.S. East Coast show coherent active intervals over the past millennium. In particular, records from New England (Boldt et al., 2010; Buynevich \& Donnelly, 2006; Donnelly et al., 2001, 2015; van de Plassche et al., 2006) and North Carolina (Mallinson et al., 2011) indicate elevated numbers of hurricanes striking during the 15th and 16th centuries.

\subsubsection{Basin-wide comparison}

Having noted many of the differences between paleohurricane records from The Bahamas, we created a compilation of Bahamas blue hole reconstructions including Long Island, South Andros and Abaco (Figure 3.7c). The methods for creating this compilation were adapted from previous work (Mann et al., 2009) and are described in detail in Section 3.S.4. The compilation offers a better measure of region-wide hurricane activity than a single individual Bahamas record. It shows increased activity from 975-1025 CE, 1400-1650 CE, and 1775-1825 CE. In addition, the combined Bahamas records indicate less hurricane activity over the observational interval (1850 - present).

It is useful to further contextualize this Bahamas regional compilation through comparison to compilations of other similarly resolved records from along the U.S. coastline (Figure 3.7). Our methods for creating these compilations and the criteria for including records are detailed in Section 3.S.4. We generated compilations for New England using two records from Massachusetts (Boldt et al., 2010; Donnelly et al., 2015) and for northwest Florida including records from Apalachee Bay (Lane et al., 2011; Brandon et al., 2013; Rodysill et al.) and Choctawhatchee Bay (Rodysill et al.). In our Florida compilations, we created a High Threshold compilation including only intense events (Category 3 and above) and a Low 
Threshold compilation include all hurricanes (Category 1 and above). Our synthesis of these different U.S. coastal compilations gives us information on potential century-scale shifts in the predominance of certain storm populations in the Atlantic.

From approximately 900-1100 CE, we document evidence for basin-wide increases in storm activity. All of our spatially diverse compilations suggest increased storm strikes during this time span. One potential driver of this basin-wide elevated activity is warmer sea surface temperatures (SSTs) in the Atlantic Main Development Region (MDR) which promotes tropical cyclone formation and potential intensity (Goldenberg et al., 2001; Kossin \& Vimont, 2007; Zhang \& Delworth, 2006). A statistical reconstruction of tropical cyclone activity driven by proxies of past climate change (Mann et al., 2009) also shows this medieval period of increased Atlantic hurricane activity from 900-1100 CE. In the model, this active period arises predominantly due to a combination of La Nina-like conditions and warmer SSTs in the Atlantic MDR.

After $1100 \mathrm{CE}$, the Bahamas compilation matches better with the New England compilation (Figure 3.7c) than the Florida compilation (Figure 3.7a). Both New England and The Bahamas observe much fewer storm events after $1100 \mathrm{CE}$. On the other hand, the Florida records (high threshold and low threshold) remain active a century longer until 1250 CE. Starting around $1400 \mathrm{CE}$, The Bahamas and New England observe increased storm strikes. The New England compilation is active from 1400-1680 CE (Figure 3.7c) which is reproduced in a variety of low resolution paleohurricane studies from the U.S. East Coast not included in this compilation (Mallinson et al., 2011; van de Plassche et al., 2006). The Bahamas compilation is also active from 1400-1650 CE. The increased activity in the $16^{\text {th }}$ century in The Bahamas is predominantly due to contributions from the Abaco Island record (Winkler et al., in review) which captured 11 events from 1500-1600 CE while the Long Island and South Andros (Wallace et al., 2019 (Chapter 2)) records captured 4 and 2 events, respectively. Unlike The Bahamas or New England, the Florida High Threshold compilation remains inactive until 1850 CE. The Florida Low Threshold compilation, on the other hand, features a short lived peak in activity from 1420-1510 CE suggesting that northwest Florida was hit by many low intensity events (Category 1-2) at the same time New England and The Bahamas started experiencing increased storm strikes. 
The Bahamas compilation differs from all the other U.S. coastline reconstructions in the late $18^{\text {th }}$ and early $19^{\text {th }}$ centuries. During this period, we see increased hurricanes passing through The Bahamas while all other records are quiet. It's possible that during this time span we are seeing a shift to more storms that recurve out into the north Atlantic Ocean. Documentary records from Bermuda (Tucker, 1982) and the Lesser Antilles (Chenoweth and Divine, 2008) support this hypothesis indicating increased storm landfalls observed from 1780-1840 CE. Alternately, it's possible that there were more storms traveling along U.S. East coastline from late $18^{\text {th }}$ and early $19^{\text {th }}$ centuries, but they met with local unfavorable environmental conditions and were not high enough intensity to leave coarse horizons in coastal basins like Salt Pond or Mattapoisett Marsh. Indeed, there is also documentary evidence for increased storms in the Southeast U.S. and Northeast U.S. from 1800-1900 CE. However, many of these storms were not very intense ( $\leq$ Category 1 ) at landfall (Boose et al, 2001; Ludlum, 1963). The increased activity in The Bahamas ends around $1825 \mathrm{CE}$ showing much fewer storms over the observational interval. At this point, we observe more storms making landfall in both northwest Florida and New England.

Wallace et al. (2019) (Chapter 2) observed that from 1150-1350 CE, more storms were striking in the southern Caribbean Sea, Gulf of Mexico, and southern Bahamas (South Andros). From 1350-1470 CE, these storms shifted away from the Gulf of Mexico continuing to hit The Bahamas (South Andros) and starting to impact the U.S. East Coast. From 1470-1670 CE, storms were predominantly making landfall only along the U.S. East Coast. Adding our new record from Long Island and Winkler et al (in review)'s record from Abaco into a compilation and comparing that compilation to other compilations of records from U.S. coastline offers a simpler picture of shifting storm activity over the past millennium than Chapter 2. Following the period of basin-wide increased activity from 900-1100 CE, there is continued increased activity along the Gulf Coast that gradually declines across the $14^{\text {th }}$ century accompanied by less activity in The Bahamas and New England. Starting around $1400 \mathrm{CE}$, this pattern shifts. More storms make landfall in The Bahamas and New England from 1400-1650 coeval with fewer intense storms in Florida. There continues to be elevated storm strikes in the Bahamas through $1825 \mathrm{CE}$ while Florida and New England are quiet.

Chapter 2 (Wallace et al., 2019) offers two hypotheses to explain the shift in activity over the past millennium from increased activity in the Gulf of Mexico from 1150-1350 CE to activity 
along the U.S. East Coast from 1400-1650 CE. The first is the local environmental conditions hypothesis. This hypothesis suggests that from 1100-1350 CE there were more storms in the Atlantic basin in general, but there was a protective barrier of unfavorable environmental conditions (i.e., high vertical wind shear (VWS), low sea surface temperatures (SSTs)) along the U.S. East Coast extending down through the northern Bahamas. These unfavorable conditions caused hurricanes to weaken as they made their way up along the U.S. East Coast. This hypothesis is inspired by recent studies (Kossin, 2017; Ting et al., 2019) documenting a dipole pattern in environmental conditions (i.e., sea surface temperatures, vertical wind shear) between U.S. East Coast and Atlantic Main Development Region (MDR) over the past 50 years. The activity in our new compilation of Bahamas reconstructions presented here can be at least partially explained by the environmental conditions hypothesis proposed in Chapter 2 (Wallace et al., 2019). We see decreased hurricane activity in both The Bahamas and U.S. East Coast when the Gulf Coast is active between 1100-1250 CE. Local unfavorable vertical wind shear conditions along the U.S. East Coast extending into The Bahamas, much like the pattern observed in Kossin (2017), coeval with basin-wide elevated activity could contribute the decreased activity we observe in The Bahamas and along the U.S. East coastline.

Similarly, the subsequent opposite pattern of activity (i.e., increased activity in New England/The Bahamas with lower activity in Florida) extending from 1400-1650 CE can also be explained with the local environmental conditions hypothesis. Simulations of environmental conditions in the Atlantic under anthropogenic warming indicate patterns of increased VWS conditions in the Gulf of Mexico but not along U.S. East Coast (Ting et al., 2019). This anthropogenic VWS pattern is attributed to Hadley cell expansion (Lu et al., 2007; Kang and Lu, 2012) and a northward shift in the mid-latitude jet (Barnes and Polvani, 2013). The presence of a similar VWS pattern from 1400-1650 CE could explain the lack of intense storms making landfall near Florida over this time span.

However, the local environmental conditions hypothesis is not the only possible explanation for the differences we observe between the U.S. East Coast and Gulf of Mexico records. A second hypothesis relies on the idea that there is climate driven geographic variability in hurricane tracks and intensity over the past millennium. In particular, there has been a shift from more straight-moving storms that impact the Caribbean Sea/Gulf of Mexico (Cluster 2 and 4 - Kossin et al., 2010) from 1150-1250 CE to more recurving storms impacting The Bahamas 
and U.S. East Coast (Clusters 1 and 3- Kossin et al., 2010) from 1400-1650 CE. While it is still uncertain exactly what climate conditions might produce these centennial-scale shifts in storm tracks, recent research suggests that shifts in the strength and position of subtropical ridges in the North Atlantic can impact hurricane tracks. In particular, the North Atlantic Subtropical High (NASH) has been shown to have a profound impact on steering currents in the North Atlantic. When the NASH is strong and displaced towards the southwest, more hurricanes are straightmoving passing through the Caribbean Sea and Gulf of Mexico (Elsner, 2003; Kossin et al., 2010; McCloskey et al., 2013; Ortegren \& Maxwell, 2014). The opposite is true when the NASH is weakened or displaced to the northeast. A high resolution reconstruction of the North Atlantic Subtropical High is needed to further investigate its contribution (if any) to the centennial scale shifts in hurricane tracks we observe across our paleohurricane reconstructions.

\subsection{Conclusions}

This work presents a new near-annually resolved reconstruction of intense hurricane activity over the past 1100 years from a blue hole on the northwest coast of Long Island in The Bahamas. Unlike other paleohurricane sites from the Atlantic, many intense storms made landfall on Long Island during the observational record (1850-present). The sediment cores from Long Island blue hole capture eight event beds dating to historic hurricanes. Attributing these event beds to modern storms highlights that using simple thresholds based on the intensity and proximity to a site of each storm does not capture the wide variety of hydrodynamics that could create event deposition. Using storm surge estimates from SLOSH, we argue only storms moving within a $75 \mathrm{~km}$ radius of LIBH have the potential to leave a deposit. Of these storms, only the most intense storms (Category 4-5) passing to the south or west leave a deposit. While storms passing to the north or east at lower intensities (Category 2 and above) can generate larger storm surge and bottom currents which suspend and transport coarse grains. Data collected from after Hurricane Matthew in 2016 and Hurricane Irma in 2017 confirm these conclusions. Both storms passed on the western side of Long Island further than $75 \mathrm{~km}$ away from LIBH at high intensity and neither of them left a coarse deposit at the bottom of LIBH. Indeed, bottom current speed and direction data collected near the blue hole in September 2017 suggest that more distal passage of Irma on the western side of the island drained the platform of water during the peak of the storm. This highlights the complicated response of shallow carbonate platforms and island 
geometries in The Bahamas to different types of storms and further supports the notion that sediment transport into blue holes is only induced during close passing and relatively intense storms. More work is needed modeling how different properties of storms (i.e., translational velocity, track orientation, wind speeds) affects the hydrodynamics and sediment transport on these carbonate platforms.

Long Island has experienced four multi-decadal periods of elevated intense hurricane activity over the past millennium (1245-1290 CE, 1395-1500 CE, 1590-1650 CE, and 1775$1845 \mathrm{CE})$. These active periods contrast with event frequency patterns reconstructed at two neighboring islands (Abaco Island - Winkler, in review and South Andros Island - Wallace et al., 2019 (Chapter 2)). We argue that these three islands while relatively close together $(<500 \mathrm{~km}$ apart) have captured largely different populations of hurricanes. This is confirmed looking at the storms that passed over Long Island in the last 169 years; only a few of these storms went on to hit Abaco or South Andros Island. We argue that the signals reconstructed in each individual record from The Bahamas are heavily influenced by randomness, geography, and site sensitivity. This makes it difficult to make useful comparisons between different records or to use any one record to reconstruct regional hurricane climate. In order to capture regional hurricane patterns over time, we need to start combining proxies from neighboring sites in The Bahamas together into a regional composite.

Thus, we present the first compilation of Bahamian paleohurricane reconstructions for the past millennium (900-2016 CE). The compilations better capture the regional hurricane record by compositing each individual island's storm history. The Bahamas compilation documents elevated storm activity from 975-1025 CE, 1400-1650 CE, and 1775-1825 CE. Much like other paleohurricane reconstructions from the Atlantic basin, this compilation shows lower storm activity over the past 150 years. This further confirms that the hurricane activity we've observed recently is on the lower end of what's occurred in the Atlantic over the past 1000 years.

Compilations from the U.S. coastline (both New England and northwest Florida) confirm the increased hurricane activity reconstructed from 900-1100 CE suggesting that the entire Atlantic basin was active over this time period. An independent statistical simulation of tropical cyclones over the past millennium (Mann et al., 2009) also shows this increased activity during this medieval period, predominantly due to warmer SSTs in the Atlantic MDR and more La Nina-like conditions in the Pacific. From 1100 CE to present, we see a shift from elevated basin- 
wide activity to shifts in the predominance of certain storm populations in the Atlantic. The Bahamas compilation matches with the New England compilation and contrasts with the Gulf

Coast compilation. We suggest that these contrasting patterns of hurricane activity reflect a shift over the past millennium from a more straight-moving populations of storms that impact the Gulf Coast (1100-1250 CE) to more recurving storms hitting The Bahamas and U.S. East Coast (1400-1650 CE) and/or a shift from unfavorable local environmental conditions along U.S. East Coast and Bahamas from 1100-1250 CE to unfavorable conditions along the Gulf Coast from 1400-1650 CE.

\subsection{Acknowledgments}

This work was funded by the National Science Foundation Graduate Research Fellowship (to E.J.W.), the Dalio Explore Foundation and National Science Foundation grant OCE-1356708 (to J.P.D. and P.J.vH.). We thank members of WHOI Coastal Systems Group, in particular Stephanie Madsen, for their help in the processing core samples. The data are available on the National Climatic Data Center (http://www.ncdc.noaa.gov/dataaccess/paleoclimatologydata) and WHOI Coastal Systems Group (https://web.whoi.edu/coastal-group/) websites. 


\subsection{Figures}

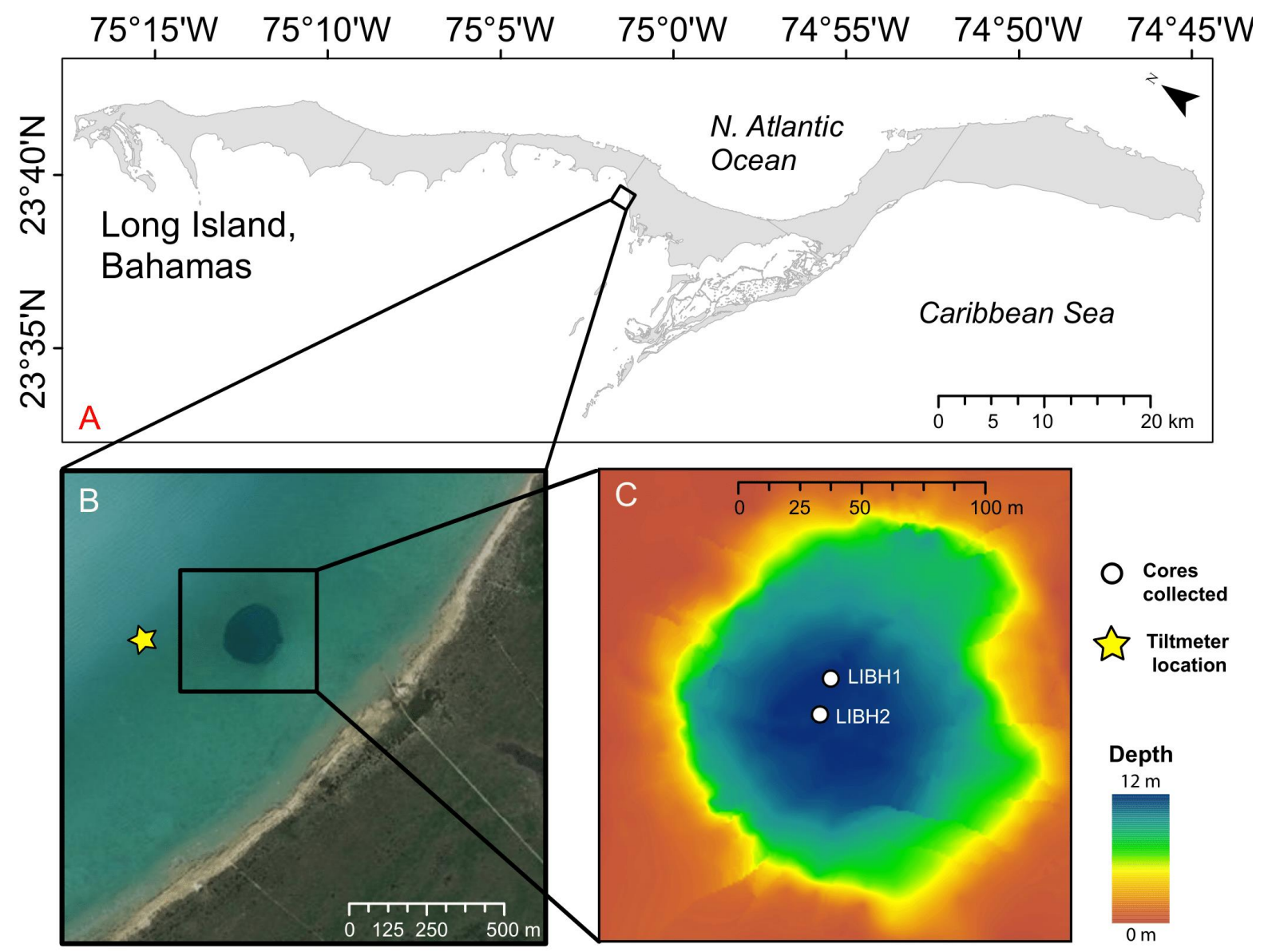

Figure 3.1: (A) Map of Long Island, The Bahamas. (B) Long Island Blue Hole (LIBH) location $\left(\mathrm{N} 23.265^{\circ}, \mathrm{W} 75.117^{\circ}\right),(\mathbf{C})$ The bathymetry of the blue hole and locations of the two cores (LIBH1 and LIBH2) are shown. The location of the tiltmeter we deployed in January 2017 is indicated by the yellow star in B. 


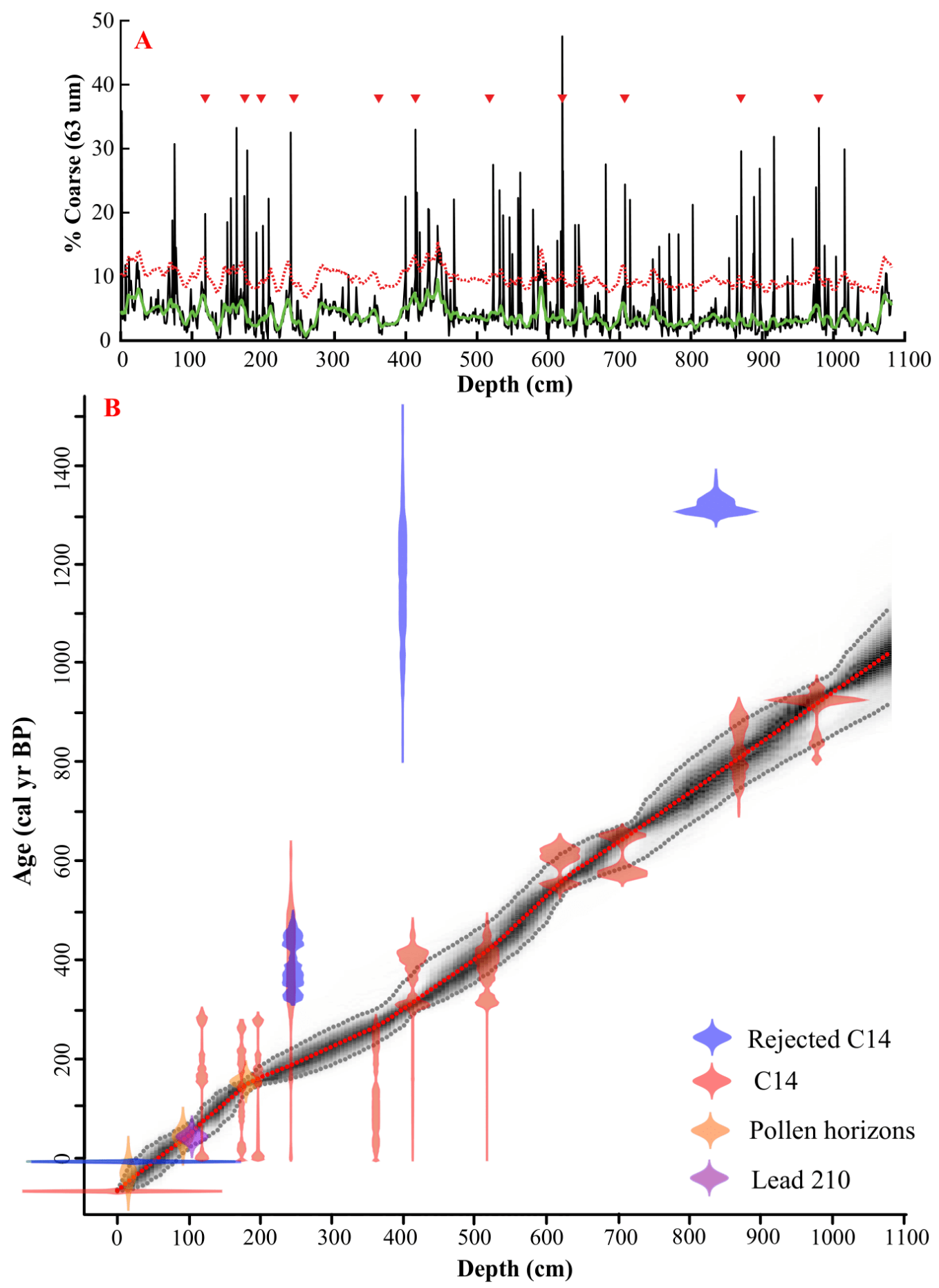

Figure 3.2: (A) Percent sand fraction $(>63 \mu \mathrm{m})$ vs. depth in core (black) from LIBH2 with a 10-point running mean filter (green) that excludes coarse fraction values above $10 \%$. The red dashed line is the event cutoff threshold added to the filter. Location of ${ }^{14} \mathrm{C}$ dates are plotted as red triangles above the coarse fraction data. (B) Age model (red dashed) derived from radiocarbon dates (red) in Table S3.1, pollen horizons (orange) from smear slides in Table S3.3, and Lead 210 decay (purple) (profile in Figure S3.3) for LIBH2. 95\% confidence bounds are shaded in grey around the age model. A tie point setting the surface of each core to modern is also shown (red horizontal bar). Rejected dates are shown in blue. These figures were generated using BACON v2.2 age modeling software (Blaauw and Christen, 2011). 


\section{Long Island Blue Hole (LIBH)}

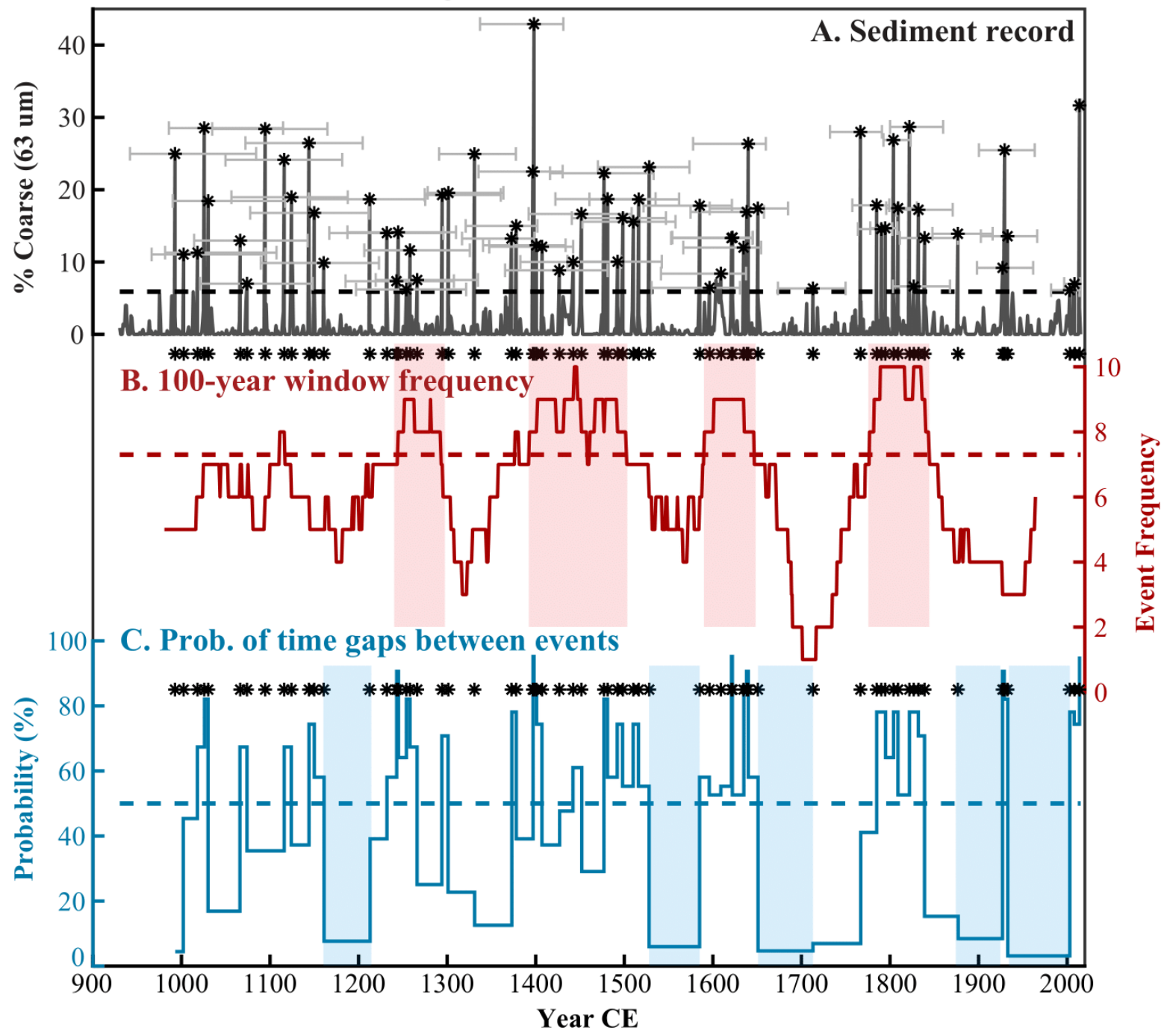

Figure 3.3: (A) Coarse anomaly plot (grey) for LIBH2 as a function of time. The dashed black line is the event bed threshold of 5.90\%. Grey error bars indicate $95 \%$ confidence bounds for the ages of each event. (B) The 100-year moving window event frequency per century. The dashed red line is the regional cutoff for active intervals ( 7.3 events/century). (C) The probabilities of having no events over the time span between each event in the record. The probabilities were calculated based on a recurrence interval of 16.4 years/event over the whole record (blue). Active and quiet intervals identified on Long Island are shaded in red and blue, respectively. 

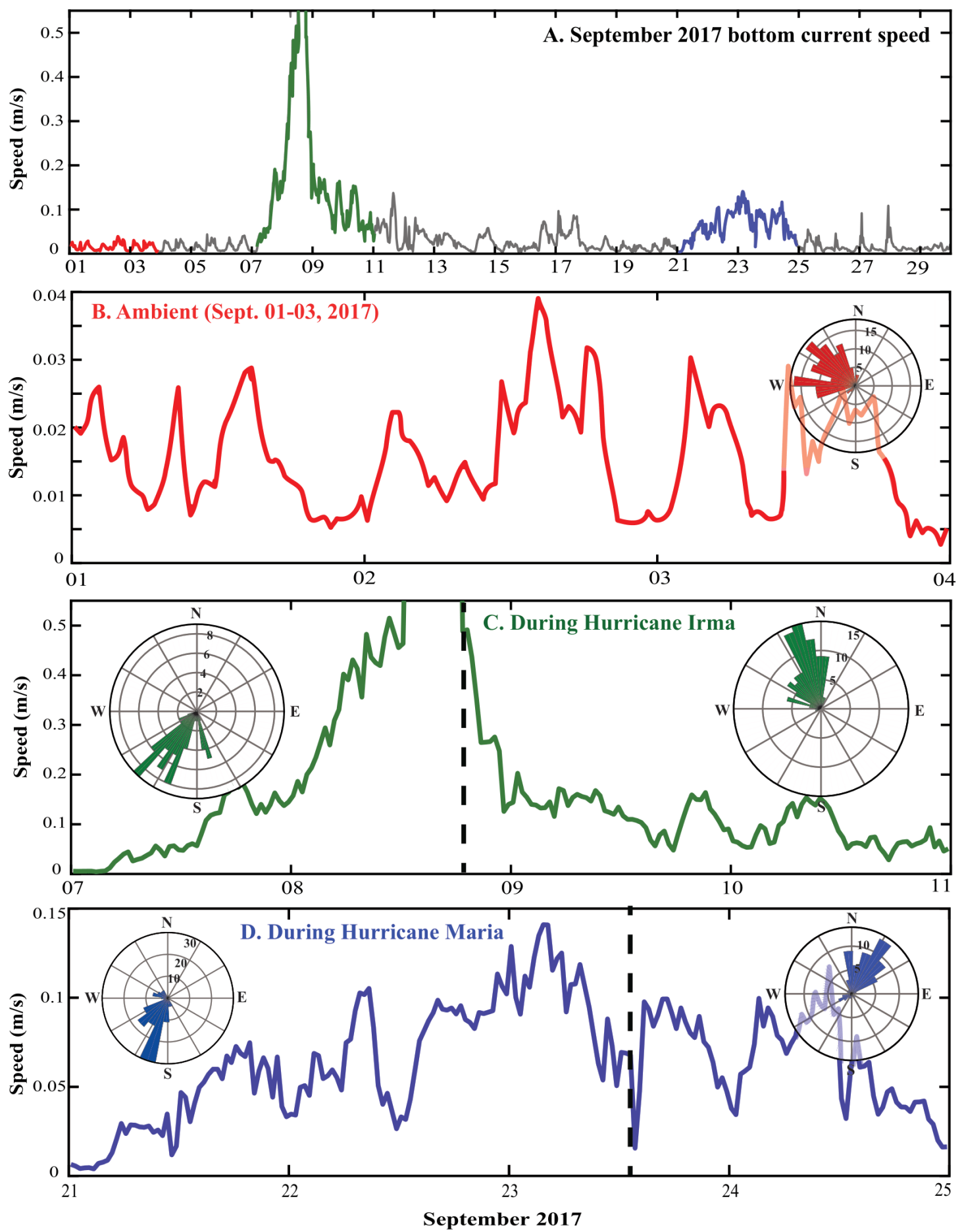

Figure 3.4: Bottom current speeds in September 2017 (A), under ambient conditions (September 1-3, 2017) (B), during Hurricane Irma (September 7-11, 2017) (C), during Hurricane Maria (September 21-25, 2017) (D). All data was taken from a Lowell Instruments LLC Tilt Current Meter (TCM) logging at a burst interval of 2 minutes, a burst rate of $8 \mathrm{~Hz}$, and a burst duration of 30 seconds. There is no data during the peak of Irma's passage, because water drained from the platform. Rose plots of current direction are shown in each panel. In $\mathrm{C}$ and $\mathrm{D}$, we displayed current direction averaged from before and after each storm. The dashed back lines denote our definition of the split between before and after each storm. 

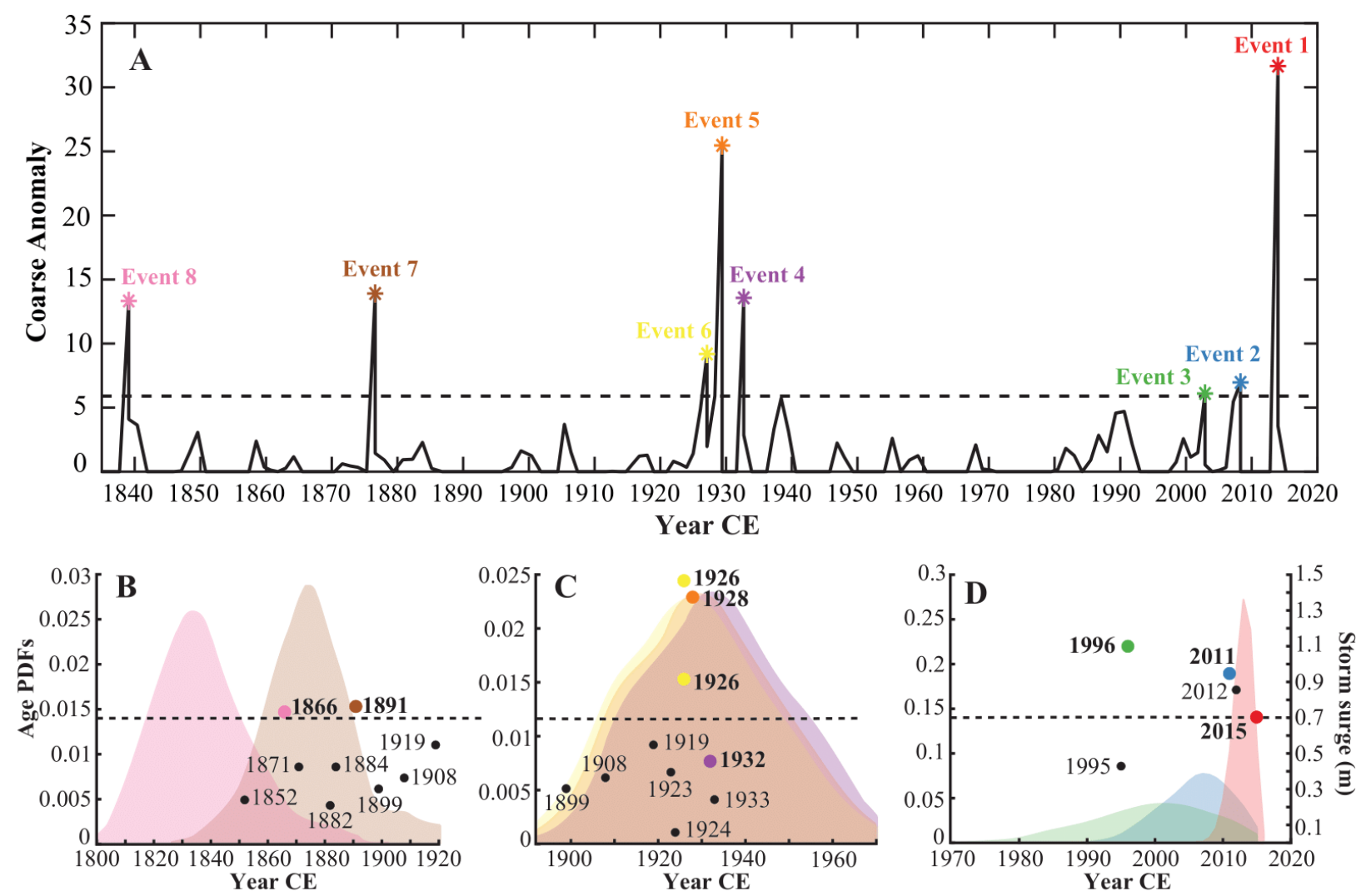

Figure 3.5: Coarse anomaly data for the modern interval (1850-2016) from LIBH2 (A). Starred peaks indicate identified event layers. 95\% age probability distributions for Events 7-8 (B), Events 4-6 (C), and Events 1-3 (D) shown in panel A. Circles on panels B-D indicate the timing of observed storms passing with $100 \mathrm{~km}$ of LIBH plotted as a function of their levels of SLOSH simulated storm surge. The colored dots indicated the observational storms to which we attributed each event bed shown in panel A. 


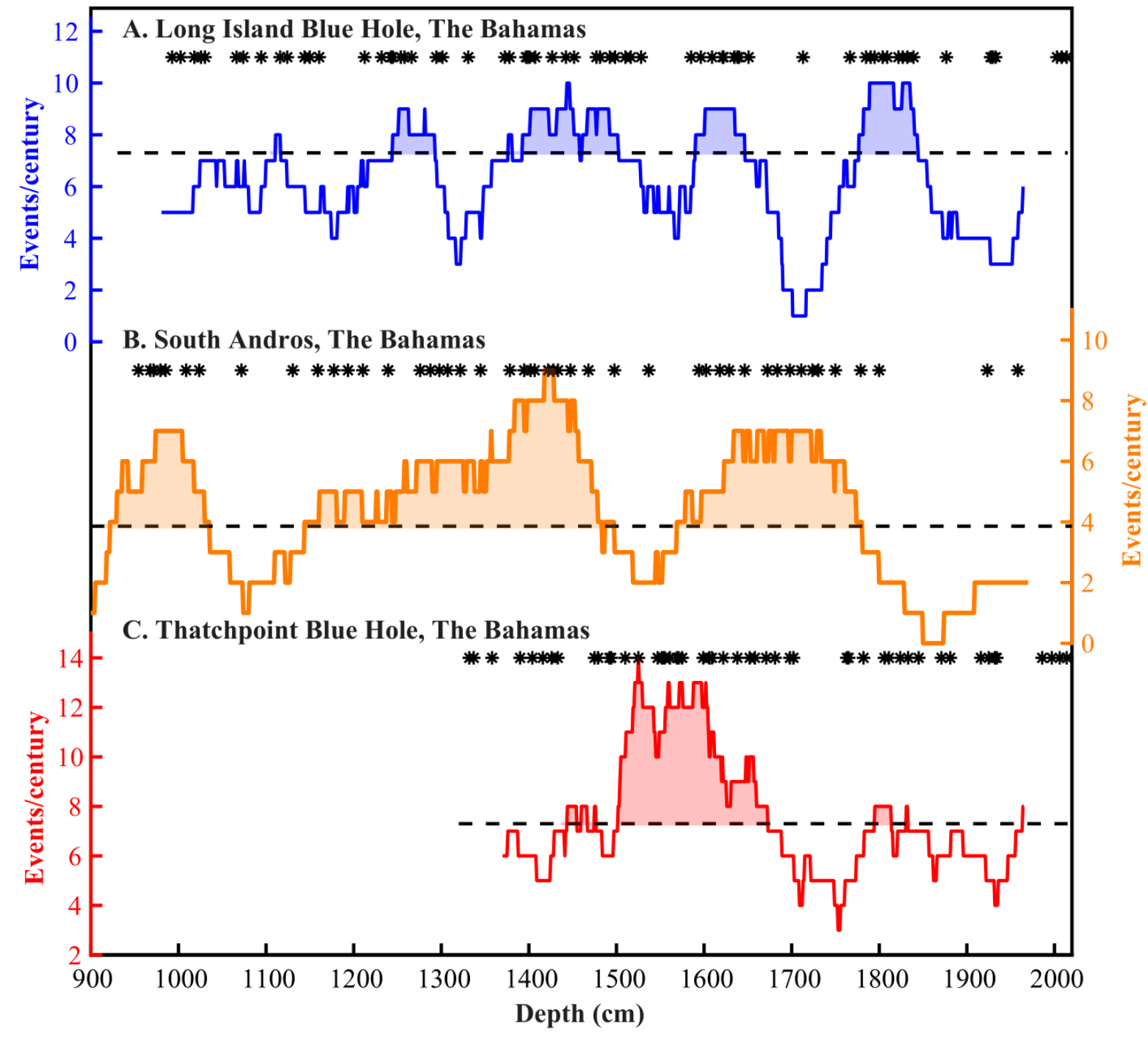

Figure 3.6: 100-year moving window event frequency for Bahamas reconstructions: (A) Long Blue Hole with 4 active intervals highlighted in blue, (B) South Andros stacked record (Wallace et al., 2019 (Chapter 2), Winkler et al, in review) with 3 active intervals highlighted in orange, and $(\mathbf{C})$ Thatchpoint Blue Hole (Winkler et al, in review) (red) with one active interval highlighted in red. The timing of each event in the records is denoted by the black stars above each panel. 


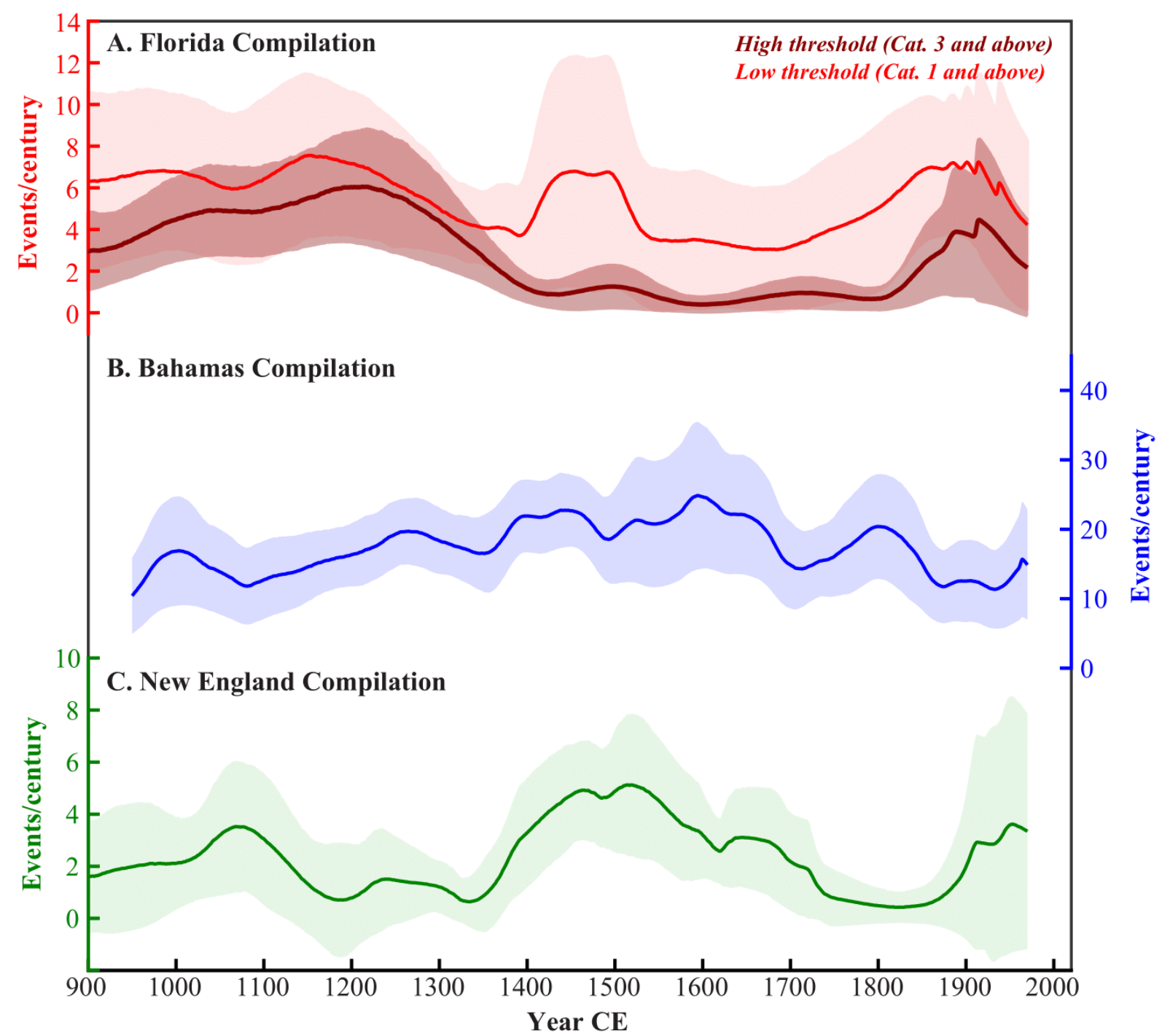

Figure 3.7: Compilations of paleohurricane records from (A) northwest Florida for intense events (dark red) and all events (red) including records from Mullet Pond, FL (Lane et al., 2011), Spring Creek Pond (Brandon et al., 2013), Shotgun Pond (Rodysill et al., in review), and Basin Bayou (Rodysill et al., in review) (B) The Bahamas (blue) including all the records shown in Figure 3.6, and (C) New England (green) including records from Salt Pond, MA (Donnelly et al., 2015) and Mattapoisett Marsh (Boldt et al., 2010; Castagno et al., in revision). The shaded confidence intervals are calculated from the spread in each of the contributing records. All three compilations shown were smoothed with a 100 -year moving window. The original compilations (without the filter) are shown in Figure S3.12-S3.13. For the Florida compilation, we include a High Threshold (dark red - Category 3 and above) and Low Threshold (red Category 1 and above) estimate. 


\section{S. Supplemental Material}

\section{S.1. Methods for CTD data collection}

In April 2016, we collected conductivity-temperature-depth (CTD) casts (Figure S3.1) from Long Island Blue Hole (LIBH) using a YSI Castaway CTD. In January 2017, we collected CTD data using the YSI EXO1 sonde. The EXO1 sonde records, in addition to profiles of temperature and salinity, profiles of dissolved oxygen and $\mathrm{pH}$. All sensors on the sonde were calibrated within 24 hours of data collection. The sonde sampled at two readings per second with a 2-3 second applied rapid averaging. We lowered the sonde into LIBH at a rate of $\sim 1 \mathrm{~cm} / \mathrm{s}$. Estimated sensor accuracy is: temperature $= \pm 0.01^{\circ} \mathrm{C}$, salinity $= \pm 0.1 \mathrm{PSU}$, dissolved oxygen $=$ $\pm 0.01 \mathrm{mg} / \mathrm{L}, \mathrm{pH}= \pm 0.01 \mathrm{pH}$ units.

\section{S.2. Tiltmeter data: Temperature and bottom current speed and direction}

Monthly climatology: The tiltmeter recorded bottom current and temperature data from near Long Island blue hole for a little over one year (from January 5, 2017 to March 20, 2018). We measured temperature at 2-minute intervals. For the current speed and direction data, we used burst logging to save battery, with a burst interval of 2 minutes, a burst rate of $8 \mathrm{~Hz}$, and a burst duration of 30 seconds. This means that the logger wakes up every 2 minutes and records data at $8 \mathrm{~Hz}$ for 30 seconds and then goes back to sleep for 1 minute and 30 seconds. This data is then post processed into 2 -minute velocity and direction records. It captured data during distant storm conditions (Hurricane Irma and Hurricane Maria) and ambient conditions. A monthly climatology of current speed from 2017-2018 shows higher average current speed $(\sim 5.5 \mathrm{~cm} / \mathrm{s})$ for the winter months (January-April) and current direction predominantly to the southwest (Figure S3.10). Current direction and speed change moving into the remainder of the year (MayDecember). Average current speed is almost half that observed in the first four months of the year $(\sim 3 \mathrm{~cm} / \mathrm{s})$. Current direction is predominantly to the northwest in May through August. September through December is characterized by a bimodal distribution in current direction both to the northwest and southwest. Temperature in the shallow waters near the blue hole shows increasing (decreasing) temperature from May to June (September to January). The temperature plateaus in the summer months with peak values close to $30^{\circ} \mathrm{C}$. Wintertime temperatures were approximately $6^{\circ} \mathrm{C}$ cooler than summer (Figure S3.11). 
Temperature changes in September 2017: Ambient water temperatures in September oscillate each day between a low of $30.6^{\circ} \mathrm{C}$ at night and $32.6^{\circ} \mathrm{C}$ in the mid-afternoon (Figure S3.11). During Hurricane Irma on September 7, 2017, water temperature near the blue hole dropped approximately $5^{\circ} \mathrm{C}$ in under 24 hours overpowering daily temperature oscillations. Over the week following the storm, temperatures rose back to pre-storm values $\left(\sim 31^{\circ} \mathrm{C}\right)$. The more distal passage of Hurricane Maria also affected temperatures near the hole to a lesser degree. Average temperatures dropped approximately $1^{\circ} \mathrm{C}$ on September 22 with peak daily temperatures at $30.1^{\circ} \mathrm{C}$ and daily lows around $28.6^{\circ} \mathrm{C}$. This lasted for approximately 2 days as Maria passed to the northeast (September 23-24) before temperatures around the blue hole began to rise again.

\section{S.3. Justification for unused radiocarbon results}

We excluded five radiocarbon dates from the age model. Three of them were not chronologically consistent with all the other dating evidence. The other two excluded dates were post-bomb radiocarbon dates from $22 \mathrm{~cm}$ and $29 \mathrm{~cm}$ downcore (Figure 3.2 and Table S3.3). The post-bomb calibration curve allows us to estimate the age of these samples with less than one year of uncertainty. Both samples calibrated to the same year (1956 \pm 1 CE). This uncertainty is too small given that it does not account for the residence time of the mangrove leaves on the landscape before they are transported into the blue hole. While both of the plant macrofossils may have died in $1956 \mathrm{CE}$, we cannot tell how many years passed before they were deposited in the blue hole, which is located about $0.5 \mathrm{~km}$ away from shore. Therefore, we expect that both samples are either 1956 or older, dependent how long they resided on the landscape before being transported into the blue hole. The fact that the second sample located $7 \mathrm{~cm}$ downcore from top sample (at $22 \mathrm{~cm}$ ) dated to the same year provides evidence that this sort of phenomenon could be happening. If both plant samples were deposited in the blue hole immediately after they died, the second sample should have an older date than the sample closer to the core top. We choose to exclude these samples, because we think they force the age model through too small of an uncertainty range. However, both of these samples are consistent with the dating evidence provided by both the ${ }^{210} \mathrm{~Pb}$ and pollen horizons (Figure 3.2). 


\section{S.4. Methods for Florida, New England, and Bahamas sediment compilation}

The sediment compilation for The Bahamas included events from the Long Island blue hole reconstruction, Abaco Island reconstruction (Thatchpoint Blue Hole (Winkler et al., in review)) and South Andros Island reconstructions (AM5, AM4 and AM2 records (Wallace et al., 2019)).

We also created compilations of paleohurricane records from New England and Florida. To allow for appropriate comparison with The Bahamas blue hole records, we only include previously published records in the New England and Florida compilations if they meet the following three criteria:

1. Each record must have at least multi-decadal resolution and extend back at least 500 years.

2. There must be clear criteria established in the paper for what is considered a storm event with clear attribution to modern tropical cyclones.

3. Each published record must provide enough information to create or replicate a welldated Bayesian age model for estimating age uncertainties.

For Florida, we create a High Threshold (HT) and Low Threshold (LT) compilation which include Category 3 and above events and Category 1 and above events, respectively. The Florida HT compilation includes work from Apalachee Bay (Spring Creek Pond (Brandon et al., 2013), Mullet Pond (Lane et al., 2011)) and Choctawhatchee Bay (Basin Bayou (Rodysill et al., in review)). The Florida LT compilation includes all the same records and one additional record from Shotgun Pond in Apalachee Bay (Rodysill et al., in review). The New England compilation includes records from Salt Pond (Donnelly et al., 2015) and Mattapoisett Marsh (Boldt et al., 2010, Castagno et al., in review).

We recreated the age models for each of these studies using BACON software (Blaauw and Christen, 2011). To form each region/island's composite, we made efforts to remove redundant counts of the same event among multiple contributing records. If multiple events on an island fell within age model uncertainties of each other, they were consolidated into single assumed hurricane strikes. We did this because many records from the same island/region capture many of the same historical landfalling hurricane events (see Wallace et al., 2019 Chapter 2). When several events from one site fell within age model uncertainties of an event from another site, we only consolidate the event that is closest in median age to that of the event 
from the second site. Figure S3.12 shows the median age of the events included in the Apalachee Bay (HT and LT), Choctawhatchee Bay (HT and LT), New England, Andros, Abaco, and Long Island-wide composites.

Having consolidated redundant events, we create age probability distributions functions (pdfs) for each event in our island composites between 900-2016 CE. Each individual distribution sums to one and provides an estimate of how probable it is that each event happened in any given year within the age uncertainties. Many of these events' age pdfs overlap. So to create our island/region-wide composites, we summed up all the overlapping age pdf values for each island/region. Figure S3.13 shows each island/region-wide composite. To create our age distributions, we sampled 1000 different age ensembles from our Bayesian age models. For region/island-wide composites where we have multiple different records each with their own independent age model contributing to the compilation, we used the age model from the record with the smallest age uncertainties for each event. In the case of Andros, this was always AM4. For New England and Apalachee Bay, the age model used for each event varied. Figure S3.13 colors the events according to which age model we used to create its pdf. We formed the final regional composite by summing up all the contributing composites shown in Figure S3.12. Confidence intervals around this estimate were calculated as the spread among the different contributing island/region-wide composites in each year. This full compilation unsmoothed is shown in Figure S3.13. 


\section{S.4. Supplemental figures and tables}
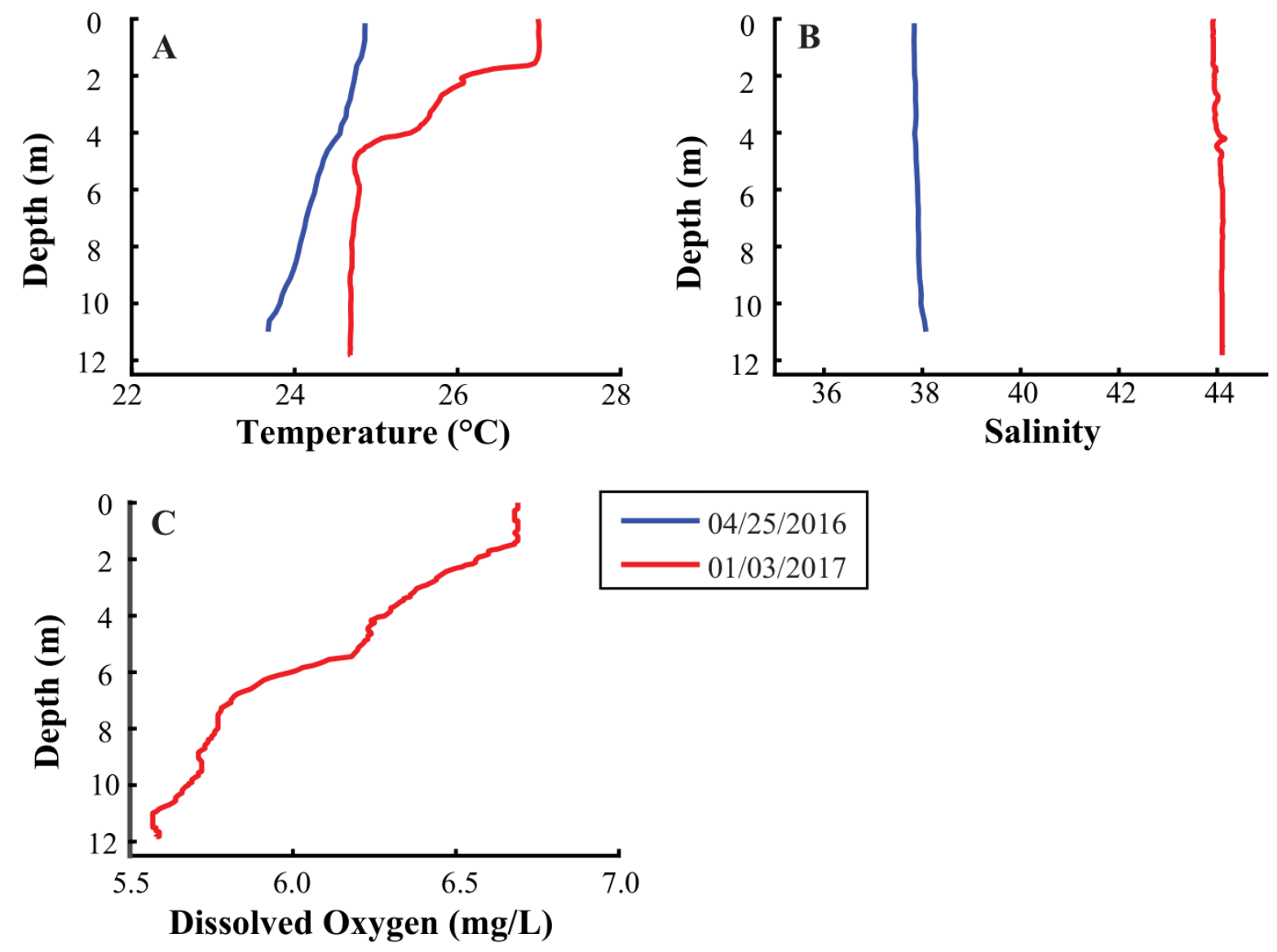

Figure S3.1. Temperature (A), salinity (B) and optical dissolved oxygen $(\mathbf{C})$ in the Long Island blue hole (LIBH). Profiles from April 2016 (blue) were collected using a YSI Castaway CTD and the profiles from January 2017 (red) were collected using a YSI EXO1 sonde. 


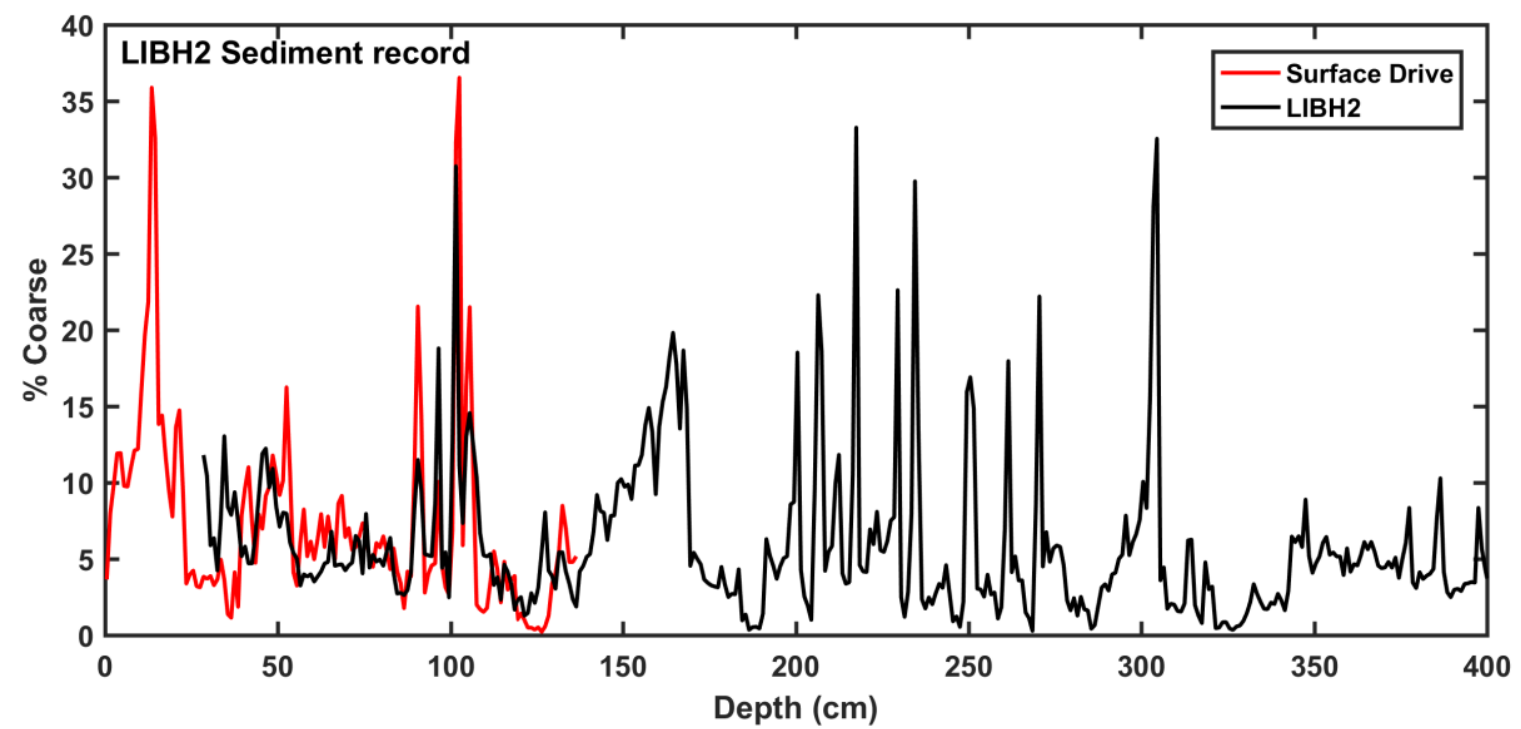

Figure S3.2. Percent sand fraction (> $63 \mu \mathrm{m}$ ) vs depth in core $(\mathrm{cm})$ for the polycarbonate surface drive in red and LIBH2 (three-inch aluminum $12 \mathrm{~m}$ drive) in black. The figure shows where the two drives were assumed to overlap given that $\mathrm{LIBH} 2$ did not capture the sediment water interface.

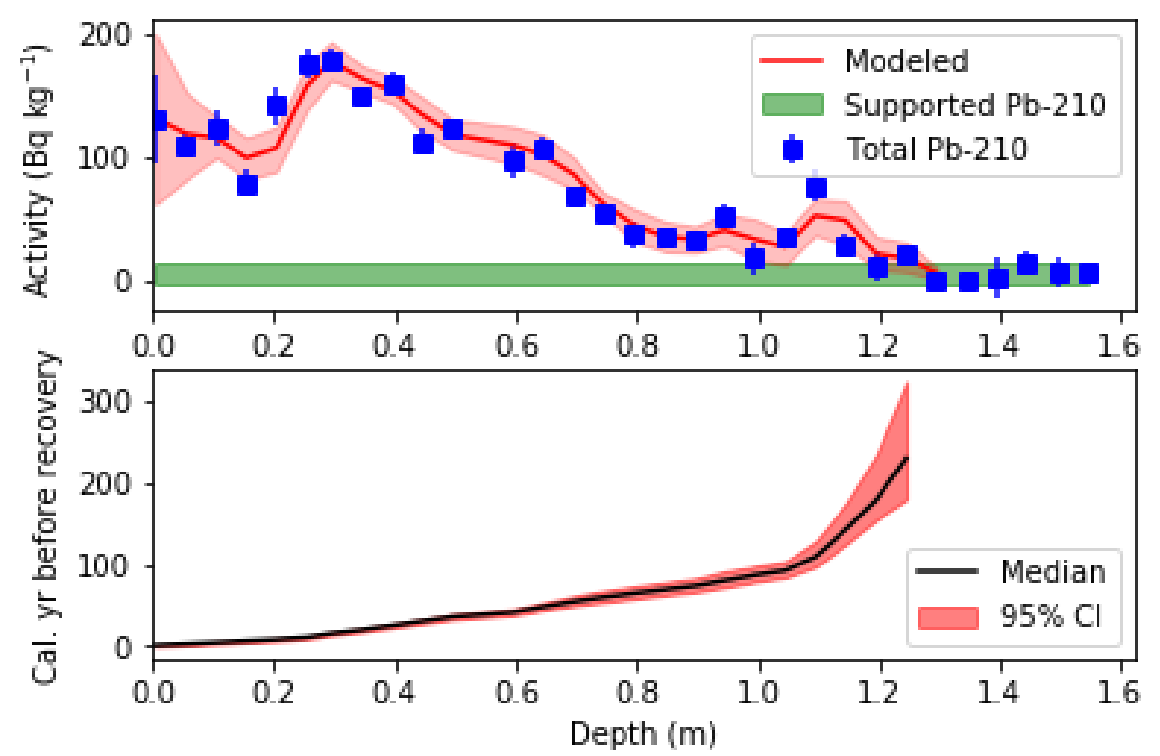

Figure S3.3. (Top panel) Total (blue) and supported (green) Lead-210 activity with depth in the LIBH2 core measured using Canberra GL2020RS low-energy Germanium gamma well detectors. (Bottom panel) Age (year before 2016 (recovery)) with depth in the top $125 \mathrm{~cm}$ of LIBH calculated using the Constant Rate of Supply (CRS) model. 95\% confidence intervals are shown in red. The ${ }^{210} \mathrm{~Pb}$ equilibrium line at $110 \mathrm{~cm}$ was dated to $1906 \pm 10 \mathrm{CE}$. 


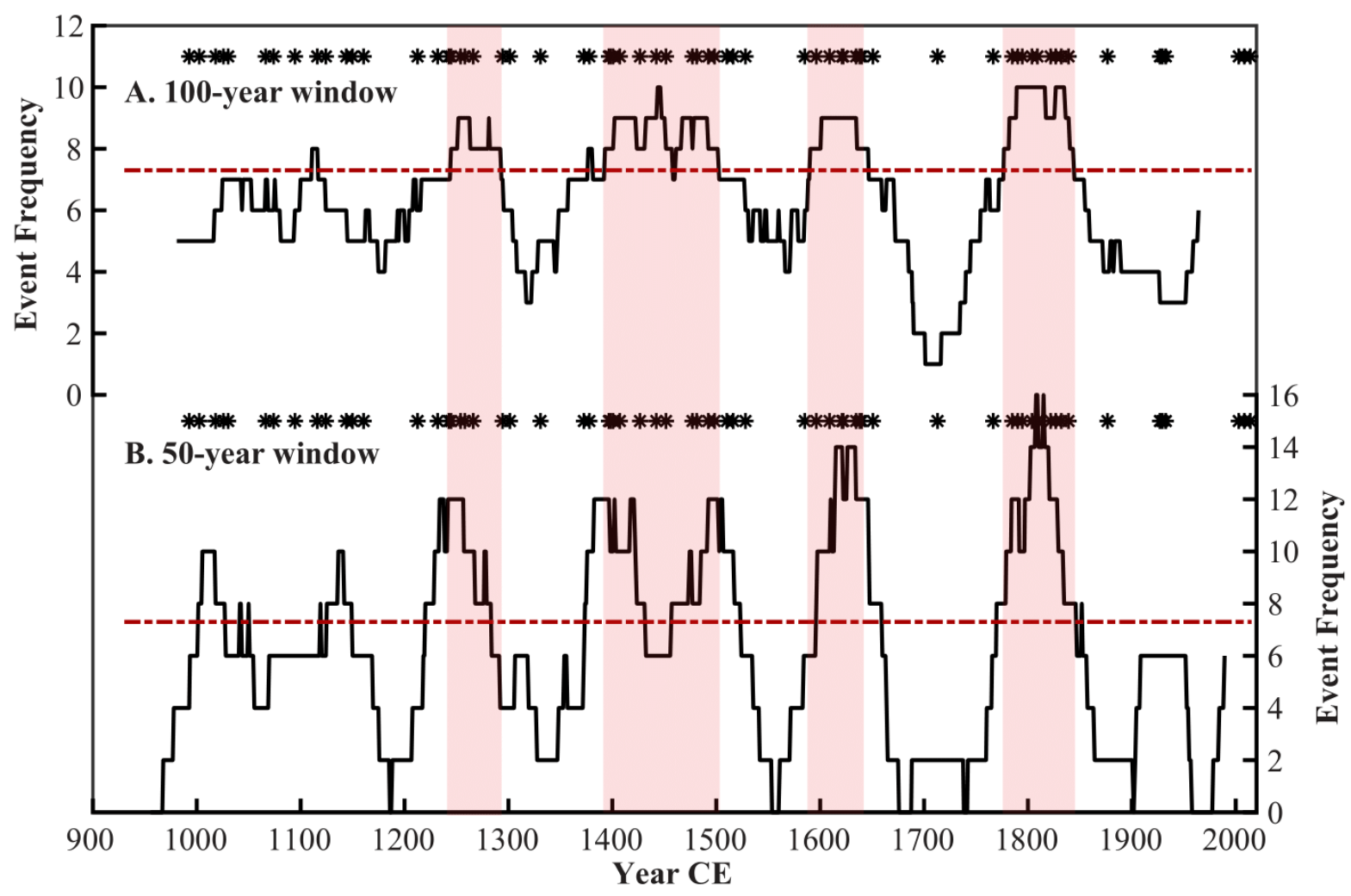

Figure S3.4: Event frequency per century for LIBH2 (black) with a 100-year sliding window (A) and a 50-year sliding window $(\mathbf{B})$. The dashed red line is the regional cutoff for active intervals (7.3 events/century). Active intervals are shaded in red and indicate time periods when the event frequency is above the regional cutoff for the 100-year window event frequency. The median timing of each event is plotted as a black star above each panel. The timing of active intervals does not change dramatically if we use the 50-year window frequency versus the 100-year. 


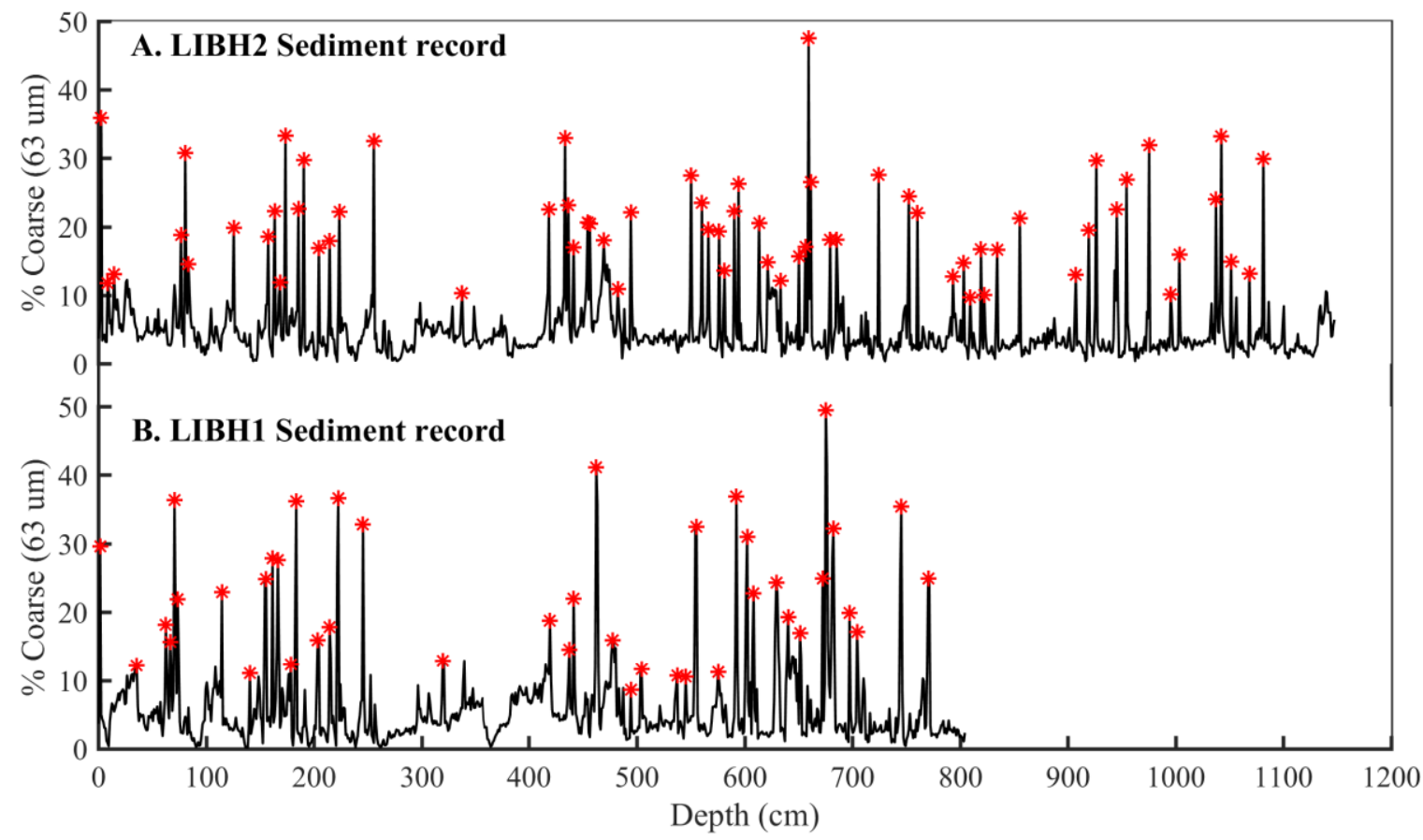

Figure S3.5. Percent sand fraction (>63 $\mu \mathrm{m})$ vs. depth in core (black) from LIBH2 (A) and LIBH1 (B). Events beds in each core are denoted by a red star. Most of the event beds from LIBH2 correspond to an equivalent deposit in LIBH1. There are 45 events in the top $800 \mathrm{~cm}$ of LIBH2 and 42 events in the entirety of LIBH1. 


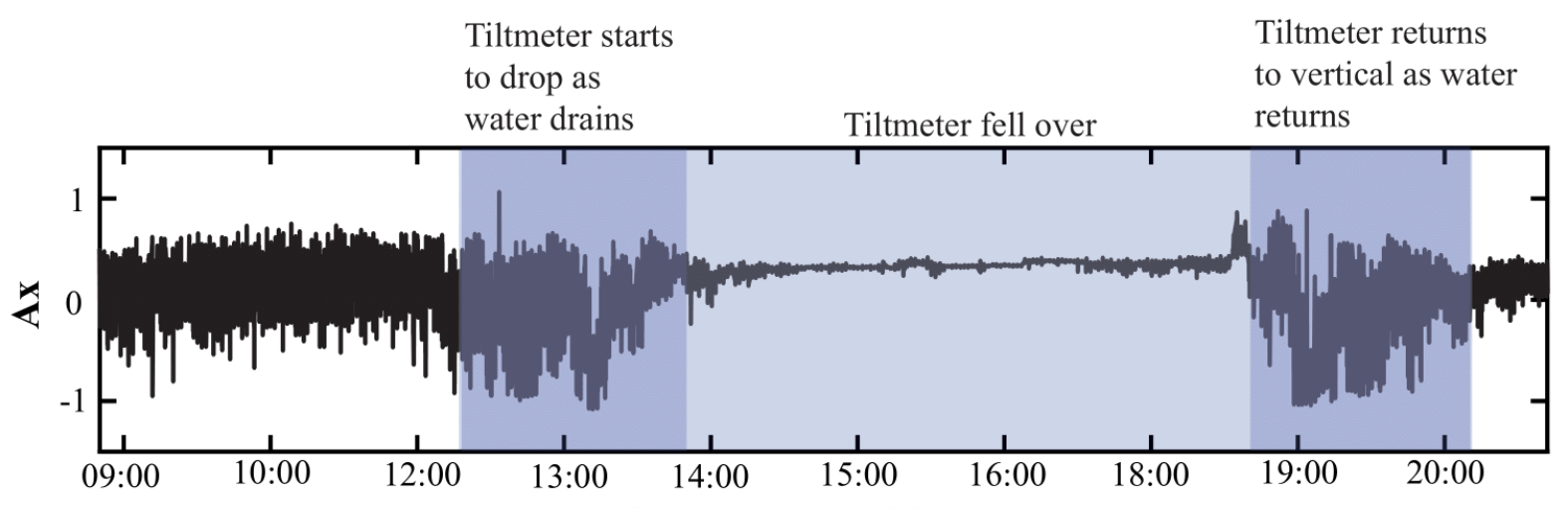

September 08, 2017
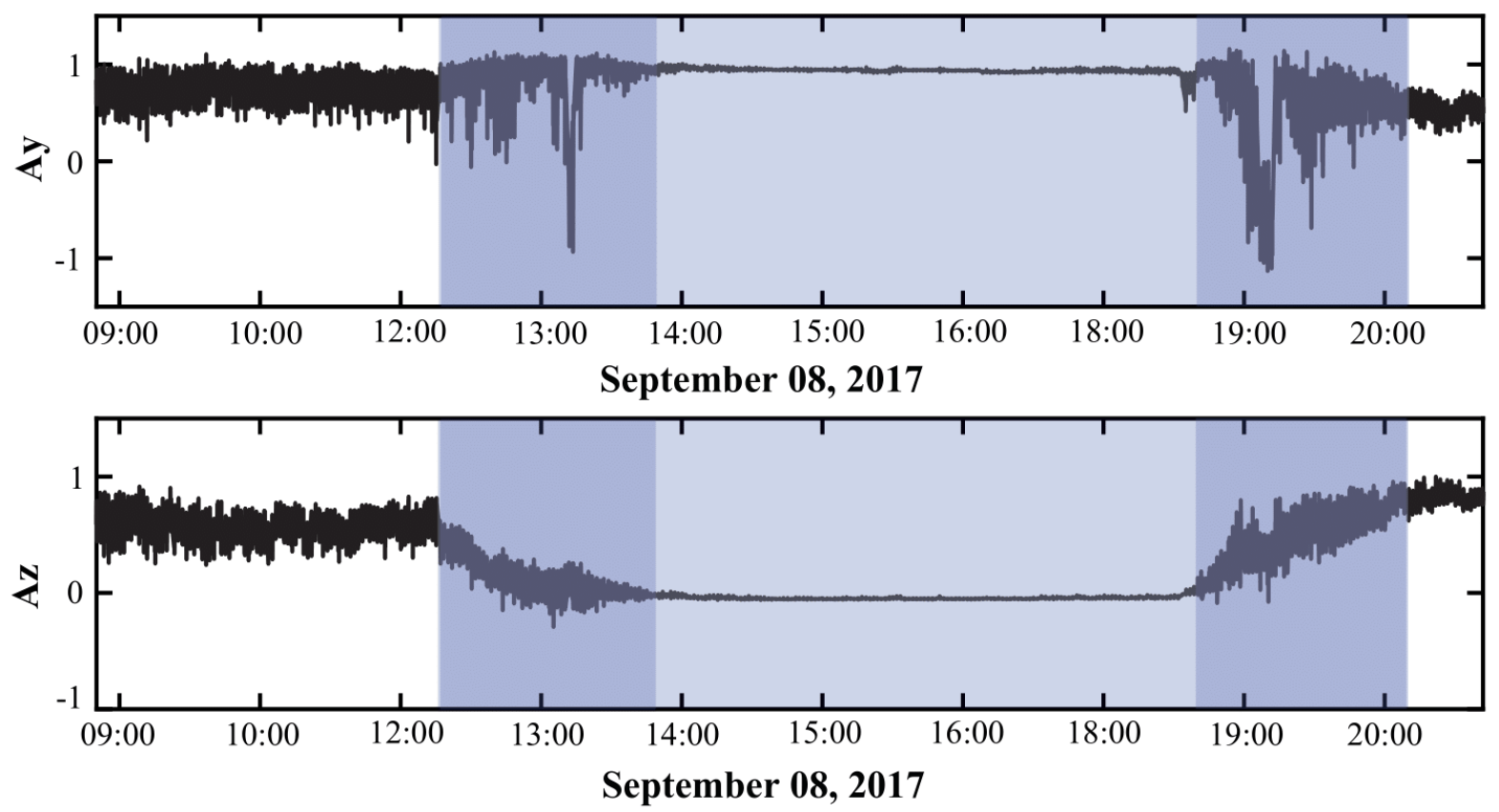

Figure S3.6: Raw accelerometer data during Hurricane Irma in 2017 measured on a Lowell Instruments LLC Tilt Current Meter (TCM). The noise prior to noon on September $8^{\text {th }}$ shows the tiltmeter moving in the water. From approximately 12:00 to 14:00, Az panel shows the tiltmeter falling over. The lack of noise from 14:00 to 19:00 indicates that the sensor was lying flat on the bank. The water returns at 19:00. 

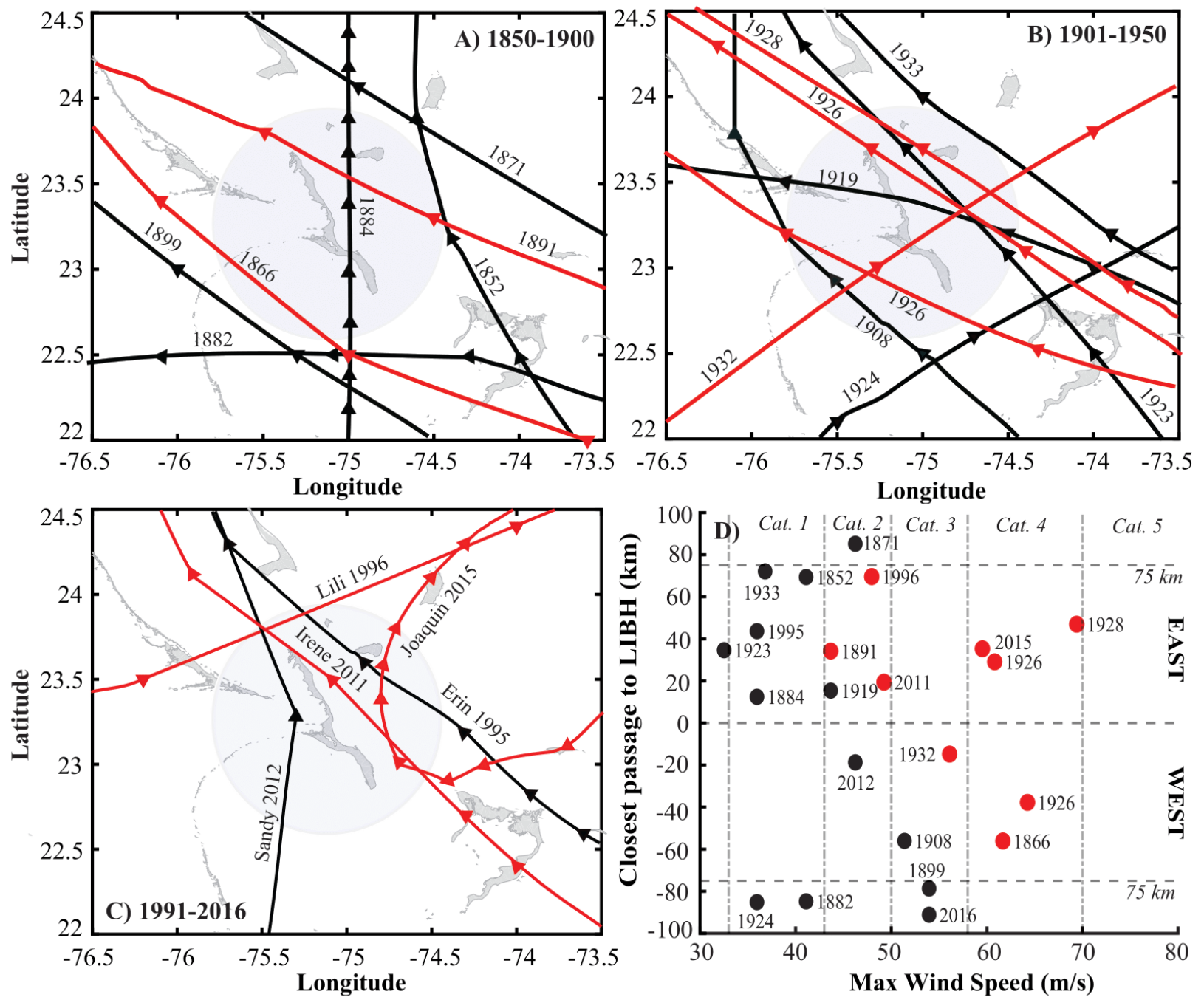

Figure S3.7: Historical hurricane tracks passing within $100 \mathrm{~km}$ of the Long Island blue hole (N $23.265^{\circ}, \mathrm{W} 75.117^{\circ}$ ) from 1850-1900 CE (A), 1901-1950 CE (B), and 1991-2016 CE (C). A grey circle shows a $75 \mathrm{~km}$ radius around the blue hole. Characteristics of the observational storms passing within $100 \mathrm{~km}$ of LIBH (D). Red dots indicate the storms that left deposits in the blue hole. Storm's closest passage to LIBH is positive if the storm moves to the north or east of LIBH and negative if the storm moves to the west or south of LIBH. 


\section{LIBH1 D2}

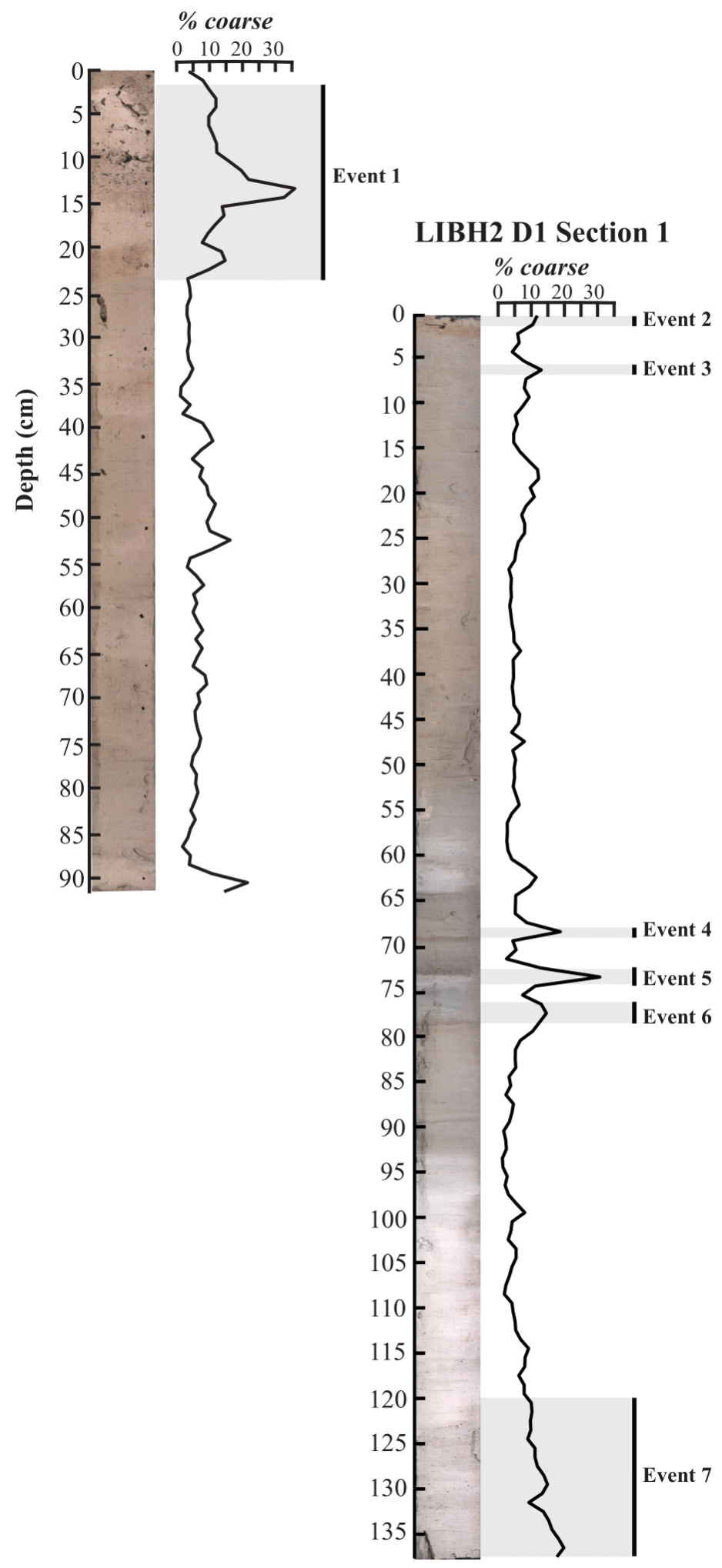

Figure S3.8: Pinpointing the overlap point between the first section of the Long Island surface drive (LIBH1 D2) and the first section of the longer drive (LIBH2 D1). The longer drive did not capture the sediment-water interface or the first event bed. Optical images from the ITRAX Xray fluorescence scanner and coarse fraction ( $>63 \mathrm{um}$ ) data were used to choose the overlap points. Gray shaded vertical black bars with event labels indicate denote the thickness of event beds identified. Visual cues for event beds included: lighter colored sediments, visibly coarser grains, and higher concentrations of organics. 


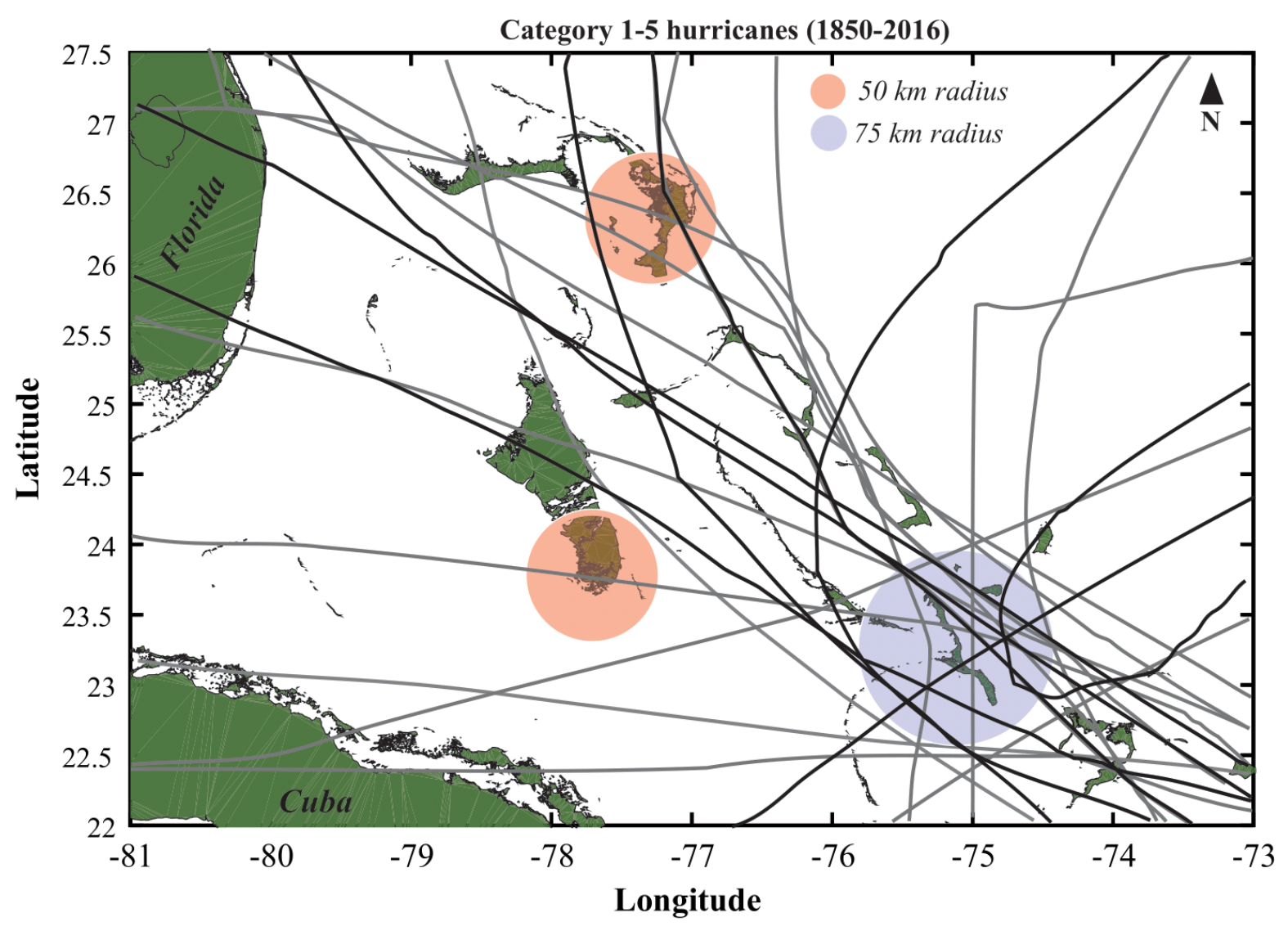

Figure S3.9: Map showing $50 \mathrm{~km}$ radii (red) around Thatchpoint Blue Hole on Abaco Island (Winkler, in review) and the AM4 blue hole on South Andros Island (Wallace et al., 2019 (Chapter 2)) and a $75 \mathrm{~km}$ radius around Long Island blue hole (blue). Historical hurricane tracks (Category 1 and above from 1850-2016) passing within $100 \mathrm{~km}$ of Long Island are plotted in grey. Five of these storms and one of these storms go on to hit Thatchpoint and AM4, respectively. 


\section{Bottom Current Direction and Speed}
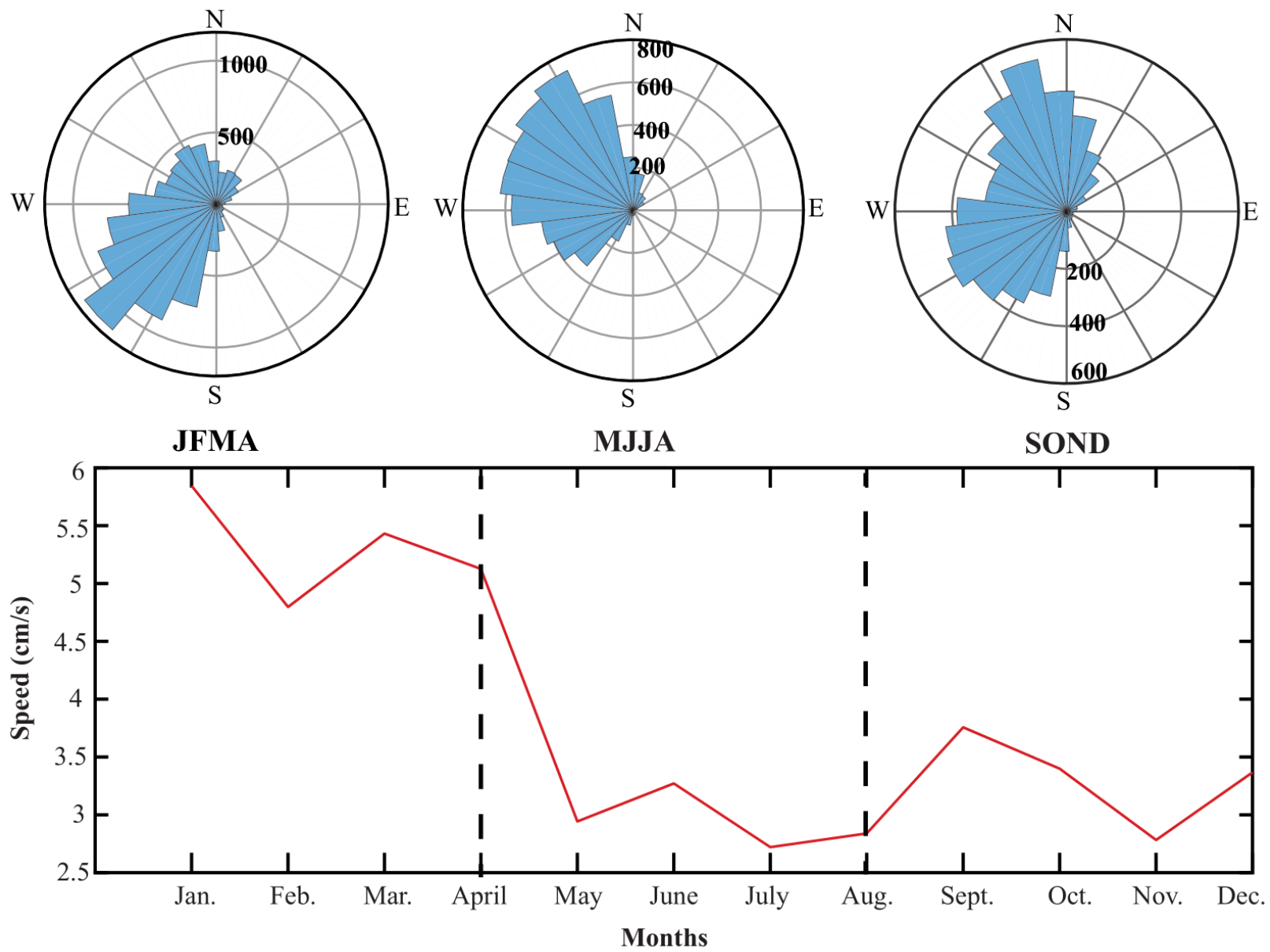

Figure S3.10: Monthly climatology of wave conditions near LIBH in 2017. We show rose plots of current direction in January-April (JFMA), May- August (MJJA), and September-December (SOND). Average bottom current speeds are shown for each month of the year. All data was taken from a Lowell Instruments LLC Tilt Current Meter (TCM). 

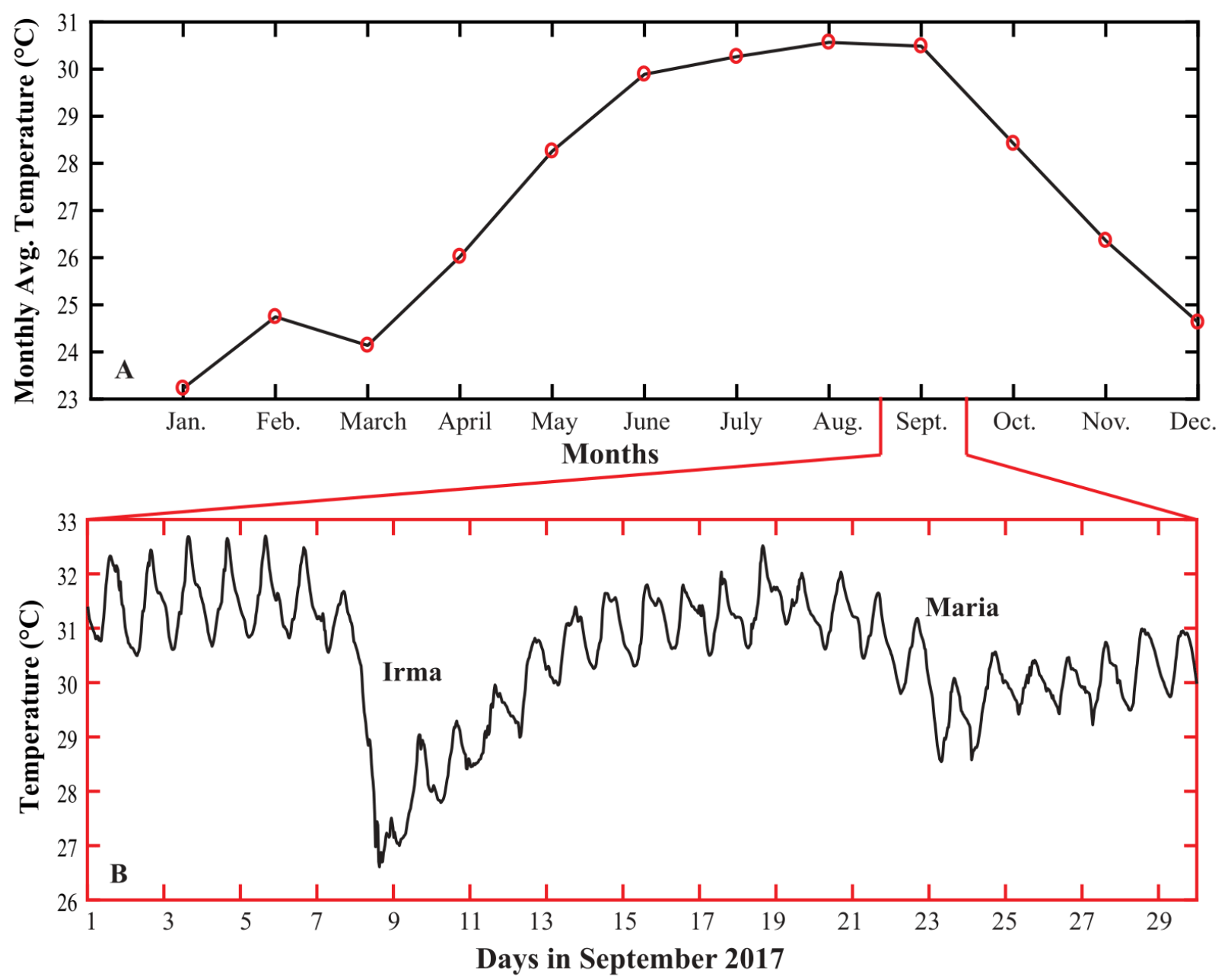

Figure S3.11: Monthly average temperature for the bank near Long Island blue hole in 2017 (A). Bottom water temperature in September 2017 (B). There is a clear drop in temperature on the bank during the distant passage of Hurricanes Irma and Maria. All data was taken from a Lowell Instruments LLC Tilt Current Meter (TCM). 
Figure S3.12: Components of regional compilations of hurricane counts from 900-2016 CE for the (A) Florida High Threshold ( $\geq$ Category 3): Spring Creek Pond (Brandon et al., 2013) (red), Mullet Pond (Lane et al., 2011) (light orange), and Basin Bayou (Rodysill et al., in review) (dark orange), (B) Florida Low Threshold ( $\geq$ Category 1): Shotgun Pond (Rodysill et al., in review) (pink), Spring Creek Pond (Brandon et al., 2013) (red), Mullet Pond (Lane et al., 2011) (light orange), and Basin Bayou (Rodysill et al., in review) (dark orange), (C) The Bahamas: Abaco (light green), Andros (dark blue), and Long Island (light blue), and (D) New England: Salt Pond (Donnelly et al., 2015) (purple) and Mattapoisett Marsh (Boldt et al., 2010) (lavender). Abaco includes events from Thatchpoint Blue Hole (Winkler et al., in review). Andros includes events from the AM5, AM4 and AM2 records (Wallace et al., 2019 (Chapter 2)). The stars at the top of each panel indicate the median age of each event used in the compilation. The compilations are the sum of the age probability distributions of each of these events. 

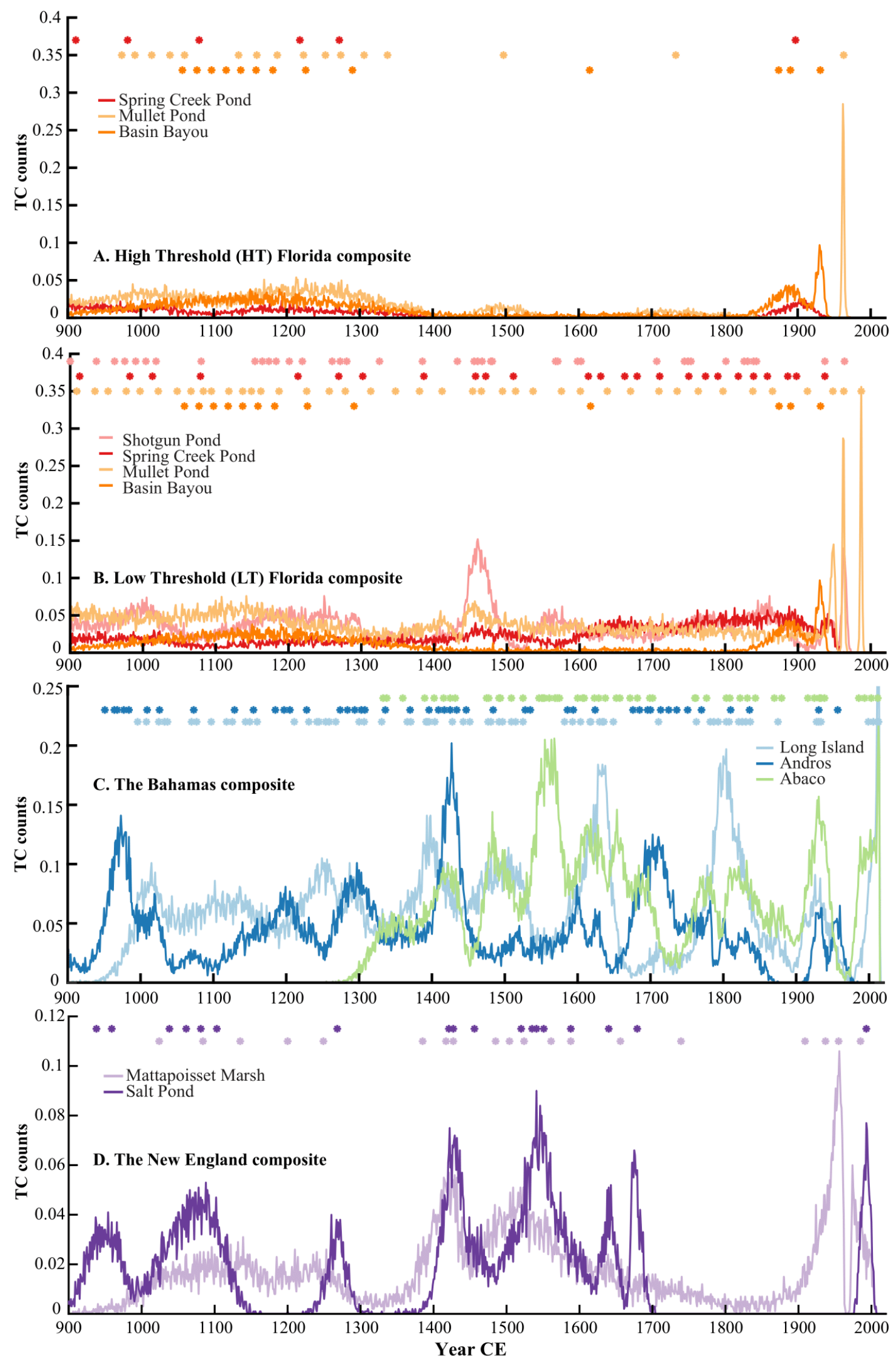
Figure S3.13: Florida High Threshold paleohurricane compilation (A), Florida Low Threshold paleohurricane compilation (B), The Bahamas paleohurricane compilation (C), and New England paleohurricane compilation (D) generated by summing the time series in Figure S3.12A, S3.12B, S3.12C, and S3.12D, respectively. Standard errors are shaded in grey around each compilations and are calculated as the spread among the estimates in Figure S3.12. The stars at the top of each panel indicate the median age of each event used in the compilation. 

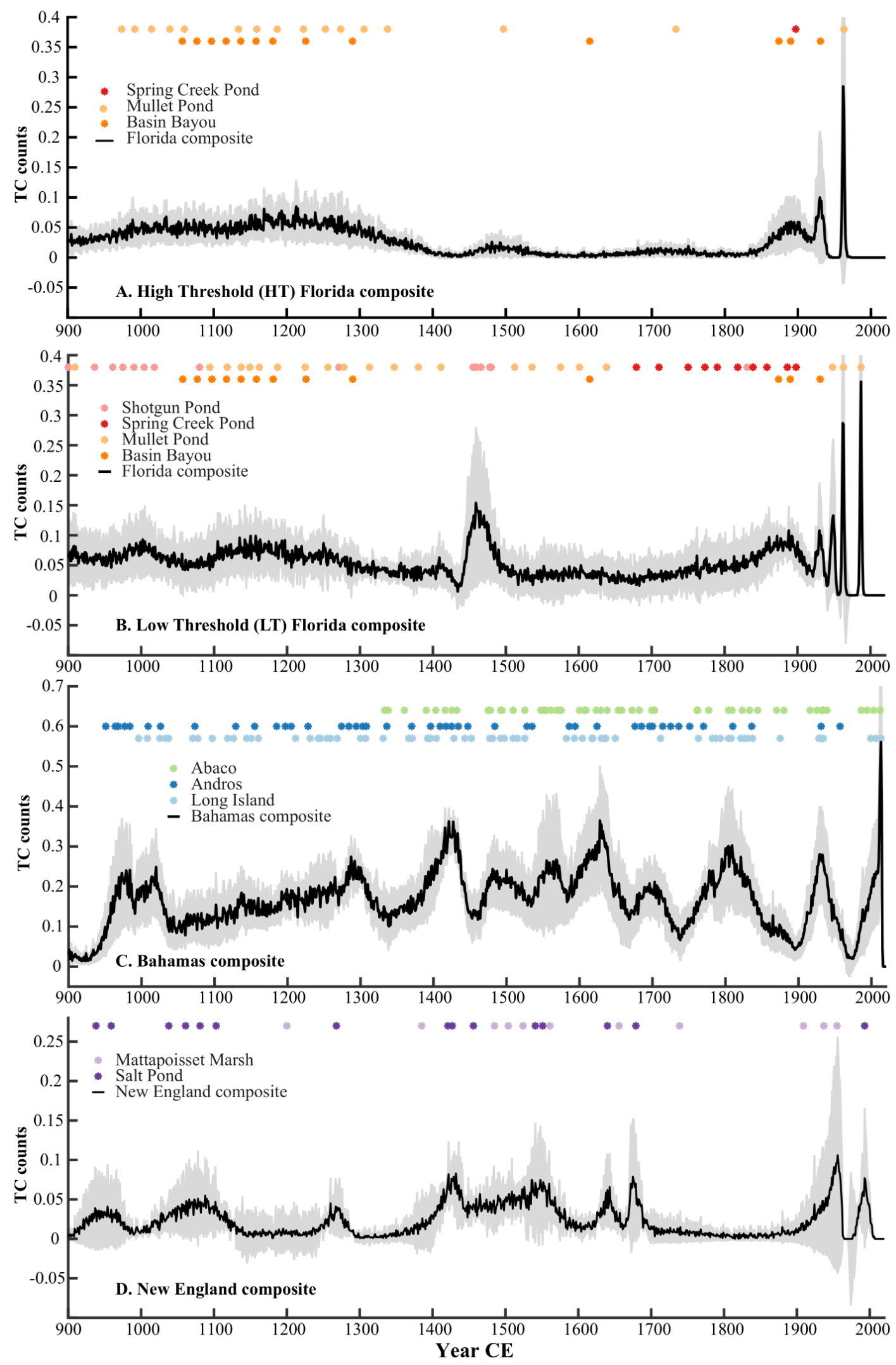
Table S3.1: Pollen smear slide data from LIBH2. This table includes identified taxa and interpretations of the environment and level of disturbance in each sample. Pollen taxa and opaque spherules are listed in order of dominance. The final column includes the dates (in year CE) and uncertainties included in the LIBH age model from these slides.

\begin{tabular}{|c|c|c|c|c|c|}
\hline Core & $\begin{array}{c}\text { Depth } \\
\text { (cm) }\end{array}$ & Taxa & Environment & Disturbance & $\begin{array}{c}\text { Year } \\
\text { CE }\end{array}$ \\
\hline $\begin{array}{l}\mathrm{LIBH} 2 \\
\mathrm{D} 1\end{array}$ & 286.5 & $\begin{array}{l}\text { Jaquemontia, Cordia, } \\
\text { Leguminosae, Buxus, } \\
\text { Terminalia, and Arecaceae }\end{array}$ & $\begin{array}{l}\text { Dry tropical hardwood } \\
\text { forest dominated by } \\
\text { diverse woody } \\
\text { vegetation and some } \\
\text { palms }\end{array}$ & Not evident & \\
\hline $\begin{array}{l}\mathrm{LIBH} 2 \\
\mathrm{D} 1\end{array}$ & 233.5 & $\begin{array}{l}\text { Caesalpinia, Swietenia, } \\
\text { Jaquemontia, Buxus, } \\
\text { Rubiaceae, Typha, and } \\
\text { Asteraceae (short spine) }\end{array}$ & $\begin{array}{l}\text { Dry tropical hardwood } \\
\text { forest dominated by } \\
\text { diverse woody } \\
\text { vegetation }\end{array}$ & $\begin{array}{l}\text { Slightly } \\
\text { evident }\end{array}$ & \\
\hline $\begin{array}{l}\mathrm{LIBH} 2 \\
\mathrm{D} 1\end{array}$ & 193.5 & $\begin{array}{l}\text { Jaquemontia, Polygonaceae, } \\
\text { Typha, Arecaceae, Caesalpinia, } \\
\text { Asteraceae (short spine), } \\
\text { Asteraceae (long spine), and } \\
\text { Ambrosia }\end{array}$ & $\begin{array}{l}\text { Dry tropical hardwood } \\
\text { forest }\end{array}$ & Very evident & $\begin{array}{r}1790 \\
+/-20\end{array}$ \\
\hline $\begin{array}{l}\text { LIBH2 } \\
\text { D1 }\end{array}$ & 181.5 & $\begin{array}{l}\text { Leguminosae, Malpighiaceae, } \\
\text { Spondias (hog plum - from } \\
\text { cultivation), Conyza, Ambrosia, } \\
\text { Asteraceae (short spine), } \\
\text { Asteraceae (long spine), and Iva }\end{array}$ & $\begin{array}{l}\text { Dry tropical hardwood } \\
\text { forest }\end{array}$ & Very evident & \\
\hline $\begin{array}{l}\mathrm{LIBH} 2 \\
\mathrm{D} 1\end{array}$ & 140.5 & $\begin{array}{l}\text { Jaquemontia, Malpighiaceae, } \\
\text { Chamaecrista lineata, Ipomoea, } \\
\text { Euphorbiaceae, and } \\
\text { Leguminosae }\end{array}$ & $\begin{array}{l}\text { Dry tropical hardwood } \\
\text { forest }\end{array}$ & Not evident & \\
\hline $\begin{array}{l}\mathrm{LIBH} 2 \\
\text { D1 }\end{array}$ & 128.5 & $\begin{array}{l}\text { Jaquemontia, Picodendron, } \\
\text { Caesalpinia, and Swietenia }\end{array}$ & $\begin{array}{l}\text { Dry tropical hardwood } \\
\text { forest }\end{array}$ & Not evident & \\
\hline $\begin{array}{l}\mathrm{LIBH} 2 \\
\mathrm{D} 1\end{array}$ & 98.5 & $\begin{array}{l}\text { Acacia, Bauhinia (non-native), } \\
\text { Rubiaceae, Leguminosae, } \\
\text { Euphorbiaceae, Cocothrinax, } \\
\text { Jaquemontia, Acacia, Typha, } \\
\text { Cordia, Ambrosia, Iva, Conyza, } \\
\text { and Agavaceae (c.f. Agave } \\
\text { sisalana) }\end{array}$ & $\begin{array}{l}\text { Dry tropical hardwood } \\
\text { forest }\end{array}$ & $\begin{array}{l}\text { Scattered with } \\
\text { sisal } \\
\text { cultivation }\end{array}$ & $\begin{array}{r}1905 \\
+/-15 \\
\end{array}$ \\
\hline $\begin{array}{l}\mathrm{LIBH} 2 \\
\text { D1 }\end{array}$ & 62.5 & $\begin{array}{l}\text { Acacia, Jacquemontia, } \\
\text { Rubiaceae, Ambrosia, and } \\
\text { Conyza }\end{array}$ & $\begin{array}{l}\text { Dry tropical hardwood } \\
\text { forest }\end{array}$ & $\begin{array}{l}\text { Slightly } \\
\text { evident }\end{array}$ & \\
\hline $\begin{array}{l}\mathrm{LIBH} 2 \\
\mathrm{D} 1\end{array}$ & 40.5 & $\begin{array}{l}\text { Rubiaceae, Jacquemontia, } \\
\text { Leguminosae, Opaque } \\
\text { spherules, Metopium, , Typha, } \\
\text { Conyza, and Spondias (hog } \\
\text { plum - from cultivation) }\end{array}$ & $\begin{array}{l}\text { Dry tropical forest. More } \\
\text { widespread use of } \\
\text { automobiles, and } \\
\text { possibly diesel } \\
\text { generators, motorized } \\
\text { boats, and tractors. }\end{array}$ & $\begin{array}{l}\text { Little (small } \\
\text { farm } \\
\text { clearings) or } \\
\text { not evident }\end{array}$ & \\
\hline $\begin{array}{l}\mathrm{LIBH} 2 \\
\mathrm{D} 1\end{array}$ & 18.5 & $\begin{array}{l}\text { Jacquemontia, Leguminosae, } \\
\text { Metopium, Rubiaceae, } \\
\text { Arecaceae, Swietenia } \\
\text { (mahogany), Passifloraceae, } \\
\text { Cyperaceae, Opaque spherules }\end{array}$ & $\begin{array}{l}\text { Dry tropical forest, with } \\
\text { less fossil fuel } \\
\text { combustion. Potentially } \\
\text { reflecting the loss of } \\
\text { farmers and farm sites. }\end{array}$ & Not evident & $\begin{array}{r}1980 \\
+/-20\end{array}$ \\
\hline
\end{tabular}


Table S3.2: Radiocarbon results from leaf and plant matter in LIBH2.

\begin{tabular}{|l|c|c|c|c|c|c|c|c|}
\hline \multicolumn{1}{|c|}{ Core } & $\begin{array}{c}\text { Laboratory } \\
\text { Number }\end{array}$ & $\begin{array}{c}\text { Core } \\
\mathbf{d e p t h} \\
\mathbf{c m}\end{array}$ & $\begin{array}{c}\text { Material } \\
\text { dated }\end{array}$ & $\begin{array}{c}\text { Conventional } \\
{ }^{14} \mathbf{C} \text { age }\end{array}$ & Error & $\begin{array}{c}\text { F } \\
\text { Modern }\end{array}$ & $\begin{array}{c}\text { F } \\
\text { Modern } \\
\text { error }\end{array}$ & D13C \\
\hline $\begin{array}{l}\text { LIBH2 } \\
\text { D1 }\end{array}$ & OS-146534 & 118.5 & Plant/Wood & 200 & 20 & 0.9753 & 0.0023 & -27.31 \\
\hline $\begin{array}{l}\text { LIBH2 } \\
\text { D1 }\end{array}$ & OS-127198 & 174 & Plant/Wood & 145 & 20 & 0.9820 & 0.0026 & -24.3 \\
\hline $\begin{array}{l}\text { LIBH2 } \\
\text { D1 }\end{array}$ & OS-130637 & 197 & Plant/Wood & 190 & 15 & 0.9766 & 0.0021 & -24.86 \\
\hline $\begin{array}{l}\text { LIBH2 } \\
\text { D1 }\end{array}$ & OS-143921 & 243 & Plant/Wood & 360 & 85 & 0.9560 & 0.0099 & -25.17 \\
\hline $\begin{array}{l}\text { LIBH2 } \\
\text { D1 }\end{array}$ & OS-130782 & 362 & Plant/Wood & 115 & 40 & 0.9856 & 0.0052 & -25.94 \\
\hline $\begin{array}{l}\text { LIBH2 } \\
\text { D1 }\end{array}$ & OS-127824 & 413.5 & Plant/Wood & 290 & 20 & 0.96440 & 0.00230 & -25.94 \\
\hline $\begin{array}{l}\text { LIBH2 } \\
\text { D1 }\end{array}$ & OS-127197 & 517.5 & Plant/Wood & 310 & 20 & 0.9622 & 0.0022 & -26.46 \\
\hline $\begin{array}{l}\text { LIBH2 } \\
\text { D1 }\end{array}$ & OS-127301 & 619.5 & Plant/Wood & 585 & 15 & 0.92950 & 0.00170 & -25.86 \\
\hline $\begin{array}{l}\text { LIBH2 } \\
\text { D1 }\end{array}$ & OS-127196 & 707 & Plant/Wood & 650 & 15 & 0.9222 & 0.0020 & -28.13 \\
\hline $\begin{array}{l}\text { LIBH2 } \\
\text { D1 }\end{array}$ & OS-130781 & 870 & Plant/Wood & 900 & 30 & 0.8940 & 0.0038 & -25.23 \\
\hline $\begin{array}{l}\text { LIBH2 } \\
\text { D1 }\end{array}$ & OS-127194 & 979 & Plant/Wood & 995 & 15 & 0.88370 & 0.00190 & -26.94 \\
\hline
\end{tabular}

Table S3.3: Unused Radiocarbon results from leaf and plant matter in LIBH2 and LIBH1.

\begin{tabular}{|l|c|c|c|c|c|c|c|c|}
\hline \multicolumn{1}{|c|}{ Core } & $\begin{array}{c}\text { Laboratory } \\
\text { Number }\end{array}$ & $\begin{array}{c}\text { Core } \\
\mathbf{d e p t h} \\
\mathbf{( c m}\end{array}$ & $\begin{array}{c}\text { Material } \\
\text { dated }\end{array}$ & $\begin{array}{c}\text { Conventional } \\
{ }^{\mathbf{1 4}} \mathbf{C} \text { age }\end{array}$ & Error & $\begin{array}{c}\mathbf{F} \\
\text { Modern }\end{array}$ & $\begin{array}{c}\text { F } \\
\text { Modern } \\
\text { error }\end{array}$ & D13C \\
\hline $\begin{array}{l}\text { LIBH2 } \\
\text { D1 }\end{array}$ & OS-146535 & 19 & Plant/Wood & -6 & 0.5 & 1.0272 & 0.0021 & -26.83 \\
\hline $\begin{array}{l}\text { LIBH2 } \\
\text { D2 }\end{array}$ & OS-144104 & 26.5 & Plant/Wood & -6.15 & 1 & 1.0378 & 0.0024 & -27.04 \\
\hline $\begin{array}{l}\text { LIBH2 } \\
\text { D1 }\end{array}$ & OS-127838 & 246 & Plant/Wood & 340 & 15 & 0.95840 & 0.00200 & -26.03 \\
\hline $\begin{array}{l}\text { LIBH2 } \\
\text { D1 }\end{array}$ & OS-127195 & 838 & Plant/Wood & 1,410 & 15 & 0.8388 & 0.0017 & -7.68 \\
\hline $\begin{array}{l}\text { LIBH1 } \\
\text { D1 }\end{array}$ & OS-144130 & 399.5 & Plant/Wood & 1,260 & 110 & 0.8544 & 0.0112 & $\begin{array}{c}\text { Not } \\
\text { measured }\end{array}$ \\
\hline
\end{tabular}




\title{
4. Sedimentary deposits of paleohurricane activity for the past 1500 years captured in a transect of cores from a blue hole off Middle Caicos in the Turks \& Caicos Islands
}

\author{
Abstract \\ Caribbean islands are particularly vulnerable to both sea-level rise and tropical cyclone induced \\ flooding. Unfortunately, both the short observational record of hurricanes in the Atlantic and \\ limited knowledge on storm surge generation during hurricanes of different strength, size and \\ orientation limit our ability to assess flooding risk on these island nations. Here, we present a \\ transect of cores collected from a blue hole off Middle Caicos in the Turks \& Caicos Islands. \\ Thick storms deposits found across cores in the transect record the passage of Category 1 and \\ above hurricanes passing to the south of Middle Caicos over the past 1500 years including \\ Hurricane Kate in 1985 and Hurricane Irma in 2017. The record indicates historically \\ unprecedented multi-decadal periods of elevated storm strikes on the island. We add this new \\ reconstruction to a growing compilation of annually-resolved paleohurricane records of the past \\ millennium in The Bahamas. This compilation indicates increased storm activity in The \\ Bahamas from 650-800 CE, 930-1060 CE, and 1400-1800 CE. Taken together with new \\ compilations of published paleohurricane records from New England and northwest Florida, we \\ observe both basin-wide periods of elevated hurricane activity over the past millennium and \\ periods when New England is active while the Bahama Archipelago and Florida are not. We \\ argue that both regional changes in the vertical wind shear patterns and shifting populations of \\ storm tracks can explain the disconnect we observe in paleohurricane patterns in different \\ regions of the North Atlantic.
}

\subsection{Introduction}

Tropical cyclones (TCs) induce strong winds, storm surge and heavy rain which cause massive losses in coastal communities both in terms of economics and human lives. The expected annual economic losses in the U.S. from hurricane winds and tropical cyclone induced flooding total to $\$ 54$ billion (Congressional Budget Office, 2019). These damages will likely only increase moving into the next century with projected increases in tropical cyclone intensity, rising sea levels and growing coastal populations (Knutson et al., 2020). Unfortunately, there is still significant uncertainty on how tropical cyclones will change regionally. The current set of 
tropical cyclone observations is limited by data quality issues (Frappier, Knutson, et al., 2007; Villarini et al., 2011; Landsea et al., 2004; Landsea and Franklin, 2013; Vecchi and Knutson, 2008; Landsea et al., 2010; Vecchi and Knutson, 2011) and only extends back over the past 169 years (1851-2020 CE). Providing coastal communities with longer term information on the scale and probability of tropical cyclone events is important for the sustainable development of these areas moving into the future.

There is a growing number of paleohurricane reconstructions from geologic archives that extend observations of landfalling hurricanes back thousands of years (e.g., Donnelly et al., 2015; Lane et al., 2011; Bregy et al., 2018; Boldt et al., 2010; Mallinson et al., 2011). The majority of these studies are concentrated along the North American coastline. In recent years, this work has expanded into new environments in the tropical Atlantic. In particular, recent studies have obtained Common Era paleohurricane records from sediment cores in blue holes scattered across the hurricane-prone tropics (Wallace et al., 2019 (Chapter 2); Denommee et al., 2014; van Hengstum et al., 2014; Winkler et al., in review). These basins serve as giant traps for coarse-grained sediment suspended and transported during storm events. They are often surrounded by high-energy shallow carbonate platforms with adjacent reefs which offer an abundant regional sediment supply (Shinn et al., 1996; Gischler et al., 2008). These relatively deep holes ( 12-100 $\mathrm{m}$ ) allow for plentiful accommodation space for sediment accumulation and anoxic to dysoxic bottom-water conditions that prevent bioturbation (Wallace et al., 2019 (Chapter 2); Gischler et al., 2008).

In past few years, three studies (Wallace et al., 2019 (Chapter 2); Winkler et al., in review; Wallace et al., Chapter 3) have reconstructed hurricane activity over the past millennium from blue holes in The Bahamas. All of these reconstructions capture modern coarse-grained deposits that date to known historical hurricanes passing proximal to each site. For example, a study from Thatchpoint blue hole in Abaco Island, The Bahamas captured coarse sediment deposits corresponding to the passage of Hurricane Jeanne 2004 and Hurricane Floyd 1999 (van Hengstum et al., 2014). Sediment cores from Long Island in The Bahamas (Chapter 3) captured a deposit from Hurricane Joaquin in 2015. All of these records indicate century-scale changes in hurricane activity over the past millennium. Each island experienced extended periods of elevated storm strikes interspersed with periods of fewer storm landfalls. These reconstructions taken together have allowed us to better understand how hurricane activity in The Bahamas has 
changed over the past couple of thousands years. With only $\sim 160$ years of observations of hurricane strikes in this region (Knapp et al., 2010), this data allows us to constrain how Bahamian hurricane activity changes on long timescales (multi-decadal to centennial scale).

Constraining how these documented long-term changes in hurricane activity relate to climate is more difficult. Quantifying the role random variability plays in shaping Caribbean paleohurricane records is challenging. Wallace et al. (Chapter 3) noted that the timing of active hurricane periods reconstructed in blue hole records from neighboring islands in The Bahamas (< $500 \mathrm{~km}$ away from each other) are at times different. In the last 500 years, for example, records from South Andros, Long Island, and Abaco Island in The Bahamas were active from 1500-1670 CE, 1570-1780 CE, and 1760-1860 CE, respectively. Each single paleohurricane reconstruction only captures changes in storm activity at or near its location. In order to capture a regional hurricane signal, one must compile records from across the Caribbean together to capture a representative population of storms passing through this area. Wallace et al. (Chapter 3) presented the first compilation of paleohurricane activity from The Bahamas pulling together records from Abaco Island, Long Island, and South Andros Island. This compilation indicates several centennial-scale periods of elevated hurricane activity over the past millennium that match with other records from the U.S. coastline (Denommee et al., 2014; Donnelly et al., 2015; Lane et al., 2011). In this paper, we add a new high resolution record from the Bahama Archipelago and update this compilation.

Another source of uncertainty in paleohurricane records from blue holes is our limited understanding of the sediment transport mechanisms at play during hurricane landfalls. In general, we find that many of these blue hole sites (Wallace et al., Chapter 3, Wallace et al., 2019 (Chapter 2); Winkler et al., in review) capture more intense storms ( $\geq$ Category 2 ) passing close to the site ( $<100 \mathrm{~km}$ radius). However, we largely don't understand what hydrodynamic processes are most important for creating these deposits. In Chapter 3, we used a low resolution hydrodynamic model SLOSH (Sea Lake and Overland Surges from Hurricanes) (Jelesnianski et al., 1992) to simulate storm surge at a blue hole site on Long Island in The Bahamas. We found that the proximal passing intense storms ( $\geq$ Category 3$)$ traveling to the south or west of the island did not create much storm surge near the blue hole. Instead, some of these southwardpassing storms suck water off the bank instead of piling it up. Meanwhile, lower intensity (Category 2 storms) passing to the east of the site create more storm surge. From these 
simulations, we conclude that the orientation of the storm with respect to the blue hole site is an important factor in determining if an event is capable of inducing coarse-grained sediment transport. In addition, other recent work from South Andros Island in The Bahamas (Wallace et al., 2019 (Chapter 2)) shows that blue holes in the same environment (in some cases just kilometers away from each other) can capture coarse deposits from different storm passages. Both of these studies have made it apparent how much there is still left to learn about hydrodynamic conditions and sedimentary processes on these shallow carbonate banks that influence event-bed deposition.

There have been many studies of Holocene sedimentary processes on The Caicos platform in the past few decades (Dravis and Wanless, 2017; Wanless, Tyrrell, et al., 1988; Wanless, Tedesco, et al., 1988; Trower et al., 2019, 2018). Some of these studies have focused on the impacts of recent hurricanes and the formation of tempestites on the platform. In particular, Wanless et al. (1988a; 1988b) documented the impacts of Hurricane Kate in 1985 on the North and Middle Caicos tidal flat system. They found evidence for resuspension of finer sand and silts and strong bedload movement of coarser sands during this relatively low intensity storm. In particular, they documented storm infilling of shrimp (Calliannassa) burrows in the Caicos platform interior (Wanless, Tedesco, et al., 1988) and layers of peloidal grainstone dumped across shore levees and inland algal marsh on North Caicos (Wanless, Tyrrell, et al., 1988).

In this study, we build off the existing literature on sedimentology of the Caicos platform and explore paleohurricane sediment deposition in a previously unstudied blue hole off the coast of Middle Caicos. We reconstruct storm activity over the past millennium on Middle Caicos including modern storms like Hurricane Irma in 2017 and Hurricane Kate in 1985. This study presents the first transect of cores across a blue hole basin and documents a lateral sorting in the grain size of modern events from the ocean side of the blue hole to the island side. We use this record to discuss the temporal variability in hurricane strikes on Caicos Island but also to explore some of the sediment processes at play in blue hole environments. 


\subsection{Methods}

\subsubsection{Study sites}

The Caicos platform is located at the southern tip of the Bahama archipelago. The platform geometry is $100 \mathrm{~km}$ by $70 \mathrm{~km}$ with the northern margin exposed to the Atlantic Ocean. The platform interior is sheltered predominately by a ring of islands and a barrier reef to the north. The three main land areas to the north of the platform interior are North, Middle, East Caicos (Figure 4.1). They are separated by tidal channels and rimmed with carbonate tidal flats extending out 6-12 km in width on their southern margins. The Caicos platform interior extends out almost $\sim 50 \mathrm{~km}$ in length and the southern margin is rimmed by sand banks and patch reefs (Wanless, Tedesco, et al., 1988; Wanless, Tyrrell, et al., 1988).

Other than tropical cyclones traveling up from the south, there is no onshore process to push sediment-laden waters onto the tidal flats of Middle Caicos Island. The platform experiences prevailing easterly winds throughout the year which generally run parallel to the island shore (Dravis and Wanless, 2017). Winter storms generate offshore directed winds, characterized by stronger winds to the northwest, north, and northeast (Wanless, Tedesco, et al., 1988).

About $2 \mathrm{~km}$ from the edge of the tidal flats ( $6 \mathrm{~km}$ from the vegetated upland) on Middle Caicos Island (at $21.72^{\circ} \mathrm{N}, 71.81^{\circ} \mathrm{W}$ ) is an unusually wide blue hole spanning almost $0.5 \mathrm{~km}$ in diameter. It is situated approximately $50 \mathrm{~km}$ north of southern end of the Caicos platform nestled up against southern shore of Middle Caicos Island (Figure 4.1). The blue hole itself is $60 \mathrm{~m}$ deep while the surrounding shallow platform is 0-2 m deep. This platform offers an ample supply of sediment to the hole. Most of sediment on the platform interior is grain-dominated with mapping studies indicating that $59 \%$ of the platform contains a mud-lean $(<10 \%)$ packstone. Moving closer to the island's southern margins, sediment becomes more matrix-dominated (Wanless, Tedesco, et al., 1988; Kaczmarek and Hasiuk, 2008). The surface sediment surrounding the Middle Caicos blue hole is matrix-dominated characterized by mostly fine grained carbonate mud with some 100 to $400 \mu \mathrm{m}$ sized particles and larger (>2 mm) shell fragments. Conductivitytemperature-depth (CTD) casts from the hole indicate a well-defined thermocline and halocline at approximately $30 \mathrm{~m}$ in depth. A dissolved oxygen profile from the hole indicates anoxic to dysoxic conditions for approximately the bottom $30 \mathrm{~m}$ of the water column (Figure S4.1). 
The Caicos Platform is impacted by tropical cyclones frequently (coast.noaa.gov/hurricanes, 2019). Since $1850 \mathrm{CE}$, sixty-two storms have been recorded passing either directly over or nearby (within $100 \mathrm{~km}$ ) of the Caicos platform. Only 27 of those storms were hurricane strength when they passed Caicos with a little less than half of them categorized as intense hurricanes ( $\geq$ Category 3 on the Saffir Simpson scale). Like many other locations in North Atlantic basin (Hall and Hereid, 2015), Turks \& Caicos experienced very few intense storms in the 2010s. Hurricane Irma in 2017 was the first intense hurricane to significantly impact the island since Hurricane Ike in 2008. Hurricane Irma passed approximately $75 \mathrm{~km}$ to the south of Middle Caicos at Category 5 strength with max sustained winds at $\sim 140$ knots. On South Caicos and Providenciales, approximately $70 \%$ of homes were destroyed. The economic losses on Providenciales are estimated at 500 million USD (Aon Benfield, 2018). Recent field studies on Little Ambergis Cay, a small island to the south of Turks \& Caicos, document small, ungraded washover fans deposited during Hurricane Irma (Jamison-Todd, 2019).

\subsubsection{Field program}

In April 2016, we collected a transect of cores from Middle Caicos blue hole using a Rossfelder P-3 vibracore from the RV Arenaria, a customized 6-m pontoon vessel. We collected three long vibracores, CAOS7 (14 m), CAOS1 (12m), and CAOS5 (12.5 m), along a transect moving northwest across the blue hole (Figure 4.1). Each core was taken approximately $100 \mathrm{~m}$ away from the next with CAOS7 $\left(21.719^{\circ} \mathrm{N}, 71.812^{\circ} \mathrm{W}\right)$ taken on the southeast side (ocean side) of blue hole, CAOS1 $\left(21.720^{\circ} \mathrm{N}, 71.812^{\circ} \mathrm{W}\right)$ in the middle, and CAOS5 $\left(21.721^{\circ} \mathrm{N}, 71.812^{\circ} \mathrm{W}\right)$ collected from the northwest side (island side) (Figure 4.1C). All three of these longer cores did not include the sediment-water interface. Therefore, we also collected shorter ( 1-2 m long) surface drives where we carefully curated the top. The data from the first $39 \mathrm{~cm}, 72 \mathrm{~cm}$, and 43 $\mathrm{cm}$ of CAOS7, CAOS1 and CAOS5, respectively, originate from their respective surface drives. We pinpointed the overlap using both the coarse fraction data and optical images from the cores (Figure S4.2).

In June 2019, we returned to the site to assess the impacts of Hurricane Irma on the blue hole environment. We collected a shorter surface drives XCAOS2 $(1.3 \mathrm{~m})$ from the blue hole using the Rossfelder P-3 vibracore from an inflatable raft. Again, we found the overlap between these surface drives and the surface cores from 2016 using both the coarse fraction data and 
optical images from the cores (Figure 4.2). To create our final coarse fraction record, we added the data from the first $25 \mathrm{~cm}$ of XCAOS2 to the top of the CAOS7 record.

\subsubsection{Sediment Analysis}

We sectioned the cores in the field and then shipped them back to the lab where they were split and described. At Woods Hole Oceanographic Institution (WHOI), we took optical scans of each core section on the ITRAX X-ray fluorescence scanner (Figure 4.2). Then, we measured the coarse fraction by dry weight at $1 \mathrm{~cm}$ intervals down the length of these sediment cores (CAOS7, CAOS1, CAOS5, XCAOS2) following established procedures (Wallace et al., 2019). The sediment processing procedures consists of four steps: 1) Sampling the core, 2) Drying the samples ( 8 hours in $100^{\circ} \mathrm{C}$ ), 3) Sieving them at $63 \mu \mathrm{m}$, and 4) Drying and weighing the residual. Using both the coarse fraction data and the optical images of each section, we visually correlated the stratigraphy across cores in the transect (CAOS7, CAOS1 and CAOS5) (Figure 4.2 and 4.3).

\subsubsection{Chronology}

Plant matter samples were radiocarbon dated at the National Ocean Sciences Accelerator Mass Spectrometry Facility (NOSAMS) at WHOI. We pulled samples from all three of the cores in the transect (CAOS7, CAOS1 and CAOS5). We pulled 18, 2, and 20 samples from CAOS7, CAOS1 and CAOS5, respectively (Tables S4.1 and S4.2). We referenced all of the depths of the samples from CAOS5 and CAOS1 to our longest core (CAOS7) using our correlated stratigraphy. We also removed all event beds prior to age modeling since we interpret them to reflect near-instantaneous deposition. All event beds were condensed down to $1 \mathrm{~cm}$ in thickness and reinserted following age-depth estimation.

Initially, we assumed that most of the plant matter we were dating was mangrove leaf samples derived from the neighboring tidal flats. The majority of terrestrial plants including mangrove plants (Rao et al., 1994) exhibit C3 photosynthesis with Carbon-13 $\left(\delta^{13} \mathrm{C}\right)$ signatures ranging from -20 to $-37 \%$ (Kohn, 2010). Only 12 of our radiocarbon samples contain Carbon-13 signatures falling within this range (Table S4.1). However, 27 of our samples exhibited an unusually enriched Carbon $13\left(\delta^{13} \mathrm{C}\right)$ signature, ranging from -5.4 to $-14.4 \%$ (Table S4.2). Such enriched Carbon-13 values are typically associated with CAM or C4 plants which include aquatic plants and algae (Wefer and Killingley, 1986; Duarte et al., 2018; Deines, 1980). 
Unfortunately, it is really difficult to date marine plants and algae, because they take up some of their carbon from the ocean. This creates a 'reservoir effect' where these marine organisms date older than they actually are (Deines, 1980). Indeed, many of our enriched $\delta^{13} \mathrm{C}$ samples appear $\sim 400$ years to old (Figure 4.4). There are variety of different species of seagrass and algae present on the Caicos platform. Previous work on North and Middle Caicos noted the prevalence of Scytonema algal mats (Wanless, Tyrrell, et al., 1988). This tufted blue green algae grows in several $\mathrm{cm}$ thick mats all over the south-facing shore levees and channel levees on Middle Caicos. It's possible that storm events rip up pieces of these algal mats and dump them into the blue hole. Alternately, we could be dating sea grass pieces transported into the blue hole during storm events. There are three different species of sea grasses commonly found on the Caicos platform: turtle grass (Thalassia testudinum), shoal grass (Halodule wrightii), and manatee grass (Syringodium filiforme) (Paddock et al., 2018). Studies show that all three of these marine grass species have enriched $\delta^{13} \mathrm{C}$ signatures (Hu et al., 2012; Campbell and Fourqurean, 2009). Unfortunately, since the reservoir correction varies quite dramatically throughout the ocean, and we were not able to identify exact what plant material we are dating, we could not accurately reservoir correct these samples. Therefore, we did not include any of these dates in our final age model (Figure S4.3).

Our age model consists of 11 dates over $941 \mathrm{~cm}$ (Figure 4.4 and Table S4.1). We created the age model in Bayesian accumulation histories for deposits (BACON) software version 2.2 (Blaauw and Christen, 2011). All the dates were calibrated using the IntCal13 (Reimer et al., 2013). We excluded two additional dates that did not exhibit the enriched $\delta^{13} \mathrm{C}$ signature (Figure 4.4), because they were not chronologically consistent with the rest of the dating evidence.

\subsubsection{Event thresholds and frequency}

To establish event frequency changes on Middle Caicos, we identified events beds in the longest core CAOS7 through a combination of interpreting the stratigraphy from the optical scans and the coarse fraction data (Figure 4.5). We used the optical scans to identify visual event beds in all three cores. Visual cues for event beds include: lighter colored sediments topped with darker colored sediment, visibly coarser grains, higher concentrations of organics, and no laminations (Figure 4.2). Any peak in coarse fraction data that corresponded to the presence of any of these visual cues was counted as an event bed. We also documented whether each 
identified event bed in CAOS7 could be tracked across the transect of cores (i.e., in CAOS1, in CAOS5) (Figure 4.3).

Independent of the optical scan data, we identified event beds using only the coarse fraction data from CAOS7. We followed the methods originally established in Donnelly et al. (2015) to set an event threshold. This method involves two steps: 1) Calculate the coarse anomaly using a 10 point moving filter from the data (excluding coarse fraction peaks over $25 \%$ ), and 2) pinpoint coarse anomaly peaks that exceed two sigma of the cumulative distribution function of the data over the observational interval (1851-2019). The threshold for CAOS 7 is $27.7 \%$ (Figure S4.4).

We calculated event frequency per century in a 100-year moving window using the visually identified event beds in CAOS7 (Figure 4.5). We define active and quiet intervals using established methods (See Wallace et al., 2019; Lane et al., 2011; Donnelly et al., 2015). Assuming event occurrence follows a Poisson process, we estimate a site specific expected event

frequency for our site. Given that 74 storms left deposits in the CAOS7 core over the past 1550 years, expected event frequency at CAOS is approximately 4.8 events/century. We calculated a 95 percentile upper confidence bound (Ulm, 1990) above our expected frequency at 5.8 events/century, respectively. Active intervals are extended periods of time when the 100-year window frequency exceeds this upper confidence bound (Figure 4.5).

Quiet intervals, on the other hand, are defined using methods established in Wallace et al. (2019). We set the recurrence interval for hurricane strikes at CAOS to 20.9 year/event using 74 storms that left a deposit in CAOS7 over the whole record (467-2019 CE). Quiet intervals were set as extended time steps ( $>50$ years) between events when the probability of having no events across this time step is below 50\% (Figure 4.5).

\subsection{Results}

\subsubsection{Correlating event beds across cores}

The sediment stratigraphy in the CAOS cores alternates between laminated to semilaminated fine grained carbonate mud and thick coarse-grained (predominantly very fine sand to coarse sand sized) beds. There is no evidence for bioturbation in the cores (Figure 4.2). The background is light grey (Munsell color 2.5Y 8/1) fine-grained carbonate sediment with white (Munsell color 7.5YR 8/0) and dark brown (Munsell color 5YR 6/2) laminations. The coarse 
beds are denoted by abrupt contacts and a fining upward sequence. The thickness of coarse beds varies from 1 to $100 \mathrm{~cm}$ with average coarse bed thickness at $7.7 \mathrm{~cm}$. Many of the larger event beds contain larger $(\sim 1 \mathrm{~mm})$ white shell fragments concentrated at the bottom of the event bed. Typically, the event beds are characterized by lighter cream colored sediment (Munsell color 5 YR 8/2) topped with a darker tan (Munsell color 5YR 7/2) fine-grained sediment (Figure 4.2).

Darker colored fine grained sediment blankets appear at the top of many of the coarse beds range from 1 to $6 \mathrm{~cm}$ in thickness (Figure 4.2). The thickness of these deposits speaks to the volume of fine grained sediment that is suspended and then gradually settles on the Caicos platform after storm events. Indeed, local pilots observed suspended plumes of mud and low visibility on the Caicos platform over 15 days after the passage of the low intensity Category 1 Hurricane Kate in 1985 (Wanless, Tedesco, et al., 1988).

The CAOS7 core exhibits a relatively uniform and high sedimentation rate at approximately $0.6 \mathrm{~cm} /$ year. We identified 74 event beds visually in CAOS7 over the past 1550 years (Figure 4.5). Only 58 of these events were identified using the coarse fraction threshold (Figure S4.4). The average event frequency on Middle Caicos is 3.9 events/century. We correlated stratigraphy across CAOS7, CAOS1, and CAOS5 identifying the same sequences of laminations and thick coarse beds (Figure 4.2). All but three event beds found in CAOS7 were identified at least one other core in the transect. Over the top $1255 \mathrm{~cm}$, we identified 69 events in CAOS7; 62 and 53 of them were found in CAOS1 and CAOS5, respectively (Figure 4.3). There were no event beds identified in either CAOS1 or CAOS5 that could not be visually correlated to a bed in CAOS7.

As each of these cores were taken approximately $100 \mathrm{~m}$ from each other (Figure 4.1), we did not expect all the events in the CAOS7 core to be contained in both CAOS1 and CAOS5. The CAOS blue hole is located in a small cove in the Middle Caicos tidal flat system (Figure 4.1). It is open to the ocean from the southeast and bordered to the west by an extending section of the tidal flat system. We assume that most storms moving north and west across the Caicos platform interior generate onshore directed winds and waves that are funneled into this cove. Therefore, we collected our transect of cores (CAOS7, CAOS1, CAOS5) moving in a north west line across the blue hole. We expect more event beds to be captured in the ocean side core (CAOS7) than the island side core (CAOS5). We also expect a landward fining trend in grain size moving across the transect. Indeed, the max coarse fraction data for event beds in CAOS7, 
CAOS1, and CAOS5 ranged from 88\%, 80\%, and 74\% sand-sized (>63 $\mu \mathrm{m}$ ) or larger particles, respectively. As CAOS7 contains the most complete record of events striking the site, we used the event beds identified in the CAOS7 core to establish the temporal frequency of events on Middle Caicos.

\subsubsection{Changing event frequency}

Using the CAOS7 record with the visually identified event beds (Figure S4.2 and Appendix A), we identify five multi-decadal (>50 consecutive years) active periods on Middle Caicos over the 1550 years as defined by the 100-year window event frequency from 660-725 CE, 960 -1100 CE, 1550-1655 CE, 1675-1840 CE and 1850-1910 CE (Figure 4.5). The period with the highest activity on Middle Caicos over the past 1550 years is from 1675-1840 CE with an average event frequency of 8.6 events/century. These active periods are replicated in the 50year window event frequency (Figure S4.5). Middle Caicos also experienced long hurricane 'droughts', or greater than 50-year periods where no storms left deposits. We found six such quiet periods from 466-565 CE, 587-657 CE, 727-778 CE, 796-862 CE, 1438-1510 CE, and 1966-2017 CE (Figure 4.5).

Most of these event frequency patterns are reproduced using just the grain size threshold (Figure S4.4). An important difference between the two methods occurs in the late $17^{\text {th }}$ century. The grain size threshold method does not capture higher activity from 1675-1775 CE. Indeed, we identified six visual event beds over this time span that had peaks in grain size below the $95 \%$ grain size threshold (27.7\%). Given that these beds involve a peak in grain size, can be visually distinguished in CAOS7, and tracked across a transect of cores, we argue that they do in fact represent storm deposits. Using visual cues in addition to peaks in grain size is a more exact method for identifying coarse deposits. Coarse fraction thresholds are useful for cores where not all event beds can be distinguished visually. However, if all event beds can be distinguished visually (as is the case for CAOS7), an arbitrary coarse fraction threshold is likely more conservative estimate of which peaks are coarse deposits. 


\subsection{Discussion}

\subsubsection{Event Attribution}

To assess the sensitivity of our Middle Caicos blue hole sediment reconstruction to different types of passing hurricanes, we investigate which recent storms have left coarse event beds in our sediment cores. Over the observational period, twenty-seven hurricanes (Category 1 and above) have passed within $100 \mathrm{~km}$ of the Middle Caicos blue hole (Figure S4.6a). Most of these storms can be characterized as Cluster 3 or 4 storms that form far to the south east of the site off the west coast of Africa ('Cape Verde' hurricanes) or in the Main Development region to the east of the Lesser Antilles (Figure S4.6b) and pass the Caicos platform in southeasterly direction. Of these 27 historical storms, 11 storms passed to the south of the site. The other sixteen passed to the north or west (Figure S4.7).

North, Middle and East Caicos islands form a crescent shape to the north of the Caicos platform interior (Figure 4.1). This nearly continuous string of islands including a barrier reef to the north provides protection for the platform interior. The Middle Caicos blue hole is nestled up against the southern side of one of these islands which makes our site more protected from storms passing north of Middle Caicos as compared to storms passing from south. When hurricanes pass to the south of Middle Caicos, the front right quadrant of each storm impacts the southern side of the island. The front right quadrant of a hurricane is generally considered to be the most destructive part of the storm, because the rotational winds and storm motion are in the same direction. Thus, southward passing hurricanes generate the strongest onshore directed winds piling water on the southern side of Middle Caicos Island. Storms passing to the north, on the other hand, will generate offshore directed winds on the platform interior as the front end of the storm passes. The wind patterns switch as the back end and less intense part of the storm

passes over the site creating onshore directed winds. How these onshore directed winds translate into storm surge and increased wave height will depend on the size of the storm and its distance from the site. If the storm passes close enough to the site that the radius of maximum winds (RMW) falls over the Caicos platform interior, there is likely to be increased wave energy and on-shore bottom currents than if the storms passes too far away for its RMW to intercept the platform interior.

In addition, southward passing storms will generally generate larger waves than northward passing storms. Wave height is affected by the fetch or the distance over water that 
wind blows in a single direction. Ultimately, waves created from onshore directed winds from northward passing storms will be fetch limited compared to their southward passing counterparts. Waves generated from storms passing to the south of the Caicos Islands will travel over the entire distance of the Caicos platform uninterrupted. Waves from northward passing storms will only have a fetch equal to how far the storm wind field extends over the Caicos platform. In general, we argue that storms passing to the south of Middle Caicos are better suited to generate on-shore directed sediment transport to leave the coarse-grained deposits we find in the Middle Caicos blue hole than their northward-passing counterparts.

CAOS7 includes nine coarse event beds that date within uncertainties to the observational period (1851-present) (Figure 4.6). The average age uncertainty for each of these events is \pm 42 years. With the high density of storms that have passed the Caicos Platform in the past century and a half and the high age uncertainty associated with each event, it is very difficult to tie each event to any one storm event with a high degree of confidence. Fortunately, we collected surface sediment cores from the Middle Caicos blue hole in 2019, after Hurricane Irma's passage in 2017. The surface core (XCAOS2) contains a single new event bed starting at $3 \mathrm{~cm}$ down in the core and extending approximately $21 \mathrm{~cm}$ in depth. Only two storms (Hurricane Irma and Hurricane Maria in 2017) passed with $100 \mathrm{~km}$ of Turks \& Caicos from 2016-2019 CE (Figure 4.6 and S4.6).

Hurricane Irma originated off the coast of west Africa on August 27, 2017. Meeting with favorable environmental conditions as it crossed the Atlantic, Irma rapidly intensified to Category 5 intensity by September $6^{\text {th }}$ when it made landfall on the north coast of Barbuda. Irma moved west-northwestward and passed $65 \mathrm{~km}$ to south of the Turks \& Caicos Islands with max sustained winds greater than $70 \mathrm{~m} / \mathrm{s}$ on September $8^{\text {th }}$ (Cangialosi et al., 2018). The front right quadrant of the storm swept over the Caicos for over 2 hours. Unfortunately, observing systems on the islands failed during the peak of Irma, but reports from the island indicated extensive property damage and flooding. On South Caicos, almost $75 \%$ of roofs were ripped off in the storm (Cangialosi et al., 2018). Hurricane Maria, on the other hand, passed approximately $96 \mathrm{~km}$ to the northeast of the Caicos platform at Category 3 strength. Middle Caicos was well outside Maria's radius of maximum winds (RMW: 46 km); an observing station on Providenciales recorded maximum sustained winds at $21 \mathrm{~m} / \mathrm{s}$ with $25 \mathrm{~m} / \mathrm{s}$ gusts. Damages reported on Turks \& Caicos during Maria were minimal (Pasch et al., 2019). Therefore, we attribute Event bed 1 to 
Hurricane Irma. Hurricane Irma provides a modern analog that allows us to discern some of the properties of landfalling storms on the Caicos platform that leave coarse-grained deposits in the Middle Caicos blue hole.

The second and third event beds occur from 48-66 cm and 88-92 $\mathrm{cm}$ into CAOS7 and date between 1910-1986 CE (median age: 1966) and 1872-1964 CE (median age: 1945), respectively. Four hurricanes passed with $100 \mathrm{~km}$ of Middle Caicos from 1940-1985 CE: Hurricane Kate in 1985, Hurricane Donna in 1960, Hurricane Betsy in 1956, and a 1945 Category 3 hurricane. Both Hurricane Donna and Betsy passed approximately $40 \mathrm{~km}$ and $50 \mathrm{~km}$, respectively, to the north of the Middle Caicos blue hole (Figure S4.7). Unfortunately, before the 1980s, there are limited observations of the radius of maximum winds (RMW) of hurricanes. Neither Donna nor Betsy have recorded RMW values as they passed Turks and Caicos. Using the Best Track data from 1988-2018 CE (Knapp et al., 2010), the average RMW for Atlantic storms passing from $20-27^{\circ} \mathrm{N}$ is $\sim 41 \mathrm{~km}$ (standard deviation: $20 \mathrm{~km}$ ). Assuming that both of these storms had a RMW at $41 \mathrm{~km}$ when they passed Middle Caicos, only Donna's RMW passed over the Middle Caicos blue hole. However, there is little evidence for significant destruction on Turks \& Caicos as a result of Hurricane Donna. Observations from Grand Turk suggest relatively modest maximum sustained winds $(23-25 \mathrm{~m} / \mathrm{s})$ during the peak of Donna. Most of the observed damages were a result of rainfall-related flooding (Dunn, 1961). Sheltered by northward facing reefs and islands, we argue that it is unlikely that the platform interior including the CAOS blue hole was significantly impacted by either Donna or Betsy.

Hurricane Kate in 1985 and the 1945 storm, on the other hand, passed to the south of Middle Caicos over the platform interior. Hurricane Kate moved east to west across the Caicos platform (passing within $13 \mathrm{~km}$ of the CAOS blue hole) at Category 1 strength (winds of $41 \mathrm{~m} / \mathrm{s}$ ) on November 18, 1985. Wanless et al. (1988) observed changes to the subtidal marine environment around North and Middle Caicos after this storm. The authors observed many signs that bottom currents on the platform were strong enough to suspend and transport coarse sediment during Hurricane Kate. Wave action during Kate scoured the bottom, caused resuspension of the finer sands and silts, and caused bedload transport of coarse sediments. In particular, the authors observed widespread flattening of burrowing shrimp (Callianassa) mounds and infilling of Callianassa burrow holes post-Hurricane Kate (Wanless, Tedesco, et al., 1988). The authors also found small coral head patches with skeletal gravel built up against the 
southern sides suggest high volumes of moving sediment driven by northerly winds. Further studies observed a 3-10 cm thick sediment layer characterized by 100-400 $\mu \mathrm{m}$ sized grains deposited on the subtidal ramp on the east and southeast facing shorelines of the North and Middle Caicos (Wanless, Tyrrell, et al., 1988). Given all of this documented evidence for both coarse and fine sediment suspension during Hurricane Kate, we attribute Event bed 2 to Hurricane Kate.

The 1945 hurricane passed approximately $40 \mathrm{~km}$ to the south of Middle Caicos at Category 3 strength with max sustained winds at $49 \mathrm{~m} / \mathrm{s}$ on closest passage. We attribute Event bed \#3 to this storm given that it was more intense than Hurricane Kate and also passed over the platform interior likely generating onshore directed winds and currents.

The next two event beds (Events 4 and 5) are placed at 101-123 cm and 137-156 cm. They date to 1859-1953 CE (median age: 1937) and 1838-1940 CE (median age: 1913). Seven hurricanes passed with $100 \mathrm{~km}$ of Middle Caicos from 1900-1940 CE: two storms in 1933, a 1932 Category 3 storm, a 1928 Category 4 storm, two 1926 storms, and a 1906 Category 3 storm Figure 4.6 and S4.6). Only two of these storms passed to the south of Middle Caicos Island. The 1928 Category 4 storm, also known as 'The Great Okeechobee Hurricane', passed across the Caicos platform interior moving to the north-west. Much like Hurricane Kate in 1985, it passed within $12 \mathrm{~km}$ of the CAOS blue hole but this time at Category 4 strength with wind speeds up to $69 \mathrm{~m} / \mathrm{s}$. Observations from after the storm suggest that most of the Caicos Islands were wiped clean of vegetation, and there was significant damage to most buildings on the islands (Neely, 2014). Given that this storm passed so close to our blue hole site and generated on-shore directed winds and current, we attribute Event bed 4 to the 1928 Great Okochobee hurricane. We attribute Event bed 5 to the only other storm that passed to the south of Middle Caicos in the early 1900's: the 1926 Category 2 July hurricane. This storm followed a similar trajectory to 1928 hurricane (Figure 4.6 and S4.6). It moved northwest across the Caicos platform passing with $30 \mathrm{~km}$ of the CAOS blue hole with wind speeds reaching up to $47 \mathrm{~m} / \mathrm{s}$.

The grain size and bed thickness of Events 4 and 5 bolster our argument that they were produced by the passage of the very intense Category 41928 hurricane and the less intense Category 21926 hurricane, respectively. Event 4 is characterized by a thicker bed with larger grains (Figure S4.8) than Event 5. Event 4 in CAOS7 has a median diameter (D50) of $182 \mu \mathrm{m}$ and stretches over $22 \mathrm{~cm}$. Event 5 in CAOS7, on the other hand has a D50 of $145 \mu \mathrm{m}$ stretches 
over $19 \mathrm{~cm}$. We expect that a more intense and closer passing storm like the 1928 hurricane transport both more and larger-sized sediment particles into the CAOS blue hole.

All of the other storms approaching Turks \& Caicos in the early $20^{\text {th }}$ century passed on the northern side of the Caicos Island with varying levels of storm intensity and distance from the blue hole site (Figure 4.6 and S4.6). Both the 1932 and 1906 passed greater than $80 \mathrm{~km}$ to the north of Middle Caicos. Assuming that both of these storms had a RMW of approximately 40 $\mathrm{km}$, they likely passed too far away from the site to generate strong winds on the Caicos platform interior. The 1933 Category 5 storm, 1933 Category 1 storm, and the 1926 Category 4 storm passed approximately $42 \mathrm{~km}, 22 \mathrm{~km}$, and $20 \mathrm{~km}$, respectively, to the north Middle Caicos. In the case of these three storms, it is possible that RMW passed over the Caicos blue hole and the back end of each of these storms generated onshore directed currents. Thus, we cannot fully rule out that these three storms contributed and/or generated Event beds 4 and 5. Given that the northward facing reefs and islands protect the platform interior and that northward passing storms generate fetch-limited waves, we think it is unlikely that these storms generated as much surge and sediment transport on the south side of Middle Caicos as the storms moving up across the platform from the southeast.

The last four modern event beds (Events 6-9) likely correspond to hurricane events passing Caicos in the second half of the $19^{\text {th }}$ century. These events date from 1828-1929 (median age: 1899 CE; Event 6), 1810-1911 (median age: 1875 CE; Event 7), 1800-1900 (median age: $1861 \mathrm{CE}$; Event 8), and 1797-1896 (median age: $1857 \mathrm{CE}$; Event 9), respectively. Event bed 6-8 range from 1-2 cm in thickness and are only recorded in the front two cores of our transect (CAO7 and CAOS1). Event bed 9, on the other hand, has a very different character. It extends 28 $\mathrm{cm}$ in thickness and is captured in all three cores from our transect.

Given the larger age uncertainties associated with these later event beds and the increased uncertainty in the observational hurricane records prior to the 1900s (Vecchi and Knutson, 2011), we cannot reasonably attribute each of these event beds to individual passing storms. From 1851-1900 CE, nine hurricanes passed within $100 \mathrm{~km}$ of the Middle Caicos blue hole (Figure 4.6 and S4.6). Of these nine storms, six of them passed on the southern side of Middle Caicos Island: a Category 2 storm in 1888, a Category 1 storm in 1882, a Category 3 storm in 1866, a Category 1 storm in 1856, and two Category 1 storms in 1852. Most of these storms (i.e., 1888 Cat. 1, 1882 Cat. 1, 1852 Cat. 1) exhibit similar paths to Hurricane Kate in 1985. They 
moved east to west across the Caicos platform within $50 \mathrm{~km}$ of the CAOS blue hole (Figure S4.7). Observations from Hurricane Kate (Wanless, Tedesco, et al., 1988) suggest that lower intensity storms passing directly parallel to the Caicos Islands can suspend and transport large quantities of fine and coarse sediment. It is likely that these smaller storms southward passing storms created event beds 6-8.

Event bed 9, on the other hand, is much thicker and coarser than event beds 6-8. There was only one intense storm that passed within $100 \mathrm{~km}$ of Middle Caicos from 1850-1900 CE. On the September 30, 1866, a Category 3 storm swept east to west over the Caicos platform. This Category 3 hurricane passed about $16 \mathrm{~km}$ to the south of our site with wind speeds estimated at $56 \mathrm{~m} / \mathrm{s}$ (Figure 4.6). The storm is estimated to have been the most destructive to hit Turks and Caicos in recent history. Almost $75 \%$ of the country's population was left homeless, and all of the industries including fishing, sea salt production, and cotton and sisal cultivation were devastated (Neely, 2006) after this hurricane. We attribute Event bed 9 to this storm.

From our analysis of the different storms that left a coarse horizon in CAOS7, we conclude that the Middle Caicos blue hole captures hurricanes that track to the south of the Caicos Islands. The reefs and island land masses to the north of the Caicos platform interior protect the platform from waves and storm surge associated with the front-end of northward passing hurricanes. It is unlikely that the intense hurricanes that passed to the north of the Caicos Islands (i.e., Hurricane Donna 1960, 1933 Category 5 hurricane) generated an event bed in the CAOS blue hole. We found that almost all storms passing with $100 \mathrm{~km}$ of Middle Caicos to the south left visible coarse horizons in our CAOS7 core. This included relatively weak storms (Saffir Simpson Scale Category 1 and 2) like Hurricane Kate in 1985. The only southward passing storms that did not leave a deposit were lower intensity storms that passed further away from the site (>50 km away and skirting south of the platform interior). Therefore, we argue that our CAOS sediment cores are sensitive to all Category 1 and above storms that pass at most 50 $\mathrm{km}$ to the south of Middle Caicos. Storms passing further away from the site on the southern side must have a higher intensity to leave a deposit (i.e. Hurricane Irma).

\subsubsection{Caribbean site comparison}

In the last few years, several new studies have reconstructed hurricane activity in The Bahamas using blue hole sediment cores. These studies include sites on Abaco Island (van 
Hengstum et al., 2014; Winkler et al.), South Andros Island (Wallace et al., 2019 (Chapter 2)), and Long Island in The Bahamas (Wallace et al., Chapter 3). All of these reconstructions have approximately near-annual resolution, record event deposits from proximal passing hurricanes of varying intensities, and extend back 1000 years or more. Middle Caicos Island lies to the southeast of all of these sites, approximately $380 \mathrm{~km}$ from Long Island and greater than $600 \mathrm{~km}$ away from South Andros and Abaco (Figure S4.6). It is situated to capture many storms passing north into The Bahamas making landfall on islands where these other paleohurricane reconstructions are located.

Recent work comparing the different blue hole sites from The Bahamas found different patterns of storm activity captured at each site (Wallace et al., Chapter 3). When comparing all these records to our Middle Caicos cores (Figure 4.7), we find that Middle Caicos hurricane activity matches reconstructed patterns of activity in the northwest Bahamas (South Andros) in the first millennium ( 450-1100 CE) and all records from the northern Bahamas (Long Island South Andros, and Abaco) in the $16^{\text {th }}$ through $18^{\text {th }}$ centuries.

During the first millennium of the record, we find fairly similar patterns of activity to the South Andros record (Wallace et al., 2019 (Chapter 2)). South Andros was stuck by more hurricanes from 640-815 CE and 920-1035 CE. Similarly, Middle Caicos captures 6 events from 660-725 CE, and 10 events from 960 -1100 CE. While neither the Long Island or the Abaco Island records extend back far enough in time to capture activity in the $7^{\text {th }}$ or $8^{\text {th }}$ centuries, Long Island does not capture increased activity in the $10^{\text {th }}$ or $11^{\text {th }}$ centuries (Figure 4.7).

The similarities with the South Andros record fade moving into the past millennium (1100-1500 CE). Middle Caicos observed very few storms strikes over this interval while Long Island and South Andros showed intervals of elevated activity (Figure 4.7). Middle Caicos becomes active again from 1550-1655 CE, 1675-1840 CE and 1850-1910 CE. The Abaco Island and South Andros records are only active for the earlier part of this interval from 1500-1675 CE and 1580-1775 CE, respectively.

Starting in the $16^{\text {th }}$ century, the Long Island cores match really well with activity reconstructed on Middle Caicos. Long Island observed increased event deposits from 1600-1655 CE with a drop off in activity in the late $17^{\text {th }}$ century (much like that seen on Middle Caicos). This quiet interval is followed by another interval of increased activity on Long Island from 1775-1840 CE, still matching Middle Caicos (Figure 4.7). However, none of the other Bahamas 
reconstructions exhibit increased activity over the last active period on Middle Caicos. Long Island was active from 1775-1845 CE, but did not continue to see increased storms strikes into the late $19^{\text {th }}$ and early $20^{\text {th }}$ centuries like Middle Caicos.

The varying levels of coherency between our Middle Caicos record and other records from the northern Bahamas likely reflect the varying populations of the storms that affect each site. Of the 27 storms that passed with $100 \mathrm{~km}$ of Middle Caicos over past 169 years, only six, one, and five of them passed within $75 \mathrm{~km}$ of Long Island blue hole, $50 \mathrm{~km}$ of South Andros, and $50 \mathrm{~km}$ of Thatchpoint blue hole on Abaco Island, respectively (Figure S4.6). Random variability and regional weather conditions play a significant role in determining where a given storm tracks and at what intensity it makes landfall. With all of these Bahamian sites capturing only proximal passing storms (100 km radii or less), many hurricanes can pass through The Bahamas without impacting a single one of the current paleohurricane sites. This is further complicated by recent work suggesting that storm properties other than intensity play a role in determining if a storm will generate enough surge and wave action to leave a coarse deposit. Recent work from Long Island in The Bahamas (Wallace et al., Chapter 3) and hydrodynamic modeling of a broad suite of synthetic storms impacting a sinkhole site in northwest Florida (Lin et al., 2014) suggest that a storm's orientation and radius of maximum winds impact which storms leave deposits. As we've seen in this paper, the orientation of a storm with respect to the CAOS blue hole is likely as important as a storm's intensity in generating coarse sediment transport on the Caicos platform interior.

Given that each site is capturing slightly different populations of storms, the best way to understand to how Bahamian paleohurricane activity over the past millennium has changed is to acquire a large spatial coverage of sites in the Bahamas and to compile them together in to a single reconstruction. This composite reconstruction will better capture the broad population of storms that have traveled in this region and remove some of the random variability driven siteby-site differences.

\subsubsection{Basin-wide comparison}

Using the same methods detailed in Chapter 3 Section 3.S.4, we update the compilation of records from The Bahamas to include our Middle Caicos reconstruction. Figure 4.8 presents our new compilation of blue hole paleohurricane reconstructions stretching from 500 to 2019 
CE. It encompasses both the northern and southern Bahama Archipelago and includes sites on South Andros, Long Island, Abaco Island, and Middle Caicos. Each single paleohurricane proxy samples only certain storms passing near to each island and provides a record of local hurricane climate. This local hurricane climate signal is likely dominated by stochasticity. Using a large set of downscaled storms run using National Center for Environmental Prediction (NCEP) Reanalysis climate (1949-2015 CE), we found that combining the storms captured by all four of these sites explains approximately $80 \%$ of the variance in all the synthetic storms passing through the Bahama Archipelago in each year (Figure S4.9; Section 4.S.1). Therefore, even though this compilation only captures approximately half the storms passing through the Bahama Archipelago, it represents the variance in the number of this population of storms really well.

Our new Bahama Archipelago compilation shows increased hurricane activity from 650$800 \mathrm{CE}, 930-1040 \mathrm{CE}$, and 1400-1800 CE. It also includes a short-lived smaller peak in activity from 1240-1300 CE. After $1800 \mathrm{CE}$, we see a decrease in the number of storms observed in the Bahama Archipelago. We compare this new regional compilation from Bahama Archipelago to compilations of paleohurricane activity from New England and northwest Florida (Figure 4.8). We use the same records and methodology detailed in the Supplemental material for Chapter 3 (Section 3.S.4).

Both the HT and LT Florida compilations includes two long lived gradual peaks in hurricane activity from 700 CE-1250 CE and 1800-1950 CE. The LT compilation includes one dramatic peak in activity from 1410-1510 CE (Figure 4.8). The New England compilation includes peaks in activity from 800-1100 CE and 1400-1680 CE. After much fewer storms during the $18^{\text {th }}$ century in New England, the record ends with an increase in landfalling storms near Massachusetts from 1875 to present (Figure 4.8).

During the earliest part of each compilation (600-800 CE), we observe a similar disconnect pattern between The Bahamas and New England as was observed in a previous study (Wallace et al., 2019 (Chapter 2)). From 650-800 CE, there was a period of elevated storm activity in The Bahamas. This directly contrasts with records from New England indicating fewer storms over this time span (Figure 4.8).

However, these contrasting storm patterns switch in the $10^{\text {th }}$ and $11^{\text {th }}$ centuries. All three regional compilations (New England, Florida, Bahama Archipelago) support previous work documenting basin-wide elevated storm activity in the North Atlantic during the Medieval Warm 
Period (MWP) (Wallace et al., Chapter 3; Mann et al., 2009). Warmer sea surface temperatures (SSTs) in the North Atlantic (Mann, 2002) and La-Nina-like conditions in the eastern Pacific likely contributed to more storms forming and intensifying in the North Atlantic basin. Following this MWP peak in storm activity, both the Bahama Archipelago and New England indicate more similar hurricane patterns. Both regions show fewer storms for the next couple of centuries (1200-1400 CE) (Figure 4.8).

Within this quiet interval, the Bahama Archipelago compilation indicates a smaller peak in activity in the $13^{\text {th }}$ century (Figure 4.8 ). The $13^{\text {th }}$ century was characterized by abundant volcanic eruptions, including the largest eruption on record, the 1257 Samalas eruption in Indonesia (Sigl et al., 2014; Gao et al., 2008). The blue hole paleohurricane reconstruction from South Andros Island (Wallace et al., 2019 (Chapter 2)) indicates an unusual gap in storm strikes over this same time interval (1204-1273 CE). In Chapter 2, we suggested that this gap in activity was connected to short-term reductions in the tropical cyclone intensity in the North Atlantic related to oceanic cooling in the aftermath of the $13^{\text {th }}$ century volcanic eruptions. However, more recent records from Middle Caicos Island and Long Island (Wallace et al., Chapter 3) document more storm strikes during the $13^{\text {th }}$ century resulting in the subdued peak in activity observed in our compilation (Figure S4.10-S4.11). This new compilation suggests that the gap in activity documented in the South Andros cores was more likely a randomly-driven local signal in hurricane activity not a climate-driven regional signal. More work is needed to establish a robust relationship between past millennium volcanic eruptions and tropical cyclone distributions in the North Atlantic.

Starting at the beginning of the $15^{\text {th }}$ century, New England and the Bahama Archipelago observe an increase in landfalling hurricanes (Figure 4.8). New England remains active through the end of the $16^{\text {th }}$ century and then undergoes a gradual transition out of the active interval by the early $18^{\text {th }}$ century. The Bahama Archipelago remains active about a century longer than the New England region dropping off to less hurricane strikes at the beginning of the $19^{\text {th }}$ century. The Florida compilations, on the other hand, differ from the Bahama Archipelago and New England. Northwest Florida continues to observe increased activity through $1250 \mathrm{CE}$. Afterwards, the Florida HT compilation remains inactive through $1825 \mathrm{CE}$. A brief peak in activity appears only in the Florida LT compilation during the $15^{\text {th }}$ century; this suggests that lower intensity storms (Category 1-2) were making landfall repeatedly during this century. 
There have been several multi-decadal to centennial scale periods in the past 1500 years where we observed contrasting patterns of activity between U.S. East Coast and U.S. Gulf Coast (in particular from 700-800 CE and 1400-1800 CE). We reiterate two possible explanations for these regional differences in hurricane activity already presented in Chapters 2-3: 1) shifts in regional scale environmental conditions that affect hurricane activity (i.e., vertical wind shear (VWS) patterns) and 2) variability in storm tracks tied to shifts in the North Atlantic Subtropical High (NASH).

While broad-scale warming patterns in SSTs likely play a big role in determining when basin-wide activity is elevated (e.g., active interval during the MWP), changes in vertical wind shear (VWS) are more likely to drive regional variations in hurricane strikes in the North Atlantic. In the past 50 years, natural decadal climate variability in the Atlantic (i.e., Atlantic Multidecadal Variability (AMV)) systematically created different environmental conditions along the U.S. East Coast and Gulf Coast. Positive phases of the AMV set up a protective barrier of enhanced vertical wind shear along U.S. East Coast preventing storms from intensifying along the U.S. East Coast (Kossin, 2017). Anthropogenic warming is expected to induce the opposite pattern with unfavorable VWS patterns in the Gulf of Mexico and Caribbean but not the U.S. East Coast (Ting et al., 2019). This VWS pattern is largely thought to be driven by predicted Hadley cell expansion (Lu et al., 2007; Kang and Lu, 2012) and a subsequent northward shift in the mid-latitude jet (Barnes and Polvani, 2013). Thus, one possible mechanism for differences in hurricane patterns between the U.S. Gulf Coast and U.S. East Coast is shifts in regional vertical wind shear patterns between these basins tied to changes in the mid-latitude jet position.

In addition, changes in storm track populations could also contribute to periods with distinctly different activity in New England versus the Gulf Coast. Changes in the North Atlantic Subtropical High (NASH), a semi-permanent high pressure system that resides over the North Atlantic in the Northern Hemisphere summer, affects the steering currents that determine Atlantic hurricane tracks (Ortegren and Maxwell, 2014). In particular, a weaker and/or northeastward displaced NASH steer hurricanes along the U.S. East Coast around the western edge of the high. A southwestward-displaced NASH, on the other hand, maintains easterly currents and pushes more storms into the Gulf of Mexico (Elsner, 2003; Kossin et al., 2010; McCloskey et al., 2013; Ortegren and Maxwell, 2014). 
In the context of our records, from 600-800 CE, we observe fewer storms in New England accompanied by more frequent storm strikes in the Bahama Archipelago and in Florida (Figure 4.8). Perhaps during this time span, there were more storms forming and traveling in the tropical Atlantic, but there were unfavorable vertical wind shear patterns along the U.S. East coastline and/or a southwestward displaced NASH generating easterly steering currents. In either case, storms forming in the tropical Atlantic would tend toward a more straight-moving storm population tracking through the Bahama Archipelago and Gulf of Mexico. In the past 600 years, we observe more hurricanes from 1400-1700 CE hitting the Bahama Archipelago and U.S. East Coast (Figure 4.8). This could indicate a shift in the 1400's towards a more recurving population of storm tracks perhaps tied to northward shift in the mid-latitude jet and North Atlantic Subtropical High. Without a reliable reconstruction of either the North Atlantic Subtropical High or North Atlantic mid-latitude jet for the past millennium, it is difficult to confirm these interpretations. Future work exploring how vertical wind shear patterns and steering currents in the North Atlantic have changed over the past millennium are key for further validation and interpretation of these paleohurricane patterns.

The Bahamas is the only regional compilation that indicates much lower storm activity in the past 200 years than any other time over the last millennium (1000-2020 CE). After $1800 \mathrm{CE}$, much fewer storm strikes are recorded in proxies from all across the Bahama Archipelago. Florida, on the other hand, shows increased storm strikes from 1780-1950 CE (Figure 4.8A- Low Threshold Compilation). In particular, records from Apalachee Bay (Brandon et al., 2013; Rodysill et al. in review; Lane et al., 2011) in Florida capture eight low intensity storm strikes across this interval (Figure S4.10-S4.11). The New England compilation, on the other hand, remains inactive for much of the $18^{\text {th }}$ and $19^{\text {th }}$ centuries but indicates an upward trend in storm strikes since $1900 \mathrm{CE}$ (Figure 4.8). However, this inactivity in the $18^{\text {th }}$ and $19^{\text {th }}$ centuries may be a result of the sensitivity of the New England sites. Both the Salt Pond (Donnelly et al., 2015) and Mattapoisett Marsh (Boldt et al., 2010) reconstructions capture Category 2 and above hurricanes. Documentary records suggest many lower intensity storms (<Category 2 ) were traveling along U.S. Northeast Coast during the 1800s (Boose et al., 2001; Ludlum, 1997). Thus, in the last 50 years, we've seen a switch from lower intensity storms making landfall both in northwest Florida and New England to just more intense storms ( $\geq$ Category 2) making landfall in New England. With anthropogenic warming, we should expect this pattern to continue. With 
predicted future expansion of the Hadley cell (Lu et al., 2007; Kang and Lu, 2012) and warmer SST's expanding into the subtropical North Atlantic (Ting et al., 2015), storms are predicted to make landfall more often along the U.S. East Coast (Ting et al., 2019).

\subsection{Conclusions}

Here, we reconstruct hurricane strikes on Middle Caicos Island over the past 1550 years from a transect of blue hole sediment cores. We find large coarse grained deposits that can be tracked across a transect of three cores each approximately $100 \mathrm{~m}$ apart. We attribute the top nine coarse event beds to historical hurricanes passing within $100 \mathrm{~km}$ of the island. We find that the orientation of passing storms with respect to the site is more important than storm intensity for inducing coarse-grained sediment transport on the Caicos platform interior. Indeed, low intensity storms, like Hurricane Kate in 1985, that pass to the south of the island leave deposits in the Middle Caicos blue hole. Other high intensity storms that passed on the northern side of Turks \& Caicos, like Hurricane Donna in 1960, do not. This finding confirms previous work studying storm deposits on Long Island, The Bahamas (Wallace et al., Chapter 3) which indicate storm surge can depend greatly on both coastal geometry and storm properties (i.e., size, speed and angle of approach). It also highlights the need for detailed hydrodynamic modeling studies on Caribbean islands investigating how storms of different properties and tracks influence surge generation. Coastal communities in developing countries in the Caribbean are particularly susceptible to tropical cyclone flooding with ill-equipped infrastructure and coastal management (Webster et al., 2005; Dasgupta et al., 2011; Hanson et al., 2011). Hurricane Dorian in 2019 devastated Abaco Island in The Bahamas causing 3.4 billion USD in damage, almost a quarter of the annual economic output of The Bahamas (Reuters, 2020). Expanding paleohurricane research and hydrodynamic modeling studies in these areas is crucial for improving flood forecasts to these especially vulnerable populations.

Taken as a whole, our record from Middle Caicos indicates elevated storm strikes in five multi-decadal periods over the past 1550 years from 660-725 CE, 960 -1100 CE, 1550-1655 CE, 1675-1840 CE and 1850-1910 CE. Like previous work, this record matches well with some neighboring records from The Bahamas and poorly with others. Ultimately, each paleohurricane site is sampling some small subset of storms passing through The Bahamas. We stress the need for compilations of large numbers of paleohurricane records from a region to capture regional 
changes in hurricane climate. Future work exploring how stochasticity impacts the signal captured in both individual records and compilations is needed before we can gain confidence in these climate interpretations of paleohurricane records.

We update regional compilations of paleohurricane activity for the past millennium in New England, The Bahamas, and northwest Florida. These records indicate synchronous periods of elevated hurricane activity and diverging periods of elevated hurricane activity over the past millennium. A synchronous active period occurred during the Medieval Warm Period from 900$1100 \mathrm{CE}$. We argue this time period corresponds to basin-wide elevated hurricane activity characterized by warmer sea surface temperatures in the Atlantic. Diverging active periods occur from 600-800 CE and 1500-1800 CE and are characterized by more activity in New England when the Gulf Coast is quiet. We argue that regional scale patterns in vertical wind shear and/or shifting storm populations contributed to these diverging active periods. Reconstructions of the North Atlantic Subtropical High and mid-latitude jet for the past millennium are needed to discern drivers of these centennial-scale hurricane landfalls. 


\subsection{Figures}

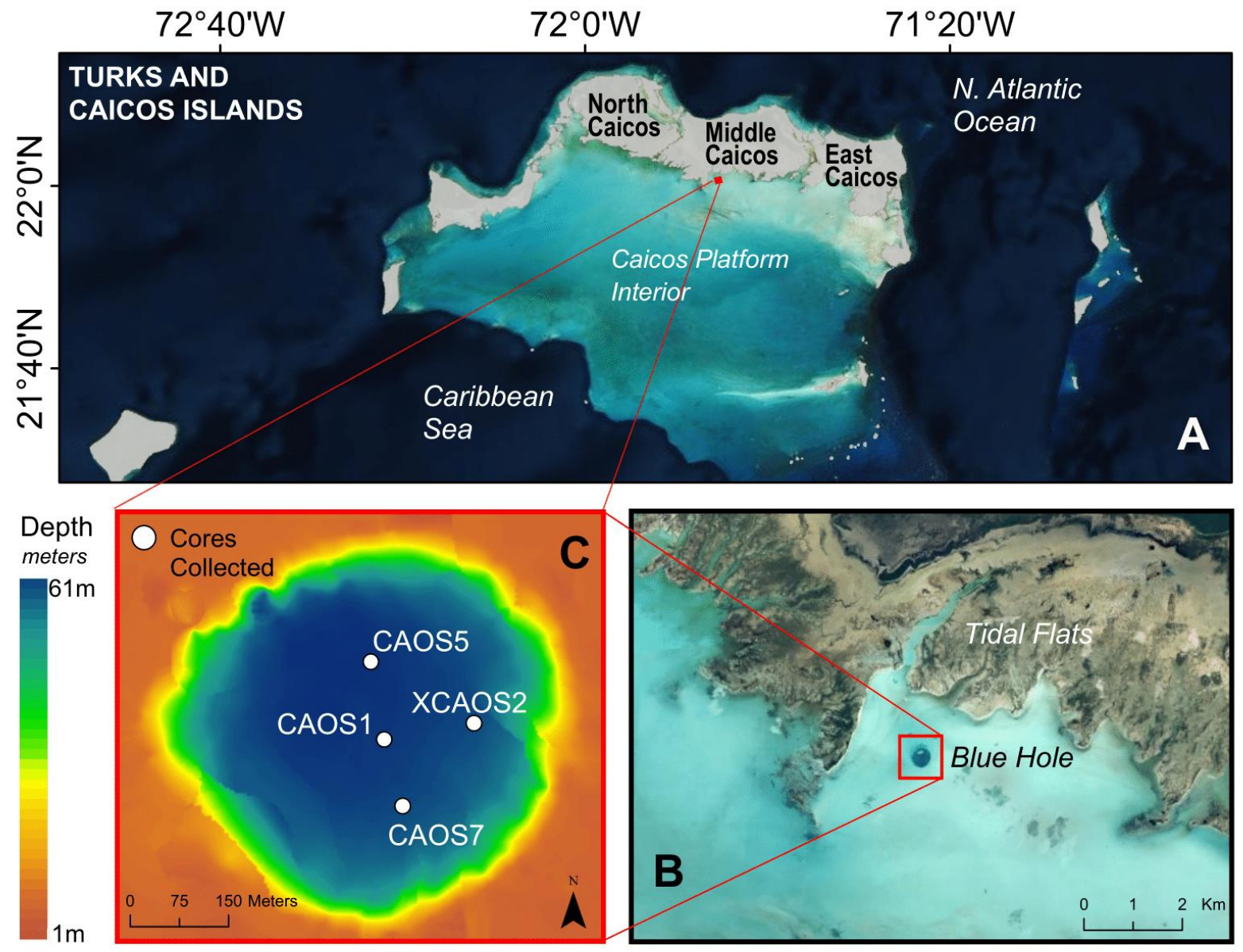

Figure 4.1: (A) Map of the Turks \& Caicos Island. (B) Middle Caicos Blue Hole (LIBH) location $\left(21.72^{\circ} \mathrm{N}, 71.81^{\circ} \mathrm{W}\right)$. (C) The bathymetry of the blue hole and locations of the original 2016 transect of longer cores (CAOS7, CAOS1, and CAOS5) and post-Irma short surface core (XCAOS2) are shown. 


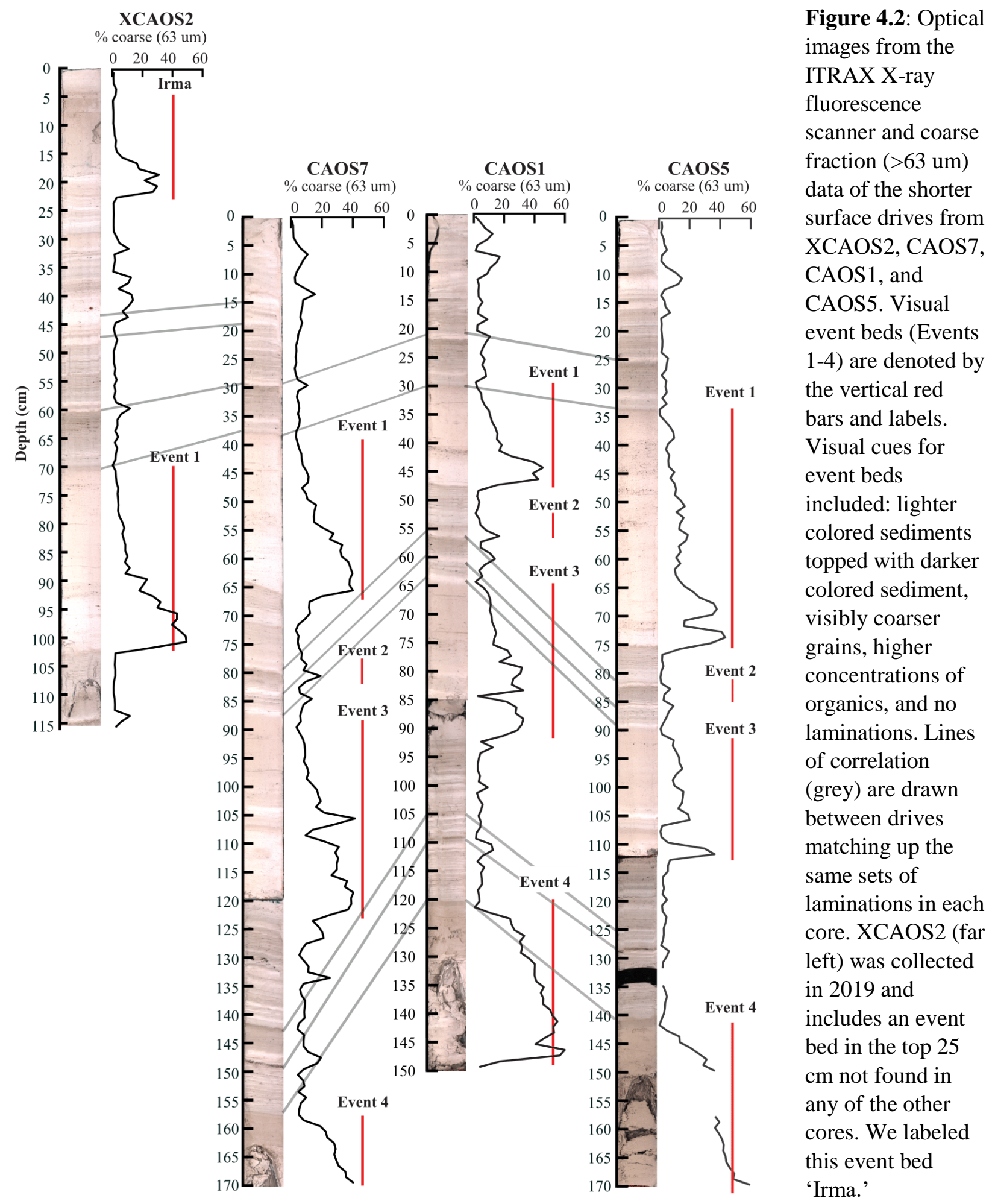




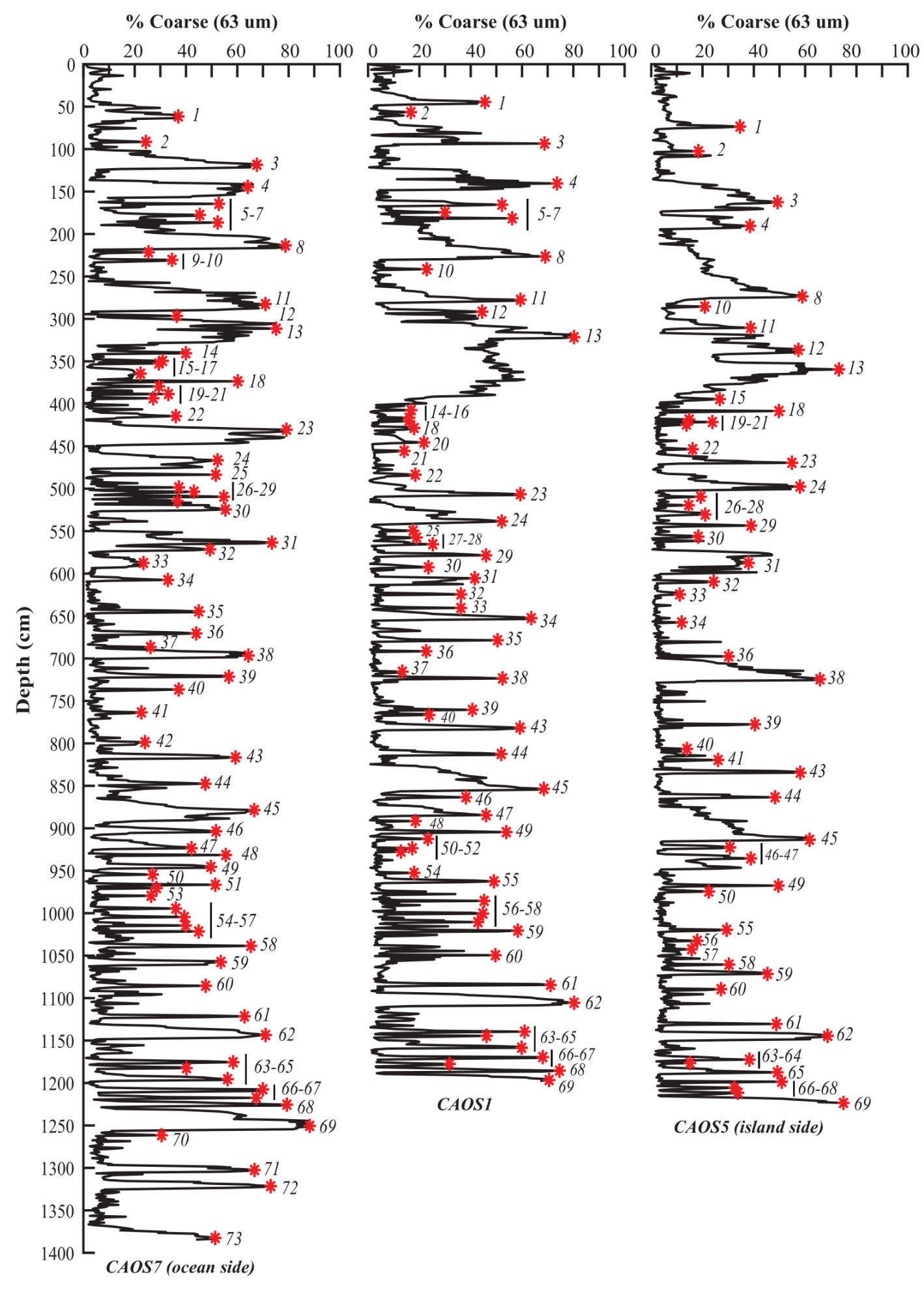

Figure 4.3: Percent sand fraction ( $>63 \mu \mathrm{m})$ vs. depth in core (black) for CAOS7 (left), CAOS1 (middle), and CAOS5 (right). Event beds (red stars) were identified using visual cues and correlated across cores (See Figure 2). Event beds are numbered from 1-73 on the CAOS7 core. It does not include the Hurricane Irma layer at the top. The same event beds found in CAOS1 and CAOS5 are labeled across. CAOS1 and CAOS5 only include 62 and 53 events, respectively. 


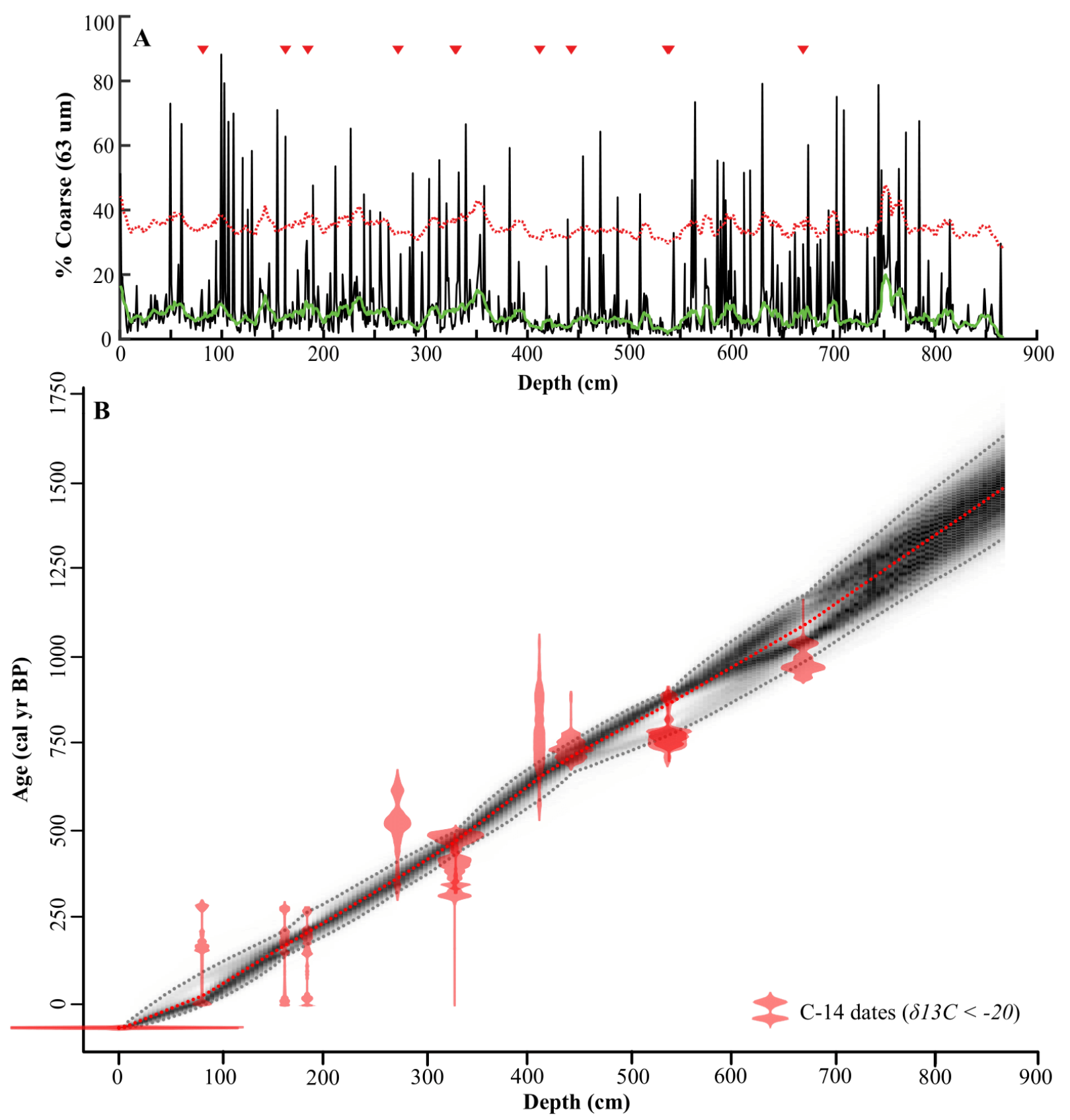

Figure 4.4: (A) Percent sand fraction ( $>63 \mu \mathrm{m}$ ) vs. depth in core (black) from CAOS7 with a 10point running mean filter (green) that excludes coarse fraction values above $25 \%$. The red dashed line is the $95 \%$ event cutoff threshold added to the filter. Location of ${ }^{14} \mathrm{C}$ dates are plotted as red triangles above the coarse fraction data. (B) Age model (red dashed) derived from radiocarbon dates (red) in Table S3.1 for CAOS7. 95\% confidence bounds are shaded in grey around the age model. A tie point setting the surface of each core to modern is also shown (red horizontal bar). Dates with enriched $\delta 13 \mathrm{C}$ values (>-14\%) thought to be marine algae samples are shown in blue and are not used in the age model. Two other unused radiocarbon samples are plotted in green. These figures were generated using BACON v2.2 age modeling software (Blaauw and Christen, 2011). 


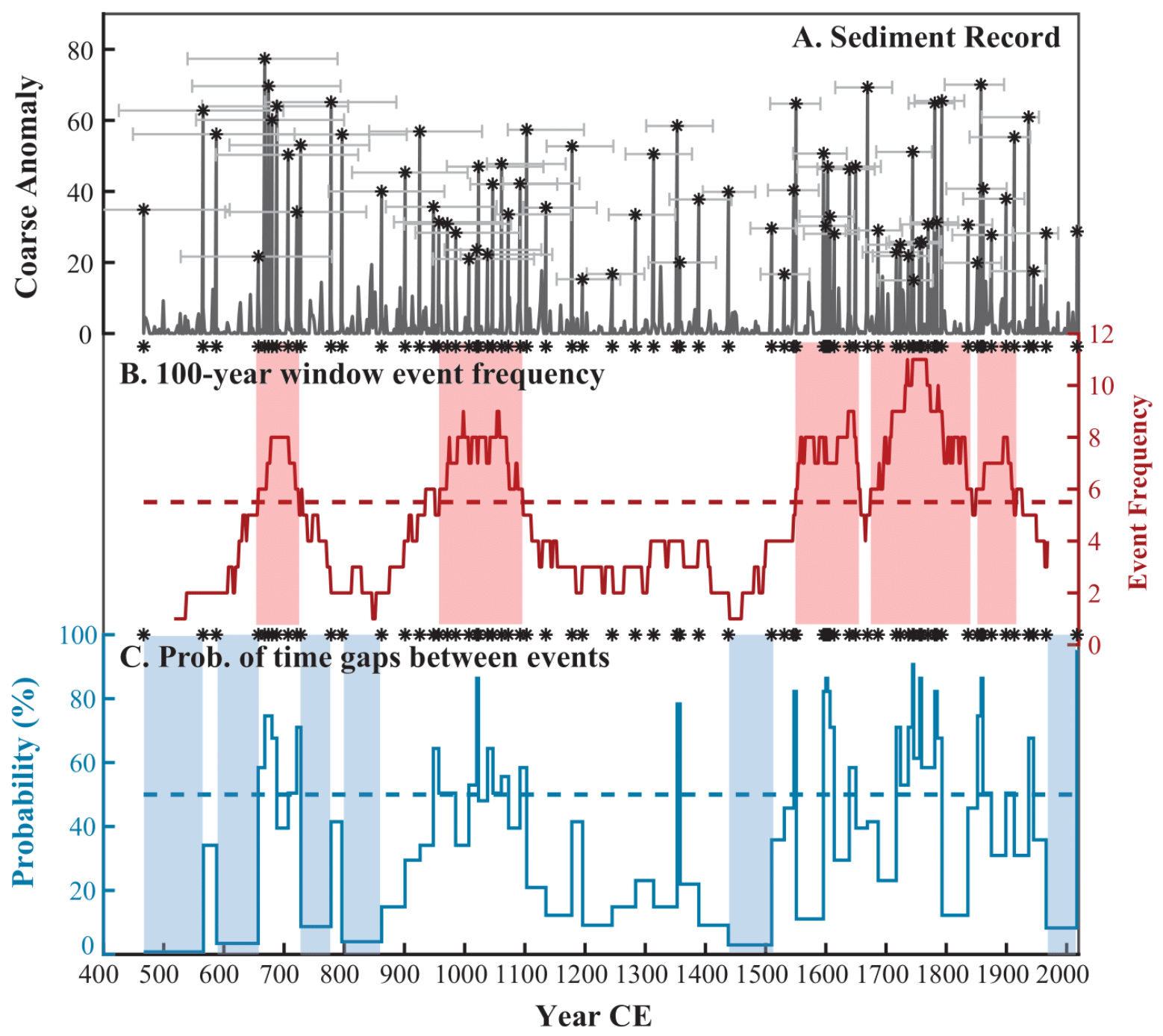

Figure 4.5: (A) Coarse anomaly plot (grey) for CAOS7 as a function of time. Black starred peaks are counted as event beds using both the optical images and coarse fraction data. Grey error bars indicate $95 \%$ confidence bounds for the ages of each event. (B) The 100-year moving window event frequency per century. The dashed red line is the site-specific cutoff for active intervals (5.7 events/century). (C) The probabilities of having no events over the time span between each event in the record. The probabilities were calculated based on a recurrence interval of 20.9 years/event over the whole record (blue). Active and quiet intervals identified on Middle Caicos are shaded in red and blue, respectively. 

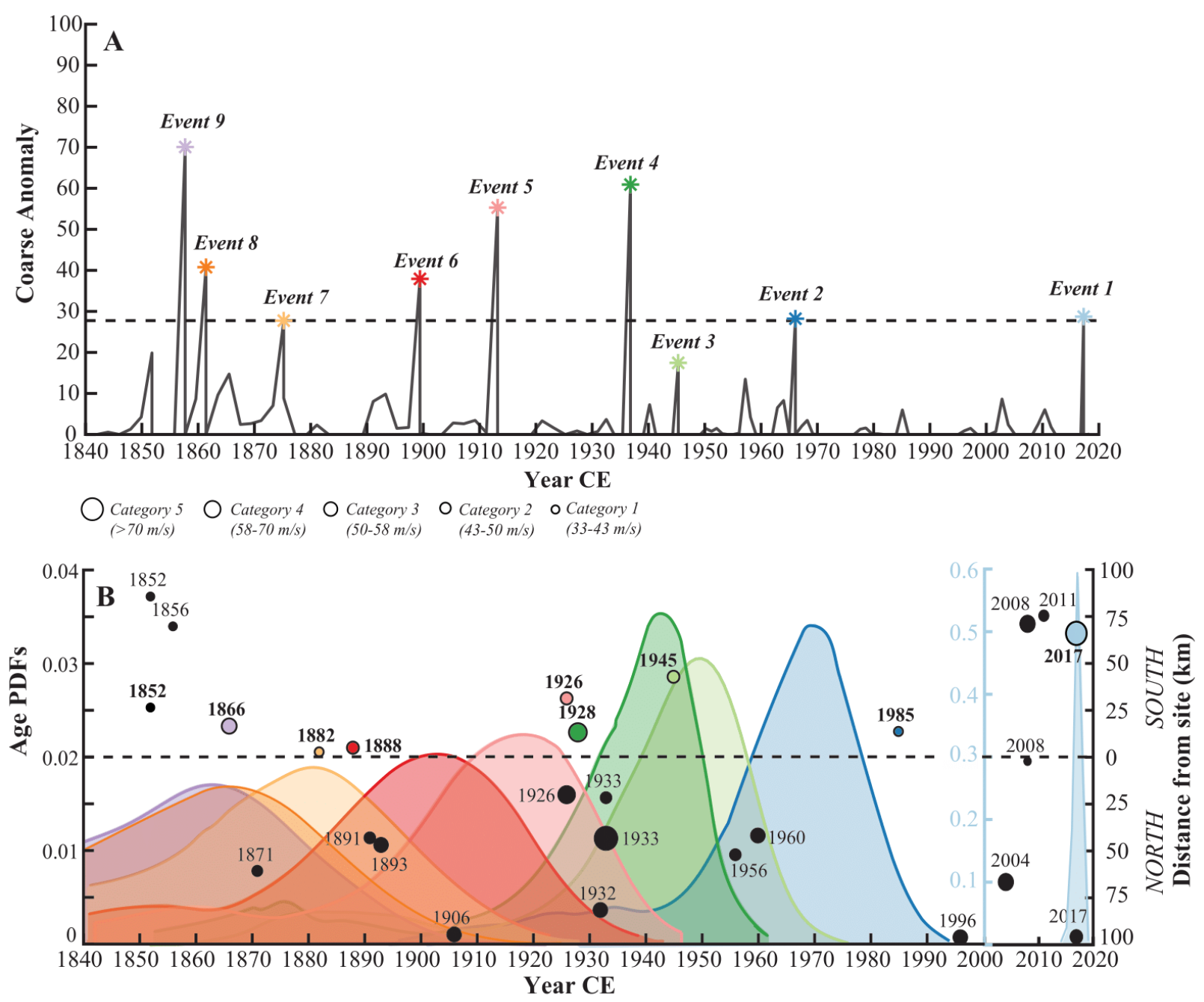

Figure 4.6: Coarse anomaly data for the modern interval (1850-2019) from CAOS7 (A). Starred peaks indicate identified event layers. 95\% age probability distributions for Events 1-9 (B).

Circles on panel B indicate the timing of observed storms passing within $100 \mathrm{~km}$ of the CAOS blue hole plotted as a function of the distance $(\mathrm{km})$ of their closest passage to the north and south of the site. The colored dots indicated the observational storms to which we attributed each event bed shown in panel A. 


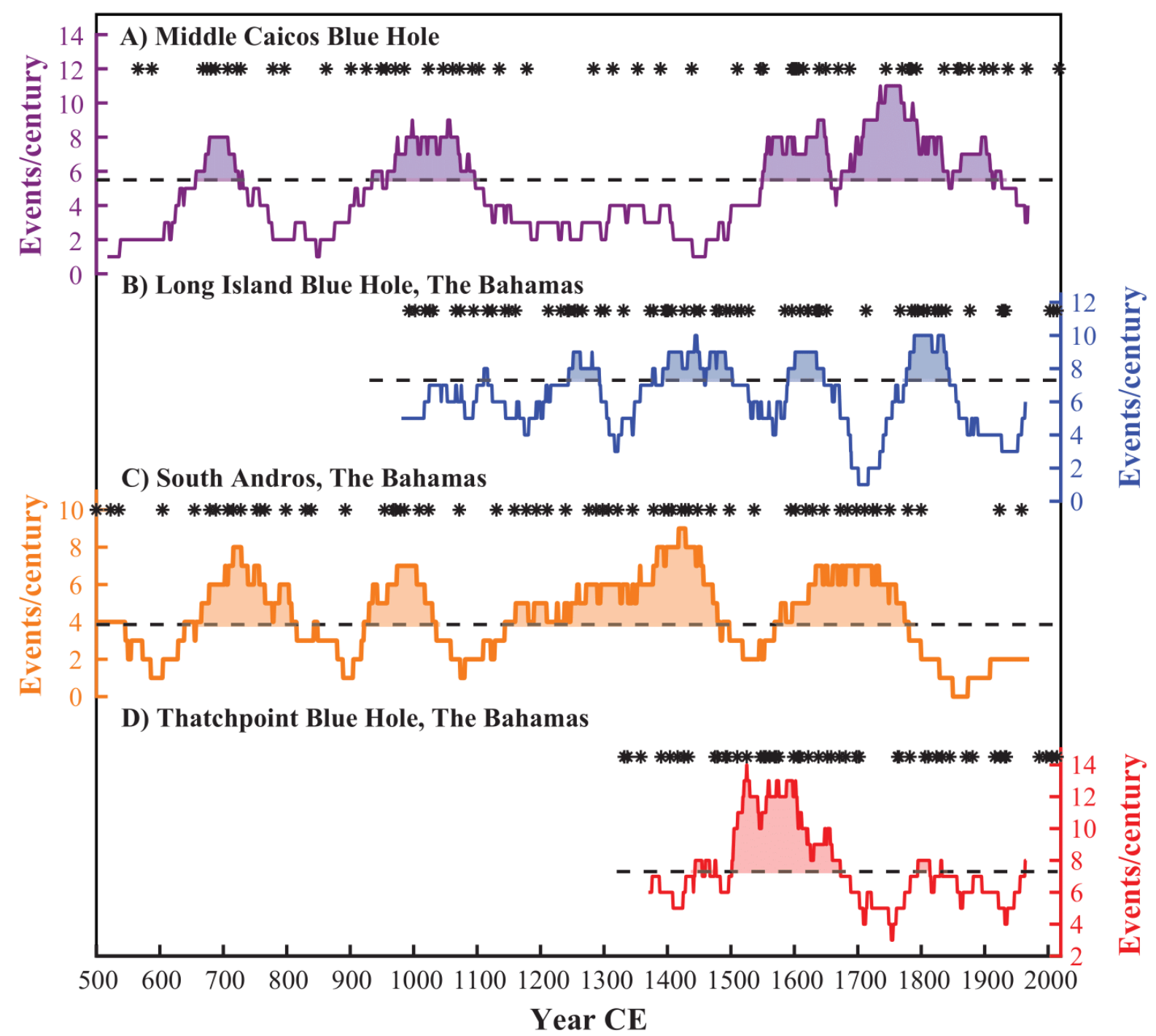

Figure 4.7: 100-year moving window event frequency for Bahamas blue hole reconstructions: (A) Middle Caicos Blue Hole with 5 active intervals highlighted in purple (B) Long Blue Hole (Wallace et al, Chapter 3) with 4 active intervals highlighted in blue, (C) South Andros stacked record (Wallace et al., 2019 (Chapter 2), Winkler et al, in review) with 4 active intervals highlighted in orange, and (D) Thatchpoint Blue Hole (Winkler et al, in review) (red) with one active interval highlighted in red. The timing of each event in the records is denoted by the black stars above each panel. The black dashed lines on each panel indicate the upper $90 \%$ threshold for active periods at each site. 


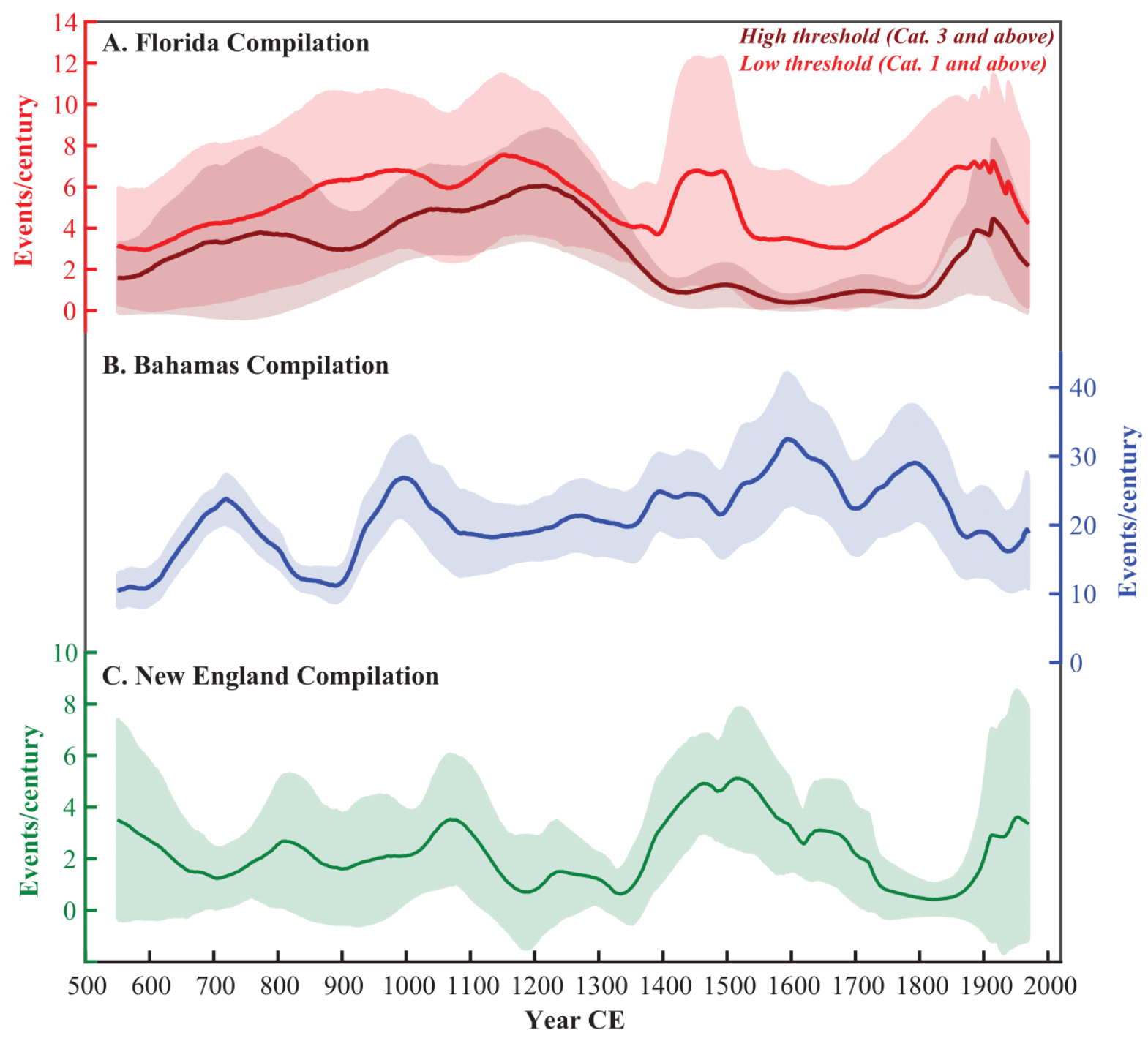

Figure 4.8: Compilations of paleohurricane records from (A) northwest Florida (red) including records from Mullet Pond, FL (Lane et al., 2011), Spring Creek Pond (Brandon et al., 2013), Shotgun Pond (Rodysill et al., in review), and Basin Bayou (Rodysill et al., in review) (B) The Bahamas (blue) including all the records shown in Figure 4.7, and (C) New England (green) including records from Salt Pond, MA (Donnelly et al., 2015) and Mattapoisett Marsh (Boldt et al., 2010; Castagno et al., in revision). The shaded confidence intervals are calculated from the spread in each of the contributing records. All three compilations shown were smoothed with a 100-year moving window. The original compilations (without the filter) are shown in Figure S4.10-S4.11. For the Florida compilation, we include a High Threshold (dark red - Category 3 and above) and Low Threshold (red - Category 1 and above) estimate. 


\section{S. Supplemental Material}

\section{S.1. Analysis of Bahama Archipelago NCEP Reanalysis synthetic storms}

We tested whether our Bahama Archipelago compilation serves as a good approximation of the overall variance in tropical cyclone counts in the Bahama Archipelago. Our compilation only samples storms at four sites: South Andros (Wallace et al., 2019 (Chapter 2)), Long Island (Wallace et al., Chapter 3), Abaco Island (Winkler et al. in review), and Middle Caicos (Wallace et al., Chapter 4) (Figure S4.9A). Each site has a different estimated sensitivity. The South Andros proxy records capture Category 3 and above hurricanes passing within $50 \mathrm{~km}$ of the site $\left(\mathrm{N} 23.78^{\circ}, \mathrm{W} 77.71^{\circ}\right)$. Both the Long Island and Abaco Island proxies capture Category 2 and above storms passing within $75 \mathrm{~km}$ of each site (Long Island blue hole - N23.27 ${ }^{\circ}$ W75.12 ${ }^{\circ}$; Thatchpoint blue hole - N26.32 ${ }^{\circ}$, W77.29 $)$. Middle Caicos captures Category 1 and above storms passing to the south of the CAOS blue hole $(75 \mathrm{~km}$ radius around the center of the Caicos platform interior - $\left.\mathrm{N} 21.55^{\circ}, \mathrm{W} 71.89^{\circ}\right)$.

Using a statistical deterministic model (Emanuel et al., 2006, 2008), we generate 11,440 synthetic storms, with a total model run time of 3462 years, passing in a polygon over the Bahama Archipelago (Figure S4.9A) from 1949-2015 CE. The model takes its boundary and initial conditions from the National Centers for Environmental Prediction (NCEP)-National Center for Atmospheric Research (NCAR) reanalysis data set (Kistler et al., 2001). These synthetic storms are simulated in three steps: genesis, track, and intensity. In the genesis stage, storms, in the form of warm core vortices, are placed randomly in the North Atlantic with the exception that no storms may form equatorward of $3^{\circ}$. Storms that meet with favorable environmental conditions (e.g., warm sea surface temperatures, low vertical wind shear) mature into tropical cyclones. In the track stage, these storms are propagated using a Beta and Advection model (BAM) (Emanuel et al., 2006). The BAM technique generates tracks for each storm using randomly generated wind fields at surface $(850 \mathrm{hPa})$ and at height $(250 \mathrm{hPa})$ which conform to the monthly means, variances, and covariances of the NCEP/NCAR dataset (Kistler et al., 2001). Finally, the intensity of each storm is set using a coupled air-sea model (Coupled Hurricane Intensity Prediction System (CHIPS)) (Emanuel et al., 2004). This model creates wind fields in angular momentum coordinates allowing for a very high resolution in each storm's inner core.

Using this large storm dataset, we analyzed how many of the synthetic storms passing through the Bahama Archipelago each year would be recorded in at least one of our four 
paleohurricane proxies (Figure S4.9B). Our compilation of all four sites captures approximately $58 \%$ of the synthetic storms passing through the whole Bahama Archipelago each year. When we performed a linear regression between the record of all storms passing through the Bahama Archipelago and the record of storms captured by our compilation, we found the storms captured by our compilation capture $80 \%$ of the variance in all storm counts (Figure S4.9C). Therefore, we can reasonably use the Bahama Archipelago compilation to represent regional changes in storm counts over the Bahama Archipelago.

\section{S.2. Grain size measurements of modern events using microscopic images}

We measured the grain size of modern events in CAOS7, CAOS1, and CAOS5 using images taken on a 34 MP microscopic camera. We imaged the sample with the largest coarse fraction from each of the modern event beds. We only imaged event beds that were found in all three cores in the transect. This included event beds 2, 3, 4, 5, and 9 as shown in Figures 4.3 and 4.6. Using the $>63 \mu \mathrm{m}$ saved samples, sediment grains were spread out on a plain black background so to minimize overlapping grains. We imaged approximately half of each sample with a resulting range of 50-175 images per sample.

We used the MATLAB image processing toolbox to detect and measure the diameter of each grain. First, all images are converted to binary. Edges are defined along a path of rapid change in image intensity. Connected edges define objects in the image (i.e., the sediment grains). We then measure the area of each object (Figure S4.12). We calculate an equivalent circular diameter (ECD) with the same identified area as the grain. This is computed by:

$$
E C D=4 * \text { Area } / \pi
$$

Using the ECDs of each sample, we calculated the D50 and D90 particle size. D50 is the median diameter of the sample and D90 is the diameter where $90 \%$ of grains in the sample have a smaller diameter and 10\% have a larger diameter. Figure S4.8 shows the D50 and D90 for each of the modern events across the transect of cores in the Middle Caicos blue hole.

There are several sources of uncertainty with these methods. The first of which arises from the existence of overlapping grains in all of the images. When grains are touching in the images, they are measured as a single large grain. We tried to minimize the number of overlapping grains in each image by manually spread out the samples. The average image contains 170 grains with 2 to 10 groups of overlapping grains. This will tend to skew the results toward larger grains on average. Another source of uncertainty arises from calculating an 
equivalent circular diameter for grains that are not circular. Many of the CAOS grains are not circular, containing fragments of shells and other angular particles. Given that both sources of uncertainty apply equally across samples in the transect, we are still able to use our results to measure relative differences in grain size across event samples in the transect.

\section{S.3. Supplemental figures and tables}
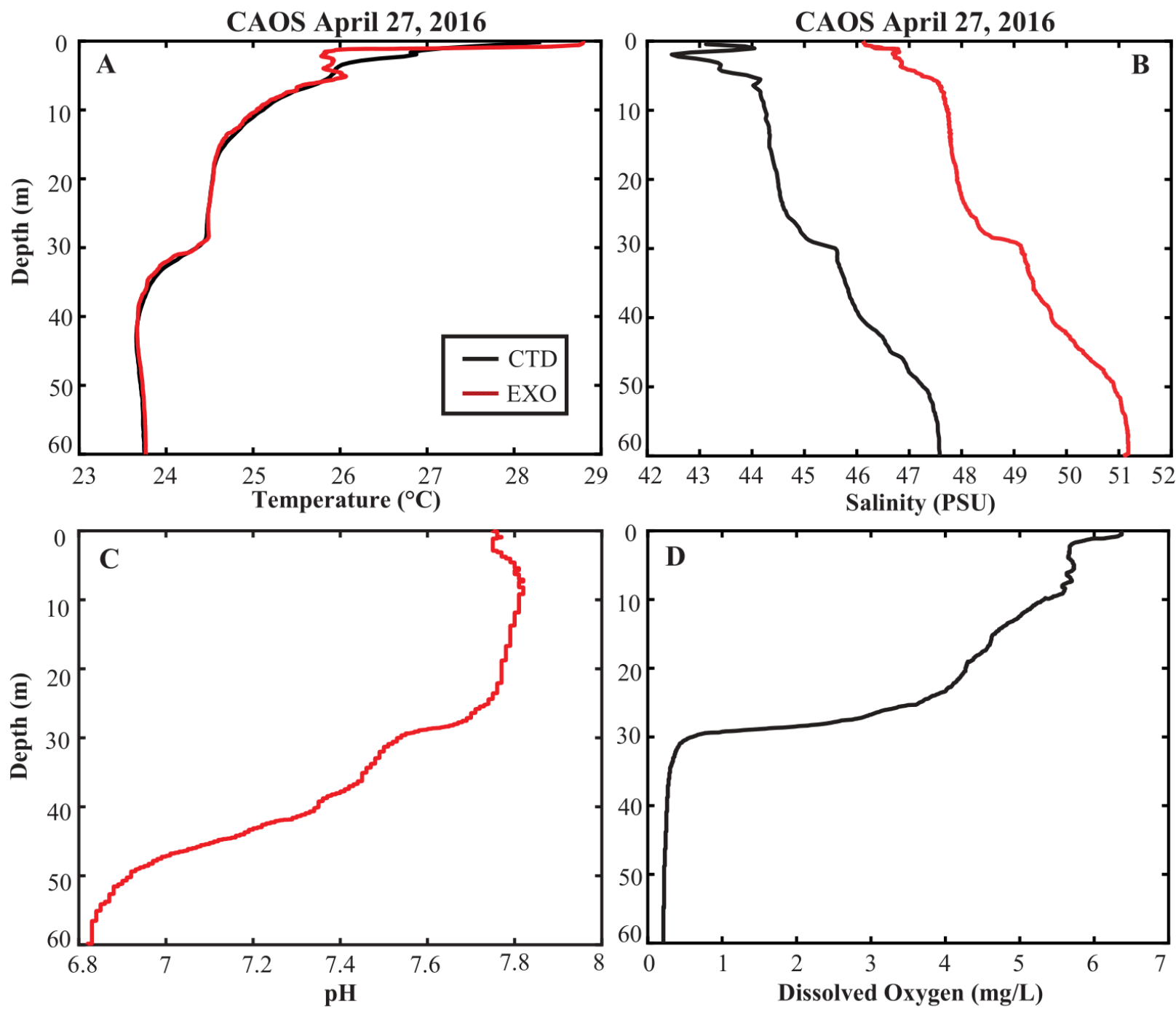

Figure S4.1: Temperature (A), salinity (B), $\mathrm{pH}(\mathrm{C})$, and optical dissolved oxygen (C) in the Middle Caicos blue hole (CAOS). Profiles were collected on April 27, 2016 using a YSI Castaway CTD (black) and a YSI EXO1 sonde (red). 
Figure S4.2: Pinpointing the overlap point between the first section of each surface drive of CAOS7, CAOS1, and CAOS5 and the first section of their respective longer drives. Longer drives did not capture the sediment-water interface. Optical images from the ITRAX X-ray fluorescence scanner and coarse fraction (>63 um) data were used to choose the overlap points. The surface drives and longer drives for CAOS7, CAOS1, and CAOS5 overlap starting at $39 \mathrm{~cm}$, $66 \mathrm{~cm}$, and $43 \mathrm{~cm}$, respectively. Lines of correlation (grey) are drawn between drives matching up the same sets of laminations in each core. Vertical black bars indicate denote the thickness of event beds identified visually. Numbers correspond to the same event beds across the cores. The location of radiocarbon samples in CAOS5 and CAOS 1 are denoted by red boxes. They are given new depths adjusted to the depths of the same sequences in the CAOS7 core. 


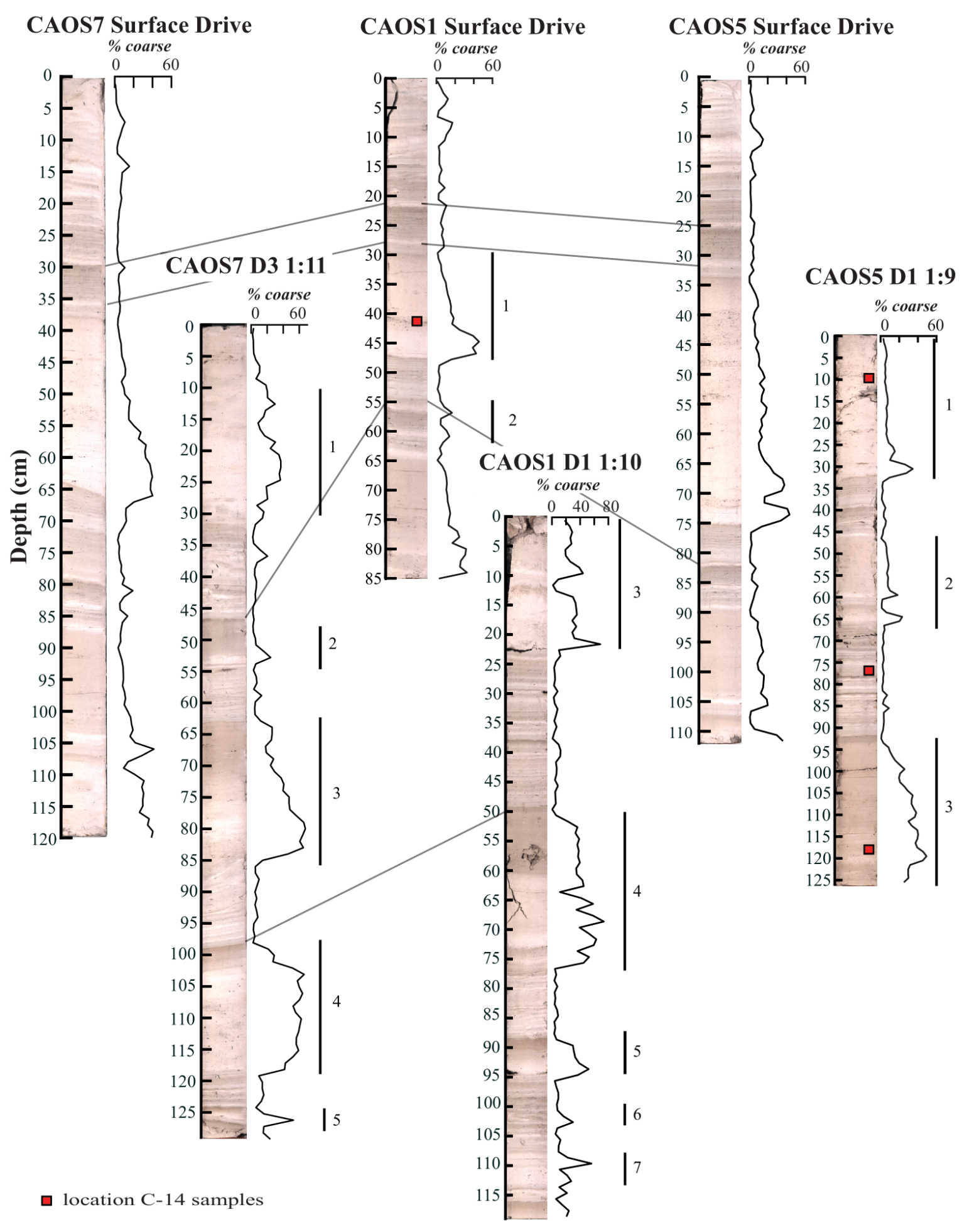




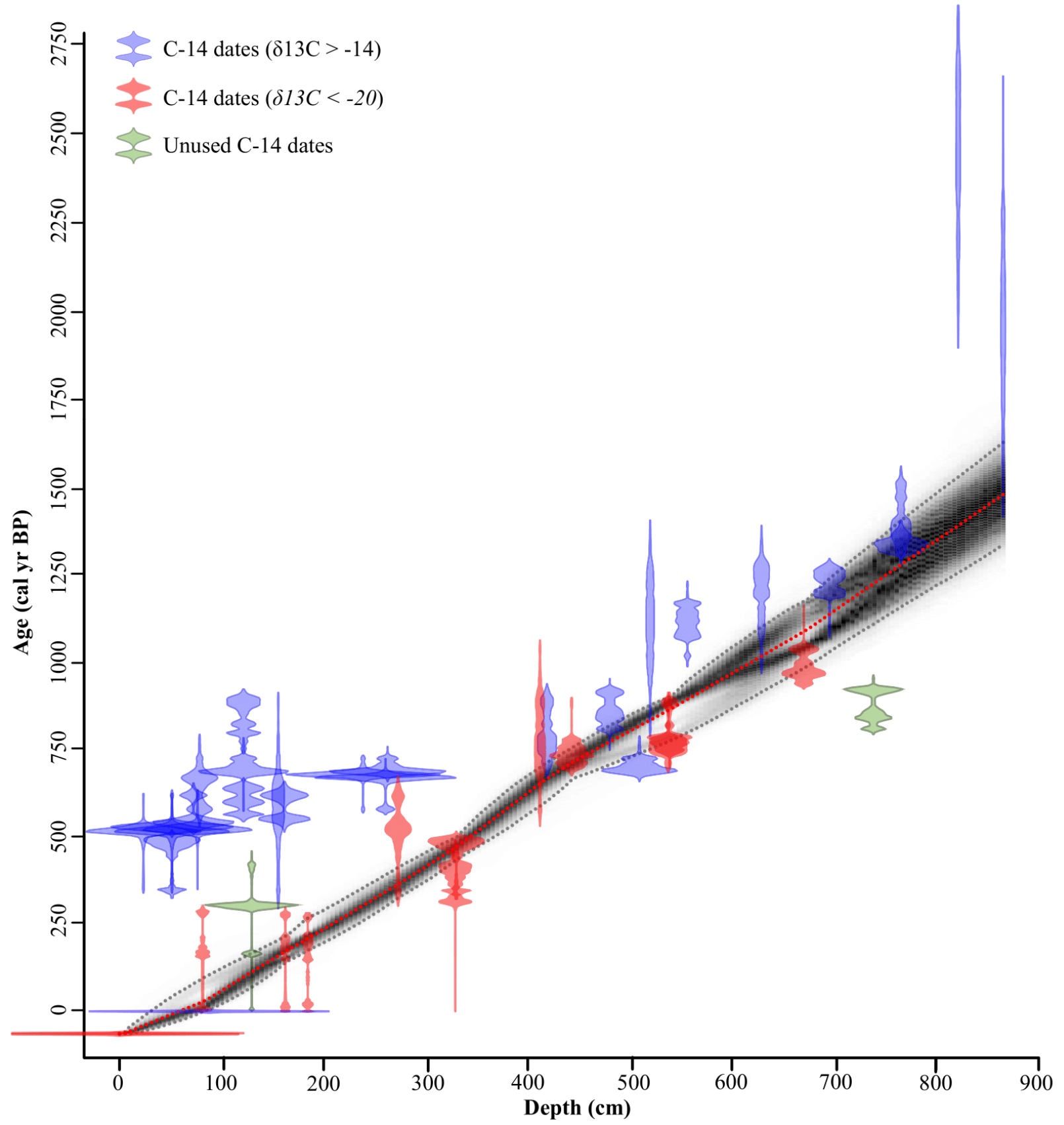

Figure S4.3: CAOS combined age model (Same as Figure 4.4). Dates with enriched $\delta 13 \mathrm{C}$ values (>-14\%) thought to be marine algae or seagrass samples are shown in blue and are not used in the age model. Two other unused radiocarbon samples are plotted in green. These figures were generated using BACON v2.2 age modeling software (Blaauw and Christen, 2011). 


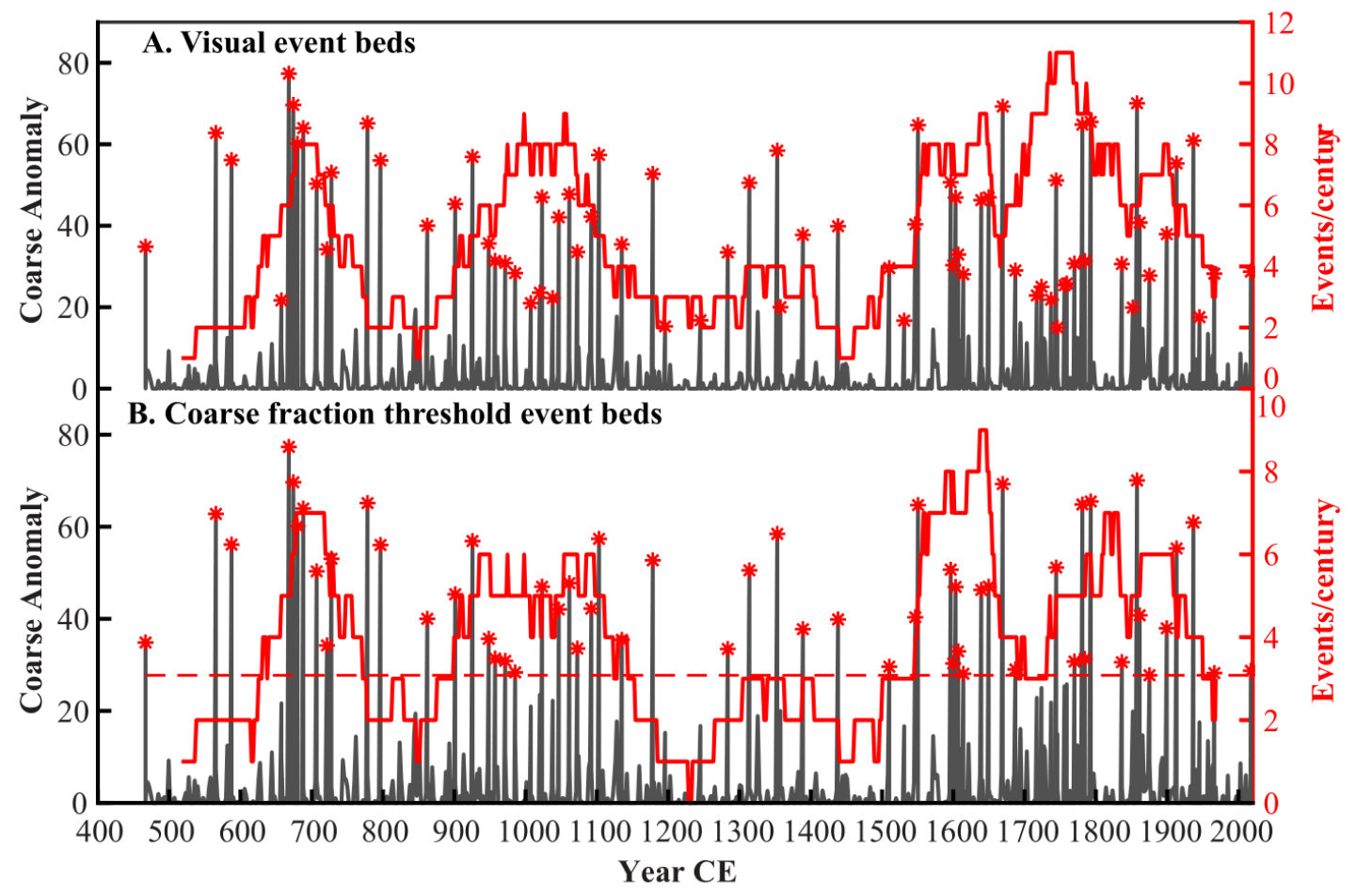

Figure S4.4: Coarse anomaly plot (grey) for CAOS7 with event beds (red stars) identified visually (A) or with a coarse fraction event bed threshold of $27.7 \%$ (B). The 100-year moving window event frequency per century for events identified using each method is plotted in red. 


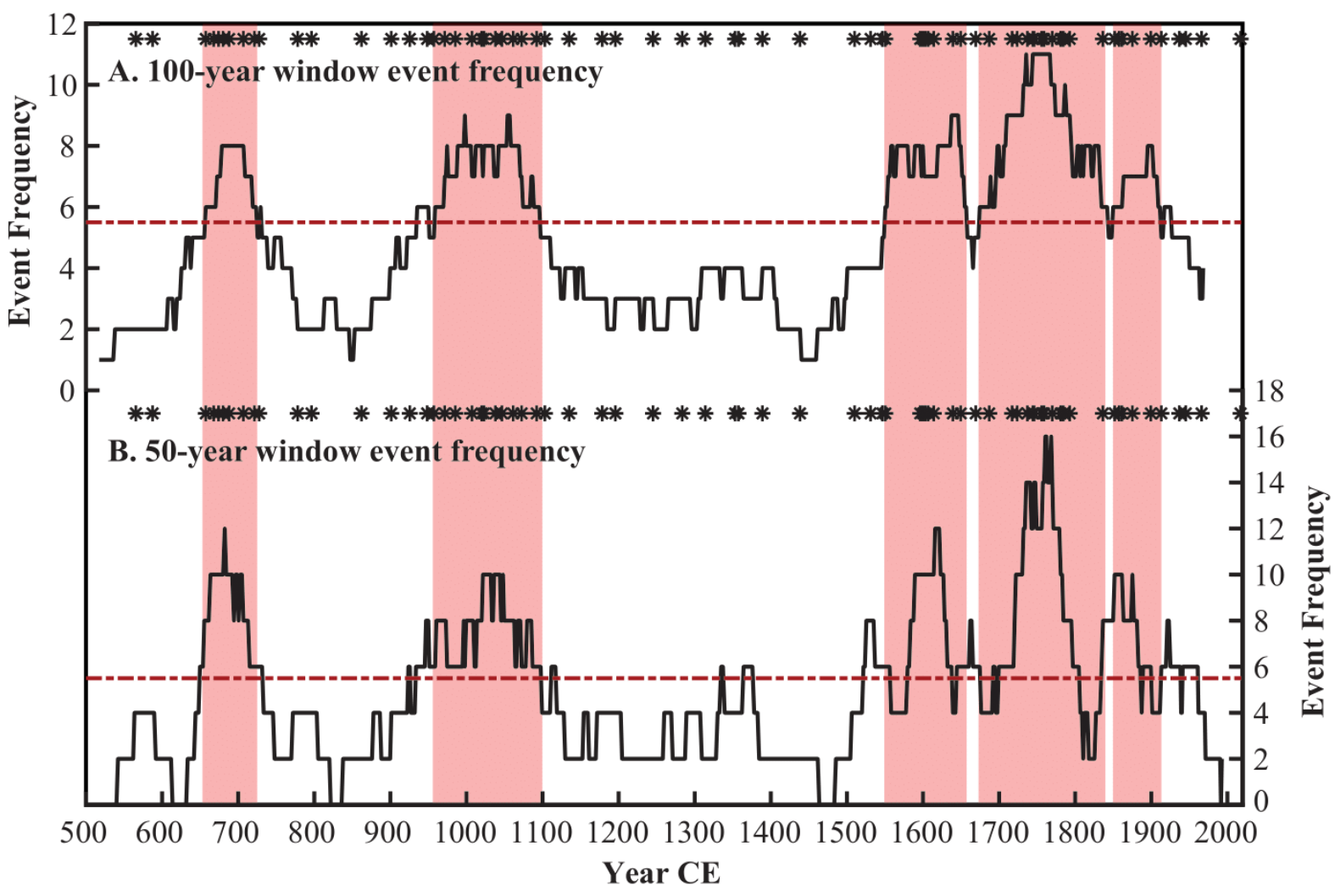

Figure S4.5: Event frequency per century for CAOS7 (black) with a 100-year sliding window (A) and a 50-year sliding window (B). The dashed red line is the site specific cutoff for active intervals (5.7 events/century). Active intervals are shaded in red and indicate time periods when the event frequency is above the cutoff for the 100-year window event frequency. The median timing of each event is plotted as a black star above each panel. The timing of active intervals does not change dramatically if we use the 50-year window frequency versus the 100-year. 

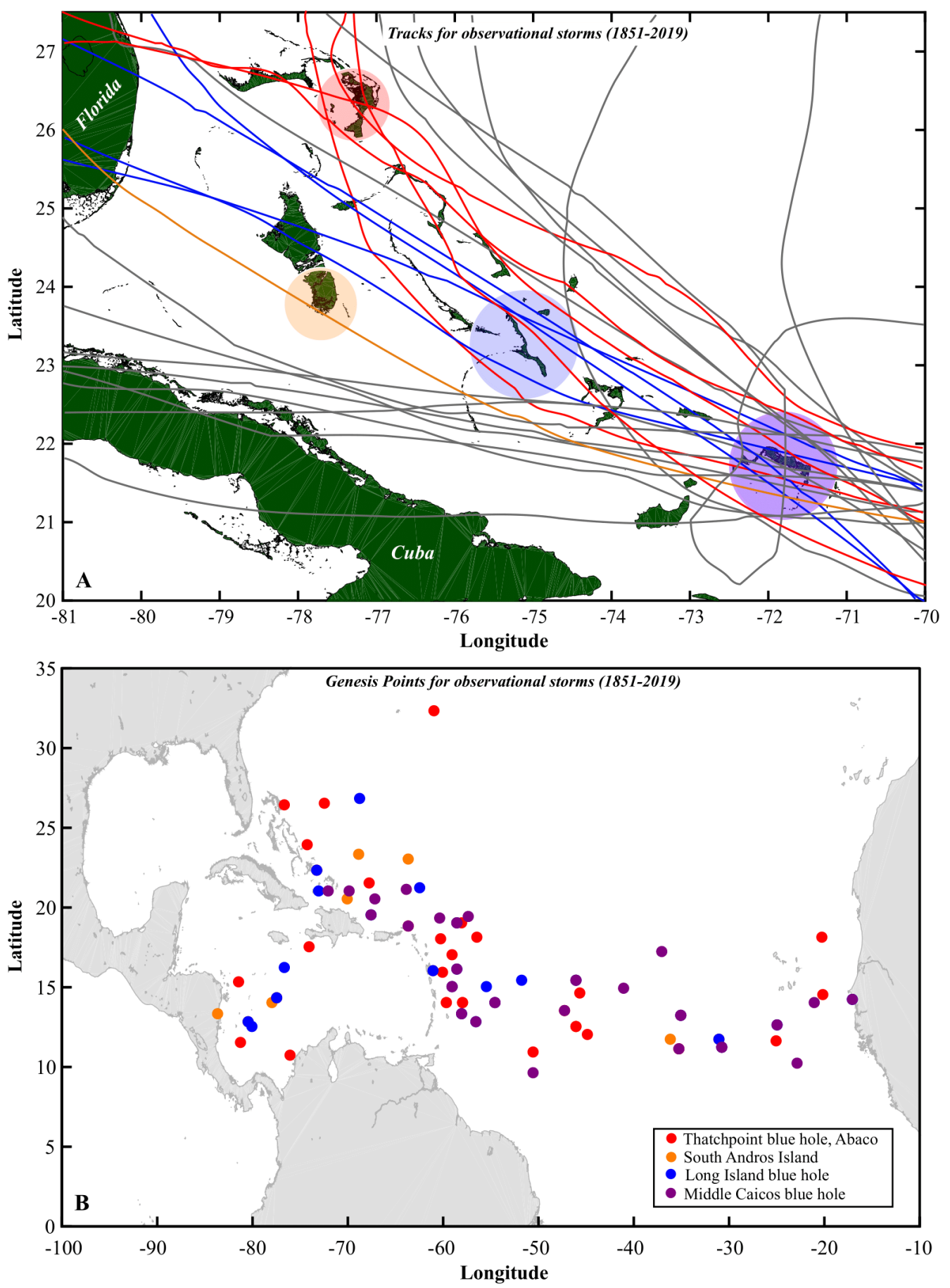

Figure S4.6: (A) Map showing $50 \mathrm{~km}$ radii around Thatchpoint Blue Hole on Abaco Island (Winkler, in review) (red) and the AM4 blue hole on South Andros Island (orange) (Wallace et al., 2019 (Chapter 2)) and $75 \mathrm{~km}$ radii around Long Island blue hole (blue) (Wallace et al., Chapter 3) and Middle Caicos blue hole (purple). Historical hurricane tracks (Category 1 and above from 1850-2019) passing within $100 \mathrm{~km}$ of Middle Caicos blue hole are plotted. Storms that pass within the radii around of Abaco Island, South Andros, and Long Island are plotted in red, orange, and blue, respectively. All other storm tracks are plotted in grey. (B) Genesis points for observational storms (1851-2015) passing within $75 \mathrm{~km}$ of Middle Caicos (purple) and Long Island (blue) and $50 \mathrm{~km}$ of South Andros (orange) and Abaco Island (red). 

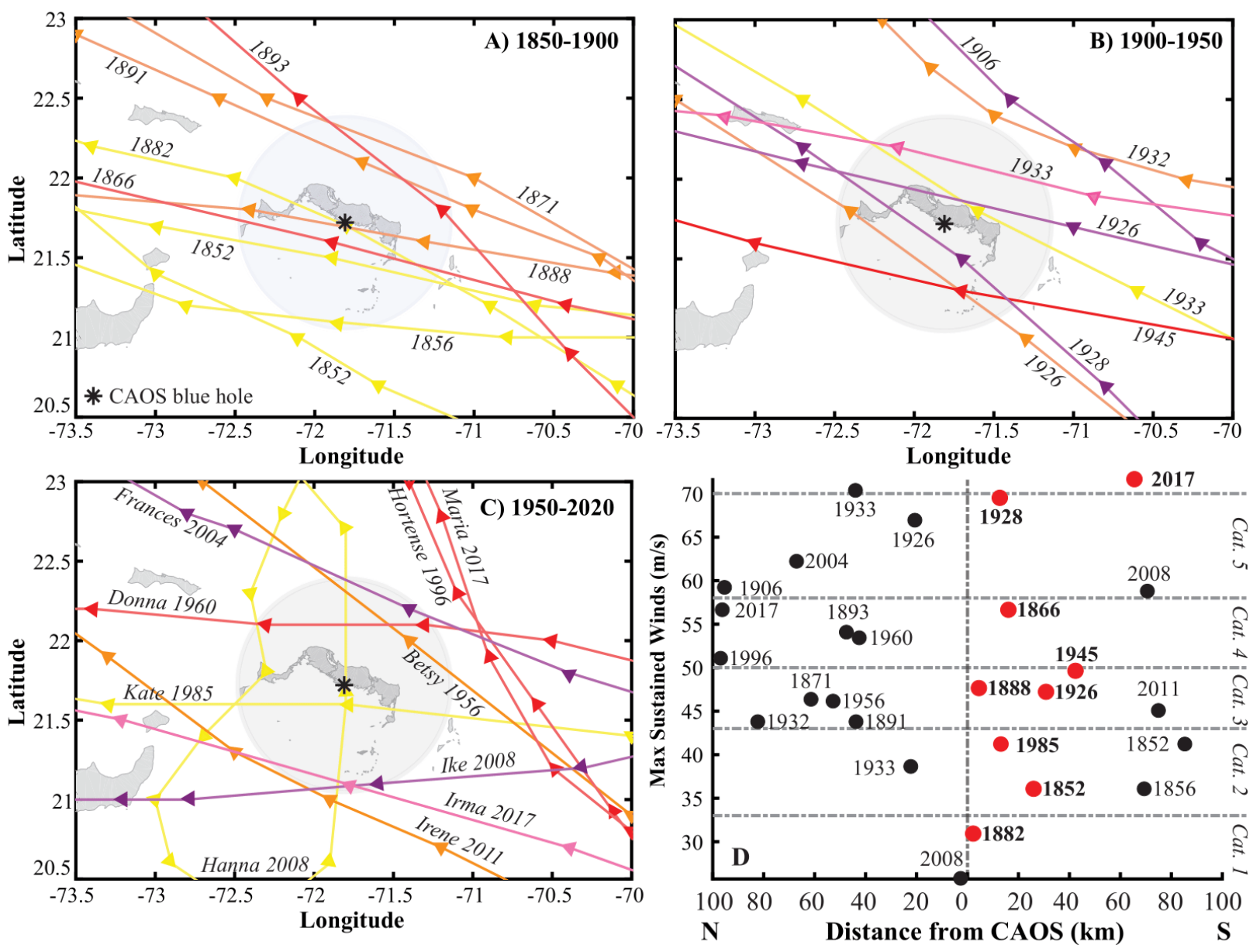

Figure S4.7: Historical hurricane tracks passing within $100 \mathrm{~km}$ of the Middle Caicos blue hole $\left(21.72^{\circ} \mathrm{N}, 71.81^{\circ} \mathrm{W}\right)$ from $(\mathbf{A}) 1850-1900 \mathrm{CE},(\mathbf{B}) 1901-1950 \mathrm{CE}$, and (C) 1950-2019 CE. A black star indicates the blue hole location and a grey circle shows a $75 \mathrm{~km}$ radius around the blue hole. (D) Storm intensity and orientation upon closest passage to the Middle Caicos blue hole. Red dots indicate the storms that left deposits in the blue hole. The storm's closest passage to the Middle Caicos blue hole is plotted to the left of zero if the storm moves to the north of the site and to the right of zero if the storm moves to the south of the site. 

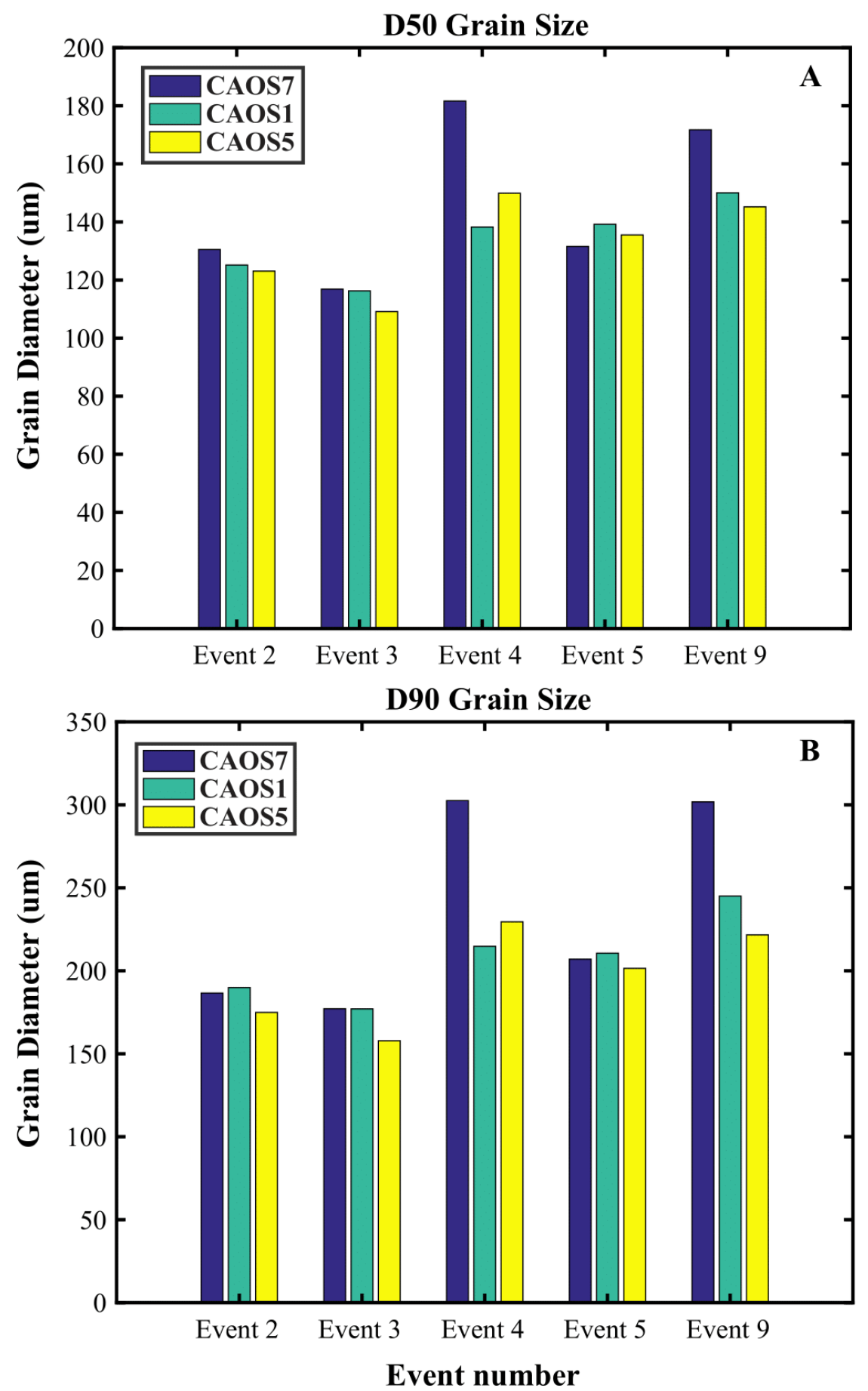

Figure S4.8: D50 (A) and D90 (B) for $>63 \mu \mathrm{m}$ sediment samples across the transect of cores at CAOS. Results are shown for the modern events beds where a coarse layer was left behind in all three cores in the transect (CAOS7, CAOS1, CAOS5). These event beds include 2-5 and 9. 

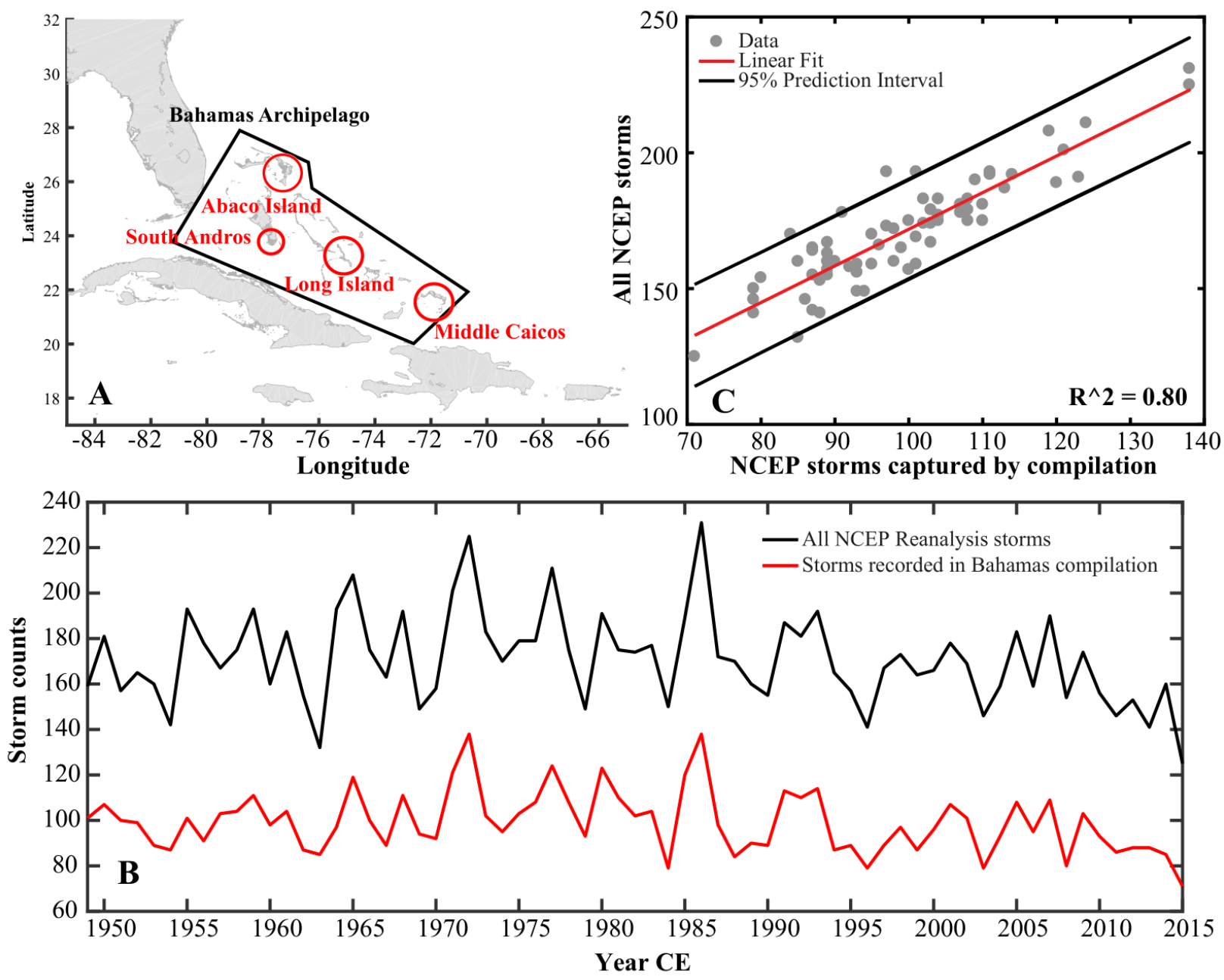

Figure S4.9: Regression of compilation storms to all storms in the Bahama Archipelago. (A) Map of the contributing sites and bounds of the polygon encompassing the Bahama Archipelago. (B) The number of synthetic storms ( $\geq$ tropical storm strength) passing through a polygon over the Bahama Archipelago (black). The number of these Bahama Archipelago storms that would be captured in the Bahama Archipelago compilation: Abaco Island (Category 2 and above within a $75 \mathrm{~km}$ radius), Long Island Island (Category 2 and above within a $75 \mathrm{~km}$ radius), South Andros Island (Category 3 and above within a $50 \mathrm{~km}$ radius), and Middle Caicos Island (Category 1 and above within a $75 \mathrm{~km}$ radius). (C) Linear fit of all storms (black) on compilation storms (red) from panel B. 95\% confidence intervals for the fit are shown. The R squared between the two variables is 0.8 . 
Figure S4.10: Components of regional compilations of hurricane counts from 500-2019 CE for the (A) Florida High Threshold ( $\geq$ Category 3): Spring Creek Pond (Brandon et al., 2013) (red), Mullet Pond (Lane et al., 2011) (light orange), and Basin Bayou (Rodysill et al., in review) (dark orange), (B) Florida Low Threshold ( $\geq$ Category 1): Shotgun Pond (Rodysill et al., in review) (pink), Spring Creek Pond (Brandon et al., 2013) (red), Mullet Pond (Lane et al., 2011) (light orange), and Basin Bayou (Rodysill et al., in review) (dark orange), (C) The Bahamas: Abaco (light green), Andros (dark blue), Middle Caicos (dark green), and Long Island (Wallace et al., Chapter 3) (light blue), and (D) New England: Salt Pond (Donnelly et al., 2015) (purple) and Mattapoisett Marsh (Boldt et al., 2010) (lavender). Abaco includes events from Thatchpoint Blue Hole (Winkler et al., in review). Andros includes events from the AM5, AM4 and AM2 records (Wallace et al., 2019 (Chapter 2)). The stars at the top of each panel indicate the median age of each event used in the compilation. The compilations are the sum of the age probability distributions of each of these events. 

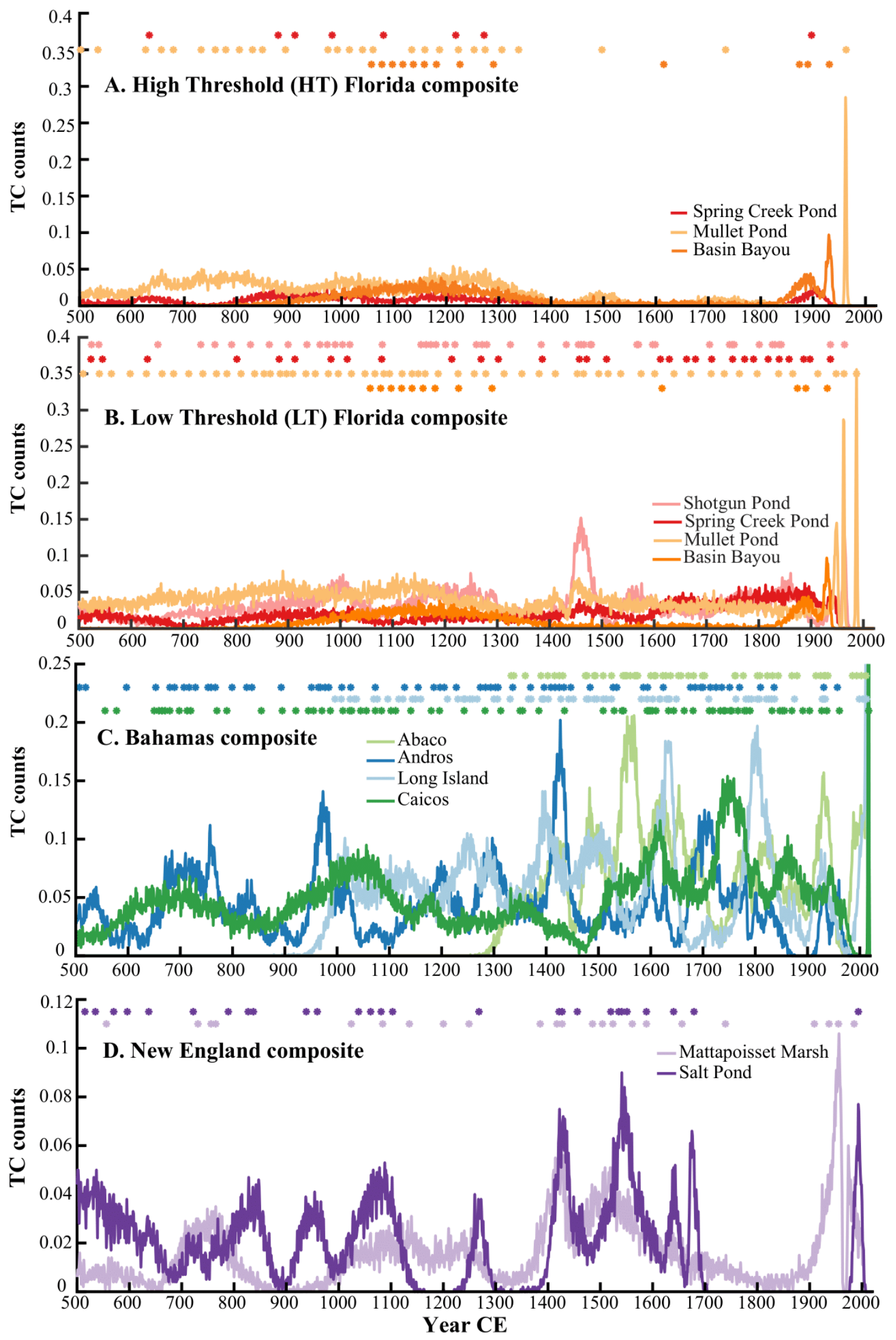
Figure S4.11: Florida High Threshold paleohurricane compilation (A), Florida Low Threshold paleohurricane compilation (B), The Bahamas paleohurricane compilation (C), and New England paleohurricane compilation (D) generated by summing the time series in Figure S4.7A, S4.7B, S4.7C, and S4.7D, respectively. Standard errors are shaded in grey around each compilations and are calculated as the spread among the estimates in Figure S4.7. The stars at the top of each panel indicate the median age of each event used in the compilation. 

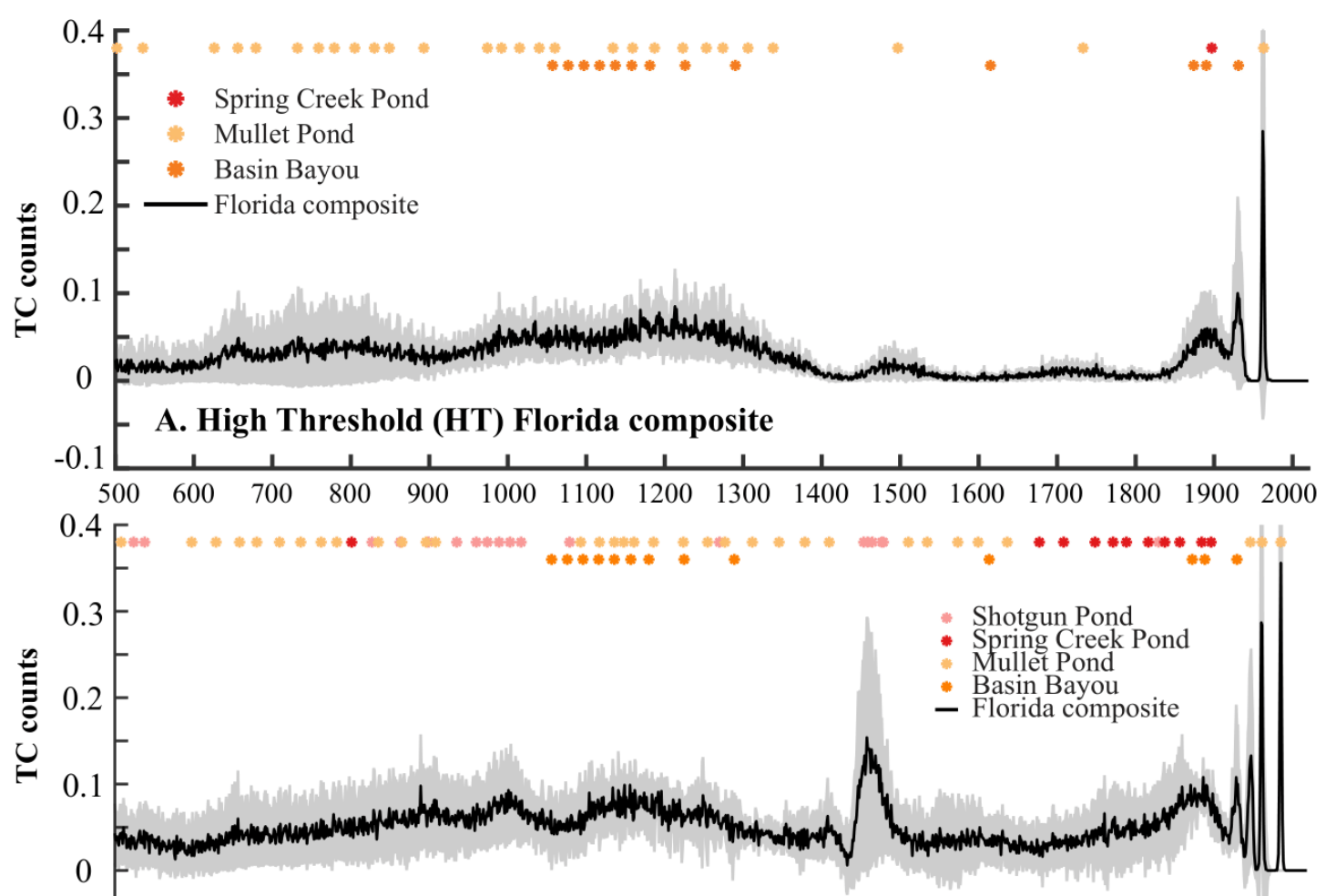

0

$-0.1$

B. Low Threshold (LT) Florida composite
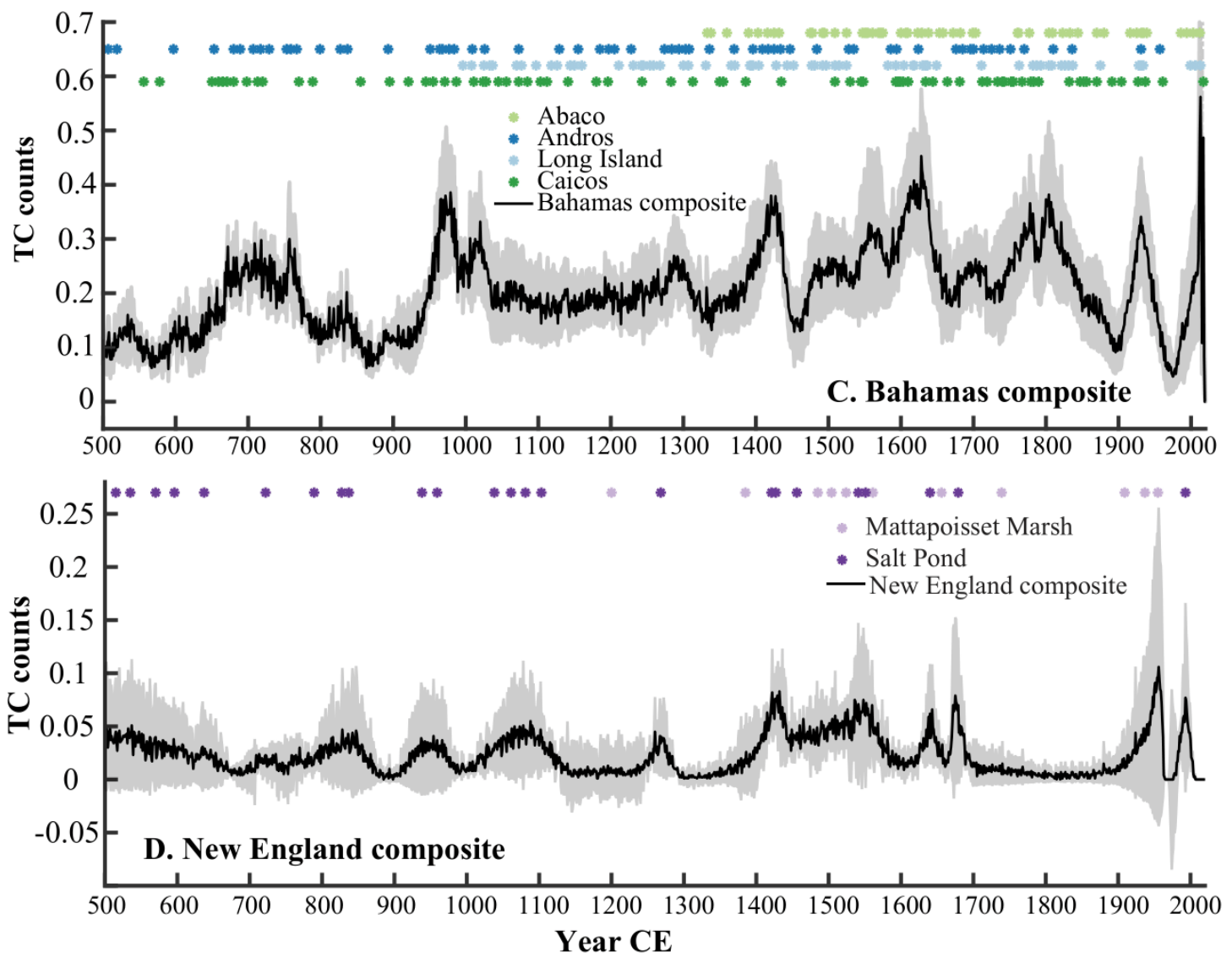
A) CAOS7 event 3 - Original

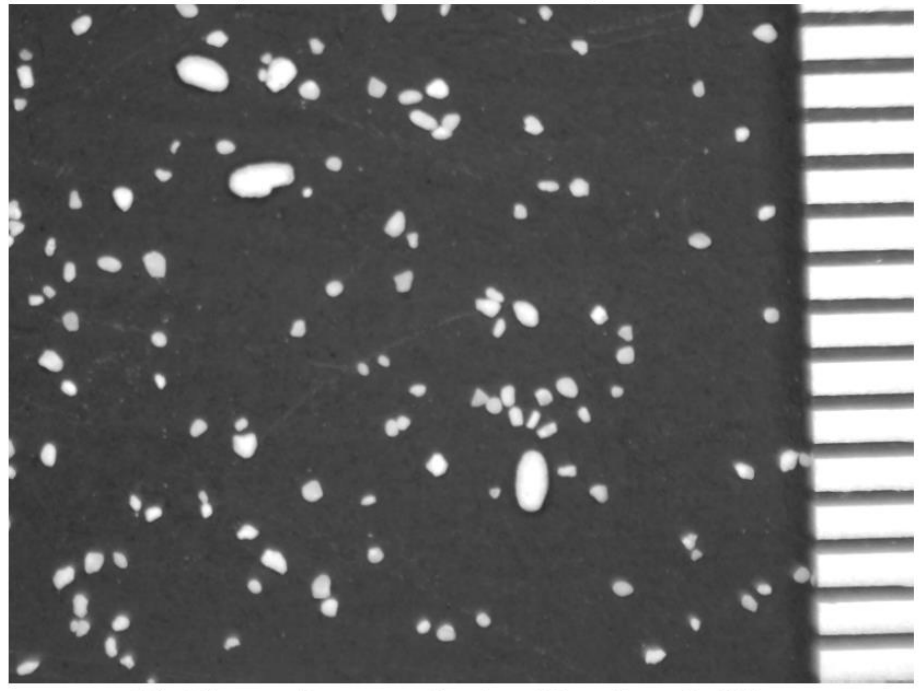

B) Binary image, obtained by thresholding

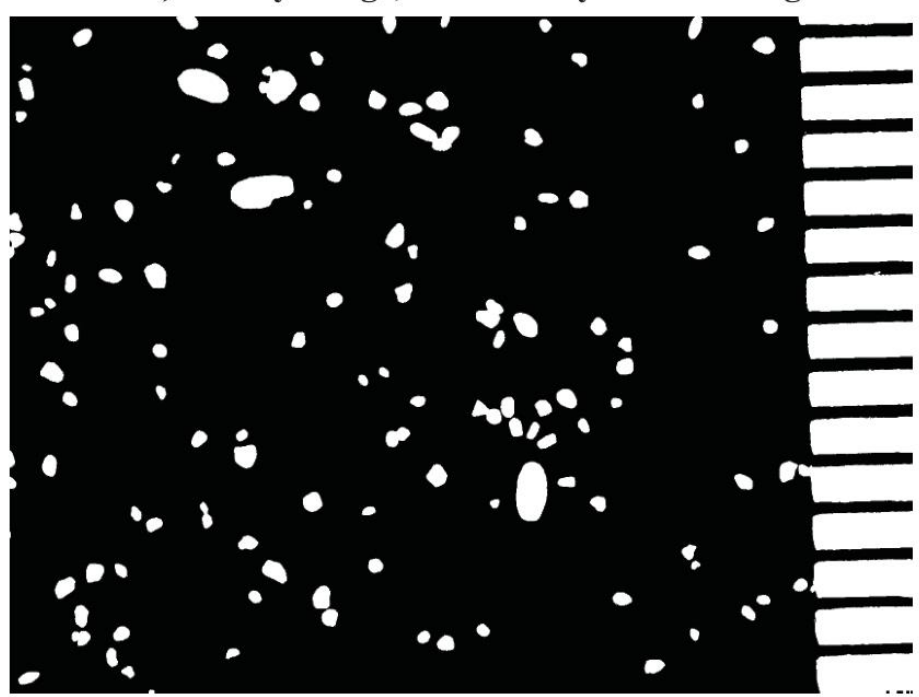

C) Area of grains outlined in green

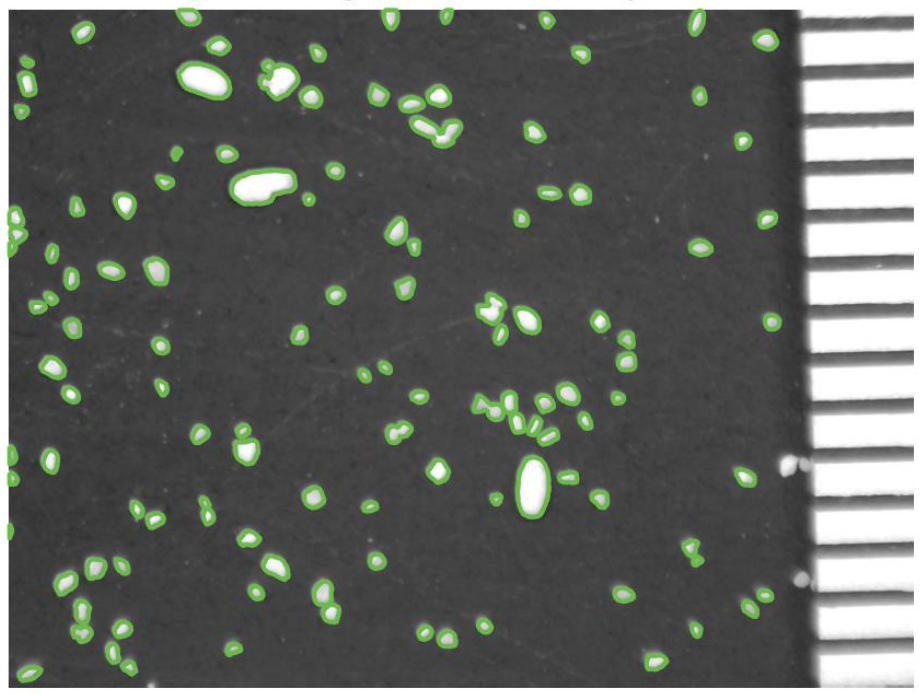

Figure S4.12: Example of image processing steps for measuring the grain size of modern event samples. (A) An example image of grains from CAOS7 event bed 3 . (B) Image from panel A converted to binary. (C) Objects identified in the original image. The area of each object (grain) is outlined in green. The scale bar on the right hand side of each image show 0.5 $\mathrm{mm}$ increments. 
Table S4.1: Radiocarbon results from leaf and plant matter in CAOS7 and CAOS5.

\begin{tabular}{|l|c|c|c|c|c|c|c|c|}
\hline \multicolumn{1}{|c|}{ Core } & $\begin{array}{c}\text { Laboratory } \\
\text { Number }\end{array}$ & $\begin{array}{c}\text { Core } \\
\text { depth } \\
\text { (cm) }\end{array}$ & $\begin{array}{c}\text { Material } \\
\text { dated }\end{array}$ & $\begin{array}{c}\text { Conventional } \\
\mathbf{1 4}_{\mathbf{C}} \text { age }\end{array}$ & Error & $\begin{array}{c}\text { F } \\
\text { Modern }\end{array}$ & $\begin{array}{c}\text { F } \\
\text { Modern } \\
\text { error }\end{array}$ & D13C \\
\hline $\begin{array}{l}\text { CAOS7 } \\
\text { D3 }\end{array}$ & OS-135711 & 162.5 & Plant/Wood & 175 & 20 & 0.9784 & 0.0022 & -26.85 \\
\hline $\begin{array}{l}\text { CAOS7 } \\
\text { D3 }\end{array}$ & OS-138247 & 273 & Plant/Wood & 490 & 60 & 0.9409 & 0.0073 & -20.3 \\
\hline $\begin{array}{l}\text { CAOS7 } \\
\text { D3 }\end{array}$ & OS-138283 & 330 & Plant/Wood & 390 & 15 & 0.9528 & 0.0020 & -26.22 \\
\hline $\begin{array}{l}\text { CAOS7 } \\
\text { D3 }\end{array}$ & OS-138262 & 443 & Plant/Wood & 830 & 20 & 0.9019 & 0.0020 & -20.97 \\
\hline $\begin{array}{l}\text { CAOS7 } \\
\text { D3 }\end{array}$ & OS-127193 & 539 & Plant/Wood & 880 & 15 & 0.8961 & 0.0018 & -24.03 \\
\hline $\begin{array}{l}\text { CAOS5 } \\
\text { D1 }\end{array}$ & OS-138261 & 81.5 & Plant/Wood & 200 & 15 & 0.9755 & 0.0021 & -25.48 \\
\hline $\begin{array}{l}\text { CAOS5 } \\
\text { D1 }\end{array}$ & OS-142284 & 184.5 & Plant/Wood & 155 & 15 & 0.9810 & 0.0019 & -28.14 \\
\hline $\begin{array}{l}\text { CAOS5 } \\
\text { D1 }\end{array}$ & OS-138363 & 329 & Plant/Wood & 300 & 20 & 0.9634 & 0.0025 & -23.16 \\
\hline $\begin{array}{l}\text { CAOS5 } \\
\text { D1 }\end{array}$ & OS-142406 & 412 & Plant/Wood & 840 & 100 & 0.9008 & 0.0116 & -23.21 \\
\hline $\begin{array}{l}\text { CAOS5 } \\
\text { D1 }\end{array}$ & OS-138365 & 537.5 & Plant/Wood & 860 & 20 & 0.8987 & 0.0021 & -22.96 \\
\hline $\begin{array}{l}\text { CAOS5 } \\
\text { D1 }\end{array}$ & OS-142283 & 670.5 & Plant/Wood & 1080 & 20 & 0.8741 & 0.0020 & -22.76 \\
\hline
\end{tabular}


Table S4.2: Unused Radiocarbon results from leaf and plant matter in CAOS7, CAOS1, and CAOS5.

\begin{tabular}{|c|c|c|c|c|c|c|c|c|}
\hline Core & $\begin{array}{l}\text { Laboratory } \\
\text { Number }\end{array}$ & $\begin{array}{c}\begin{array}{c}\text { Core } \\
\text { depth } \\
(\mathrm{cm})\end{array} \\
\end{array}$ & $\begin{array}{c}\text { Material } \\
\text { dated }\end{array}$ & $\begin{array}{l}\text { Conventional } \\
{ }^{14} \mathrm{C} \text { age }\end{array}$ & Error & $\underset{\text { Modern }}{\mathbf{F}}$ & $\begin{array}{c}\mathbf{F} \\
\text { Modern } \\
\text { error } \\
\end{array}$ & D13C \\
\hline CAOS7 D1 & OS-142282 & 73.5 & Plant/Wood & 535 & 20 & 0.9356 & 0.0021 & -5.51 \\
\hline CAOS7 D3 & OS-135709 & 94.5 & Plant/Wood & -5 & 1 & 1.0006 & 0.0020 & -6.87 \\
\hline CAOS7 D3 & OS-131476 & 122.5 & Plant/Wood & 905 & 15 & 0.8932 & 0.0018 & -26.03 \\
\hline CAOS7 D3 & OS-138248 & 156.5 & Plant/Wood & 590 & 110 & 0.9295 & 0.0129 & -9.35 \\
\hline CAOS7 D3 & OS-135710 & 239.5 & Plant/Wood & 730 & 15 & 0.9132 & 0.0019 & -6.22 \\
\hline CAOS7 D3 & OS-131477 & 263.5 & Plant/Wood & 760 & 15 & 0.9100 & 0.0020 & -7.7 \\
\hline CAOS7 D3 & OS-150244 & 419.5 & Plant/Wood & 865 & 45 & 0.8980 & 0.0053 & -8.31 \\
\hline CAOS7 D3 & OS-127192 & 510 & Plant/Wood & 770 & 20 & 0.9087 & 0.002 & -7.77 \\
\hline CAOS7 D3 & OS-135853 & 629.5 & Plant/Wood & 1290 & 60 & 0.8519 & 0.0062 & -14.46 \\
\hline CAOS7 D3 & OS-150243 & 766 & Plant/Wood & 1500 & 45 & 0.8298 & 0.0047 & -7.84 \\
\hline CAOS7 D3 & OS-153953 & 766 & Plant/Wood & 1450 & 15 & 0.8350 & 0.0018 & -6.47 \\
\hline CAOS7 D3 & OS-154063 & 822 & Plant/Wood & 2430 & 190 & 0.7393 & 0.0176 & $\begin{array}{c}\text { Not } \\
\text { measured }\end{array}$ \\
\hline CAOS7 D3 & OS-154062 & 866 & Plant/Wood & 2010 & 180 & 0.7788 & 0.0172 & $\begin{array}{c}\text { Not } \\
\text { measured }\end{array}$ \\
\hline CAOS1 D2 & OS-142286 & 52.5 & Plant/Wood & 390 & 15 & 0.9525 & 0.0018 & -5.94 \\
\hline CAOS1 D1 & OS-153911 & 739 & Plant/Wood & 970 & 15 & 0.8863 & 0.0019 & -26.64 \\
\hline CAOS5 D2 & OS-138367 & 24.5 & Plant/Wood & 465 & 20 & 0.9437 & 0.0023 & -6.26 \\
\hline CAOS5 D1 & OS-142287 & 52.5 & Plant/Wood & 465 & 20 & 0.9435 & 0.0023 & $\begin{array}{c}\text { Not } \\
\text { measured }\end{array}$ \\
\hline CAOS5 D2 & OS-150346 & 52.5 & Plant/Wood & 500 & 15 & 0.9396 & 0.0018 & -5.42 \\
\hline CAOS5 D2 & OS-138368 & 77.5 & Plant/Wood & 480 & 20 & 0.9422 & 0.0021 & -7.14 \\
\hline CAOS5 D1 & OS-150245 & 79.5 & Plant/Wood & 695 & 45 & 0.917 & 0.0052 & -8.97 \\
\hline CAOS5 D1 & OS-150347 & 122.5 & Plant/Wood & 610 & 15 & 0.9269 & 0.0018 & -6.28 \\
\hline CAOS5 D1 & OS-142285 & 122.5 & Plant/Wood & 760 & 20 & 0.9100 & 0.0020 & -6.55 \\
\hline CAOS5 D1 & OS-138097 & 130.5 & Plant/Wood & 255 & 15 & 0.9686 & 0.0019 & -25.51 \\
\hline CAOS5 D1 & OS-138250 & 162.5 & Plant/Wood & 565 & 20 & 0.9323 & 0.0021 & -6.5 \\
\hline CAOS5 D1 & OS-138098 & 261.5 & Plant/Wood & 700 & 15 & 0.9167 & 0.0018 & -7.55 \\
\hline CAOS5 D1 & OS-138364 & 481 & Plant/Wood & 950 & 20 & 0.8884 & 0.0021 & -8.33 \\
\hline CAOS5 D1 & OS-150038 & 520.5 & Plant/Wood & 1200 & 110 & 0.8610 & 0.0115 & $\begin{array}{c}\text { Not } \\
\text { measured }\end{array}$ \\
\hline CAOS5 D1 & OS-150345 & 557 & Plant/Wood & 1180 & 15 & 0.8634 & 0.0018 & -9.61 \\
\hline CAOS5 D1 & OS-138366 & 696 & Plant/Wood & 1280 & 20 & 0.8530 & 0.0021 & -9.05 \\
\hline
\end{tabular}




\title{
5. Centennial-scale patterns in individual paleohurricane records in the Bahamas are predominantly driven by randomness
}

\begin{abstract}
Paleohurricane reconstructions of the last millennium, including a recent reconstruction of intense hurricane activity at South Andros Island, indicate dramatic changes in the frequency of landfalling hurricanes on centennial timescales. It is difficult to assess whether the variability captured in these paleorecords is related to changing climate or simply a result of randomness. Here we assess whether active and quiet intervals of intense hurricane activity occur in a set of synthetic storms derived from tropical cyclone simulations run with boundary conditions from a state-of-the-art earth system model simulation of the last millennium. We generate 1000 records of storm occurrence at South Andros Island using a Poisson random draw from our synthetic storm dataset. Pseudo sedimentary records are then generated using a prescribed threshold for deposit and a temporal resolution set by sedimentation rates at the site. We find that any single pseudo sedimentary record contains active and quiet intervals of hurricane activity, much like that observed in the proxy reconstruction. The 1000-record ensemble average, which reflects the common signal of climate variability across the synthetic storm dataset, does not. This strongly suggests that the record of paleohurricane activity from The Bahamas reflects variability in hurricane tracks driven by randomness and not variability in the climatic boundary conditions. Nevertheless, the underlying climate signal captured in a pseudo record is coherent across neighboring sites, which highlights the promise of using regional or larger scale compilations of records to characterize hurricane activity and its drivers.
\end{abstract}

\subsection{Introduction}

With rising sea levels (Woodruff et al., 2013; Kopp et al., 2016) and projected increases in the frequency of intense tropical cyclones (TCs) (Emanuel et al., 2008; Emanuel, 2013; Sobel et al., 2016; Walsh et al., 2016; Korty et al., 2017), coastal communities are becoming more vulnerable to TC-induced inundation. Unfortunately, the models we use to predict TC activity in real time and into the future can only be validated on a limited observational record. Specifically, with only 168 years of observations that suffer from biases (Frappier, Knutson, et al., 2007; Villarini et al., 2011; Landsea et al., 2004; Landsea and Franklin, 2013; Vecchi and Knutson, 
2008; Landsea et al., 2010; Vecchi and Knutson, 2011; Knutson et al., 2019), we cannot characterize the influence of climate variability on TC activity or elucidate TC-climate interactions during climatic states different from today. Natural archives of paleohurricane activity have been developed to extend the record of landfalling hurricanes back thousands of years, with these records exhibiting substantial variability in hurricane activity on centennial timescales. Very little work has been done to integrate paleohurricane records with existing TC models, and it is thus difficult to assess the underlying cause of this variability. Here, we integrate paleohurricane records with a TC model run over the past millennium to assess the significance of centennial-scale variability in TC activity recorded in reconstructions from The Bahamas.

In the last few decades, there has been a growing number of high resolution sedimentary records of paleohurricane activity from coastal basins in the Atlantic (Lane et al., 2011; Wallace et al., 2019 (Chapter 2); Donnelly et al., 2015; Denommee et al., 2014; van Hengstum et al., 2016). Tropical cyclones generate strong winds, wave run-up, and storm surge that displace and transport coarse grains into depositional environments where finer grained sediments dominate (e.g., lagoons, marshes). There, they form event beds, distinct layers of coarse material among the fine mud and/or peat. Documenting and dating event beds in sediment cores provides high resolution archives of tropical cyclone activity at a location over thousands of years. Recent paleohurricane research has seen both an increase in the length of the cores recovered and the resolution of those records. In particular, collecting cores from blue holes in the Caribbean Sea have allowed for near-annual resolution records extending back over a thousand years (Winkler et al., in review; Wallace et al., 2019 (Chapter 2); van Hengstum et al., 2014; Denommee et al., 2014). While there is a myriad of different storm properties (e.g., intensity, track, and size) that could influence storm surge at a site, both modern event attribution in these sediment cores (Wallace et al., 2019 (Chapter 2); Winkler et al.; Lane et al., 2011) and hydrodynamic modeling of large suites of synthetic tropical cyclones passing the sites (Lin et al., 2014) indicate that the vast majority of storms that leave deposits are above some intensity threshold (>Category 2 or 3 ) and proximal passing (within $<100 \mathrm{~km}$ ).

Paleohurricane reconstructions indicate that there have been dramatic changes in hurricane activity over the past two millennia (Brandon et al., 2013; Lane et al., 2011; Wallace et al., 2019 (Chapter 2); Donnelly et al., 2015; Bregy et al., 2018; van Hengstum et al., 2014; 
Winkler et al., in review; Boldt et al., 2010). In particular, these records capture multi-decadal to centennial scale periods with an elevated frequency of hurricane strikes ('active intervals') followed by extended time periods of relative quiescence ('quiet intervals'). Many studies have attributed these active and quiet intervals to changes in the large-scale climatic boundary conditions (e.g., the Intertropical Convergence Zone (Donnelly et al., 2015; van Hengstum et al., 2016), North Atlantic Subtropical High (Wallace et al., 2019 (Chapter 2); Baldini et al., 2016), West African monsoon (Donnelly and Woodruff, 2007), El Nino Southern Oscillation (Donnelly and Woodruff, 2007). However, these interpretations rely on the assumption that the signal captured in these records is dominated by climate. In reality, there are likely two important contributors: 1) climate variability (the assumption) and 2) random clustering of events independent of climate. The first contributor encompasses large-scale and slowly varying climate factors (e.g., changes in Atlantic sea surface temperatures (Emanuel, 2008), vertical wind shear (Elsberry and Jeffries, 1996; Wong and Chan, 2004), vorticity (Emanuel, 2008)) that contribute to how many storms are forming and their tracks. The latter encompasses factors like local weather that affect whether a storm will pass close enough to a site or at high enough intensity to leave a deposit. While local weather is connected to climate, it is difficult, even today, to forecast the path or intensity of a tropical cyclone from hours to days before its occurrence. The highly chaotic nature of TC-local weather interactions justifies their characterization as random within the context of paleohurricane research.

In this paper, we assess how much of the variability captured in Bahamian paleohurricane records is due to large scale climate variability. In particular, we focus on a blue hole site from a recently published paper on South Andros Island in The Bahamas (Wallace et al., 2019 (Chapter 2)). We create 1000 pseudo sedimentary records of paleohurricane activity at South Andros using an annual Poisson process-based draw (Woodruff et al., 2008) from an archive of synthetic storms consistent with modeled past millennium climate. Only storms meeting a prescribed threshold for deposit and a temporal resolution set by sedimentation rates at the site leave an event bed. We use these pseudo sediment records to rigorously determine the capacity of individual paleohurricane records from the Caribbean to distinguish climate signal from noise. This work has critical implications for use of paleohurricane records to infer climate impacts on intense hurricane activity. 


\subsection{Producing paleohurricane activity with synthetic storms}

We convert synthetic storm data into pseudo sediment records by mimicking the processes that affect whether a TC leaves an event bed in the blue hole on South Andros Island. The input to the model is a large number ( 50 storms/year from $850-2005 \mathrm{CE}-57,796$ storms) of synthetic tropical cyclones passing within $100 \mathrm{~km}$ of South Andros. The storms were generated used a statistical deterministic hurricane model (Emanuel et al., 2008, 2006), driven by the MPI-ESM-P (Max Planck Institute (MPI) Earth System Model) millennial simulation (8501850 CE) (Jungclaus et al., 2010) and the historical simulation (1850-2005 CE) (Giorgetta et al., 2013) as the initial and boundary conditions. The genesis points, tracks, and intensities of these synthetic storms over the historical period (1850-present) broadly match those of observed storms (Figure S5.1). We generate 1000 pseudo sediment records for South Andros Island utilizing a Poisson random draw from our synthetic storm dataset, an intensity threshold for deposit, and imposing a temporal resolution based on the existing proxy reconstruction (Section 5.6.2).

All of the pseudo sediment records show dramatic changes in hurricane activity over the past millennium, much like we find in the actual reconstruction (Figure 5.1). On average, the 100-year window event frequency for single a pseudo sediment record varies from $\sim 8$ events/century to less than 1 event/century. Clustering of event beds in time lead to extended periods ('active intervals') when the 100-year window event frequency continuously lies above the threshold for expected activity on South Andros (4.9 events/century- Section 5.6.3). Across the 1000 pseudo records, we observe on average $1.2 \pm 1.8$ centennial ( $>100$ years) timescale active intervals and 2.9 \pm 3.5 multi-decadal scale (20-100 years) active intervals. Often directly following these active intervals, we see quiet periods or extended periods of time ( $>50$ years) without an intense hurricane strike on South Andros. We record on average $6.2 \pm 3.3$ quiet periods over the past millennium. In general, pseudo sediment records contain similar numbers of events as the South Andros reconstruction as well as a similar number and length of active and quiet intervals (Figure S5.2).

\subsection{Quantifying the climate signal to noise in paleohurricane records}

Each of the fifty synthetic storms for each year in our dataset are generated using the same climate conditions, namely the ocean-atmosphere states from that year in the MPI-ESM 
simulation. By using a Poisson process-based random draw from these fifty storms, we are generating 1000 different scenarios of storm occurrence all consistent with the climate conditions that occurred in that year, but also accounting for randomness. Averaging the 1000 pseudo sediment records together quantifies the climate signal. We find that this ensemble average (our climate signal) has much less variability than any single record (Figure 5.2), with a range of $3.4-$ 4.2 events/century. Although subdued, the variability in the 1000 ensemble average is outside the expected Poisson noise of $\sim 0.06$ events/century (Section 5.6.4). Comparing the variability in each of the 1000 individual records (containing the climate signal and randomness) to the climate signal, we find a signal-to-noise ratio (SNR) of 2 . Thus, only $68 \%$ of the individual records would give you a value in a given year within 2 events/century of actual climate signal ( $2 \mathrm{x}$ the range of entire climate signal). The other third of the individual records would give you an even wilder estimate. While each of the pseudo sediment records contain active and quiet intervals of hurricane activity, the timing of these intervals are very different from record to record. Thus, when we average the 1000 different records together, the SNR is low (Figure 5.2, Figure S5.3). This low SNR suggests that there is too much noise to use a single reconstruction from South Andros to infer climate impacts on hurricane activity. Instead, hurricane activity in a single reconstruction, even on centennial timescales, is dominated by random variations in intense hurricane strikes.

To test the underlying cause of dramatic centennial scale variability in the individual pseudo sediment records, we create a second set of pseudo sediment records using a pure Poisson process (i.e., without hurricane or climate model data). Any single record created using this pure Poisson process contains centennial-scale variations like the reconstruction (Figure S5.4). Finding similar centennial-scale variability in a single record dictated purely by randomness further confirms that random clustering of intense hurricane strikes creates most of the signal observed in a single reconstruction.

\subsection{A coherent signal across sites in The Bahamas}

While significantly dampened compared to a single record, the ensemble average does contain an underlying centennial-scale climate signal (Figure 5.2). We see more hurricanes from 1015-1115 CE, 1270-1450 CE, and 1750-1850 CE and fewer hurricanes from approximately 915-1015 and 1460-1740 CE. The existence of a climate signal on South Andros raises the question of whether this climate signal extends to other islands in The Bahamas. This is 
motivated by recent efforts to collect paleohurricane records from blue holes throughout the Caribbean region to better constrain regional and basin scale hurricane activity. Using the same random draw methods from independent sets of randomly seeded synthetic storms forced by the same MPI climate model output, we create 1000 pseudo sediment records for two other sites in the northern Caribbean where paleohurricane reconstructions from blue holes have been collected: Long Island, The Bahamas and Caicos Island. Long Island is situated $\sim 250 \mathrm{~km}$ to the southeast of South Andros and Caicos Island is $\sim 650 \mathrm{~km}$ to the southeast of South Andros. Long Island is only $\sim 380 \mathrm{~km}$ away from Caicos Island (Figure 5.3). The ensemble averages (climate signals) for these other two sites also show centennial scale variations in hurricane activity over the past millennium. The climate signals for the sites that are less than $400 \mathrm{~km}$ apart (Long Island and South Andros; Long Island and Caicos) correlate significantly with each other at the $95 \%$ confidence level ( $\mathrm{r}=0.32 ; \mathrm{r}=0.36$, respectively). However, the common climate signals degrade for Caicos Island and South Andros Island $(r=-0.05)$, which are further apart (Figure 5.3).

Importantly, the pseudo sediment records for each site in the analysis above were produced from independent sets of synthetic storms, yet we still observe a common climate signal across neighboring sites (i.e., South Andros and Long Island). Nevertheless, it is clear from this exploratory work that the climate signal can degrade between sites as close as $650 \mathrm{~km}$ apart (i.e., South Andros and Caicos). Together these results suggest that there is promise in trying to compile reconstructions from sites that are close enough to experience the same climate signal but far enough apart to sample different storms. Compiling paleohurricane reconstructions together into regional or basin-scale estimates of hurricane activity is important for placing modern Atlantic hurricane activity into a longer term context and for regional preparedness and planning. Previous work shows that an Atlantic basin-integrated reconstruction formed from compiling regional paleohurricane records together is statistically consistent with a completely independent model of TC activity driven by proxy reconstructions of past climate (Mann et al., 2009). However, as the number of paleohurricane reconstructions grow and as the field of paleotempestology moves toward compiling new and old paleohurricane reconstructions together, it is important to understand how much of the changes we observe in hurricane activity in these records and compilations of these records are driven by climate. Thus, future work 
exploring the best ways to compile paleohurricane records together to maximize climate signal and quantify regional and basin scale hurricane activity is needed.

\subsection{Implications for paleohurricane research}

The results presented herein have the potential to transform the way we understand paleohurricane research. Interpretation of paleohurricane records often relies on an assumption that the signal in each record is directly related to climate variability and change. In this study, we find that this is not true for any individual record of paleohurricane activity from the Caribbean. These records suffer from a significant sampling bias; each site samples only a small subset of storms moving through the Caribbean. Whether a storm passes close to a site and at high enough intensity to leave an event bed is driven more by random variability (i.e., driven by local weather) than by climate.

Previous work from the Bahamas (van Hengstum et al., 2014, 2016; Wallace et al., 2019 (Chapter 2); Winkler et al., in review) and Belize (Denommee et al., 2014) have used a single paleohurricane record to make claims about the climatic drivers of Atlantic and Bahamian hurricane activity over the past few thousand years. The sampling bias explored in this work means that each of these sites alone should not be used in this context. In short, we need to exercise caution in making climate interpretations or inferring regional to basin scale hurricane activity from a single record.

This work also offers an explanation for why recent paleohurricane records from neighboring islands in the Caribbean observe different patterns of hurricane activity (Winkler et al. in review; Wallace et al., 2019 (Chapter 2)). They are each capturing a small subset of storms that pass through the Caribbean and the variability in each record is thus dominated by randomness. It is currently unclear whether this sampling issue applies to all paleohurricane sites in the Atlantic. During the hurricane season (June-November), sea surface temperatures in the Caribbean are generally warm enough for the development and maintenance of hurricanes (Locarnini et al., 2013). Variability in local hurricane activity is thus likely to be dominated by the tracking of hurricanes after development. Given the lack of climate signal in Caribbean records, we can infer that hurricane tracks are driven by local-to-regional weather rather than by climate. At paleohurricane sites in temperate locales (e.g., Brandon et al., 2013; Boldt et al., 2010; Donnelly et al., 2015; Lane et al., 2011; Bregy et al., 2018), however, climate is less favorable to hurricane growth and survival. Instead, shifts in large scale climate like the Atlantic 
Multidecadal Variability, the Intertropical Convergence Zone, or North Atlantic Subtropical High could create more or less favorable conditions for the development of hurricanes that will eventually reach the U.S. East and Gulf Coasts. If this is the case, we might expect a stronger climate signal in paleohurricane records from these regions. In general, paleohurricane reconstructions from the U.S. East (Boldt et al., 2010; Donnelly et al., 2015) and Gulf Coasts (Bregy et al., 2018; Brandon et al., 2013; Lane et al., 2011) tend to have more reproducible patterns in centennial-scale variability from site to site than records from The Bahamas. Future work simulating past millennium storms for the U.S. coastlines is needed to determine if this sampling bias extends to subtropical paleohurricane sites.

Ultimately, this study is the first to highlight the value in integrating TC models with existing paleohurricane reconstructions. Unfortunately, our results are limited to a single global climate model (MPI-ESM-P), largely due to the lack of daily wind data (required for the TC model simulations) archived for last millennium simulations from other global climate models. Given inter-model differences in the simulation of large scale climate variability during the last millennium (e.g. Coats, Smerdon, et al., 2015; Coats, Cook, et al., 2015), it is likely that there is a larger climate signal in other models. Future studies using an ensemble of different models are needed to characterize the true magnitude of the climate signal at paleohurricane sites. To do this, however, will require that high temporal resolution outputs are archived even for long model simulations like those of the past millennium.

Even with a multi-model ensemble of past millennium hurricanes, model-based results will not capture some properties of past millennium hurricanes at paleohurricane sites like South Andros. This is because the real world and simulated climate of the past millennium both result from a combination of internal variability, which will follow different trajectories, and common externally forced processes. Likewise, the simulation of these processes suffers from biases inherent to the modelling of the earth system and from uncertainties regarding the character and imposition of the external forcing. Many global climate model (GCM) simulations disagree with a proxy reconstructions and instrumental data about the timing, amount and spatial extent of surface temperature changes over the past millennium (e.g., Brohan et al., 2012; PAGES 2kPMIP3 group, 2015; Fernandez-Donado et al., 2013).

In addition, we make simplifying assumptions of real world processes in the creation of our pseudo-sediment records. These include using a uniform sedimentation rate of $1 \mathrm{~cm} / \mathrm{yr}$ for all 
the sites and assuming a site sensitivity dictated only by storm intensity and proximity of storm passage. While these simplifying assumptions are reasonable, there are often small differences in sedimentation rate within cores and across sites, and it is likely that other storm properties (e.g., translational velocity, track orientation, size, site geometry) play a role in event deposition for some storms (Lin et al., 2014). Site geometry, in particular, likely plays a larger role in event deposition for island sites like The Bahamas where storms can pass from many different directions. Despite these inherent and methodological uncertainties, we expect the results of our analyses to be largely conservative - if we conclude that there is a significant climate sampling issue using simplifying assumptions, this issue will likely worsen using more site-specific assumptions. To address these uncertainties directly, we need more hydrodynamic modeling in blue hole systems to explore the storm characteristics that are most important for generating coarse sediment transport on carbonate platforms and more simulations of the last millennium from state-of-the-art climate models with the necessary outputs archived.

This work highlights the promise in compiling reconstructions from neighboring sites together to maximize the climate signal and to better characterize regional to basin scale hurricane activity. Indeed, the climate signal from pseudo records at neighboring islands can be coherent if they are proximal enough. Future studies exploring the best ways to compile reconstructions from the Caribbean, and elsewhere, are needed. Here, we have shown that integrating tropical cyclone model and proxy data together is a critical step towards this goal.

\subsection{Methods}

\subsubsection{Generating the storm dataset}

Coarse sediment is only deposited in blue holes on South Andros Island during the proximal passage ( $<50 \mathrm{~km}$ radius away) of intense hurricanes (Category 3 and above). Such close moving and intense hurricanes strikes on the island are rare. From 1850-2014 CE, only two hurricanes left deposits in the blue holes. To overcome this small numbers problem, we generate a large number of synthetic tropical cyclones ( $\sim 0$ storms) passing within a $100 \mathrm{~km}$ radius of South Andros Island for each year between 850-2005 CE using a statistical deterministic hurricane model (Emanuel et al., 2006, 2008). This higher resolution regional model produces its own tropical cyclone climatology using the boundary conditions of a global climate model (GCM) in a technique known as downscaling. 
Here, we use the MPI-ESM (Max Planck Institute (MPI) Earth System Model) millennial simulation (850-1850 CE) and the historical simulation (1850-2005 CE) as the initial and boundary conditions for the tropical cyclone model. The MPI-ESM-P (Max Planck Institute (MPI) Earth System Model) model consists of two general circulation models for the atmosphere (ECHAM6) (Stevens et al., 2013) and ocean (MPIOM) (Jungclaus et al., 2013) coupled with a land surface model (JSBACH) and dynamical land vegetation (DYNVEG) (Reick et al., 2013; Schneck et al., 2013). The simulations have a spatial resolution of $1.865^{\circ} \times 1.875^{\circ}$ (Giorgetta et al., 2013).

The downscaling hurricane model generates storms through a three step process. In the first step, the storms are initiated through a random seeding process. Storms are placed randomly in space and time, regardless of season, latitude, or climate. The only exception is that storms cannot form equatorward of $\pm 3^{\circ}$. The 'seeds' are warm core vortices with peak wind speeds at 6 $\mathrm{m} / \mathrm{s}$ and no mid-level humidity anomaly in their cores. If these seeds meet with favorable environmental conditions, they survive and can develop into storms.

The second step involves generating tracks for the surviving storms using a Beta and Advection model (BAM). The BAM propagates storms according to a weighted average of the local 850 and $250 \mathrm{hPa}$ winds with a constant beta drift correction (Emanuel et al., 2006). The winds are represented as random-phase Fourier series with monthly means, variances, and covariances calculated using daily data from the MPI-ESM-P simulation. The winds are also constrained by a geostrophic turbulence power law distribution of kinetic energy.

Finally, the intensity and wind field of each synthetic storm track is created using a deterministic coupled air-sea model known as the Coupled Hurricane Intensity Prediction System (CHIPS) (Emanuel et al., 2004). The inputs to CHIPS are the monthly thermodynamic state (detailed in Emanuel, 2006) and wind shear based on daily mean winds from the MPIESM-P simulation. In addition, CHIPS uses MPI-ESM-P's monthly mean entropy at 600 hPa to represent the mid-tropospheric temperature and relative humidity. The wind fields for each storm are framed in angular momentum coordinates to allow for high resolutions (less than $1 \mathrm{~km}$ ) at the storm's inner core.

We generate a database of 57,796 synthetic storms - approximately 50 tropical depressions to Category 5 storms passing within $100 \mathrm{~km}$ of South Andros per year of the MPIESM-P last millennium simulation. 


\subsubsection{Creating a pseudo sediment record}

Using our storm dataset, we generate 1000 pseudo sediment records for South Andros Island loosely following previously published methods (Woodruff et al., 2008). First, we generate records of storm occurrence at our site. To produce multiple synthetic records, each with a realistic number of storms from 850 to $2005 \mathrm{CE}$, we utilize a Poisson process-based (Bove et al., 1998; Elsner and Bossak, 2001) random draw. The probability $(P)$ of $x$ number of storms occurring in a given year at South Andros is defined by:

$$
P=\frac{\lambda^{x} e^{-\lambda}}{x !}
$$

$\lambda$ is the annual storm frequency determined by the ratio of the specified number of surviving storms (50) to the number of storms seeded to produce that number for each year of the MPI simulation. In years from the MPI simulation where the large-scale climate conditions are favorable for storm development and subsequent tracking to South Andros, $\lambda$ is greater and thus the probability of a larger $x$ is greater. $\lambda$ is a fractional quantity, ranging from 0.06 storms/yr to a maximum of 0.55 storms/yr. The random draw produces an integer quantity $x$ of local hurricanes in a given year of a given record, such that the combination of deterministic and stochastic processes underlying local hurricane activity are captured. This random draw allows for more or fewer local hurricanes $(x)$ than suggested by $\lambda$ in a single year of a single record, while maintaining that the average $x$ across all 1000 records is approximately equal to $\lambda$ for each year. Once we have determined how many storms occur in a given year of a given record $(x)$, we randomly select which $x$ storms occur from the fifty synthetic storms from that year. Thus, each of our 1000 records of storm occurrence will have different numbers of and different actual storms occurring in a given year (Figure 5.1).

Using our records of storm occurrence, we apply the published criteria for event deposition at South Andros (Wallace et al., 2019 (Chapter 2)) to each storm to determine whether that storm left a deposit (i.e., our pseudo sediment record). In particular, only Category 3 and above hurricanes (max sustained wind speeds $>96$ knots) that passed within $50 \mathrm{~km}$ of the site left a deposit in the South Andros blue hole record. We decide to use a wider radius (100 $\mathrm{km}$ ) for the purposes of this study since there is some uncertainty associated with how close a storm must pass South Andros to leave a deposit. In addition, we limit the number of storms recorded in pseudo sediment records based on the sedimentation rate at the site $(\sim 1 \mathrm{~cm} / \mathrm{yr})$. Thus, 
if two or more storms with high enough intensity occur in a given year, only one deposit is created in the pseudo sediment record, since these separate storm layers would not be distinguishable in a sediment record. The final pseudo sediment record is just a binary outcome. In each year of the record, there will be either be a deposit or no deposit. Figure 5.1B shows an example of one record of storm occurrence with the storms that would leave a deposit highlighted in red. To analyze event frequency changes in these records on centennial timescales, as is standard practice in paleohurricane studies, we count up the number of events in a 100-year sliding window.

\subsubsection{Define active and quiet intervals in the pseudo sediment records}

We determine active and quiet intervals in our pseudo sediment records using established methods (Wallace et al., 2019 (Chapter 2); Donnelly et al., 2015; Winkler et al., in review; Lane et al., 2011) for comparison with the number observed in the South Andros proxy (Figure S5.2). Active intervals are defined as consecutive years when the 100-year window event frequency is above an upper confidence limit encompassing the expected random variability of hurricane strikes at a site. We calculate this expected frequency for all pseudo records from South Andros using the average frequency of events in the record. Specifically, an average of 43.7 storms leave deposits in the 1000 pseudo records from 850-2005 CE, resulting in an expected frequency of 3.78 events/century. Assuming that event deposition follows a Poisson process with the rate of 3.78 events/century, we compute an upper $90 \%$ confidence interval (4.9 events/century) (Ulm, 1990). Quiet intervals are defined as 50-year periods or more where no events are recorded in a pseudo record (Figure 5.1).

Typically, sediment proxy records contain both multi-decadal (20-50 consecutive years above threshold) and centennial-scale (100 consecutive years above threshold) active intervals. Indeed, the South Andros proxy contains two centennial scale and three multi-decadal scale active intervals (Wallace et al., 2019 (Chapter 2)). To compare with the South Andros reconstruction, we calculate an average number and 2 sigma range of both the shorter timescale (multi-decadal) and longer timescale (centennial) active intervals as well as the quiet intervals in our 1000 pseudo sediment records (Figure S5.2). 


\subsubsection{Defining the climate signal and quantifying the signal-to-noise ratio (SNR)}

We average the 1000 different 100-year window event frequencies for the pseudosediment records together to get a representation of the underlying centennial-scale climate signal of hurricane strikes at our site (Figure 5.2). The climate signal-to-noise ratio (SNR) between single pseudo sediment records and the climate signal is calculated as the value of the 1000-member ensemble average in each year divided by the standard deviation of the 1000 members for that year. The expected Poisson noise in the ensemble average is defined by:

$$
\text { Noise }=\frac{\sqrt{N}}{\sqrt{x}}
$$

$N$ is the mean value of the $x$-member ensemble average (3.78 events/century).

We also estimate how many ensemble members are required to converge on the centennial-scale climate signal captured by the 1000-member ensemble average of 100-year window event frequencies. We calculate 100 different ensemble averages using only 10, 25, 50, 100, 250, 500, and 750 randomly sampled members (Figure S5.3a). We calculate the Pearson correlation coefficients between each of these smaller ensembles to the 1000-member ensemble (Figure S5.3b).

\subsubsection{Creating a pure Poisson record}

To determine whether the observed variability in paleohurricane reconstructions and pseudo records arises purely from randomness, we conduct an additional experiment to see if we could simulate records with active and quiet intervals using a Poisson process where $\lambda$ does not vary in time. In this case, we set $\lambda$ to the approximate average of event frequency per year from the synthetic storms ( 0.5 events/year). We assume that the wind speed, associated with each storm, is randomly drawn from an exponential distribution. We set the magnitude of the proxy threshold as proportional to the squared power of the wind speed over an arbitrary threshold of 2 (Figure S5.4). Any storms with wind speeds over this arbitrary threshold leave deposits in our pure Poisson pseudo records. With these assumptions, we generate 1000 records of 1156 years in length to match our pseudo sediment records. Since we do not use real world or climate model data, there is no underlying climate signal by design (Figure S5.4). 


\subsection{Acknowledgements}

E.J.W. is funded by a National Science Foundation Graduate Research Fellowship. We thank R. O'Shea and A. Solow for productive discussions. 


\subsection{Figures}

\section{A. Wallace et al. (2019) South Andros Island Sediment Reconstruction}
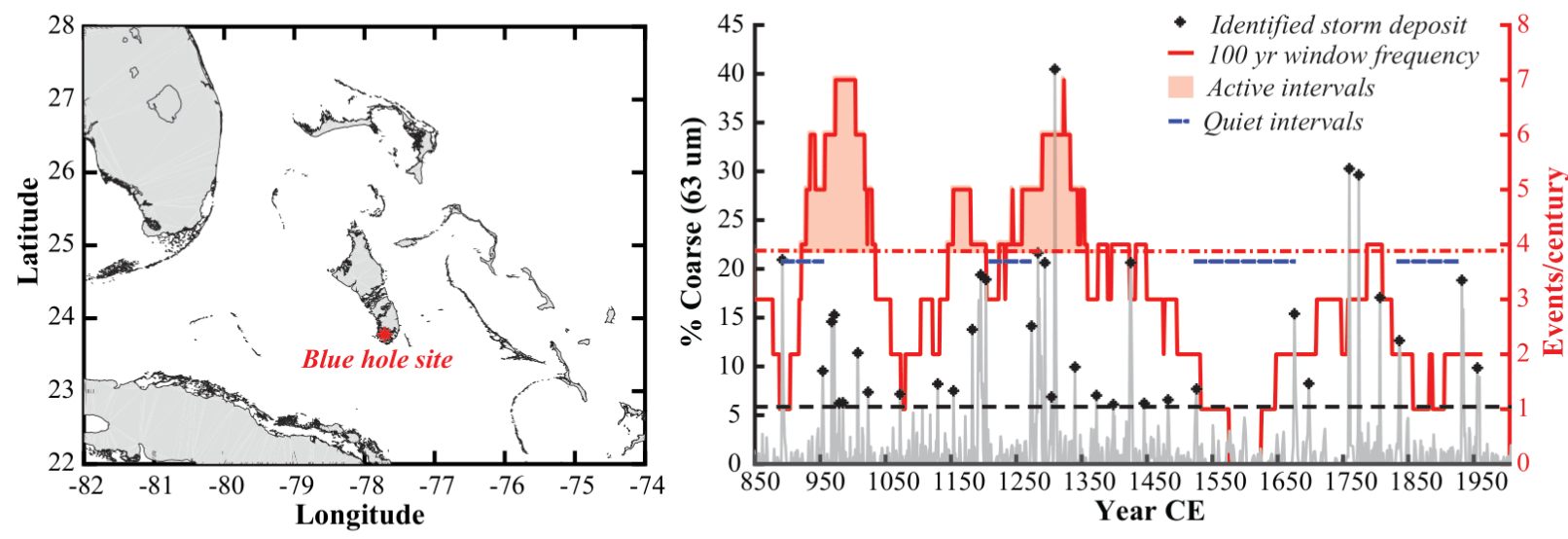

B. Example South Andros Island Pseudo Sediment Record
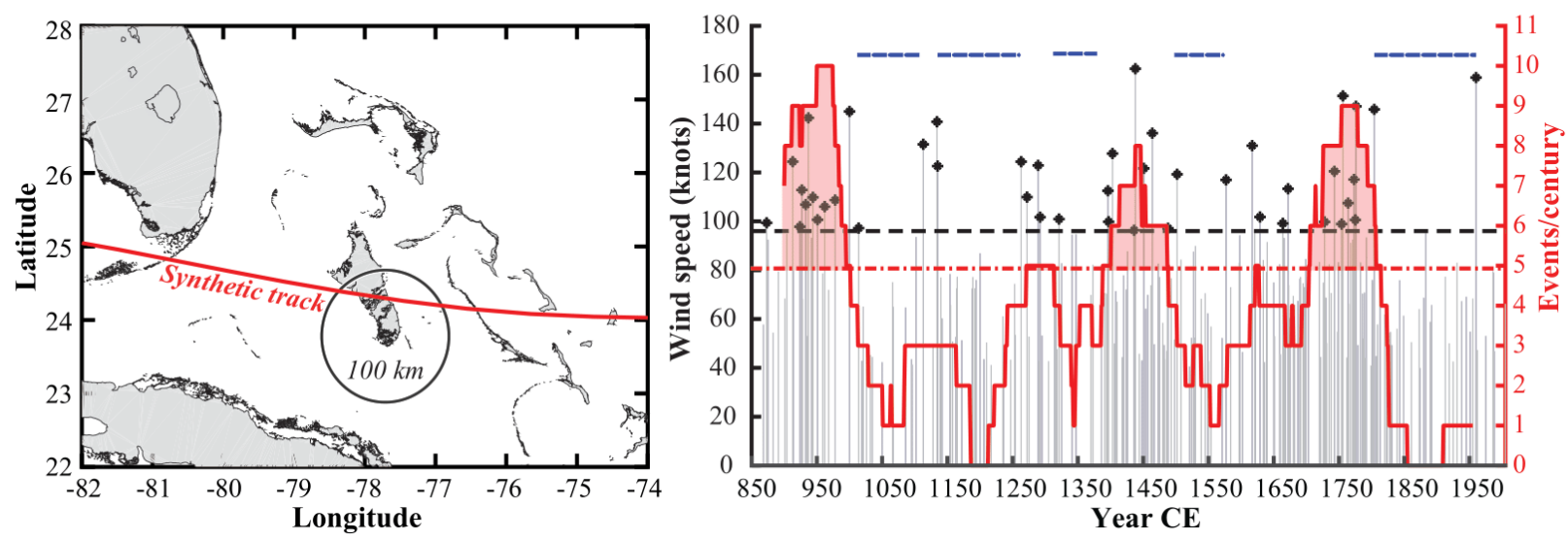

Figure 5.1: South Andros paleohurricane sediment reconstruction compared to an example pseudo record. (A) Paleohurricane site and sediment reconstruction from the AM4 blue hole $\left(23.78^{\circ} \mathrm{N} 77.72^{\circ} \mathrm{W}\right)$ on South Andros Island (Wallace et al., 2019 (Chapter 2)). Coarse anomaly data (grey) as a function of time derived from radiocarbon dates. The dashed black line is the event bed threshold. Event beds documented in this record are denoted as black diamonds. (B) An example synthetic storm track passing within a $100 \mathrm{~km}$ radius circle of the AM4 blue hole and an example pseudo sediment record. All storms were generated using a downscaling model (Emanuel et al., 2006, 2008) run using boundary conditions from the MPI past millennium (Jungclaus et al., 2010) and historical simulations (Giorgetta et al., 2013). Gray bars indicate maximum radial winds upon closest passage to the AM4 blue hole of each synthetic storm selected using a Poisson random draw (Section 5.6.2). Black diamond marked bars indicate storms that left a deposit in the pseudo record by exceeding the Category 3 and above wind speed threshold (horizontal black dashed line). The 100-year moving window event frequency per century for each type of record is plotted in red (note the different vertical scales in the top and bottom panel). The dashed red lines in both panels indicate the active interval threshold. Extended periods of time when the 100-year event frequency is above this threshold are defined as active intervals (red highlighted regions). Quiet intervals (blue dashed lines) are defined as 50-year gaps between events. 


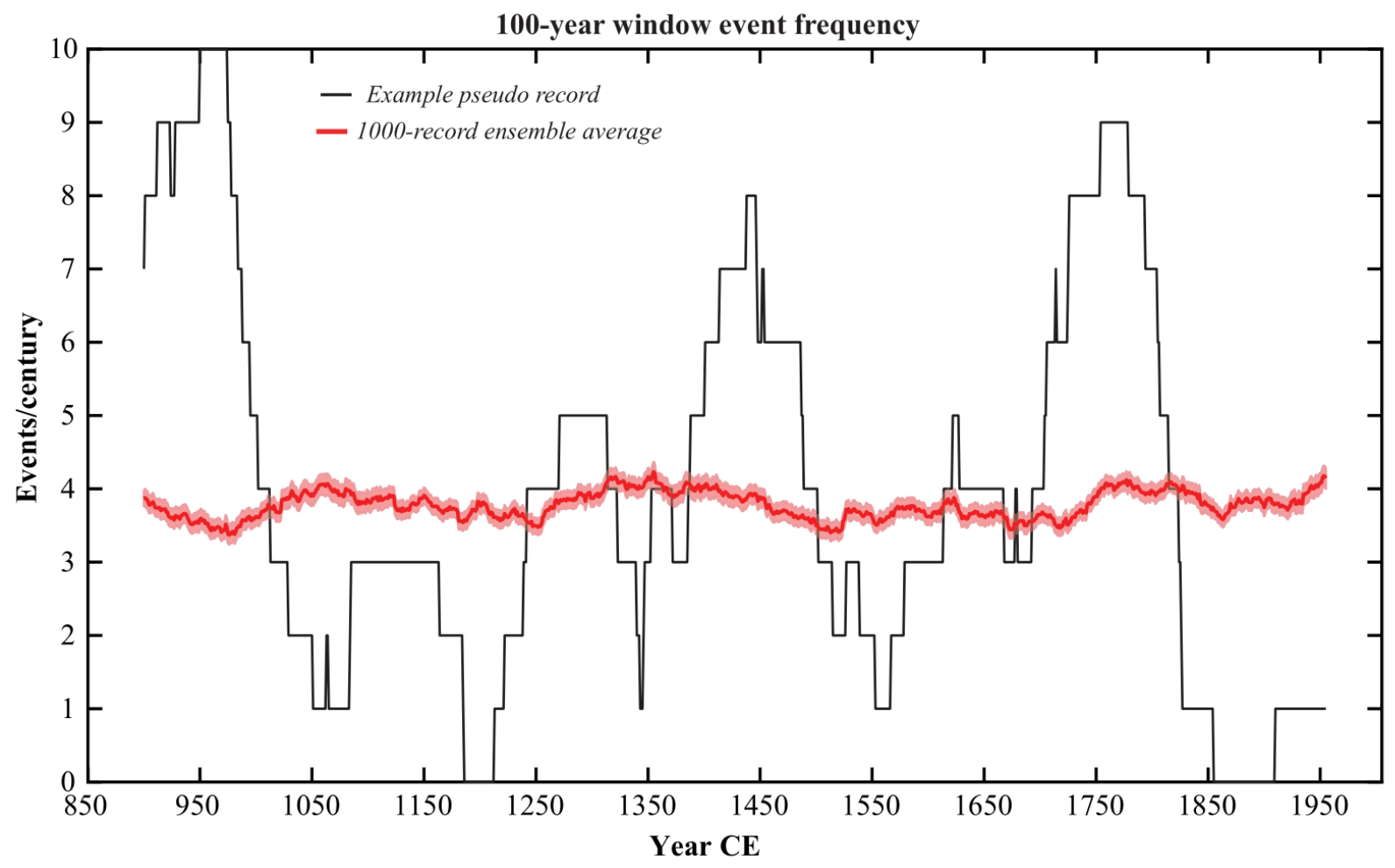

Figure 5.2: A single pseudo record compared to the 1000-member ensemble average. 100year window event frequency from 850-2005 CE for an example pseudo sediment record (same as Figure 5.1b) created for South Andros Island (black). The 1000 record ensemble average, or the climate signal, is shown in red. The $95 \%$ confidence intervals (red shading) for the climate signal were calculated using the values from 100 different sets of 1000 pseudo sediment records generated for South Andros. 

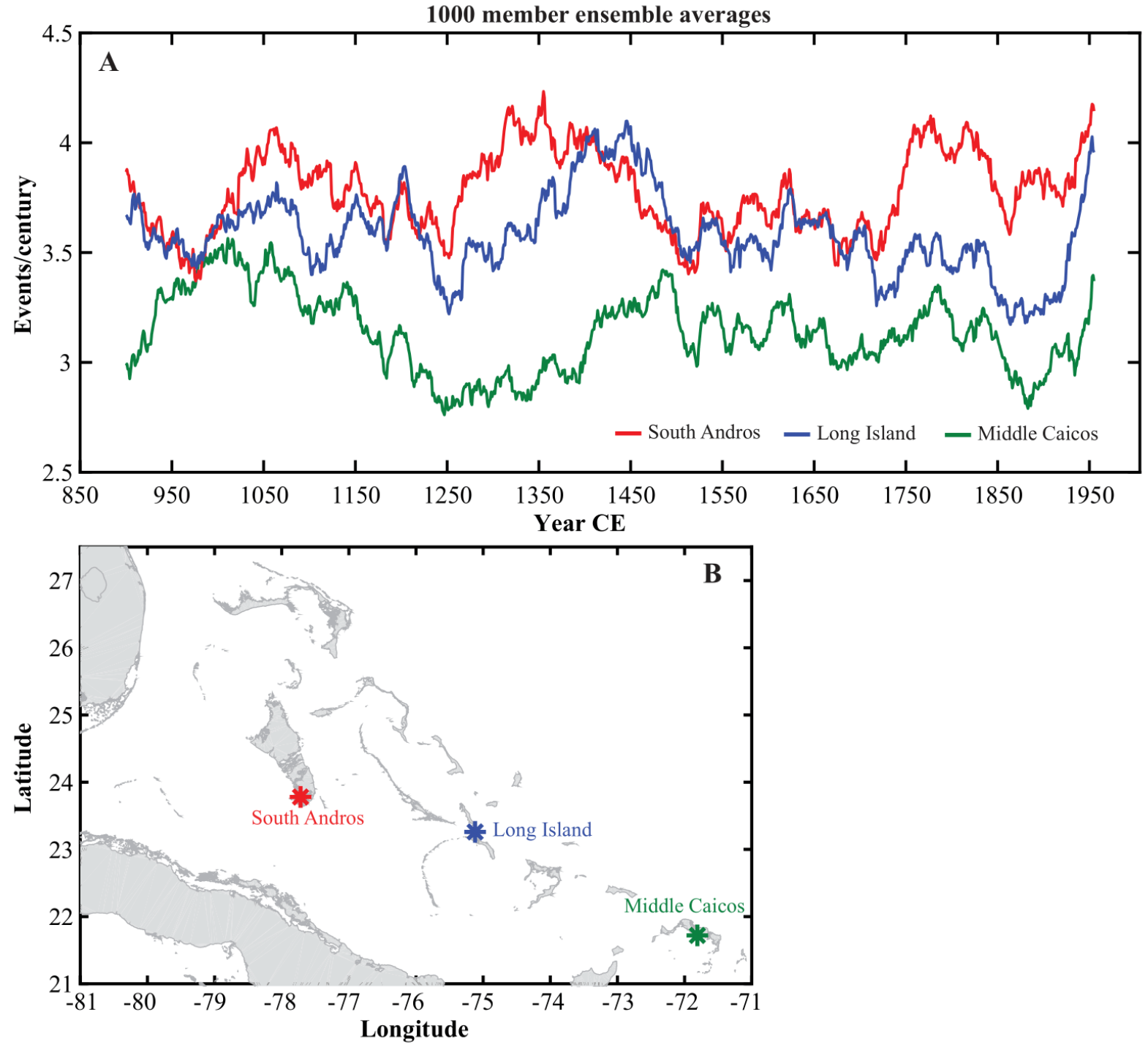

Figure 5.3: Comparison of climate signals for neighboring paleohurricane sites in the Caribbean. (A) 1000-member ensemble averages of the 100-year window event frequency of pseudo sediment records created from synthetic storms passing within $100 \mathrm{~km}$ of South Andros (Chapter 2 - red), Long Island (Chapter 3 - blue) and Middle Caicos (Chapter 4 - green). (B) Map of the blue hole sites on South Andros $\left(23.78^{\circ} \mathrm{N} 77.72^{\circ} \mathrm{W}\right)$, Long Island $\left(23.26^{\circ} \mathrm{N} 75.11^{\circ} \mathrm{W}\right)$, and Middle Caicos $\left(21.72^{\circ} \mathrm{N} 71.81^{\circ} \mathrm{W}\right)$. 


\section{S. Supplemental Material}

\section{S.1. Supplemental Figures}
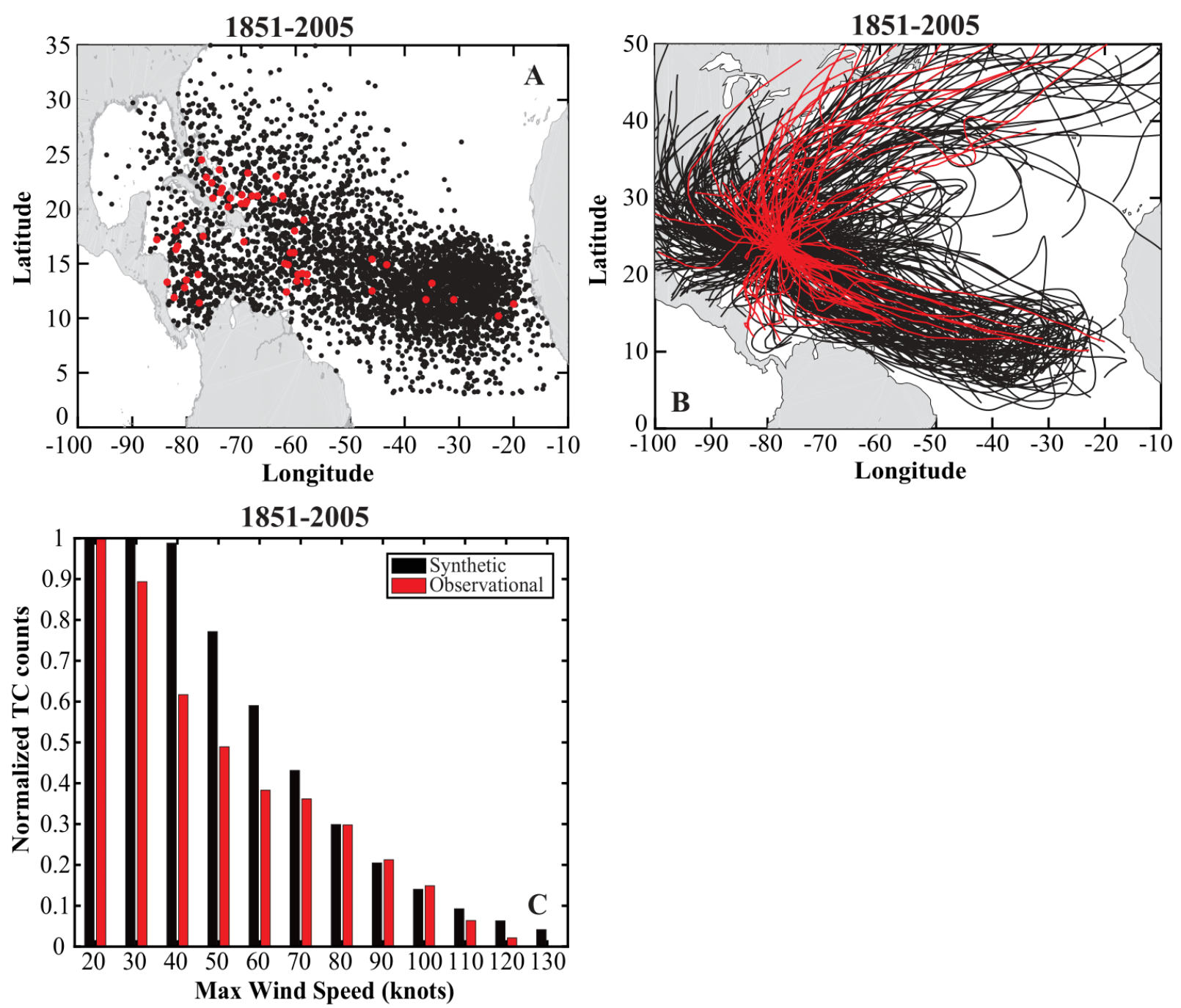

Figure S5.1: Genesis, track, and intensity comparisons between synthetic and observed storms. (A) Genesis points and (B) tracks for observed (red) and synthetic (black) tropical cyclones passing within $100 \mathrm{~km}$ of the AM4 blue hole from 1851-2005. A randomly chosen set of 500 of the synthetic tracks were plotted for clarity. (C) Cumulative frequency distribution for maximum sustained wind speed for observed and synthetic storms passing with $100 \mathrm{~km}$ of AM4. The tropical cyclone counts are normalized by the total number of storms in each dataset. All synthetic storms were generated by a published downscaling model (Emanuel et al., 2006, 2008) run using boundary conditions from the MPI-ESM-P historical simulation (Giorgetta et al., 2013). All observed storms were drawn from the IBTrACS best track tropical cyclone database (Knapp et al., 2010). 

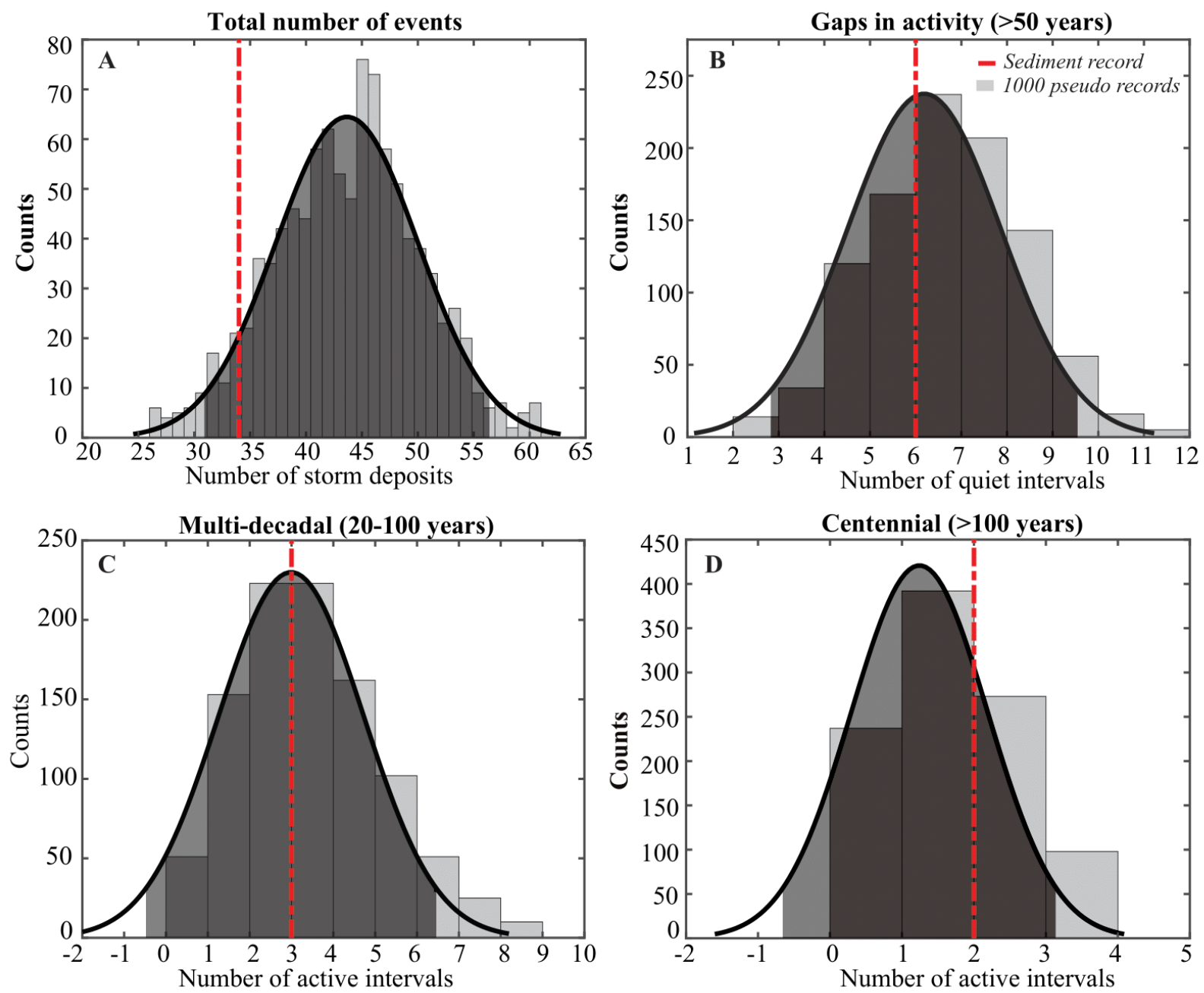

Figure S5.2: Comparing properties of the South Andros Island paleohurricane reconstruction and the pseudo sediment records. Histograms (grey bars) of the total number of event beds (A), the number of gaps in storm activity extending longer than 50 years (B), and the number of multi-decadal (C) and centennial-scale (D) active intervals across the 1000 different pseudo sediment records. We fit a normal distribution (black curve) to each of these histograms, and the $95 \%$ confidence intervals defined by these normal distributions are shaded in grey under the curve. The actual number of each property in the South Andros Island reconstruction (Wallace et al., 2019 (Chapter 2)) from 850-2005 CE is indicated by the dashed red line. 

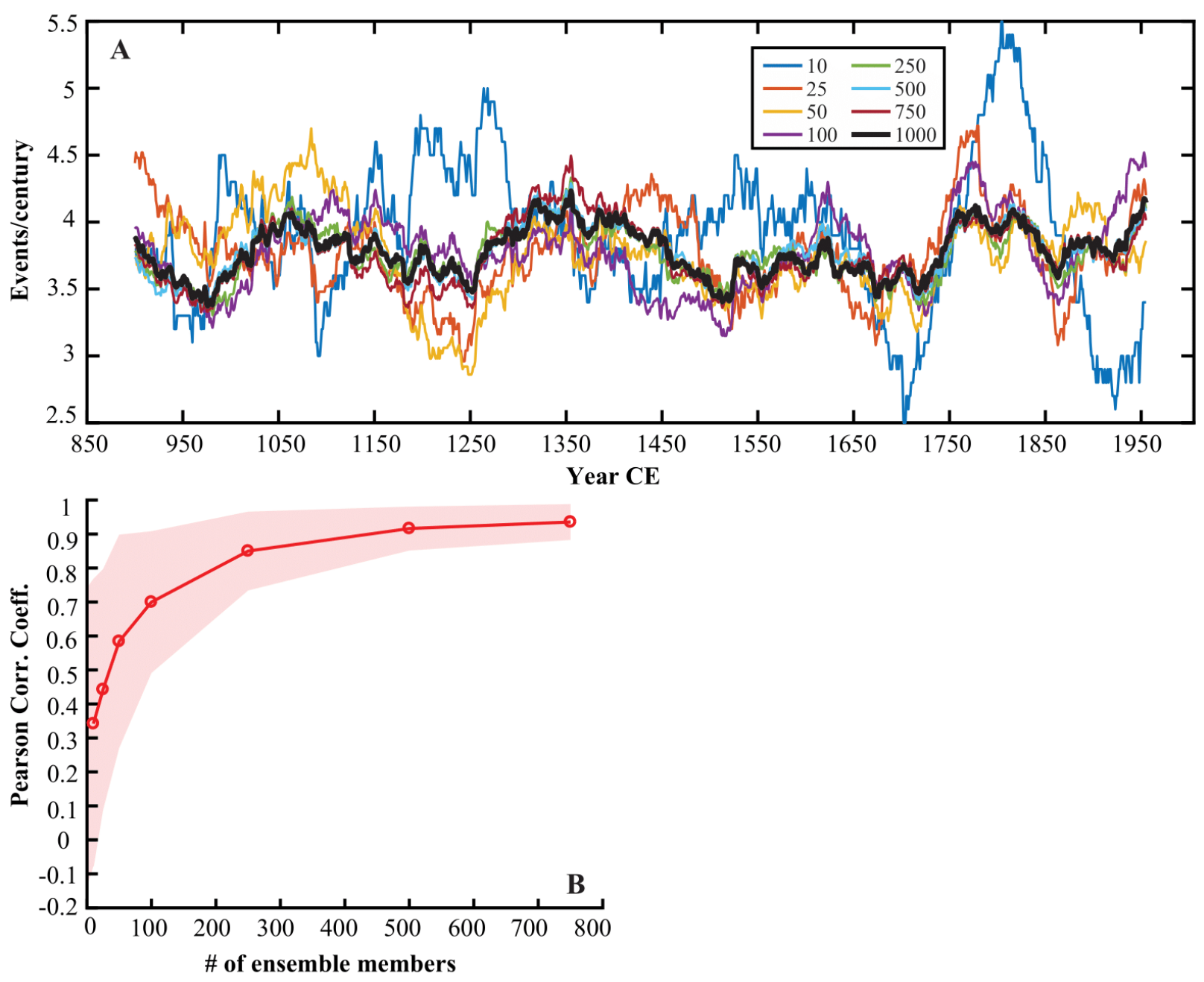

Figure S5.3: The number of members needed to converge on the climate signal for South Andros pseudo sediment records. (A) An example ensemble average of the 100-year window event frequency for the South Andros pseudo sediment records from 850-2005 CE ranging from 10-1000 members. (B) The average Pearson correlation coefficient (red) and 2 sigma range between each of the smaller member ensemble averages show in panel A with the 1000-member ensemble average. 

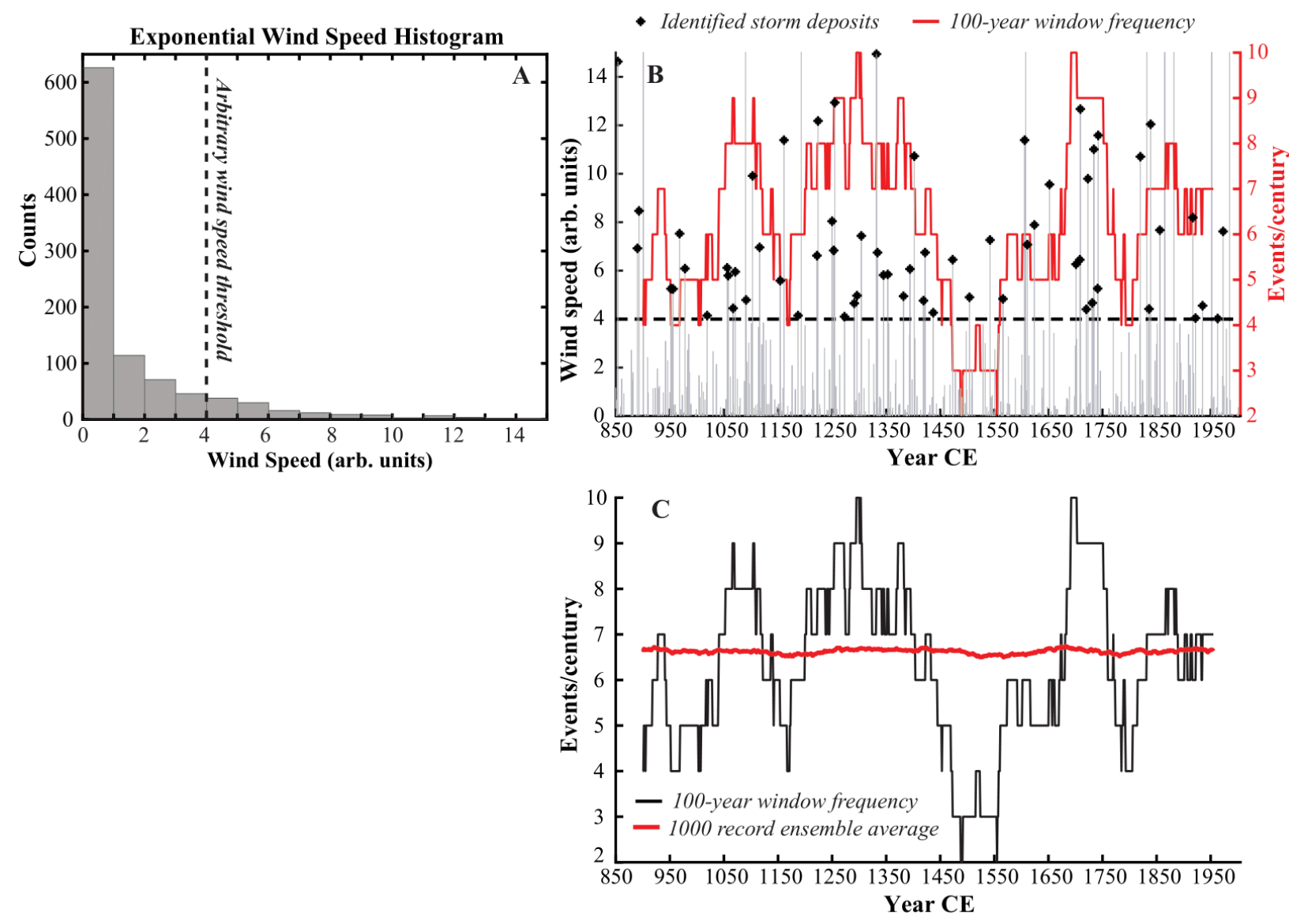

Figure S5.4: An example of a pure Poisson process based record with its 1000-member ensemble average. (A) An example of an exponential distribution of the wind speed in arbitrary units. The arbitrary wind speed threshold above which hypothetical storms leave a deposit is indicated by the dashed black line. (B) Gray bars indicate the wind speed of hypothetical storms that occurred over a 1156-year stretch drawn from the exponential wind speed distribution in panel A. The number of hypothetical storms affecting the site in any year is based on a pure Poisson process with a constant frequency of 0.5 storms/year. Black diamond marked bars indicate storms that left a deposit by exceeding the arbitrary wind speed threshold of 4 (horizontal black dashed line). The 100-year moving window event frequency per century for the example record is plotted in red. (C) The 100-year window event frequency from panel B is plotted in black. The ensemble average of the event frequency for 1000 records is shown in red-this is flat by construction. 


\section{Summary and Conclusions}

\subsection{Thesis Summary}

The field of paleotempestology has grown substantially in the past few decades. A growing number of researchers have published studies reconstructing past tropical cyclone activity using a variety of different natural archives (Oliva et al., 2018). Unfortunately, many of these records are short, low resolution (e.g., lower sedimentation rates making individual events difficult to distinguish), and concentrated along the U.S. coastline (Oliva et al., 2018; Wallace et al., 2014). This thesis presented a new set of high resolution sedimentary reconstructions of past hurricane strikes over the past millennium from blue holes in the Bahama Archipelago. I explored the suitability of blue hole basins for recording passing hurricanes and the sensitivity of each site to storms of different properties. This thesis also provided some of the first work using existing tropical cyclone models to rigorously assess uncertainties in paleohurricane records. I now summarize the main results of this thesis and provide recommendations for future research.

In Chapters 2-4, I present near-annually resolved reconstructions of hurricane strikes over the past 1000-1500 years from blue holes on three different islands in the Bahama Archipelago. In Chapter 2, cores collected from three different blue holes in the carbonate tidal flats on South Andros Island reconstruct local hurricane strikes on the island over the past 1500 years. Coarse-grained sediment layers dating to the observational period correspond to intense hurricanes (Category 3 and above) passing within $50 \mathrm{~km}$ of our site. Each of the three blue holes captured a slightly different record of events due to each hole's different geomorphologic positions and orientations. However, all three records observe similar patterns of hurricane frequency over the past millennium. We found that the frequency of intense hurricane strikes on South Andros has varied dramatically over the past millennium. In particular, we record less activity over the observational interval (1850 CE-present) than most other centuries over the past millennium. Most of the multi-decadal periods of elevated hurricane activity reconstructed on South Andros Island correspond to northward shifts in the Intertropical Convergence Zone (ITCZ), and an unusual gap in activity spanning the $13^{\text {th }}$ century corresponds to a period of unusually high volcanic activity. This chapter presented the longest high resolution Caribbean paleohurricane record ever collected and explored the potential of blue hole environments to serve as accurate recorders of local hurricane strikes over time. 
In Chapters 3 and 4, I reconstruct storms strikes on Long Island, The Bahamas and Middle Caicos Island over the past 1100 years and 1500 years, respectively, using blue hole sediment cores. The historic sediment records from both Long Island and Middle Caicos highlight the problems with using sweeping thresholds based on proximity and intensity of storms to define a site's sensitivity to event bed deposition. In Chapter 3, simple hydrodynamic modeling of modern storms passing Long Island and observations from Hurricane Irma's distant passage in 2017 indicate that storm surge can depend greatly on both coastal geometry and storm properties (i.e., size, speed, angle of approach). In general, storms passing to the north and east of Long Island generate larger storm surge and bottom currents than storms passing to the south or west. In Chapter 4, we found that storm intensity was also less important than the orientation of passing storms for inducing coarse-grained sediment transport on the Caicos platform. The Middle Caicos blue hole captured coarse sediment deposits from low intensity hurricanes (Category 1) like Hurricane Kate in 1985 that passed to the south of the island. Both chapters highlight the need for detailed hydrodynamic modeling studies on Caribbean islands investigating how storms of different properties and tracks influence surge generation.

Both the Long Island reconstruction (Chapter 3) and the Middle Caicos reconstruction (Chapter 4) demonstrate dramatic changes in event frequency over the past millennium with multi-decadal active and quiet intervals. However, the timing of the active intervals on each island directly contrasts with hurricane patterns on neighboring islands including South Andros Island (Chapter 2) and Abaco Island (Winkler et al. in review). We argue that these differences arise because each island is capturing a largely different population of storms. We hypothesize that the signal captured in these records from the Bahama Archipelago is heavily influenced by randomness and site sensitivity.

To allow for a regional comparison of hurricane activity in the North Atlantic, we create a compilation of paleohurricane activity from the Bahama Archipelago including all the sites from my thesis and a record from Abaco Island (Winkler et al. in review). We find that the storms captured by this compilation capture approximately $80 \%$ of the variance in all storms passing through the Bahama Archipelago. We compare this compilation to new compilations from New England and northwest Florida. Taken together, these compilations indicate a basinwide increase in activity during the Medieval Climate Anomaly (900-1100 CE). Afterwards (1100 CE to present), there are century-scale periods with a predominance of certain storm 
populations in the Atlantic. In general, the Bahama Archipelago compilation matches with the New England compilation and contrasts with the Florida compilation. We argue that there has been shift from straight-moving storms impacting the U.S. Gulf Coast to recurving storms impacting the U.S. East Coast over the past millennium. This could be a result of changes in hurricane tracks related to variations in the North Atlantic Subtropical High (NASH) (Elsner, 2003; Kossin et al., 2010; Ortegren and Maxwell, 2014) and/or changes in local environmental conditions (i.e., sea surface temperature, vertical wind shear) (Ting et al., 2019; Kossin, 2017). More high resolution reconstructions of shifts in the subtropical jet and the NASH position over the past millennium are needed to determine which mechanism are more important. Much like Chapter 2, the Bahama Archipelago compilation also shows lower storm activity over the past 150 years. This further confirms that hurricane activity we've observed recently is on the lower end of what's occurred in the Atlantic over the past 1500 years.

In Chapter 5, I confirmed the hypothesis proposed in Chapters 3 and $\mathbf{4}$ that most of the signal captured in a single paleohurricane record from the Bahama Archipelago is driven by randomness. Using a random draw from a large set of synthetic tropical cyclones run over simulated past millennium climate, we generated 1000 records of storm occurrence on South Andros Island, The Bahamas. We created pseudo sediment records by selecting which storms would have left a deposit using an intensity threshold and a prescribed sedimentation rate. We found that any single pseudo sediment record contains multi-decadal scale active and quiet intervals much like those reconstructed in Chapter 2. However, the 1000 pseudo record ensemble average (i.e., the common climate signal) contains a significantly damped signal compared to the single record. This suggest that an individual record of paleohurricane activity from the Bahama Archipelago is driven more by random local variability in hurricane tracks (e.g., local weather, topography) proximal to a site than by large-scale climate variability. The existence of a coherent climate signal across neighboring sites suggests there is promise in creating and using regional or wider-scale compilations to investigate hurricane climate.

\subsection{Future directions}

There are so many aspects of blue hole environments that make them well suited for paleohurricane reconstructions (e.g., high sedimentation rates, little to no bioturbation, prevalence in hurricane-prone regions). However, there is still so much we need to learn about the mechanisms that induce coarse-grained sediment transport on the carbonate platforms 
surrounding many blue holes. My thesis has shown that local conditions (e.g., coastline geometry, sources/sinks of sediments) and storm properties (e.g., angle of passage, translational velocity, radius of maximum winds) can dramatically impact storm surge and bottom currents near blue holes. We need more observations and simulations of blue hole environments during tropical cyclone passages. One of the major obstacles for hydrodynamic modeling studies is the lack of high resolution bathymetric grids available for coastlines in the Caribbean. Future efforts should concentrate on generating high resolution grids for Bahamian islands and expanding hydrodynamic modeling studies into these vulnerable regions.

Additionally, I have shown in this thesis that a single paleohurricane site from The Bahamas is only capturing a record of past hurricanes in that single location. I've stressed the importance of using compilations of records to capture a more regional hurricane record. Indeed, the presented compilation of records from the Bahama Archipelago captures most of the variance in storm counts in the region with only four contributing members. More work creating compilations of paleohurricane reconstructions to make basin-wide comparisons is needed. I hope that the compilations presented in this body of work will set a precedent for future paleohurricane studies. To allow for these efforts, the field of paleotempestology desperately needs a comprehensive and detailed database of published paleohurricane reconstructions. In order for this to be possible, there needs to be more metadata (e.g., age model information, grain size data) accompanying published studies (Khider et al., 2019).

Finally, the time is ripe for integrating tropical cyclone models with existing paleohurricane records in a novel two-way conversation. I've shown in this thesis that we can use hurricane model data to assess whether variability in paleohurricane records is related to climate variability or just random clustering of events under a stationary climate. Further work is needed to quantify and characterize the climate signal in each existing paleohurricane record in the North Atlantic. Furthermore, with knowledge of the climate signal in each record, we can begin to develop novel methods by which to combine sediment records from neighboring sites to maximize the regional-to-global climate signal relative to local noise. This information will allow us to better use paleohurricane reconstructions to enhance our fundamental understanding of the processes that lead to changes in tropical cyclone activity in the North Atlantic and improve our ability to model these changes and project future tropical cyclone risk for coastal communities. 


\section{Appendices}

\section{Appendix A. Visual correlation of events in the transect of cores from Middle Caicos blue hole}

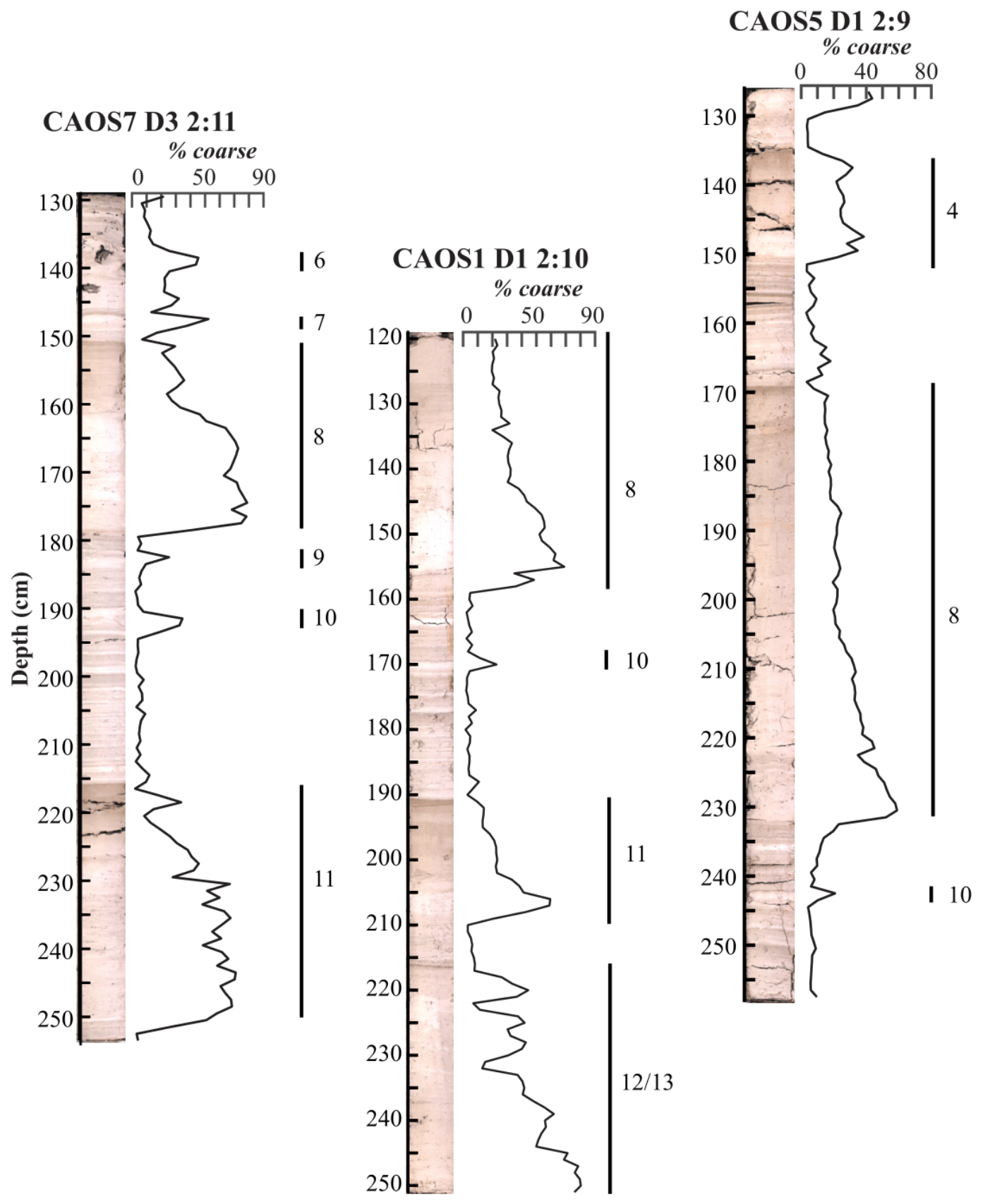

Figure A1. Optical images from the ITRAX X-ray fluorescence scanner and coarse fraction ( $>63 \mathrm{um})$ data from CAOS7 section 2:11, CAOS1 section 2:10, and CAOS5 section 2:9. Visual event beds are denoted by the vertical bar and labels. Visual cues for event beds included: lighter colored sediments topped with darker colored sediment, visibly coarser grains, higher concentrations of organics, and no laminations. Lines of correlation (grey) are drawn between drives matching up the same sets of laminations in each core. 


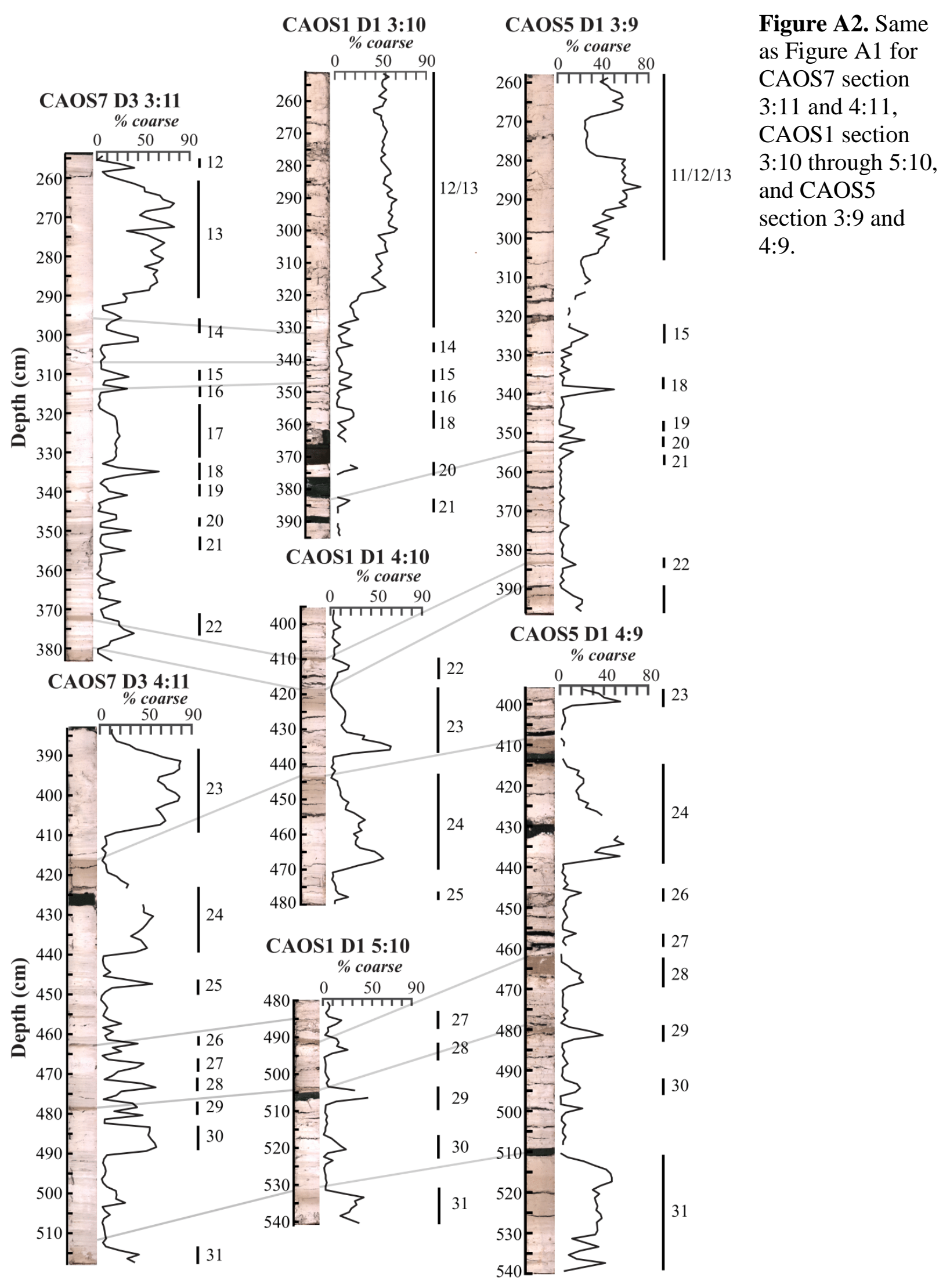




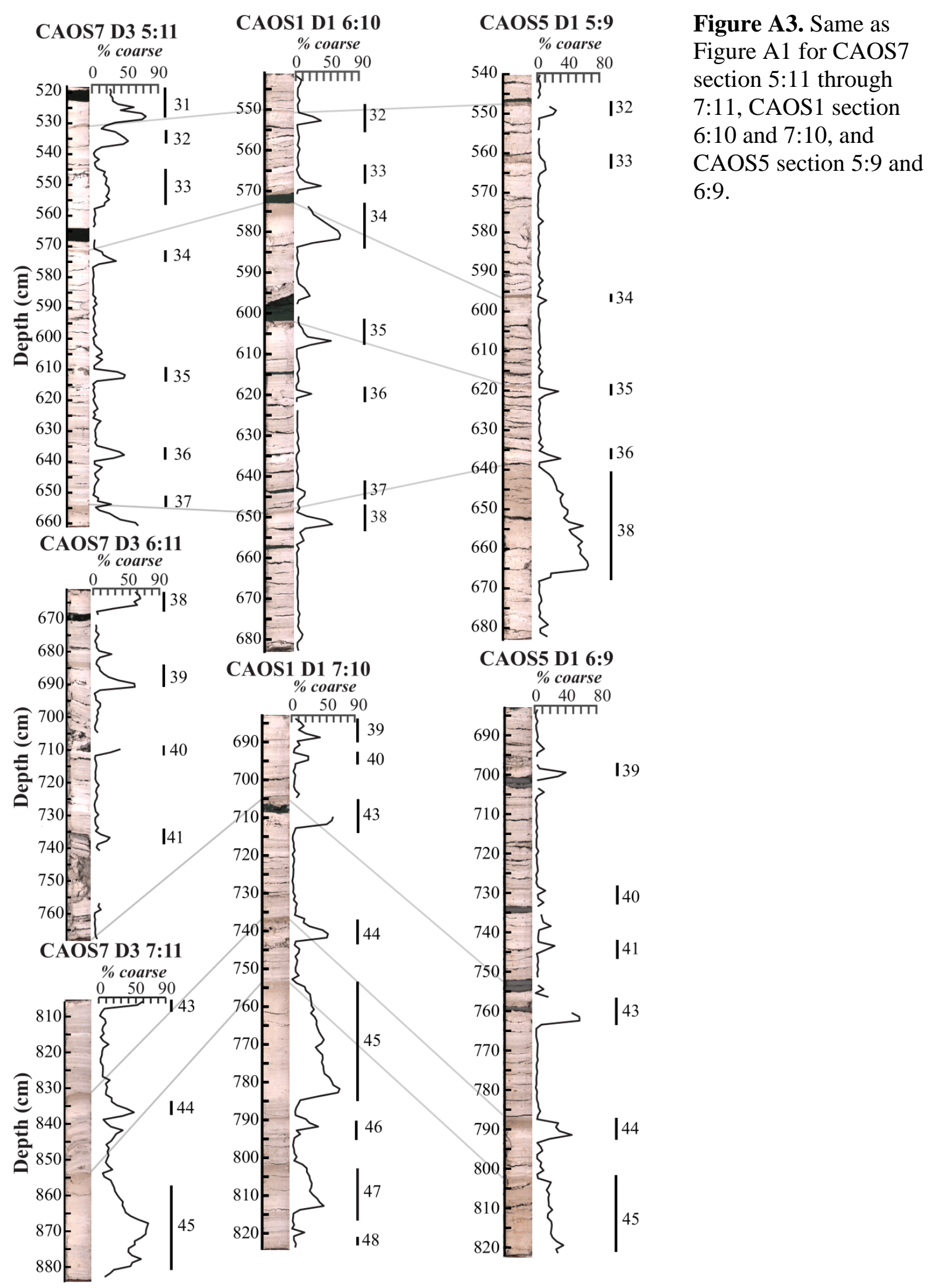




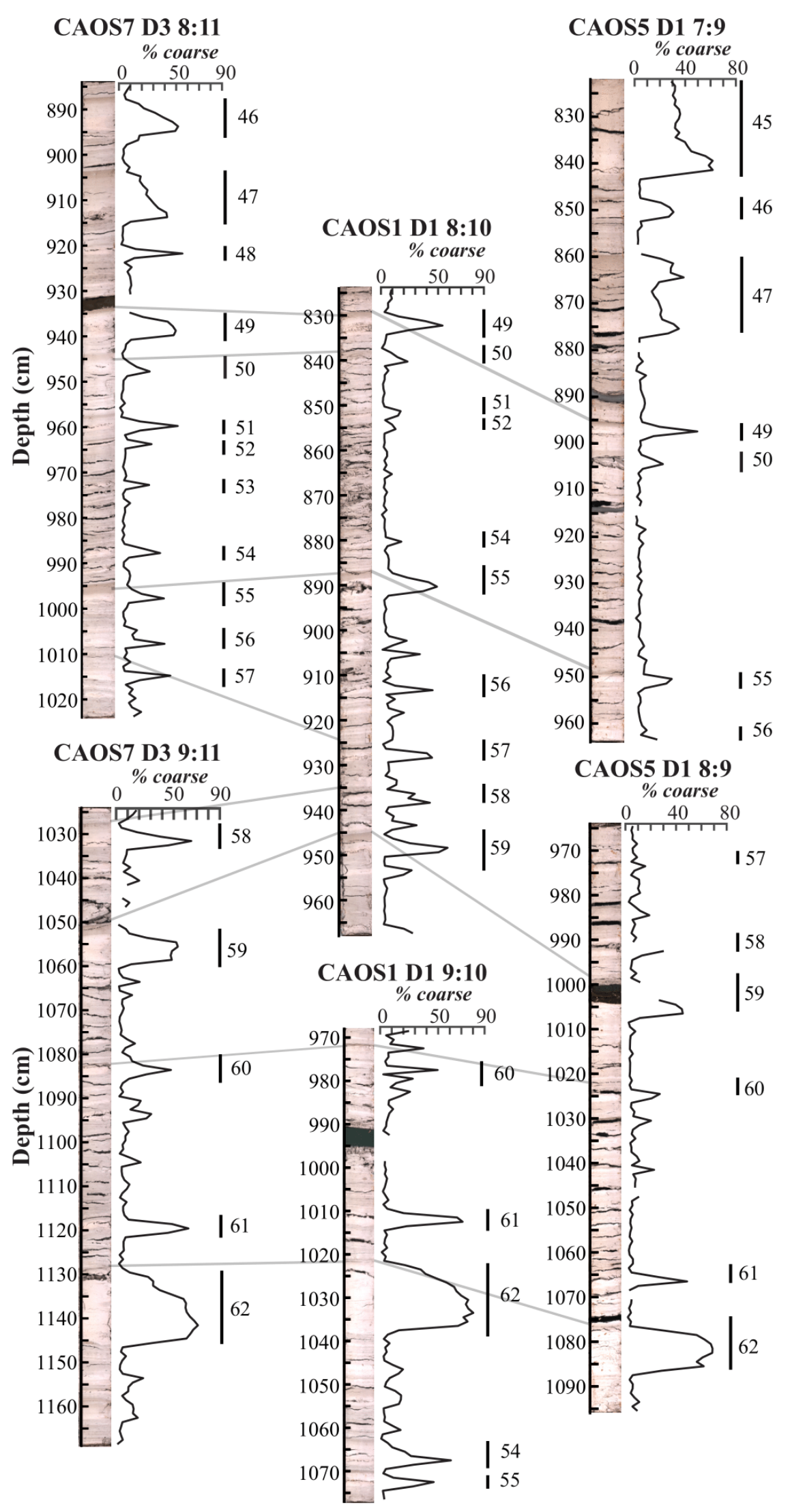

Figure A4. Same as Figure A1 for CAOS7 section 8:11 and 9:11, CAOS1 section $8: 10$ and $9: 10$, and CAOS5 section 7:9 and 8:9. 


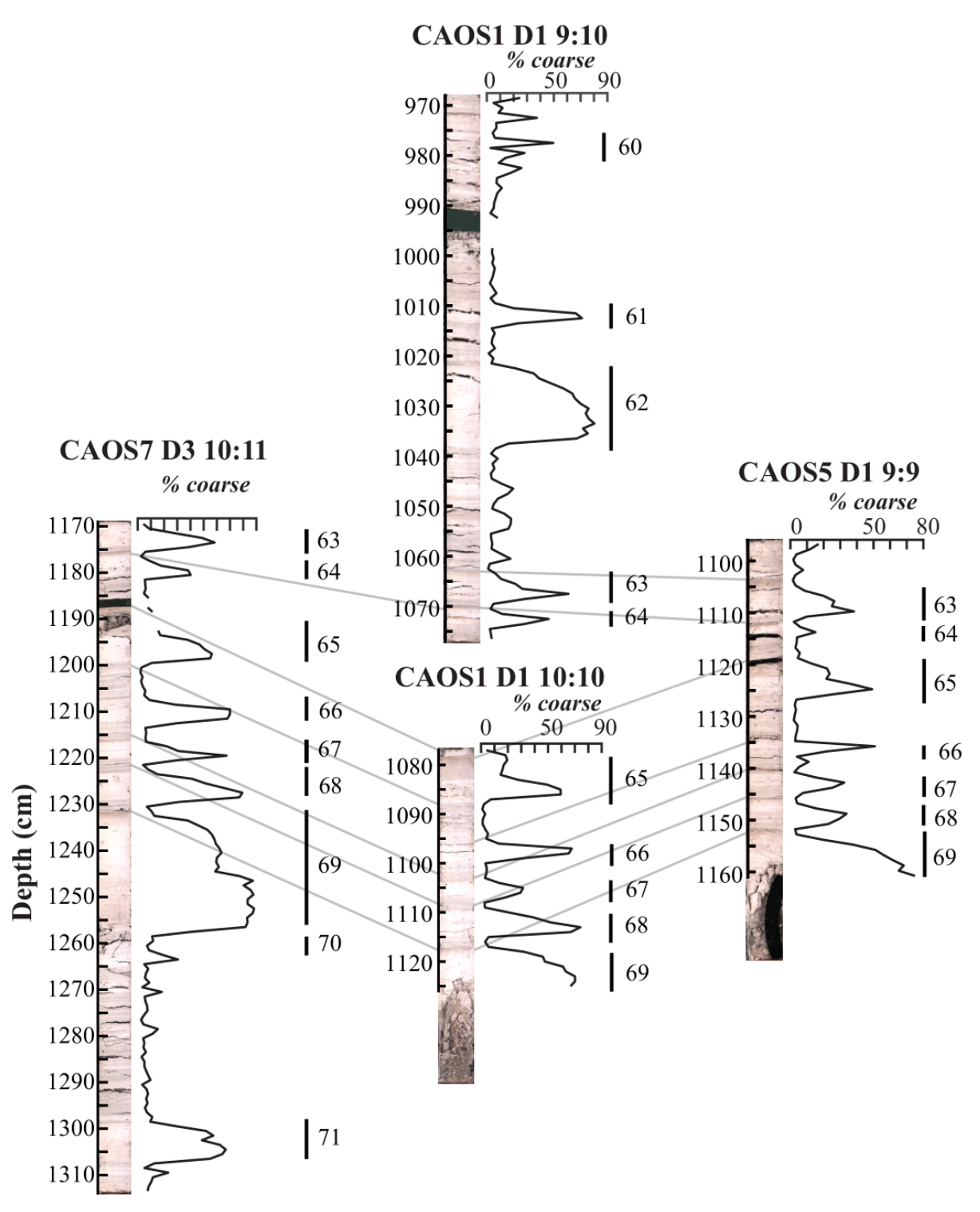

Figure A5. Same as

Figure A1 for

CAOS7 section

10:11 and 11:11,

CAOS1 section

9:10 and 10:10, and

CAOS5 section 9:9.

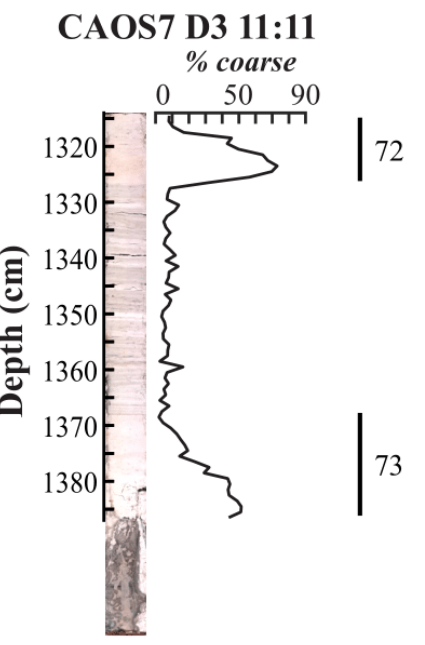




\section{References}

Altman, J., Ukhvatkina, O.N., Omelko, A.M., Macek, M., Plener, T., Pejcha, V., Cerny, T., Petrik, P., Srutek, M., Song, J.-S., Zhmerenetsky, A.A., Vozmishcheva, A.S., Krestov, P. V., Petrenko, T., et al., 2018, Poleward migration of the destructive effects of tropical cyclones during the 20th century: Proceedings of the National Academy of Sciences, v. 115, p. 11543-11548, doi: 10.1073/pnas.1808979115.

Appleby, P.G., 2001, Chronostratigraphic Techniques in Recent Sediments, in Last, W.M. and Smol, J.P. eds., Tracking Environmental Change Using Lake Sediments: Volume 2:

Physical and Geochemical Methods, Dordrecht, Kluwer Academic Publishers, p. 171-202.

Appleby, P.G., and Oldfield, F., 1978, The Calculation of Lead-210 dates assuming a constant rate of supply of unsupported 210-Pb to the sediment: Catena, v. 5, p. 1-8.

Avila, L.A., and Cangialosi, J.P., 2011, Tropical Cyclone Report Hurricane Irene AL092011.: Baldini, L.M., Baldini, J.U.L., McElwaine, J.N., Frappier, A.B., Asmerom, Y., Liu, K., Prufer, K.M., Ridley, H.E., Polyak, V., Kennett, D.J., Macpherson, C.G., Aquino, V. V., Awe, J., and Breitenbach, S.F.M., 2016, Persistent northward North Atlantic tropical cyclone track migration over the past five centuries: Scientific Reports, v. 6, doi: 10.1038/srep37522.

Barnes, E., and Polvani, L., 2013, Response of the Midlatitude Jets, and of Their Variability, to Increased Greenhouse Gases in the CMIP5 Models: Journal of Climate, v. 26, p. 71177135, doi: 10.1175/JCLI-D-12-00536.1.

Benfield, A., 2018, Hurricane Irma Event Recap Report.:

Berg, R.J., 2016, Hurricane Joaquin (AL112015).:

Bhatia, K., Vecchi, G., Murakami, H., Underwood, S., and Kossin, J., 2018, Projected response of tropical cyclone intensity and intensification in a global climate model: Journal of Climate, v. 31, p. 8281-8303, doi: 10.1175/JCLI-D-17-0898.1.

Blaauw, M., and Christen, J.A., 2011, Flexible paleoclimate age-depth models using an autoregressive gamma process: Bayesian Analysis, v. 6, p. 457-474, doi: 10.1214/11BA618.

Black, M., 1933, The Algal Sediments of Andros Island, Bahamas: Philosophical Transactions of the Royal Society of London, v. 222, p. 165-192.

Blake, E.S., Kimberlain, T.B., Berg, R.J., Cangialosi, J.P., and Beven, J.L., 2013, Tropical Cyclone Report Hurricane Sandy AL182012.:

Boardman, M.R., and Neumann, A.C., 1984, Sources of periplatform carbonates: Northwest Providence Channel, Bahamas: Journal of Sedimentary Petrology, v. 54, p. 1110-1123.

Boldt, K. V., Lane, P., Woodruff, J.D., and Donnelly, J.P., 2010, Calibrating a sedimentary record of overwash from Southeastern New England using modeled historic hurricane surges: Marine Geology, v. 275, p. 127-139, doi: 10.1016/j.margeo.2010.05.002.

Boose, E.R., Chamberlin, K.E., and Foster, D.R., 2001, Landscape and regional impacts of hurricanes in New England: Ecological Monographs, v. 71, p. 27-48, doi: 10.1890/00129615(2001)071[0027:LARIOH]2.0.CO;2.

Bourrouilh-le Jan, F.G., 2007, Very high energy sedimentation (supratidal hurricane deposits) and Mid-Holocene highstand on carbonate platforms, Andros, Bahamas: An alternative view: Sedimentary Geology, v. 199, p. 29-49, doi: 10.1016/j.sedgeo.2005.12.032.

Bove, M.C., Elsner, J.B., Landsea, C.W., Niu, X., and O'Brien, J.J., 1998, Effect of El Nino on U.S. Landfalling Hurricanes, Revisited: Bulletin of the American Meteorological Society, v. 79, p. 2477-2482. 
Brandon, C.M., Woodruff, J.D., Lane, D.P., and Donnelly, J.P., 2013, Tropical cyclone wind speed constraints from resultant storm surge deposition: A 2500 year reconstruction of hurricane activity from St. Marks, FL: Geochemistry, Geophysics, Geosystems, v. 14, p. 2993-3008, doi: 10.1002/ggge.20217.

Bregy, J.C., Wallace, D.J., Minzoni, R.T., and Cruz, V.J., 2018, 2500-year paleotempestological record of intense storms for the northern Gulf of Mexico, United States: Marine Geology, doi: 10.1016/j.margeo.2017.09.009.

Brohan, P., Allan, R., Freeman, E., Wheeler, D., Wilkinson, C., and Williamson, F., 2012, Constraining the temperature history of the past millennium using early instrumental observations: Climate of the Past, v. 8, p. 1551-1563, doi: 10.5194/cp-8-1551-2012.

Brown, A.L., Reinhardt, E.G., van Hengstum, P.J., and Pilarczyk, J.E., 2014, A Coastal Yucatan Sinkhole Records Intense Hurricane Events: Journal of Coastal Research, v. 30, p. 418-429, doi: 10.2112/JCOASTRES-D-13-00069.1.

Buynevich, I. V., and Donnelly, J.P., 2006, Geological Signatures of Barrier Breaching and Overwash, Southern Massachusetts, USA: Journal of Coastal Research, v. I, p. 112-116.

Camargo, S.J., 2013, Global and Regional Aspects of Tropical Cyclone Activity in the CMIP5 Models: Journal of Climate, v. 26, p. 9880-9902, doi: 10.1175/JCLI-D-12-00549.1.

Camargo, S.J., Emanuel, K., and Sobel, A.H., 2007, Use of a Genesis Potential Index to Diagnose ENSO Effects on Tropical Cyclone Genesis: Journal of Climate, v. 20, p. 48194834, doi: 10.1175/JCLI4282.1.

Camargo, S.J., and Wing, A.A., 2016, Tropical cyclones in climate models: Wiley Interdisciplinary Reviews: Climate Change, v. 7, p. 211-237, doi: 10.1002/wcc.373.

Campbell, J.E., and Fourqurean, J.W., 2009, Interspecific variation in the elemental and stable isotope content of seagrasses in South Florida: Marine Ecology Progress Series, v. 387, p. 109-123, doi: 10.3354/meps08093.

Cangialosi, J.P., Latto, A.S., and Berg, R., 2018, Hurricane Irma (AL112017).:

Carew, J.L., Mylroie, J.E., and Schwabe, S.J., 1998, The geology of South Andros Island, Bahamas: A reconnaissance report: Cave and Karst Science, v. 25, p. 57-66.

Chenoweth, M., and Divine, D., 2008, A document-based 318-year record of tropical cyclones in the Lesser Antilles, 1690-2007: Geochemistry, Geophysics, Geosystems, v. 9, p. 1-21, doi: 10.1029/2008GC002066.

Chu, P., 2004, ENSO and Tropical Cyclone Activity, in Murnane, R.J. and Liu, K. eds., Hurricanes and Typhoons: Past, Present, and Future., New York, Columbia University Press, p. 297-332.

Church, J.A., White, N.J., and Arblaster, J.M., 2005, Significant decadal-scale impact of volcanic eruptions on sea level and ocean heat content: Nature, doi: 10.1038/nature04237.

Clark, J.S., and Patterson, W.A.I., 1984, Pollen, Pb-210, and opaque spherules: an integrated approach to dating and sedimentation in the intertidal environment: Journal of Sedimentary Petrology, v. 54, p. 1251-1265.

Clement, A., Bellomo, K., Murphy, L.N., Cane, M.A., Mauritsen, T., and Stevens, B., 2015, The Atlantic Multidecadal Oscillation without a role for ocean circulation: Science, v. 350, p. 320-324, doi: 10.1126/science.aab3980.

Coats, S., Cook, B.I., Smerdon, J.E., and Seager, R., 2015, North American Pancontinental Droughts in Model Simulations of the Last Millennium: Journal of Climate, v. 28, p. 20252043, doi: 10.1175/JCLI-D-14-00634.1.

Coats, S., Smerdon, J.E., Cook, B.I., and Seager, R., 2015, Are Simulated Megadroughts in the 
North American Southwest Forced? Journal of Climate, v. 28, p. 124-141, doi:

10.1175/JCLI-D-14-00071.1.

Congressional Budget Office, 2019, Expected Costs of Damage from Hurricane Winds and

Storm-Related Flooding:, www.cbo.gov/publication/55019.

Correll, D.S., and Correll, H.B., 1982, Flora of the Bahama Archipelago: including the Turks and Caicos Islands: A .R. G. Verlag, 1-1692 p.

Craton, M., and Saunders, G., 1992, Islanders in the Stream: A History of the Bahamian People: Volume One: From Aboriginal Times to the End of Slavery: Athens, University of Georgia Press, 1-496 p.

Craton, M., and Saunders, G., 1998, Islanders in the Stream: A History of the Bahamian People: Volume Two: From the Ending of Slavery to Twenty-First Century: Athens, University of Georgia Press.

Daloz, A.S., Camargo, S.J., Kossin, J.P., Emanuel, K.A., Horn, M., Jonas, J.A., Kim, D., LaRow, T., Lim, Y.-K., Patricola, C.M., Roberts, M., Scoccimarro, E., Shaevitz, D., Vidae, P.L., et al., 2015, Cluster Analysis of Downscaled and Explicitly Simulated North Atlantic Tropical Cyclone Tracks: Journal of Climate, v. 28, p. 1333-1361, doi: 10.1175/JCLI-D-13-00646.1.

Dasgupta, S., Laplante, B., Murray, S., and Wheeler, D., 2011, Exposure of developing countries to sea-level rise and storm surges: Climatic Change, v. 106, p. 567-579, doi:

10.1007/s10584-010-9959-6.

Deines, P., 1980, The isotopic composition of reduced organic carbon, in Fritz, P. and Fontes, J.C. eds., Handbook of Environmental Isotope Geochemistry, Vol. 1., New York, Elsevier, p. 329-406.

Denommee, K.C., Bentley, S.J., and Droxler, A.W., 2014, Climatic controls on hurricane patterns: a 1200-y near-annual record from Lighthouse Reef, Belize: Scientific Reports, v. 4, doi: 10.1038/srep03876.

Dietrich, J.C., Westerink, J.J., Kennedy, A.B., Smith, J.M., Jensen, R.E., Zijlema, M., Holthuijsen, L.H., Dawson, C., Luettich Jr., R.A., Powell, M.D., Cardone, V.J., Cox, A.T., Stone, G.W., Pourtaheri, H., et al., 2011, Hurricane Gustav (2008) Waves and Storm Surge: Hindcast, Synoptic Analysis, and Validation in Southern Louisiana: Monthly Weather Review, v. 139, p. 2488-2522, doi: 10.1175/2011MWR3611.1.

Dietrich, J.C., Zijlema, M., Westerink, J.J., Holthuijsen, L.H., Dawson, C., Luettich Jr., R.A., Jensen, R.E., Smith, J.M., Stelling, G.S., and Stone, G.W., 2011, Modeling hurricane waves and storm surge using integrally-coupled, scalable computations: Coastal Engineering, v. 58, p. 45-65, doi: 10.1016/j.coastaleng.2010.08.001.

Dill, R.F., 1977, The blue holes - Geologically significant submerged sink holes and caves off British Honduras and Andros, Bahama Islands: Proceedings of Third International Coral Reef Symposium, v. 2, p. 237-242.

Donnelly, J.P., Bryant, S.S., Butler, J., Dowling, J., Fan, L., Hausmann, N., Newby, P., Shuman, B.N., Stern, J., Westover, K., and Webb, T., 2001, 700 yr sedimentary record of intense hurricane landfalls in southern New England: Geological Society of America Bulletin, v. 113, p. 714-727.

Donnelly, J.P., Hawkes, A.D., Lane, P., Macdonald, D., Shuman, B.N., Toomey, M.R., Van Hengstum, P.J., and Woodruff, J.D., 2015, Climate forcing of unprecedented intensehurricane activity in the last 2000 years: Earth's Future, v. 3, p. 49-65, doi: 10.1002/2014EF000274.

Donnelly, J.P., and Woodruff, J.D., 2007, Intense hurricane activity over the past 5,000 years 
controlled by El Niño and the West African monsoon.: Nature, v. 447, p. 465-468, doi: 10.1038/nature05834.

Dravis, J.J., and Wanless, H.R., 2017, Impact of strong easterly trade winds on carbonate petroleum exploration - Relationships developed from Caicos Platform, southeastern Bahamas: Marine and Petroleum Geology, v. 85, p. 272-300, doi:

10.1016/j.marpetgeo.2017.04.010.

Duarte, C.M., Delgado-huertas, A., Anton, A., Carrillo-de-Albornoz, P., López-Sandoval, D.C., Agustí, S., Almahasheer, H., Marba, N., Hendriks, I.E., Krause-Jensen, D., and GarciasBonet, N., 2018, Stable Isotope $(\delta 13 \mathrm{C}, \delta 15 \mathrm{~N}, \delta 18 \mathrm{O}, \delta \mathrm{D})$ Composition and Nutrient Concentration of Red Sea Primary Producers: Frontiers in Marine Science, v. 5, p. 1-12, doi: 10.3389/fmars.2018.00298.

Dunn, G.E., 1961, The Hurricane Season of 1960: Monthly Weather Review, p. 99-108.

Elsberry, R.L., and Jeffries, R.A., 1996, Vertical Wind Shear Influences on Tropical Cyclone Formation and Intensification during TCM-92 and TCM-93: Monthly Weather Review, v. 124, p. 1374-1387.

Elsner, J.B., 2003, Tracking hurricanes: Bulletin of the American Meteorological Society, v. 84, p. 353-356, doi: 10.1175/BAMS-84-3-353.

Elsner, J.B., and Bossak, B.H., 2001, Bayesian Analysis of U.S. Hurricane Climate: Journal of Climate, v. 14, p. 4341-4350.

Elsner, J.B., and Kocher, B., 2000, Global Tropical Cyclone Activity: A Link to the North Atlantic Oscillation: Journal of Geophysical Research, v. 27, p. 129-132, doi: 10.1029/1999GL010893.

Elsner, J.B., Liu, K., and Kocher, B., 2000, Spatial variations in major U.S. hurricane activity: Statistics and a physical mechanism: Journal of Climate, v. 13, p. 2293-2305, doi: 10.1175/1520-0442(2000)013<2293:SVIMUS>2.0.CO;2.

Emanuel, K.A., 2006, Climate and Tropical Cyclone Activity: A New Model Downscaling Approach: Journal of Climate, v. 19, p. 4797-4802.

Emanuel, K.A., 2013, Downscaling CMIP5 climate models shows increased tropical cyclone activity over the 21st century: Proceedings of the National Academy of Sciences, v. 110, p. 12219-12224, doi: 10.1073/pnas.1301293110.

Emanuel, K., 1987, The dependence of hurricane intensity on climate: Nature, v. 326, p. 483485.

Emanuel, K., 1989, The finite-amplitude nature of tropical cyclogenesis: Journal of Atmospheric Sciences, v. 46, p. 3431-3456.

Emanuel, K., 2008, The Hurricane-Climate Connection: Bulletin of the American Meteorological Society, p. 11-20, doi: 10.1175/BAMS-89-5-Emanuel.

Emanuel, K., 1988, The Maximum Intensity of Hurricanes: Journal of Atmospheric Sciences, v. 45, p. $1143-1155$.

Emanuel, K., 2010, Tropical Cyclone Activity Downscaled from NOAA-CIRES Reanalysis, 1908-1958: Journal of Advances in Modeling Earth Systems, v. 2, p. 1-12, Art. \#1, doi: 10.3894/JAMES.2010.2.1.

Emanuel, K., 2003, Tropical Cyclones: Annual Review of Earth and Planetary Sciences, v. 31, p. 75-104, doi: 10.1146/annurev.earth.31.100901.141259.

Emanuel, K., DesAutels, C., Holloway, C., and Korty, R., 2004, Environmental Control of Tropical Cyclone Intensity: Journal of the Atmospheric Sciences, v. 61, p. 843-858, doi: 10.1175/1520-0469(2004)061<0843:ECOTCI>2.0.CO;2. 
Emanuel, K., Ravela, S., Vivant, E., and Risi, C., 2006, A statistical deterministic approach to hurricane risk assessment: Bulletin of the American Meteorological Society, v. 87, p. 299314, doi: 10.1175/BAMS-87-3-299.

Emanuel, K., Sundararajan, R., and Williams, J., 2008, Hurricanes and global warming: Results from downscaling IPCC AR4 simulations: Bulletin of the American Meteorological Society, v. 89, p. 347-367, doi: 10.1175/BAMS-89-3-347.

Eneas, W.J.G., 1998, Agriculture in the Bahamas: its historical development 1492-1992: Nassau, Media Publishing, 1-152 p.

Evan, A.T., 2012, Atlantic hurricane activity following two major volcanic eruptions: Journal of Geophysical Research: Atmospheres, v. 117, p. n/a-n/a, doi: 10.1029/2011JD016716.

Fairbanks, R.G., 1989, A 17,000-year glacio-eustatic sea level record: influence of glacial melting rates on the Younger Dryas event and deep-ocean circulation: Nature, v. 342, p. 637-642, doi: 10.1038/342637a0.

Faure, G., 1986, Principles of Isotope Geology: New York City, Wiley, 374-377 p.

Fedorov, A. V, Brierley, C.M., and Emanuel, K., 2010, Tropical cyclones and permanent El Nino in the early Pliocene epoch: Nature, v. 463, p. 1066-1070, doi: 10.1038/nature08831.

Fernandez-Donado, L., Gonzalez-Rouco, J.F., Raible, C.C., Ammann, C., Barriopedro, D., Garcia-Bustamante, E., Jungclaus, J.H., Lorenz, S.J., Luterbacher, J., Phipps, S.J., Servonnat, J., Swingedouw, D., Tett, S.F.B., Wagner, S., et al., 2013, Large-scale temperature response to external forcing in simulations and reconstructions of the last millennium: Climate of the Past, v. 9, p. 393-421, doi: 10.5194/cp-9-393-2013.

Frappier, A., Knutson, T., Liu, K.B., and Emanuel, K., 2007, Perspective: Coordinating paleoclimate research on tropical cyclones with hurricane-climate theory and modelling: Tellus, Series A: Dynamic Meteorology and Oceanography, v. 59 A, p. 529-537, doi: 10.1111/j.1600-0870.2007.00250.x.

Frappier, A.B., Sahagian, D., Carpenter, S.J., Gonzalez, L.A., and Frappier, B.R., 2007, Stalagmite stable isotope record of recent tropic cyclone events: Geology, v. 35, p. 111114, doi: 10.1130/G23145A.1.

Gao, C., Robock, A., and Ammann, C., 2008, Volcanic forcing of climate over the past 1500 years: An improved ice core-based index for climate models: Journal of Geophysical Research Atmospheres, v. 113, p. 1-15, doi: 10.1029/2008JD010239.

Garner, A.J., Mann, M.E., Emanuel, K.A., Kopp, R.E., Lin, N., Alley, R.B., Horton, B.P., Deconto, R.M., Donnelly, J.P., and Pollard, D., 2017, Impact of climate change on New York City's coastal flood hazard: Increasing flood heights from the preindustrial to 2300 CE: Proceedings of the National Academy of Sciences, v. 114, p. 11861-11866, doi: 10.1073/pnas.1703568114.

Giorgetta, M.A., Jungclaus, J., Reick, C.H., Legutke, S., Bader, J., Böttinger, M., Brovkin, V., Crueger, T., Esch, M., Fieg, K., Glushak, K., Gayler, V., Haak, H., Hollweg, H.-D., et al., 2013, Climate and carbon cycle changes from 1850 to 2100 in MPI-ESM simulations for the Coupled Model Intercomparison Project phase 5: Journal of Advances in Modeling Earth Systems, v. 5, p. 572-597, doi: 10.1002/jame.20038.

Gischler, E., Anselmetti, F.S., and Shinn, E.A., 2013, Seismic stratigraphy of the Blue Hole (Lighthouse Reef, Belize), a late Holocene climate and storm archive: Marine Geology, v. 344, p. 155-162, doi: 10.1016/j.margeo.2013.07.013.

Gischler, E., Shinn, E.A., Oschmann, W., Fiebig, J., and Buster, N.A., 2008, A 1500-Year Holocene Caribbean Climate Archive from the Blue Hole, Lighthouse Reef, Belize: Journal 
of Coastal Research, v. 246, p. 1495-1505, doi: 10.2112/07-0891.1.

Goldenberg, S.B., Landsea, C.W., Mestas-Nuñez, A.M., and Gray, W.M., 2001, The Recent Increase in Atlantic Hurricane Activity: Causes and Implications: Science, v. 293, p. 474479, doi: 10.1126/science. 1060040.

Goldenberg, S.B., and Shapiro, L.J., 1996, Physical mechanisms for the association of El Niño and west African rainfall with Atlantic major hurricane activity: Journal of Climate, v. 9, p. 1169-1187, doi: 10.1175/1520-0442(1996)009<1169:PMFTAO>2.0.CO;2.

Gray, W.M., 1984, Atlantic Seasonal Hurricane Frequency. Part I: El Niño and 30 mb QuasiBiennial Oscillation Influences: Monthly Weather Review, v. 112, p. 1649-1668, doi: 10.1175/1520-0493(1984)112<1649:ASHFPI>2.0.CO;2.

Gray, W.M., 1998, The Formation of Tropical Cyclones: Meteorology and Atmospheric Physics, v. 67, p. 37-69, doi: 10.1007/BF01277501.

Gregory, B.R.B., Reinhardt, E.G., and Gifford, J.A., 2017, The Influence of Morphology on Sinkhole Sedimentation at Little Salt Spring, Florida: Journal of Coastal Research, v. 33, p. 359-372, doi: 10.2112/JCOASTRES-D-15-00169.1.

Griffin, J.J., and Goldberg, E.D., 1975, The Fluxes of Elemental Carbon in Coastal Marine Sediments: Limnology and Oceanography, v. 20, p. 456.

Hall, T., and Hereid, K., 2015, The frequency and duration of U.S. hurricane droughts: Geophysical Research Letters, p. 3482-3485, doi: 10.1002/2015GL063652.

Hansen, J., Sato, M., Ruedy, R., Nazarenko, L., Lacis, A., Schmidt, G.A., Russell, G., Aleinov, I., Bauer, M., Bauer, S., Bell, N., Cairns, B., Canuto, V., Chandler, M., et al., 2005, Efficacy of climate forcings: Journal of Geophysical Research D: Atmospheres, doi: 10.1029/2005JD005776.

Hanson, S., Nicholls, R., Ranger, N., Hallegatte, S., Corfee-Morlot, J., Herweijer, C., and Chateau, J., 2011, A global ranking of port cities with high exposure to climate extremes: Climatic Change, v. 104, p. 89-111, doi: 10.1007/s10584-010-9977-4.

Haug, G.H., Hughen, K.A., Sigman, D.M., Peterson, L.C., Röhl, U., Peterson, L.C., Overpeck, J.T., Kipp, N.G., Imbrie, J., Hughen, K.A., Overpeck, J.T., Peterson, L.C., Trumbore, S.E., Peterson, L.C., et al., 2001, Southward migration of the intertropical convergence zone through the Holocene.: Science (New York, N.Y.), v. 293, p. 1304-8, doi: 10.1126/science.1059725.

van Hengstum, P.J., Donnelly, J.P., Fall, P.L., Toomey, M.R., Albury, N.A., and Kakuk, B., 2016, The intertropical convergence zone modulates intense hurricane strikes on the western North Atlantic margin: Scientific Reports, v. 6, p. 21728, doi: 10.1038/srep21728.

van Hengstum, P.J., Donnelly, J.P., Toomey, M.R., Albury, N.A., Lane, P., and Kakuk, B., 2014, Heightened hurricane activity on the Little Bahama Bank from 1350 to 1650 AD: Continental Shelf Research, v. 86, p. 103-115, doi: 10.1016/j.csr.2013.04.032.

Hsu, S.A., and Yan, Z., 1998, A Note on the Radius of Maximum Wind for Hurricanes: Journal of Coastal Research, v. 14, p. 667-668, papers2://publication/uuid/0036E3C2-66E9-4C65BF14-E7E4D3387E01.

$\mathrm{Hu}$, X., Burdige, D.J., and Zimmerman, R.C., 2012, $\delta 13 \mathrm{C}$ Is a Signature of Light Availability and Photosynthesis in Seagrass: Limnology and Oceanography, v. 57, p. 441-448, doi: 10.4319/lo.2012.57.2.0441.

Hua, Q., Barbetti, M., and Rakowski, A., 2013, Atmospheric radiocarbon for the period 19502010: Radiocarbon, v. 55, p. 2059-2072.

Hubbard, D.K., Zankl, H., Van Heerden, I., and Gill, I.P., 2005, Holocene Reef Development 
Along the Northeastern St. Croix Shelf, Buck Island, U.S. Virgin Islands: Journal of Sedimentary Research, v. 75, p. 97-113, doi: 10.2110/jsr.2005.009.

Jamison-Todd, S., 2019, Hurricane Irma Deposits on Modern Carnonate Platform: University of Colorado at Boulder, 1-35 p.

Jelesnianski, C.P., Chen, J., and Shaffer, W.A., 1992, SLOSH: Sea, Lake and Overland Surges from Hurricanes.:

Juberthie, C., and Iliffe, T.M., 1994, Bahama Islands: Encyclopaedia Biospeologica, p. 449-458. Jungclaus, J.H., Fischer, N., Haak, H., Lohmann, K., Marotzke, J., Matei, D., Mikolajewicz, U., Notz, D., and Von Storch, J.S., 2013, Characteristics of the ocean simulations in the Max Planck Institute Ocean Model (MPIOM) the ocean component of the MPI-Earth system model: Journal of Advances in Modeling Earth Systems, v. 5, p. 422-446, doi: 10.1002/jame.20023.

Jungclaus, J.H., Lorenz, S.J., Timmreck, C., Reick, C.H., Brovkin, V., Six, K., Segschneider, J., Giorgetta, M.A., Crowley, T.J., Pongratz, J., Krivova, N.A., Vieira, L.E., Solanki, S.K., Klocke, D., et al., 2010, Climate and carbon-cycle variability over the last millennium: Climate of the Past, v. 6, p. 723-737, doi: 10.5194/cp-6-723-2010.

Kaczmarek, S.E., and Hasiuk, F., 2008, Mapping surficial sediment distributions on Caicos Platform: A quantitative approach integrating statistical analysis of Landsat spectral data and field observations, in Morgan, W.A. and Harris, P.M. eds., Developing Models and Analogs for Isolated Carbonate Platforms - Holocene and Pleistocene Carbonates of Caicos Platform, British West Indies, Society for Sedimentary Geology, p. 57-72, doi: 10.2110/pec.08.22.0057.

Kang, S.M., and Lu, J., 2012, Expansion of the Hadley Cell under Global Warming: Winter versus Summer: Journal of Climate, v. 25, p. 8387-8393, doi: 10.1175/JCLI-D-12-00323.1.

Khan, N.S., Ashe, E., Horton, B.P., Dutton, A., Kopp, R.E., Brocard, G., Engelhart, S.E., Hill, D.F., Peltier, W.R., Vane, C.H., and Scatena, F.N., 2017, Drivers of Holocene sea-level change in the Caribbean: Quaternary Science Reviews, v. 155, p. 13-36, doi: 10.1016/j.quascirev.2016.08.032.

Khider, D., Geay, J.E., Mckay, N.P., Gil, Y., Garijo, D., and Ratnakar, V., 2019, PaCTS 1.0: A Crowdsourced Reporting Standard for Paleoclimate Data: Paleoceanography and Paleoclimatology, v. 34, p. 1570-1596, doi: 10.1029/2019PA003632.

Kier, J.S., and Pilkey, O.H., 1971, The influence of sea level changes on sediment carbonate mineralogy, Tongue of the Ocean, Bahamas: Marine Geology, v. 11, p. 189-200.

Kishore, N., Marques, D., Mahmud, A., Kiang, M., Rodriguez, I., Fuller, A., Ebner, P., Sorensen, C., Racy, F., Lemery, J., Maas, L., Learning, J., Irizarry, R.A., Balsari, S., et al., 2018, Mortality in Puerto Rico after Hurricane Maria: The New England Journal of Medicine, v. 379, p. 162-170, doi: 10.1056/NEJMsa1803972.

Kistler, R., Kalnay, E., Collins, W., Saha, S., White, G., Woollen, J., Chelliah, M., Ebisuzaki, W., Kanamitsu, M., Kousky, V., Van Den Dool, H., Jenne, R., and Fiorino, M., 2001, The NCEP-NCAR 50-year reanalysis: Monthly means CD-ROM and documentation: Bulletin of the American Meteorological Society, v. 82, p. 247-267, doi: 10.1175/1520-

0477(2001)082<0247:TNNYRM>2.3.CO;2.

Knapp, K., Kruk, M.C., Levinson, D.H., Diamond, H.J., and Neumann, C.J., 2010, The International Best Track Archive for Climate Stewardship (IBTrACS): Bulletin of the American Meteorological Society, v. March, p. 363-376, doi: 10.1175/2009BAMS2755.1. Knutson, T., Camargo, S.J., Chan, J.C.L., Emanuel, K., Ho, C., Kossin, J.P., Mohapatra, M., 
Satoh, M., Sugi, M., Walsh, K.J., and Wu, L., 2019, Tropical Cyclones and Climate Change Assessment: Part I . Detection and Attribution: Bulletin of the American Meteorological Society, doi: 10.1175/BAMS-D-18-0189.1.

Knutson, T., Camargo, S.J., Chan, J.C.L., Emanuel, K., Ho, C., Kossin, J., Mohapatra, M., Satoh, M., Sugi, M., Walsh, K., and Wu, L., 2020, Tropical Cyclones and Climate Change Assessment Part II: Projected Response to Anthropogenic Warming: Bulletin of the American Meteorological Society, p. 303-322, doi: 10.1175/BAMS-D-18-0194.1.

Knutson, T.R., Sirutis, J.J., Garner, S.T., Held, I.M., and Tuleya, R.E., 2007, Simulation of the recent multidecadal increase of Atlantic hurricane activity using an 18-km-grid regional model: Bulletin of the American Meteorological Society, v. 88, p. 1549-1565, doi: 10.1175/BAMS-88-10-1549.

Knutson, T.R., Sirutis, J.J., Vecchi, G.A., Garner, S., Zhao, M., Kim, H.S., Bender, M., Tuleya, R.E., Held, I.M., and Villarini, G., 2013, Dynamical Downscaling Projections of TwentyFirst-Century Atlantic Hurricane Activity: CMIP3 and CMIP5 Model-Based Scenarios: Journal of Climate, v. 26, p. 6591-6616, doi: 10.1175/JCLI-D-12-00539.1.

Knutson, T.R., and Tuleya, R.E., 2004, Impact of CO2-induced warming on simulated hurricane intensity and precipitation: Sensitivity to the choice of climate model and convective parameterization: Journal of Climate, v. 17, p. 3477-3495, doi: 10.1175/15200442(2004)017<3477:IOCWOS>2.0.CO;2.

Kohn, M.J., 2010, Carbon isotope compositions of terrestrial C3 plants as indicators of (paleo) ecology and (paleo) climate: Proceedings of the National Academy of Sciences, v. 107, p. 19691-19695, doi: 10.1073/pnas.1004933107.

Kopp, R.E., Kemp, A.C., Bittermann, K., Horton, B.P., Donnelly, J.P., Gehrels, W.R., Hay, C.C., Mitrovica, J.X., Morrow, E.D., and Rahmstorf, S., 2016, Temperature-driven global sealevel variability in the Common Era: Proceedings of the National Academy of Sciences, v. 113.

Korty, R.L., Camargo, S.J., and Galewsky, J., 2011, Tropical Cyclone Genesis Factors in Simulations of the Last Glacial Maximum: Journal of Climate, v. 25, p. 4348-4365, doi: 10.1175/JCLI-D-11-00517.1.

Korty, R.L., Camargo, S.J., and Galewsky, J., 2012, Variations in tropical cyclone genesis factors in simulations of the Holocene epoch: Journal of Climate, v. 25, p. 8196-8211, doi: 10.1175/JCLI-D-12-00033.1.

Korty, R.L., Emanuel, K.A., Huber, M., and Zamora, R.A., 2017, Tropical cyclones downscaled from simulations with very high carbon dioxide levels: Journal of Climate, doi: 10.1175/JCLI-D-16-0256.1.

Kossin, J.P., 2017, Hurricane intensification along United States coast suppressed during active hurricane periods: Nature, v. 541, p. 390-393, doi: 10.1038/nature20783.

Kossin, J.P., Camargo, S.J., and Sitkowski, M., 2010, Climate modulation of North Atlantic hurricane tracks: Journal of Climate, v. 23, p. 3057-3076, doi: 10.1175/2010JCLI3497.1.

Kossin, J.P., Emanuel, K.A., and Vecchi, G.A., 2014, The poleward migration of the location of tropical cyclone maximum intensity: Nature, v. 509, p. 349-352, doi: 10.1038/nature13278.

Kossin, J.P., and Vimont, D.J., 2007, A more general framework for understanding atlantic hurricane variability and trends: Bulletin of the American Meteorological Society, v. 88, p. 1767-1781, doi: 10.1175/BAMS-88-11-1767.

Kozar, M.E., Mann, M.E., Emanuel, K.A., and Evans, J.L., 2013, Long-term variations of North Atlantic tropical cyclone activity downscaled from a coupled model simulation of the last 
millennium: Journal of Geophysical Research Atmospheres, v. 118, p. 13383-13392, doi: 10.1002/2013JD020380.

Landsea, W.C., Anderson, C., Charles, N., Clark, G., Dunion, J., Partagas, J., Hungerford, P., Neumann, C., and Zimmer, M., 2004, The Atlantic Hurricane Database Reanalysis Project: Documentation for 1851-1910 Alterations and Additions to the HURDAT Database: 178221 p., http://www.aoml.noaa.gov/hrd/Landsea/rpibook-final04.pdf.

Landsea, C.W., and Franklin, J.L., 2013, Atlantic Hurricane Database Uncertainty and Presentation of a New Database Format: Monthly Weather Review, v. 141, p. 3576-3592, doi: 10.1175/MWR-D-12-00254.1.

Landsea, C.W., Vecchi, G.A., Bengtsson, L., and Knutson, T.R., 2010, Impact of duration thresholds on Atlantic tropical cyclone counts: Journal of Climate, doi: 10.1175/2009JCLI3034.1.

Lane, P., and Donnelly, J.P., 2012, Hurricanes and Typhoons - Will tropical cyclones become stronger and more frequent? Past. PAGES News, v. 20, p. 33.

Lane, P., Donnelly, J.P., Woodruff, J.D., and Hawkes, A.D., 2011, A decadally-resolved paleohurricane record archived in the late Holocene sediments of a Florida sinkhole: Marine Geology, v. 287, p. 14-30, doi: 10.1016/j.margeo.2011.07.001.

Lawrence, M.B., 1996, Preliminary Report, Hurricane Lili, 14-27 October 1996.:

Lee, C.-Y., Camargo, S.J., Sobel, A.H., and Tippett, M.K., 2020, Statistical-Dynamical Downscaling Projections of Tropical Cyclone Activity in a Warming Climate: Two Diverging Genesis Scenarios: Journal of Climate, v. 33, p. 4815-4834, doi: 10.1175/JCLID-19-0452.1.

Lin, N., Emanuel, K., Oppenheimer, M., and Vanmarcke, E., 2012, Physically based assessment of hurricane surge threat under climate change: Nature Climate Change, v. 2, p. 462-467, doi: 10.1038/nclimate1389.

Lin, N., Emanuel, K.A., Smith, J.A., and Vanmarcke, E., 2010, Risk assessment of hurricane storm surge for New York City: Journal of Geophysical Research, v. 115, p. 1-11, doi: 10.1029/2009JD013630.

Lin, N., Lane, P., Emanuel, K.A., Sullivan, R.M., and Donnelly, J.P., 2014, Heightened hurricane surge risk in northwest Florida revealed from climatological-hydrodynamic modeling and paleorecord reconstruction: Journal of Geophysical Research, v. 119, doi: 10.1002/2014JD021584.

Little, B.G., Buckley, D.K., Cant, R., Henry, P.W.T., Jefferiss, A., Mather, J.D., Stark, J., and Young, R.N., 1977, Land resources of the Bahamas: a summary: Surbiton, Surrey, England, Land Resources Division, Ministry of Overseas Development, 1-88 p.

Little, C.M., Horton, R.M., Kopp, R.E., Oppenheimer, M., Vecchi, G.A., and Villarini, G., 2015, Joint projections of US East Coast sea level and storm surge: Nature Climate Change, v. 5, p. 1114-1120, doi: 10.1038/NCLIMATE2801.

Liu, K., and Fearn, M.L., 1993, Lake-sediment record of late Holocene hurricane: Geology, v. 21, p. 793-796, doi: 10.1130/0091-7613(1993)021<0793.

Locarnini, R.A., Mishonov, A. V., Antonov, J.I., Boyer, T.P., Garcia, H.E., Baranova, O.K., Zweng, M.M., Paver, C.R., Reagan, J.R., Johnson, D.R., Hamilton, M., and Seidov, D., 2013, World Ocean Atlas 2013, Volume 1: Temperature, in Levitus, S. and Mishonov, A. V. eds., NOAA Atlas NESDIS 73, Silver Spring, MD, p. 1-40, doi: 10.7289/V55X26VD.

Lu, J., Vecchi, G.A., and Reichler, T., 2007, Expansion of the Hadley cell under global warming: Geophysical Research Letters, v. 34, p. 2-6, doi: 10.1029/2006GL028443. 
Ludlum, D.M., 1963, Early American Hurricanes, 1492-1870: American Meterological Society.

Ludlum, D.M., 1997, Early American Hurricanes 1492-1870: Boston, American Meterological Society, 1910-1997 p.

Maiklem, W.R., 1968, Some hydraulic properties of bioclastic carbonate grains: Sedimentology, v. 10, p. 101-109.

Mallinson, D.J., Smith, C.W., Mahan, S., Culver, S.J., and McDowell, K., 2011, Barrier island response to late Holocene climate events, North Carolina, USA: Quaternary Research, v. 76, p. 46-57, doi: 10.1016/j.yqres.2011.05.001.

Maloof, A.C., and Grotzinger, J.P., 2012, The Holocene shallowing-upward parasequence of north-west Andros Island, Bahamas: Sedimentology, v. 59, p. 1375-1407, doi: 10.1111/j.1365-3091.2011.01313.x.

Mann, M., 2002, Medieval Climatic Optimum: Encyclopedia of Global environmental change, v. 1, p. 514-516, http://holocene.meteo.psu.edu/shared/articles/medclimopt.pdf\%5Cnhttp://www.meteo.psu.e du/holocene/public_html/Mann/articles/articles/medclimopt.pdf.

Mann, M.E., Bradley, R.S., and Hughes, M.K., 1999, Northern Hemisphere Temperatures During the Past Millennium: Inferences, Uncertainties, and Limitations: Geophysical Research Letters, v. 26, p. 759-762.

Mann, M.E., Woodruff, J.D., Donnelly, J.P., and Zhang, Z., 2009, Atlantic hurricanes and climate over the past 1,500 years.: Nature, v. 460, p. 880-883, doi: 10.1038/nature08219.

McCloskey, T., Bianchette, T., and Liu, K., 2013, Track Patterns of Landfalling and Coastal Tropical Cyclones in the Atlantic Basin, Their Relationship with the North Atlantic Oscillation (NAO), and the Potential Effect of Global Warming: American Journal of Climate ..., v. 2, p. 12-22, doi: doi: 10.4236/ajcc.2013.23A002.

McCloskey, T.A., and Keller, G., 2009, 5000 year sedimentary record of hurricane strikes on the central coast of Belize: Quaternary International, v. 195, p. 53-68, doi: 10.1016/j.quaint.2008.03.003.

McCloskey, T.A., and Liu, K.B., 2012a, A 7000 year record of paleohurricane activity from a coastal wetland in Belize: The Holocene, v. 23, p. 278-291, doi: Doi 10.1177/0959683612460782.

McCloskey, T.A., and Liu, K.B., 2012b, A sedimentary-based history of hurricane strikes on the southern Caribbean coast of Nicaragua: Quaternary Research (United States), v. 78, p. 454464, doi: 10.1016/j.yqres.2012.07.003.

Mckee, K.L., Cahoon, D.R., and Feller, I.C., 2007, Caribbean mangroves adjust to rising sea level through biotic controls on change in soil elevation: Global Ecology and Biogeography, v. 16, p. 545-556, doi: 10.1111/j.1466-8238.2007.00317.x.

McTaggart-Cowan, R., Deane, G.D., Bosart, L.F., Davis, C.A., and Galarneau, T.J., 2007, Climatology of Tropical Cyclogenesis in the North Atlantic (1948 -2004): Monthly Weather Review, v. 136, p. 1284-1304, doi: 10.1175/2007MWR2245.1.

Mendelsohn, R., Emanuel, K., Chonabayashi, S., and Bakkensen, L., 2012, The impact of climate change on global tropical cyclone damage: Nature Climate Change, v. 2, p. 205209, doi: 10.1038/nclimate1357.

Merrill, R.T., 1987, Environmental Influences on Hurricane Intensification: Journal of Atmospheric Sciences, v. 45, p. 1678-1687.

Miller, M.C., McCave, I.N., and Komar, P.D., 1977, Threshold of sediment motion under unidirectional currents: Sedimentology, doi: 10.1111/j.1365-3091.1977.tb00136.x. 
Miller, D.L., Mora, C.I., Grissino-Mayer, H.D., Mock, C.J., Uhle, M.E., and Sharp, Z., 2006, Tree-ring isotope records of tropical cyclone activity: Proceedings of the National Academy of Sciences, v. 103, p. 14294-14297.

Milliman, J.D., Freile, D., Steinen, R.P., and Wilber, R.J., 1993, Great Bahama Bank Aragonitic Muds: Mostly Inorganically Precipitated, Mostly Exported: Journal of Sedimentary Petrology, v. 63, p. 589-595.

Milne, G.A., and Peros, M., 2013, Data-model comparison of Holocene sea-level change in the circum-Caribbean region: Global and Planetary Change, v. 107, p. 119-131, doi: 10.1016/j.gloplacha.2013.04.014.

Mullins, H.T., and Lynts, G.W., 1977, Origin of the northwestern Bahama Platform: Review and reinterpretation: Geological Society of America Bulletin, v. 88, p. 1447-1461.

Mylroie, J.E., Carew, J.L., and Moore, A.I., 1995, Blue holes: Definition and genesis: Carbonates and Evaporites, doi: 10.1007/BF03175407.

Neely, W., 2013, The Great Bahamas Hurricane of 1929: Bloomington, IN, iUniverse LLC, 1$215 \mathrm{p}$.

Neely, W., 2014, The Great Okeechobee Hurricane of 1928: Bloomington, IN, iUniverse LLC.

Neely, W., 2006, The Major Hurricanes to Affect The Bahamas: Bloomington, AuthorHouse, 1$258 \mathrm{p}$.

Nyberg, J., Malmgren, B.A., Winter, A., Jury, M.R., Kilbourne, K.H., and Quinn, T.M., 2007, Low Atlantic hurricane activity in the 1970s and 1980s compared to the past 270 years: Nature, v. 447, p. 698-701, doi: 10.1038/nature05895.

Oliva, F., Viau, A.E., Peros, M.C., and Bouchard, M., 2018, Paleotempestology database for the western North Atlantic basin: The Holocene, v. 28, p. 1664-1671, doi: 10.1177/0959683618782598.

Ortegren, J.T., and Maxwell, J.T., 2014, Spatiotemporal Patterns of Drought/Tropical Cyclone Co-occurrence in the Southeastern USA: Linkages to North Atlantic Climate Variability: Geography Compass, v. 8, p. 540-559.

Otvos, E.G., 2011, Hurricane signatures and landforms-toward improved interpretations and global storm climate chronology: Sedimentary Geology, v. 239, p. 10-22, doi: 10.1016/j.sedgeo.2011.04.014.

Paddock, J., Baker, S., Cullen-Unsworth, L., Smith, A., and Unsworth, R., 2018, Coupled SocialEcological Systems: Insights from Seagrass Meadows in the Turks and Caicos Islands, in Terry Marsden ed., The Sage Handbook of Nature, SAGE Publications, p. 392-417.

PAGES 2k-PMIP3 group, 2015, Continental-scale temperature variability in PMIP3 simulations and PAGES 2k regional temperature reconstructions over the past millennium: Climate of the Past, v. 11, p. 1673-1699, doi: 10.5194/cp-11-1673-2015.

Pasch, R.J., Penny, A.B., and Berg, R., 2019, Hurricane Maria (AL152017).:

Patricola, C.M., and Wehner, M.F., 2018, Anthropogenic influences on major tropical cyclone events: Nature, v. 563, p. 339-346, doi: 10.1038/s41586-018-0673-2.

Pausata, F.S.R., and Camargo, S.J., 2019, Tropical cyclone activity affected by volcanically induced ITCZ shifts: v. 116, doi: 10.1073/pnas.1900777116.

Pausata, F.S.R., Emanuel, K.A., Chiacchio, M., Diro, G.T., Zhang, Q., Sushama, L., Stager, J.C., and Donnelly, J.P., 2017, Tropical cyclone activity enhanced by Sahara greening and reduced dust emissions during the African Humid Period: Proceedings of the National Academy of Sciences of the United States of America, doi: 10.1073/pnas.1619111114.

Peltier, W.R., and Fairbanks, R.G., 2006, Global glacial ice volume and Last Glacial Maximum 
duration from an extended Barbados sea level record: Quaternary Science Reviews, v. 25, p. 3322-3337, doi: 10.1016/j.quascirev.2006.04.010.

Pielke Jr., R. a., Gratz, J., Landsea, C.W., Collins, D., Saunders, M.A., and Musulin, R., 2008, Normalized Hurricane Damage in the United States: 1900-2005: Natural Hazards Review, v. 9, p. 29-42, doi: 10.1061/(ASCE)1527-6988(2008)9:1(29).

Pilskaln, C.H., Neumann, A.C., and Bane, J.M., 1989, Periplatform carbonate flux in the northern Bahamas: Deep-Sea Research, v. 36, p. 1391-1406.

van de Plassche, O., Erkens, G., van Vliet, F., Brandsma, J., van der Borg, K., and de Jong, A.F.M., 2006, Salt-marsh erosion associated with hurricane landfall in southern New England in the fifteenth and seventeenth centuries: Geology, v. 34, p. 829-832, doi: 10.1130/G22598.1.

Ramcharan, E.K., and McAndrews, J.H., 2006, Holocene Development of Coastal Wetland at Maracas Bay, Trinidad, West Indies: Journal of Coastal Research, v. 223, p. 581-586, doi: 10.2112/04A-0001.1.

Rankey, E.C., Enos, P., Steffen, K., and Druke, D., 2004, Lack of Impact of Hurricane Michelle on Tidal Flats, Andros Island, Bahamas : Integrated Remote Sensing and Field Observations: Journal of Sedimentary Research, v. 74, p. 654-661.

Rao, R.G., Woitchik, A.F., Goeyens, L., van Riet, A., Kazungu, J., and Dehairs, F., 1994, Carbon, nitrogen contents and stable carbon isotope abundance in mangrove leaves from an east African coastal lagoon (Kenya): Aquatic Botany, v. 47, p. 175-183.

Reed, A.J., Mann, M.E., Emanuel, K.A., and Titley, D.W., 2015, An analysis of long-term relationships among count statistics and metrics of synthetic tropical cyclones downscaled from CMIP5 models: Journal of Geophysical Research, v. 120, doi: 10.1002/2015JD023357.

Reick, C.H., Raddatz, T., Brovkin, V., and Gayler, V., 2013, Representation of natural and anthropogenic land cover change in MPI-ESM: Journal of Advances in Modeling Earth Systems, v. 5, p. 459-482, doi: 10.1002/jame.20022.

Reimer, P.J., Bard, E., Bayliss, A., Beck, J.W., Blackwell, P.G., Bronk Ramsey, C., Buck, C.E., Cheng, H., Edwards, R.L., Friedrich, M., Grootes, P.M., Guilderson, T.P., Haflidason, H., Hajdas, I., et al., 2013, IntCal13 and Marine13 Radiocarbon Age Calibration Curves 050,000 Years cal BP: Radiocarbon, v. 55, p. 1869-1887, doi: 10.2458/azu_js_rc.55.16947.

Reimer, P.J., Brown, T.A., and Reimer, R.W., 2004, Discussion: reporting and calibration of post-bomb 14C data.: Radiocarbon, v. 46, p. 1299-1304, doi: 10.2458/azu_js_rc.46.4183.

Reuters, 2020, Between Two Storms: Caribbean Braces for Hurricanes in Coronavirus Era: New York Times, https://www.nytimes.com/reuters/2020/05/29/world/americas/29reutershealth-coronavirus-caribbean-hurricanes.html.

Richey, J.N., Poore, R.Z., Flower, B.P., Quinn, T.M., and Hollander, D.J., 2009, Regionally coherent Little Ice Age cooling in the Atlantic Warm Pool: Geophysical Research Letters, v. 36, p. 3-7, doi: 10.1029/2009GL040445.

Rios-Berrios, R., and Torn, R.D., 2017, Climatological Analysis of Tropical Cyclone Intensity Changes under Moderate Vertical Wind Shear: Monthly Weather Review, v. 145, p. 17171738, doi: 10.1175/MWR-D-16-0350.1.

Rodysill, J., Donnelly, J.P., Sullivan, R.M., Lane, P.D., Toomey, M.R., Woodruff, J.D., Hawkes, A.D., Macdonald, D., D’Entrement, N., McKeon, K., Wallace, E.J., and Van Hengstum, P.J. Historically unprecedented Northern Gulf of Mexico hurricane activity from 650 to 1250 CE: Scientific Reports,. 
Sahoo, B., Jose, F., and Bhaskaran, P.K., 2019, Hydrodynamic response of Bahamas archipelago to storm surge and hurricane generated waves - A case study for Hurricane Joaquin: Ocean Engineering, v. 184, p. 227-238.

Schneck, R., Reick, C.H., and Raddatz, T., 2013, Land contribution to natural CO<inf $>2</$ inf $>$ variability on time scales of centuries: Journal of Advances in Modeling Earth Systems, v. 5, p. 354-365, doi: 10.1002/jame.20029.

Schneider, T., Bischoff, T., and Haug, G.H., 2014, Migrations and dynamics of the intertropical convergence zone.: Nature, v. 513, p. 45-53, doi: 10.1038/nature13636.

Sharmila, S., and Walsh, K.J.E., 2018, Recent poleward shift of tropical cyclone formation linked to Hadley cell expansion: Nature Climate Change, v. 8, p. 730-737, doi: 10.1038/s41558-018-0227-5.

Shinn, E.A., Lloyd, R.M., and Ginsburg, R.N.., 1969, Anatomy of Modern Carbonate Tidal Flat, Andros Island, Bahamas: Journal of Sedimentary Petrology, v. 39, p. 1202-1228.

Shinn, E.A., Reich, C.D., Locker, S.D., and Hine, A.C., 1996, A Giant Sediment Trap in the Florida Keys: Journal of Coastal Research, v. 12, p. 953-959.

Shinn, E.A., Steinen, R.P., Dill, R.F., and Major, R., 1993, Lime-mud layers in high-energy tidal channels: A record of hurricane deposition: Geology, v. 21, p. 603-606.

Sicre, M.-A., Yiou, P., Dahhaoui, I., Knudsen, K., Jansen, E., and Turon, J., 2008, A 4500-year reconstruction of sea surface temperature variability at decadal time-scales off North Iceland: v. 27, p. 2041-2047, doi: 10.1016/j.quascirev.2008.08.009.

Sigl, M., McConnell, J.R., Toohey, M., Curran, M., Das, S.B., Edwards, R., Isaksson, E., Kawamura, K., Kipfstuhl, S., Krüger, K., Layman, L., Maselli, O.J., Motizuki, Y., Motoyama, H., et al., 2014, Insights from antarctica on volcanic forcing during the common era: Nature Climate Change, v. 4, p. 693-697, doi: 10.1038/nclimate2293.

Sobel, A.H., Camargo, S.J., Hall, T.M., Lee, C.Y., Tippett, M.K., and Wing, A.A., 2016, Human influence on tropical cyclone intensity: Science, doi: 10.1126/science.aaf6574.

Spencer, M., 1967, Bahamas Deep Test: Bulletin of the American Association of Petroleum Geologists, v. 51, p. 263-268.

Stevens, B., Giorgetta, M., Esch, M., Mauritsen, T., Crueger, T., Rast, S., Salzmann, M., Schmidt, H., Bader, J., Block, K., Brokopf, R., Fast, I., Kinne, S., Kornblueh, L., et al., 2013, Atmospheric component of the MPI-M earth system model: ECHAM6: Journal of Advances in Modeling Earth Systems, v. 5, p. 146-172, doi: 10.1002/jame.20015.

Stevenson, S., Fasullo, J.T., Otto-Bliesner, B.L., Tomas, R.A., and Gao, C., 2017, Role of eruption season in reconciling model and proxy responses to tropical volcanism: Proceedings of the National Academy of Sciences, v. 114, p. 1822-1826, doi: 10.1073/pnas.1612505114//DCSupplemental.www.pnas.org/cgi/doi/10.1073/pnas.1612505114.

Stewart, S.R., 2017, Hurricane Matthew (AL142016).:

Studholme, J., and Gulev, S., 2018, Concurrent changes to hadley circulation and the meridional distribution of tropical cyclones: Journal of Climate, v. 31, p. 4367-4389, doi: 10.1175/JCLI-D-17-0852.1.

Sugi, M., Yoshida, K., and Murakami, H., 2015, More tropical cyclones in a cooler climate? Geophysical Research Letters, v. 42, p. 6780-6784, doi: 10.1002/2015GL064929.

The hurricane season 2017: a cluster of extreme storms Munich Re, https://www.munichre.com/topics-online/en/climate-change-and-natural-disasters/naturaldisasters/storms/hurricane-season-2017.html (accessed November 2018). 
Ting, M., Camargo, S.J., Li, C., and Kushnir, Y., 2015, Natural and Forced North Atlantic Hurricane Potential Intensity Change in CMIP5 Models*: Journal of Climate, v. 28, p. 3926-3942, doi: 10.1175/JCLI-D-14-00520.1.

Ting, M., Kossin, J.P., Camargo, S.J., and Li, C., 2019, Past and Future Hurricane Intensity Change along the U. S. East Coast: Scientific Reports, v. 9, p. 1-8, doi: 10.1038/s41598019-44252-w.

Tippett, M.K., Camargo, S.J., and Sobel, A.H., 2011, A Poisson Regression Index for Tropical Cyclone Genesis and the Role of Large-Scale Vorticity in Genesis: Journal of Climate, p. 2335-2357, doi: 10.1175/2010JCLI3811.1.

Toomey, M.R., Curry, W.B., Donnelly, J.P., and Van Hengstum, P.J., 2013, Reconstructing 7000 years of North Atlantic hurricane variability using deep-sea sediment cores from the western Great Bahama Bank: Paleoceanography, v. 28, p. 31-41, doi: 10.1002/palo.20012.

Toscano, M.A., and Macintyre, I.G., 2003, Corrected western Atlantic sea-level curve for the last 11,000 years based on calibrated 14C dates from Acropora palmata framework and intertidal mangrove peat: Coral Reefs, v. 22, p. 257-270, doi: 10.1007/s00338-003-0315-4.

Trower, E.J., Cantine, M.D., Gomes, M.L., Grotzinger, J.P., Knoll, A.H., Lamb, M.P., Lingappa, U., O’Reilly, S.S., Present, T.M., Stein, N., Strauss, J. V, and Fischer, W.W., 2018, Active ooid growth by sediment transport in a high-energy shoal, Little Ambergis Cay, Turks and Caicos Islands: Journal of Sedimentary Petrology, v. 88, p. 1132-1151, doi: http://dx.doi.org/10.2110/jsr.2018.59.

Trower, E.J., Lamb, M.P., and Fischer, W.W., 2019, The Origin of Carbonate Mud: Geophysical Research Letters, p. 2696-2703, doi: 10.1029/2018GL081620.

Tucker, T., 1982, Beware The Hurricane! Bermuda, Island Press, 1-168 p.

U. S. Billion-Dollar Weather \& Climate Disasters 1980-2019, 2019, https://www.ncdc.noaa.gov/billions/.

Ulm, K., 1990, A simple method to calculate the confidence interval of a standardized mortality ratio (SMR): American journal of epidemiology, v. 131, p. 373-5, doi: 10.1093/oxfordjournals.aje.a115507.

Vecchi, G.A., and Knutson, T.R., 2011, Estimating annual numbers of Atlantic hurricanes missing from the HURDAT database (1878-1965) using ship track density: Journal of Climate, doi: 10.1175/2010JCLI3810.1.

Vecchi, G.A., and Knutson, T.R., 2008, On estimates of historical North Atlantic tropical cyclone activity: Journal of Climate, doi: 10.1175/2008JCLI2178.1.

Villarini, G., and Vecchi, G.A., 2013a, Projected increases in North Atlantic tropical cyclone intensity from CMIP5 models: Journal of Climate, doi: 10.1175/JCLI-D-12-00441.1.

Villarini, G., and Vecchi, G.A., 2013b, Projected Increases in North Atlantic Tropical Cyclone Intensity from CMIP5 Models: Journal of Climate, v. 26, p. 3231-3240, doi: 10.1175/JCLID-12-00441.1.

Villarini, G., Vecchi, G.A., Knutson, T.R., and Smith, J.A., 2011, Is the recorded increase in short-duration North Atlantic tropical storms spurious? Journal of Geophysical Research Atmospheres, doi: 10.1029/2010JD015493.

Wallace, E.J., Donnelly, J.P., van Hengstum, P.J., Wiman, C., Sullivan, R.M., Winkler, T.S., D'Entrement, N.E., Toomey, M.R., and Albury, N.A., 2019, Intense hurricane activity over the past 1500 years at South Andros Island, The Bahamas: Paleoceanography and Paleoclimatology, doi: 10.1029/2019PA003665.

Wallace, D.J., Woodruff, J.D., Anderson, J.B., and Donnelly, J.P., 2014, Palaeohurricane 
reconstructions from sedimentary archives along the Gulf of Mexico, Caribbean Sea and western North Atlantic Ocean margins: Sedimentary Coastal Zones from High to Low Latitudes: Similarities and Differences, v. 388, p. 481-501, doi: 10.1144/SP388.12.

Walsh, K.J., Camargo, S.J., Vecchi, G.A., Daloz, A.S., Elsner, J.B., Emanuel, K., Horn, M., Lim, Y.-K., Roberts, M., Patricola, C., Scoccimarro, E., Sobel, A.H., Strazzo, S., Villarini, G., et al., 2015, Hurricanes and climate. The U.S. CLIVAR Working Group on Hurricanes: Bulletin of the American Meteorological Society, p. 997-1017, doi: 10.1175/BAMS-D-1300242.1.

Walsh, K., Lavender, S., Scoccimarro, E., and Murakami, H., 2013, Resolution dependence of tropical cyclone formation in CMIP3 and finer resolution models: Climate Dynamics, v. 40, p. 585-599, doi: 10.1007/s00382-012-1298-z.

Walsh, K.J.E., Mcbride, J.L., Klotzbach, P.J., Balachandran, S., Camargo, S.J., Holland, G., Knutson, T.R., Kossin, J.P., Lee, T. cheung, Sobel, A., and Sugi, M., 2016, Tropical cyclones and climate change: Wiley Interdisciplinary Reviews: Climate Change, v. 7, doi: 10.1002/wcc.371.

Wang, C., Liu, H., Lee, S.K., and Atlas, R., 2011, Impact of the Atlantic warm pool on United States landfalling hurricanes: Geophysical Research Letters, v. 38, p. 1-7, doi: 10.1029/2011GL049265.

Wanless, H.R., Tedesco, L.P., and Tyrrell, K.M., 1988, Production of subtidal tubular and surficial tempestites by Hurricane Kate, Caicos Platform, British West Indies: Journal of Sedimentary Petrology, v. 58, p. 739-750.

Wanless, H.R., Tyrrell, K.M., Tedesco, L.P., and Dravis, J.J., 1988, Tidal-Flat Sedimentation from Hurricane Kate, Caicos Platform, British West Indies: Journal of Sedimentary Petrology, v. 58, p. 724-738.

Webster, P.J., Holland, G.J., Curry, J. a, and Chang, H., 2005, Changes in Tropical Cyclone Number, Duration , and Intensity in a Warming Envi ...: Library, v. 309, p. 1844-1846, doi: $10.1126 /$ science. 1116448 .

Wefer, G., and Killingley, J.S., 1986, Carbon isotopes in organic matter from a benthic alga Halimeda incrassata (Bermuda): Effects of light intensity: Chemical Geology (Isotope Geoscience Section), v. 59, p. 321-326.

Wilber, R.J., Milliman, J.D., and Halley, R.B., 1990, Accumulation of bank-top sediment on the western slope of Great Bahama Bank: Rapid progradation of a carbonate megabank: Geology, p. 970-974.

Winkler, T.S., Van Hengstum, P.J., Donnelly, J.P., Wallace, E.J., Sullivan, R.M., Macdonald, D., and Albury, N.A. Revising evidence of hurricane strikes on Abaco Island (The Bahamas) over the last 680 years: Scientific Reports,

Winter, A., Zanchettin, D., Miller, T., Kushnir, Y., Black, D., Lohmann, G., Burnett, A., Haug, G.H., Estrella-Martinez, J., Breitenbach, S.F.M., Beaufort, L., Rubino, A., and Cheng, H., 2015, Persistent drying in the tropics linked to natural forcing: Nature Communications, v. 6, p. 2-8, doi: 10.1038/ncomms8627.

Wong, M.L.M., and Chan, J.C.L., 2004, Tropical Cyclone Intensity in Vertical Wind Shear: Journal of Atmospheric Sciences, v. 61, p. 1859-1876.

Woodruff, J.D., Donnelly, J.P., Emanuel, K., and Lane, P., 2008, Assessing sedimentary records of paleohurricane activity using modeled hurricane climatology: Geochemistry, Geophysics, Geosystems, v. 9, doi: 10.1029/2008GC002043.

Woodruff, J.D., Irish, J.L., and Camargo, S.J., 2013, Coastal flooding by tropical cyclones and 
sea-level rise.: Nature, v. 504, doi: 10.1038/nature12855.

Wright, D.B., Knutson, T.R., and Smith, J.A., 2015, Regional climate model projections of rainfall from U. S. landfalling tropical cyclones: Climate Dynamics, v. 45, p. 3365-3379, doi: 10.1007/s00382-015-2544-y.

Wu, L., Chou, C., Chen, C.-T., Huang, R., Knutson, T.R., Sirutis, J.J., Garner, S.T., Kerr, C., Lee, C.-J., and Feng, Y.-C., 2014, Simulations of the Present and Late-Twenty-FirstCentury Western North Pacific Tropical Cyclone Activity Using a Regional Model: Journal of Climate, v. 27, p. 3405-3424, doi: 10.1175/JCLI-D-12-00830.1.

Xie, L., Yan, T., Pietrafesa, L.J., Morrison, J.M., and Karl, T., 2005, Climatology and interannual variability of North Atlantic hurricane tracks: Journal of Climate, v. 18, p. 5370-5381, doi: 10.1175/JCLI3560.1.

Yoo, J., Galewsky, J., Camargo, S.J., Korty, R.L., and Zamora, R.A., 2016, Dynamical downscaling of tropical cyclones from CCSM4 simulations of the Last Glacial Maximum: Journal of Advances in Modeling Earth Systems, v. 8, p. 1229-1247, doi: 10.1002/2016MS000685.

Zanchettin, D., Timmreck, C., Toohey, M., Jungclaus, J.H., Bittner, M., Lorenz, S.J., and Rubino, A., 2019, Clarifying the relative role of forcing uncertainties and initial-condition unknowns in spreading the climate response to volcanic eruptions.: Geophysical Research Letters, doi: 10.1029/2018GL081018.

Zhang, R., and Delworth, T.L., 2006, Impact of Atlantic multidecadal oscillations on India/Sahel rainfall and Atlantic hurricanes: Geophysical Research Letters, v. 33, p. 1-5, doi: 10.1029/2006GL026267.

Zhang, L., Karnauskas, K.B., Donnelly, J.P., and Emanuel, K., 2017, Response of the North Pacific tropical cyclone climatology to global warming: Application of dynamical downscaling to CMIP5 models: Journal of Climate, doi: 10.1175/JCLI-D-16-0496.1. 